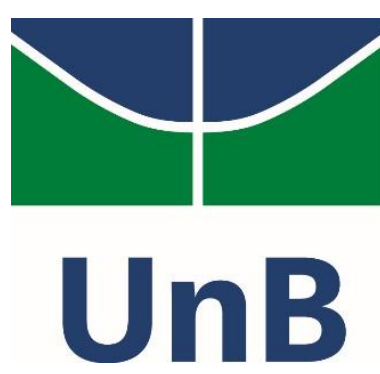

Instituto de Química

Programa de Pós-Graduação em Química

Avaliação do efeito estéreo no rearranjo de Hurd-Claisen em adutos de Morita-Baylis-Hillman

DISSERTAÇÃO DE MESTRADO

VINICIUS SOBRAL SILVA

Orientador: Prof. Dr. Ângelo Henrique de Lira Machado

Brasília, DF 


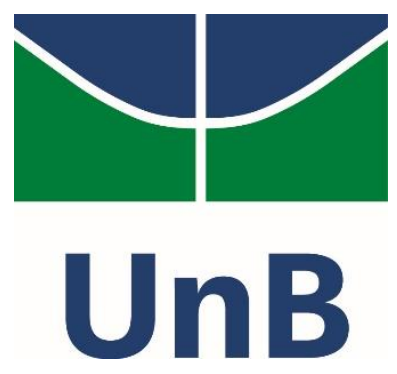

Instituto de Química

Programa de Pós-Graduação em Química

\section{Avaliação do efeito estéreo no rearranjo de Hurd-Claisen em adutos de} Morita-Baylis-Hillman

VINICIUS SOBRAL SILVA

Dissertação de Mestrado apresentada à banca examinadora em cumprimento às exigências para a obtenção do título de Mestre em Química - Área de concentração "Química Orgânica" pelo Programa de Pós-Graduação em Química da Universidade de Brasília - UnB.

Orientador: Prof. Dr. Ângelo Henrique de Lira Machado.

Brasília, DF 


\section{FOLHA DE APROVAÇÃO}

Comunicamos a aprovação da Defesa de Dissertação de Mestrado

do (a) aluno (a) Vinicius Sobral Silva, matrícula № 15/0104111, intitulada "Avaliação do efeito estéreo no rearranjo de Hurd-Claisen em Adultos de Morita-Baylis-Hillman", apresentada no (a) Sala PADCT do Instituto de Química (IQ) da Universidade de Brasília (UnB) em 17 de fevereiro de 2017.

Prof. Dr. Angelo Henrique de Lira Machado Presidente de Banca (IQ/UnB)

Prof. Dr. Wender Alves da Silva Membro Titular (IQ/UnB)

Prof.a Dra. Michelle Pereira Quintino Membro Titular (UEG)

Dr. Carlos Eduardo de Melo Salvador Membro Suplente (IQ/UnB)

Em 17 de fevereiro de 2017. 
DEDICATÓRIA

Aos meus pais, José Emilio e Eulália, razão da minha vida. A minha tia Maria Leite Sobral. 


\section{AgRADECIMENTOS}

Primeiramente agradeço a Deus pelo dom da vida e aos meus pais, José Emilio Gomes da Silva e Eulália Leite Sobral Silva, por todo amor carinho e incentivo aos estudos durante todos esses anos. A minha mãe gostaria de fazer um agradecimento especial, que por razões de forças maiores foi não somente mãe como pai. Ela que sempre esteve ao meu lado me ajudando nos momentos mais difíceis da minha vida.

Agradeço a minha tia Maria Leite Sobral (Milta) por me apoiar neste últimos anos me dando força para continuar sempre e a cada dia estudando para que possa galgar na vida.

A minha namorada Maria Cecília, pelo companheirismo, contribuições intelectuais, amor, carinho e apoio emocional nos momentos mais difíceis desde os primórdios da minha ida a Brasília.

Ao meu irmão Luiz Augusto Sobral, pelo companheirismo.

Ao professor Dr. Ângelo Henrique de Lira Machado por ter me aceitado como orientando e por compartilhar todo seu conhecimento e experiência, um excelente profissional, sempre disposto a ensinar.

A professora Dra. Michelle Pereira Quintino pela contribuição em minha formação, pelo incentivo à Pós-Graduação e colaborações no trabalho.

Ao professor Dr. Wender Alves Silva pelas contribuições e sugestões em meu trabalho.

Ao professor Dr. Rafael Oliveira Rocha por toda experiência e contribuições durante o desenvolvimento da minha pesquisa.

Ao professor Dr. Carlos Eduardo de Melo Salvador por toda experiência e contribuições durante o desenvolvimento da minha pesquisa.

Aos colegas de trabalho do LITMO, Robson, José, Leandro, Charley, Diana, Terezinha, Fernanda, que de alguma forma contribuíram para o desenvolvimento do meu trabalho. Um agradecimento especial ao Saulo por auxiliar na rotina de laboratório, pelas análises de RMN, camaradagem e demais contribuições.

Aos técnicos e estagiários da Central Analítica, Alan, Luiz, Julia, Mateus, Gabriela e Bruno.

À Universidade de Brasília (UnB) e ao Instituto de Química.

À Fundação de Apoio e Pesquisa do Distrito Federal (FAPDF) pelo auxílio financeiro. 


\section{LISTA DE ABREVIATURAS E ACRÔNIMOS}

(+)-Ipc2BCl: diisopinocamfenil-borana

AcO2: anidrido acético

AcOH: ácido acético

AlCl3: cloreto de alumínio

AMBH: Aduto de Morita-Baylis-Hilman

Ar: argônio

ATR: refletância total atenuada

BINOL: [1,1'-binaftaleno] -2,2'-diol

CCD: cromatografia em camada delgada

$\mathrm{CH}_{2} \mathrm{Cl}_{2}$ : diclorometano

$\mathrm{CH}_{3} \mathbf{N H}_{2}$ : metilamina

$\mathrm{CoCl}_{2} \cdot \mathrm{HH}_{2} \mathrm{O}$ : cloreto de cobalto (II) hexahidratado

d: dupleto

DABCO: 1,4-diazobiciclo[2.2.2]octano

dd: duplo dupleto

ddd: duplo duplo dupleto

dt: dupleto de tripleto

EI: ionização por elétrons

EM: espectrometria de massas

ET: estado de transição

Et3N: trietilamina

EtOAc: acetato de etila 
EtOH: etanol

$\mathbf{e V}$ : elétron volts

EVE: etil vinil éter

FeCl3: cloreto de ferro (III)

GC/MS: cromatografia gasosa acoplada a espectrometria de massas

GDE: grupo doador de elétrons

GRE: grupo retirador de elétrons

$\mathbf{H}_{2} \mathbf{O}_{2}$ : peróxido de hidrogênio

Hg (0): mercúrio zero

$\operatorname{Hg}(\mathbf{O A c}) 2$ : acetato de mercúrio

Hz: Hertz

IV: infravermelho

$J$ : constante de acoplamento

$\mathrm{K}_{2} \mathrm{CO}_{3}$ : carbonato de potássio

KBr: brometo de potássio

LDA: diisopropilamida de lítio

m/z: razão massa-carga

m: multipleto

MBH: Morita-Baylis-Hillman

m-CPBA: ácido meta cloroperbenzóico

MeOH: metanol

NaBH4: borohidreto de sódio

NaH: hidreto de sódio 
NOE: Efeito Nuclear Overhauser

OEt: etóxido

OMF: orbitais moleculares de fronteira

Ot-Bu: terc-butóxido

Pd/C: Paládio em carvão

PhOH: fenol

PhSeCl: cloreto de fenilselenilo

ppm: partes por milhão

q: quadrupleto

qt: quadrupleto de tripleto

QV: química verde

RMN de ${ }^{13} \mathbf{C}$ : ressonância magnética nuclear de carbono 13

RMN de ${ }^{\mathbf{1}} \mathbf{H}$ : ressonância magnética nuclear de hidrogênio

s: simpleto

t: tripleto

Ta: temperatura ambiente

THF: tetraidrofurano

TosMIC: $p$-toluenossulfonilmetil isocianeto

TsOH: ácido $p$-toluenossulfônico

tt: tripleto de tripleto

$\boldsymbol{\delta}:$ deslocamento químico 


\section{RESUMO}

A reação de Morita-Baylis-Hillman (MBH), uma importante reação de formação de ligação C$\mathrm{C}$, proporciona moléculas multifuncionalizadas. $\mathrm{O}$ produto formado possui ampla versatilidade em síntese orgânica devido à ortogonalidade presente nos grupos funcionais do aduto de MBH. Dentre as diversas reações subsequentes que os adutos de MBH podem sofrer, destaca-se a formação do alil vinil éter pela reação do álcool alílico (aduto de $\mathrm{MBH}$ ) com etil vinil éter, na presença $\mathrm{Hg}(\mathrm{OAc})_{2}$ como catalisador que, sob aquecimento, sofre um rearranjo sigmatrópico $[3,3]$ de Claisen, conduzindo à formação de compostos carbonílicos $\gamma, \delta$-insaturados. Iniciando pela síntese de adutos de $\mathrm{MBH}$ aromáticos e alifáticos, este trabalho se propôs a avaliar a influência de três fatores (temperatura, quantidade de catalisador, tempo reacional) na conversão, seletividade e rendimento no rearranjo de Hurd-Claisen em adutos de MBH e, consequentemente, sua diastereosseletividade através da substituição do grupo alcóxido (OEt $\rightarrow$ Ot-Bu). O estudo de otimização possibilitou a redução do tempo reacional, proporcionando conversões superiores a 79\%, além de auxiliar no entendimento da diastereosseletividade $(\boldsymbol{E}: \boldsymbol{Z})$. Para os adutos aromáticos a menor razão $\boldsymbol{E}: \boldsymbol{Z}$ foi de 12:1 e para adutos alifático 3,4:1. Um modelo de estado de transição, baseado em efeitos estéreo e estereoeletrônico, também foi sugerido neste trabalho para explicar a diastereosseletividade $\boldsymbol{E}$ preferencial.

Palavras chave: rearranjo sigmatrópico, transvinilação, estereosseletividade. 


\begin{abstract}
The Morita-Baylis-Hillman (MBH) reaction is an outstanding C-C bond forming transformation that provides multifunctionalized molecules. The product of this reaction has wide versatility in organic synthesis due to orthogonality present in the functional groups of the $\mathrm{MBH}$ adduct. Among the many subsequent reactions that $\mathrm{MBH}$ adducts may undergo, one can find the formation of allyl vinyl ether, by the allylic alcohol (MBH adduct) reaction with ethyl vinyl ether in the presence of $\mathrm{Hg}(\mathrm{OAc})_{2}$ as catalyst. This intermediate, upon heating, undergoes a [3,3] sigmatropic rearrangement called Claisen rearrangement, leading to the formation of $\gamma, \delta$-unsaturated carbonylic compounds. Starting by the synthesis of aromatic and aliphatic MBH adducts, this study aimed to evaluate the influence of temperature, amount of catalyst and reaction time for the conversion, selectivity and yield of the Hurd-Claisen rearrangement in adducts of $\mathrm{MBH}$ and also the effect of substitution of the alkoxide group (OEt $\rightarrow \mathrm{Ot}-\mathrm{Bu}$ ) for their diastereoselectivity. The optimization study allowed the reduction of the reaction time, providing conversions greater than $79 \%$, besides helping to understand the observed diastereoselectivity (E:Z ratio). The lowest E:Z ratio for aromatic and aliphatic adducts was 12:1 and 3,4:1, respectively. A transition state model, based on stereo and stereoelectronic effects, was also proposed to explain the preferred $\boldsymbol{E}$ diastereoselectivity.
\end{abstract}

.Keywords: sigmatropic rearrangement, transvinylation, stereoselectivity. 


\section{SUMÁRIO}

1-INTRODUÇÃ

2-OBJETIVOS

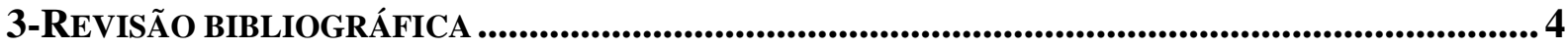

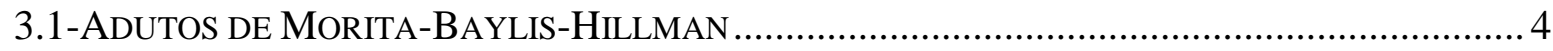

3.2-REARRANJO DE Claisen EM AdUTOS DE MoritA-BAYLIS-HILlMAN ............................. 7

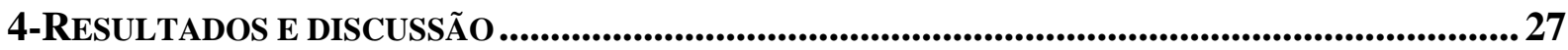

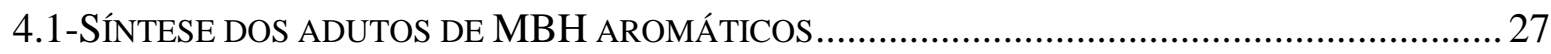

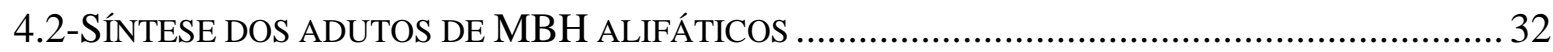

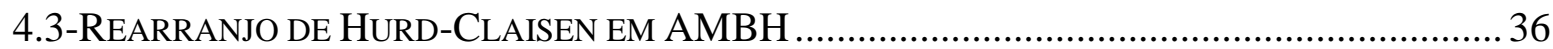

4.3.1-OtimizaÇÃo do ReARranjo de HuRd-Claisen em adutos de Morita-Baylis-

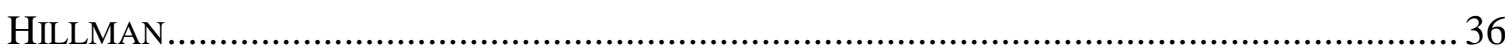

4.3.2-ESTEREOSSELETIVIDADE DO REARRANJO DE HuRD-CLAISEN EM ADUTOS DE MORITA-

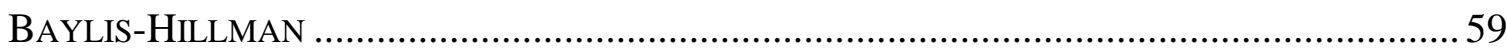

4.3.3-JUSTIFICATIVA PARA ESTEREOSSELETIVIDADE DO REARRANJO DE HURD-CLAISEN EM

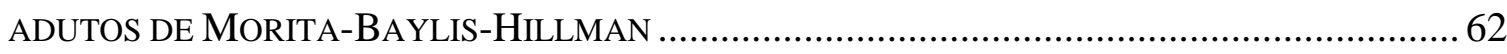

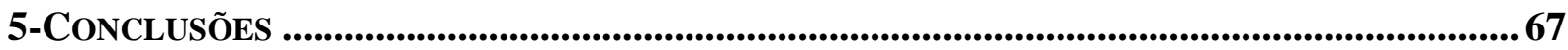

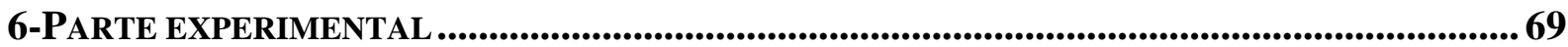

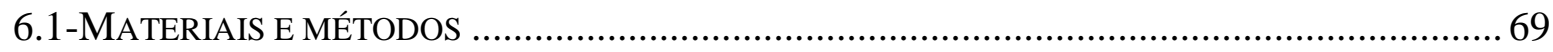

6.2-FormaÇão dos Adutos de Morita-BAYlis-HiLlman ARomÁticos ......................... 71

6.2.1-FORMAÇÃO DO 2-(HIDROXI(3-NITROFENIL)METIL) ACRILATO DE TERC-BUTILA E 2(HIDROXI(4-NITROFENIL)METIL) ACRILATO DE TERC-BUTILA …...................................... 73

6.2.2-FORMAÇÃO DOS ADUTOS DE MORITA-BAYLIS-HILlMAN AROMÁticos SOB

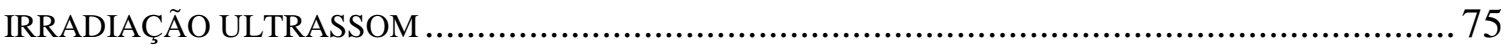

6.3-FoRMAÇÃo dOS ADUTOS DE MORITA-BAYLIS-HILlMAN AlifÁticos ............................. 77

6.4-REARRANJO DE HuRd-Claisen EM Adutos DE MoritA-BAYLIS-HILlman ................... 80

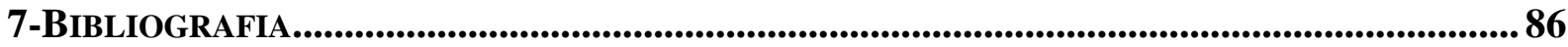

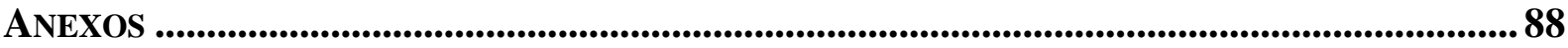




\section{ÍNDICE DE FiguRAS}

Figura 1. Alguns catalisadores utilizados nas reações de Morita-Baylis-Hillman...................5

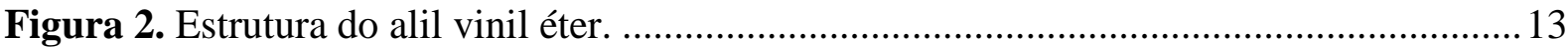

Figura 3. ET proposto por Perrin e Faulkner, baseado na interação $s y n$-axial....................... 13

Figura 4. ET de Faulkner e Petersen para explicar a seletividade $\boldsymbol{E}$. Baseado na tensão 1,3diaxial clássica.

Figura 5. ET proposto por D. Basavaiah e colaboradores para explicar a estereosseletividade do rearranjo de Johnson-Claisen em AMBH

Figura 6. Espectro de $\mathrm{RMN} \mathrm{de}{ }^{1} \mathrm{H}\left(600 \mathrm{MHz}, \mathrm{CDCl}_{3}\right)$ - AMBH-3a...................................... 30

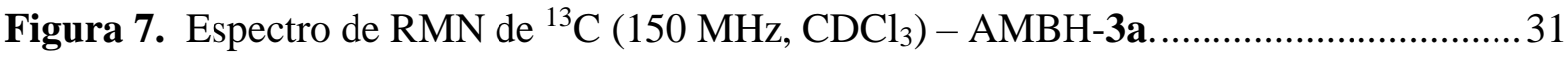

Figura 8. Espectro de massas do 2-(hidroxi(fenil)metil) acrilato de terc-butila - AMBH 3a.32

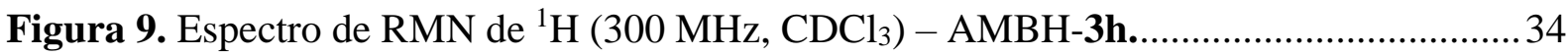

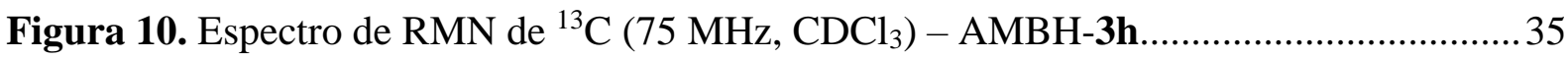

Figura 11. Espectro de massa do 3-hidróxi-2-metilenobutanoato de terc-butila AMBH 3h..36

Figura 12. Espectro de RMN de ${ }^{1} \mathrm{H}(600 \mathrm{MHz})$ do bruto de reação do rearranjo de Hurd-Claisen com 18 horas

Figura 13. Sobreposição dos espectros de $\mathrm{RMN}{ }^{1} \mathrm{H}$ do bruto de reação do rearranjo de HurdClaisen do AMBH-3a nas temperatura de 120,100 e $80^{\circ} \mathrm{C}$.

Figura 14. Espectro de $\mathrm{RMN}$ de ${ }^{1} \mathrm{H}(600 \mathrm{MHz})$ do bruto de reação do rearranjo de Hurd-Claisen realizado sem $\mathrm{Hg}(\mathrm{OAc})_{2}$.

Figura 15. Espectro de RMN de ${ }^{1} \mathrm{H}(600 \mathrm{MHz})$ do bruto de reação do rearranjo de Hurd-Claisen realizado sem $\mathrm{Hg}(\mathrm{OAc})_{2}$ com respectivas ampliações dos sinais dos acetais.

Figura 16. Espectro de $\mathrm{RMN}$ de ${ }^{13} \mathrm{C}(150 \mathrm{MHz})$ bruto de reação do rearranjo de Hurd-Claisen realizado sem $\mathrm{Hg}(\mathrm{OAc})_{2}$. 43

Figura 17. Sobreposição dos espectros de $\mathrm{RMN}{ }^{1} \mathrm{H}$ do bruto de reação do rearranjo de HurdClaisen do $\mathrm{AMBH}$ 3a variando a concentração de $\mathrm{Hg}(\mathrm{OAc})_{2}$ 44 
Figura 18. Espectro de RMN $1 \mathrm{H}(600 \mathrm{MHz})$ do bruto da tentativa de isomerização do produto de rearranjo $\boldsymbol{E}$ quando submetido a aquecimento em etil vinil éter, $100^{\circ} \mathrm{C}$, na presença de $\mathrm{Hg}(\mathrm{OAc})_{2}$

Figura 19. Espectro de RMN de ${ }^{1} \mathrm{H}(600 \mathrm{MHz})$ do bruto de reação do rearranjo de Hurd-Claisen de 24 horas com os isômeros $\mathbf{4 h}(\boldsymbol{E})$ e $\mathbf{4 h}(\boldsymbol{Z})$.

Figura 20. Espectro de $\mathrm{RMN}$ de ${ }^{1} \mathrm{H}\left(600 \mathrm{MHz}, \mathrm{CDCl}_{3}\right)$ do rearranjo de Hurd-Claisen $4 \mathbf{a}(\boldsymbol{E})$.

Figura 21. Espectro de $\mathrm{RMN}$ de ${ }^{13} \mathrm{C}\left(150 \mathrm{MHz}, \mathrm{CDCl}_{3}\right)$ do rearranjo de Hurd-Claisen $4 \mathbf{a}(\boldsymbol{E})$.

Figura 22. Espectro de NOE do produto de rearranjo do isômero $4 \mathbf{a} \boldsymbol{E}$ puro. 53

Figura 23. Espectro de $\mathrm{RMN}$ de ${ }^{1} \mathrm{H}\left(600 \mathrm{MHz}, \mathrm{CDCl}_{3}\right)$ do rearranjo de Hurd-Claisen $4 \mathbf{h} . . .55$

Figura 24. Espectro de $\mathrm{RMN}$ de ${ }^{13} \mathrm{C}\left(150 \mathrm{MHz}, \mathrm{CDCl}_{3}\right)$ do rearranjo de Hurd-Claisen da mistura contendo os isômeros $4 \mathrm{~h}(\boldsymbol{E})$ e $\mathbf{4 h}(\boldsymbol{Z})$.

Figura 25. Espectro de NOE do produto de rearranjo de Hurd-Claisen da mistura dos isômeros 4h $(\boldsymbol{E})$ e $4 \mathbf{h}(\boldsymbol{Z})$, irradiando a metila do isômero $\boldsymbol{E}(1,81 \mathrm{ppm})$.

Figura 26. Espectro de NOE do produto de rearranjo de Hurd-Claisen da mistura dos isômeros 4h $(\boldsymbol{E})$ e $\mathbf{4 h}(\boldsymbol{Z})$, irradiando a metila do isômero $\boldsymbol{Z}(1,94$ ppm). 58

Figura 27. Dados apresentados por Rodrigues e Basavaiah e colaboradores. 59

Figura 28. Similaridade do caráter aromático do grupo $\mathbf{R}$ presente no rearranjo de HurdClaisen-4f com o grupo naftila. 65 


\section{ÍNDICE DE ESQUEMAS}

Esquema 1. Estado de transição proposto para estereosseletividade do rearranjo de HurdClaisen em AMBH. ${ }^{3}$ 2

Esquema 2. Reação de Morita-Baylis-Hillman a partir do acrilato de terc-butila....................3

Esquema 3. Rearranjo de Hurd-Claisen e seus possíveis isômeros geométricos......................3

Esquema 4. Reação de Ken-ichi Morita e colaboradores.$^{5}$.................................................... 4

Esquema 5. Reação geral de Morita-Baylis-Hillman. ${ }^{8}$ …..................................................

Esquema 6. Mecanismo de reação proposta por Hill e Issacs. ${ }^{13}$......................................... 6

Esquema 7. Mecanismos de reação de MBH propostos por Aggarwal e McQuade. ${ }^{14,15}$........7

Esquema 8. Síntese da 3-metileno cumarinas via rearranjo de Claisen de adutos de MBH.....8

Esquema 9. Estados de transição e OMF envolvidos no rearranjo de Claisen..........................

Esquema 10. Diastereosseletividade simples no rearranjo de Claisen................................. 10

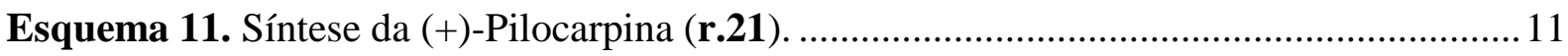

Esquema 12. Algumas variações do rearranjo de Claisen................................................. 12

Esquema 13. Síntese de olefinas trissubstituídas com diastereosseletividade $\boldsymbol{E}$..................... 14

Esquema 14. Reação de Johnson-Claisen, com formação de éster $\gamma, \delta$-insaturada.................. 15

Esquema 15. Síntese de éster $\gamma, \delta$-insaturada a partir de alquil 3-hidroxi-2-metil butanoato.. 15

Esquema 16. Síntese de piperidina-2,6-dionas, realizada por D. Basavaiah. ${ }^{38}$. 17

Esquema 17. Mecanismos propostos por D. Basavaiah e colaboradores para formar as piperidina-2,6-dionas $(\boldsymbol{E}){ }^{38}$

Esquema 18. Síntese de piperidin-2-onas, realizada por D. Basavaiah e colaboradores. ${ }^{39}$..... 19

Esquema 19. Síntese do fragmento estrutural $[1,8]$ naftiridina-2-ona...................................2 20

Esquema 20. Síntese total da (+)-cis-Hediona. ${ }^{42}$

Esquema 21. Síntese do (+)-jasmonato de metila a partir do rearranjo de Johnson-Claisen em $\mathrm{AMBH}^{42}$ 
Esquema 22. Resultados preliminares do rearranjo de Hurd-Claisen em AMBH obtidos por Rodrigues. $^{3}$

Esquema 23. Mecanismos proposto para formação do subproduto acetal e do polímero de EVE.

Esquema 24. Condição de reação otimizada para o rearranjo de Hurd-Claisen em adutos de $\mathrm{MBH}$.

Esquema 25. Modelo de ET proposto por Rodrigues baseado em efeito anomérico e na competição entre tensão alílica $\mathrm{A}^{1,3}$ versus tensão 1,3-diaxial aplicado ao rearranjo de HurdClaisen de adutos oriundos do acrilato de terc-butila. 62

Esquema 26. Interações orbitalres proposta para explicar a diastereosseletividade $\boldsymbol{E}$ no produto de rearranjo de Hurd-Claisen e Johnson-Claisen em adutos MBH. 64 


\section{ÍNDICE DE TABELAS}

Tabela 1. Resultados de D. Basavaiah para estereosseletividade em AMBH....................... 16

Tabela 2. Resultados obtidos por D. Basavaiah e colaboradores para síntese de r.43 .......... 18

Tabela 3. Resultados obtidos por D. Basavaiah e colaboradores para Síntese de r.46.......... 19

Tabela 4. Resultados obtidos por D. Basavaiah e Reddy para síntese de r.53 e tetraciclos....21

Tabela 5. Resultados obtidos por Das e colaboradores alterando o substrato.......................22

Tabela 6. Resultados obtidos por Kim e colaboradores alterando o substrato........................25

Tabela 7. Rendimentos obtidos para adutos de MBH aromáticos.......................................22

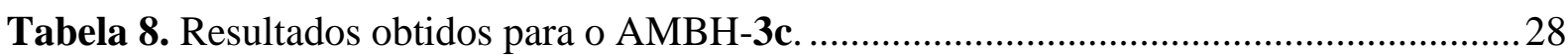

Tabela 9. Dados Espectroscópicos de $\mathrm{RMN} \mathrm{de}{ }^{1} \mathrm{H}$ e ${ }^{13} \mathrm{C}$ para o AMBH-3a.......................... 29

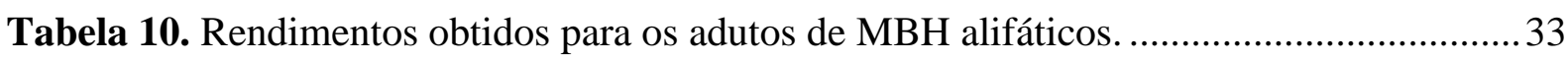

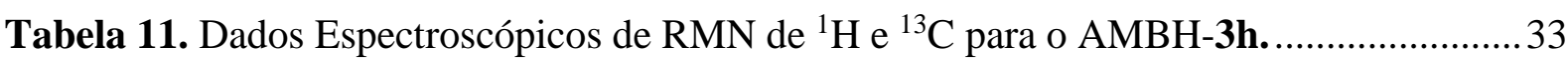

Tabela 12. Resultados obtidos para otimização do rearranjo de Hurd-Claisen variando os

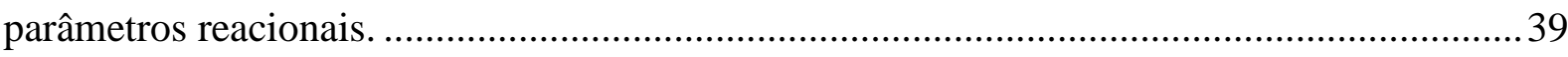

Tabela 13. Rendimentos obtidos para rearranjo de Hurd-Claisen dos AMBH 3c e 3h. .........48

Tabela 14. Dados Espectroscópicos de $\mathrm{RMN}$ de ${ }^{1} \mathrm{H}$ e ${ }^{13} \mathrm{C}$ para o rearranjo de Hurd-Claisen $4 \mathbf{a}$.

Tabela 15. Dados Espectroscópicos de RMN de ${ }^{1} \mathrm{H}$ e ${ }^{13} \mathrm{C}$ para o rearranjo de Hurd-Claisen $4 \mathbf{h}$

$(\boldsymbol{E})$ e $4 \mathrm{~h}(\boldsymbol{Z})$ 54

Tabela 16. Resultados obtidos para o rearranjo de Hurd-Claisen em AMBH aromáticos 3a-g.

Tabela 17. Resultados obtidos para o rearranjo de Hurd-Claisen em AMBH alifáticos 3h-k.61

Tabela 18. Comparação entre as razões $\boldsymbol{E}: \boldsymbol{Z}$ para o rearranjo de Hurd-Claisen em AMBH com diferentes substituintes $\mathrm{R}$ e R'. 63 


\section{ÍNDICE DE GRÁFICOS}

Gráfico 1. Concentração de acetato de mercúrio pela razão $\boldsymbol{E}: Z$..................................... 45

Gráfico 2. Estudo Cinético e tentativa de cessar a reação com adição de $\mathrm{Hg}(0)$. 


\section{1-INTRODUÇÃO}

Em 1991, Trost introduziu o princípio de economia de átomos no qual um método sintético ideal deveria incorporar todos os átomos dos reagentes no produto e, sendo necessário um catalisador, que este seja utilizado em quantidades sub estequiométricas, ou seja, com a mínima geração de resíduos. Metodologias assim parecem ser impossíveis mas, apesar das dificuldades, há várias reações como cicloadição, rearranjos e a reação de Morita-BaylisHillman (MBH), nas quais podemos minimizar os resíduos gerados. ${ }^{1}$

Além da economia de átomos outro requerimento fundamental para uma rota sintética eficiente, também discutido por Trost, diz respeito à seletividade: quimio (reatividade química preferencial por um grupo, sítio reativo), régio (quebra ou formação de ligações químicas preferencialmente sobre as demais) e estéreo (formação preferencial de um estereoisômero em detrimento do outro, enantiosseletividade ou - diastereosseletividade). ${ }^{2}$

Assim, a reação de $\mathrm{MBH}$, conduz à formação de um álcool alílico, passível de ser convertido em compostos carbonílicos $\gamma, \delta$-insaturado, via rearranjo de Claisen (clássico ou modificado), duas reações átomo econômicas. Os Adutos de Morita-Baylis-Hillman (AMBH), um $\alpha$-hidroxi alquil (benzil) acrilato, podem ser convertidos em um alceno com estereoquímica relativa $\boldsymbol{E}$ e $\boldsymbol{Z}$ por meio do rearranjo de Claisen. A razão diastereoisomérica, $\boldsymbol{E}: \boldsymbol{Z}$, do rearranjo de Claisen em AMBH tem sido discutida frente à preferência que determinados grupos alifáticos ou aromáticos tem de acomodar-se na posição pseudo equatorial ou pseudo axial no estado de transição cíclico concertado assíncrono de seis membros proposto para esta transformação. Deste modo, alguns modelos de estado de transição visam explicar a estereoespecificidade para a seletividade $\boldsymbol{E}$ ou $\boldsymbol{Z}$.

Recentemente, Rodrigues realizou um estudo da estereosseletividade do rearranjo de Hurd-Claisen em AMBH, observando uma significativa seletividade para a formação do produto de rearranjo com geometria $\boldsymbol{E}$, obtendo uma razão $\boldsymbol{E}: \boldsymbol{Z}$ entre 3 a 3,5:1 em adutos oriundos de aldeídos alifáticos e superiores a 14:1 para adutos oriundos de aldeídos aromáticos.

\footnotetext{
${ }^{1}$ Trost, B. M. Science. 1991, 254, 1471

${ }^{2}$ Trost, B. M. Science, 1983, 219, 245.
} 
Também foi proposto um modelo de estado de transição para esta transformação, que está baseado em efeitos estéreos e no efeito anomérico (Esquema 1). ${ }^{3}$

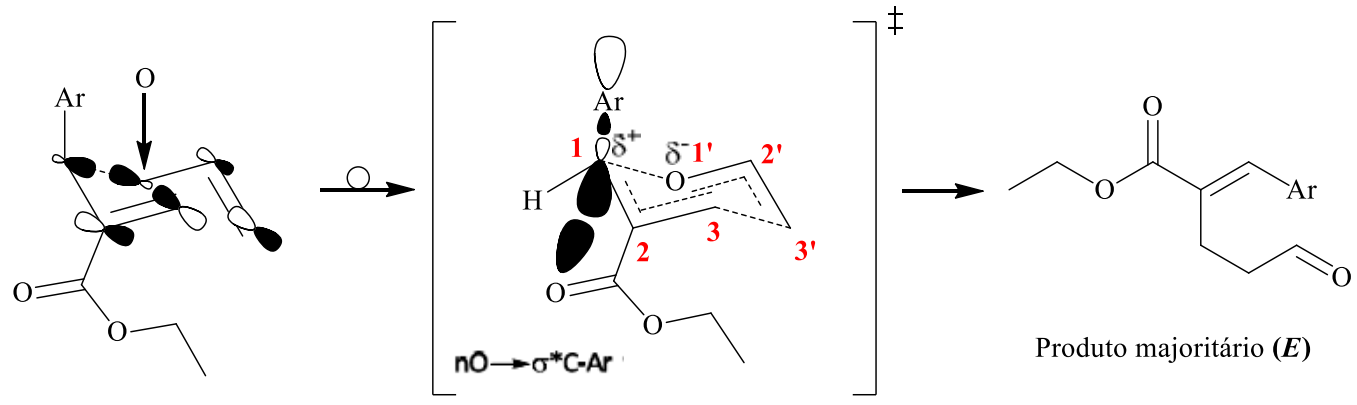

Esquema 1. Estado de transição proposto para estereosseletividade do rearranjo de HurdClaisen em AMBH. ${ }^{3}$

${ }^{3}$ Rodrigues, T. C. A. F. Rearranjo de Claisen clássico em adutos de Morita-Baylis-Hillman. 2014. 128 f. Dissertação (Mestrado em Química) - Instituto de Química, Universidade de Brasília, Brasília. 


\section{2-OBJETIVOS}

A presente dissertação de mestrado tem como objetivo principal avaliar o efeito estéreo do grupo terc-butila na estereosseletividade do rearranjo de Hurd-Claisen em adutos de MoritaBaylis-Hillman sob aquecimento convencional.

O primeiro objetivo específico deste trabalho é sintetizar adutos de Morita-BaylisHillman aromáticos e alifáticos através da reação entre o acrilato de terc-butila e diversos aldeídos (Esquema 2).

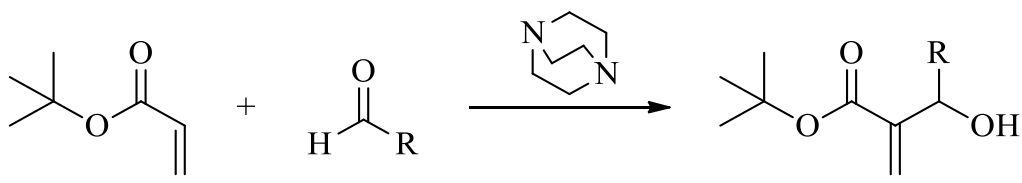

Esquema 2. Reação de Morita-Baylis-Hillman a partir do acrilato de terc-butila.

O segundo objetivo específico é a realização do estudo sistemático das conversões e estereosseletividade do rearranjo de Hurd-Claisen sob aquecimento convencional pela ação de acetato de mercúrio (II) e etil vinil éter (Esquema 3).

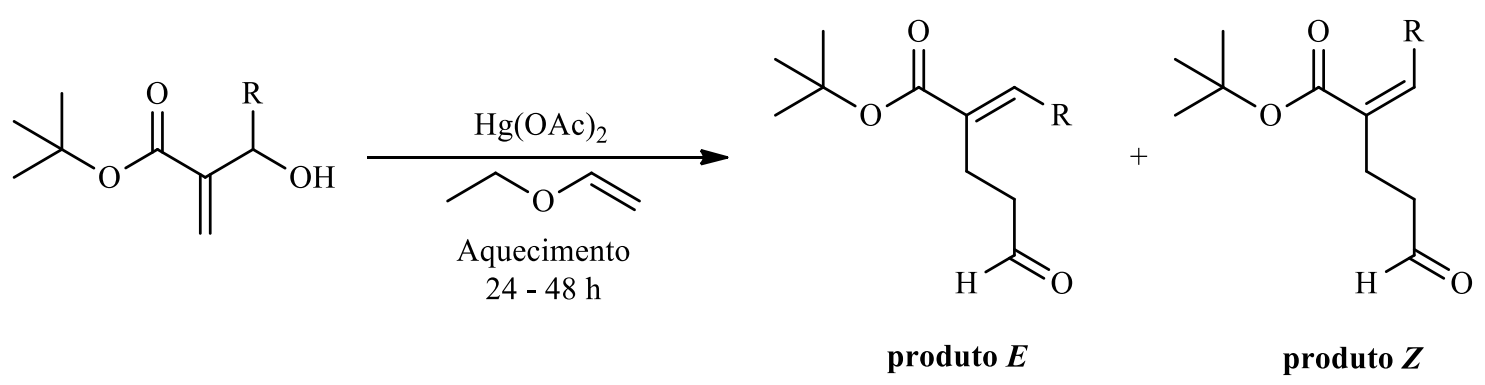

Esquema 3. Rearranjo de Hurd-Claisen e seus possíveis isômeros geométricos.

De posse dos resultados de conversão e estereosseletividade para o rearranjo de HurdClaisen em AMBH e por meio da comparação dos resultados obtidos pelos trabalhos desenvolvidos anteriormente na literatura, aprimorar o modelo de estado de transição proposto para explicar a estereosseletividade do rearranjo de Hurd-Claisen em Adutos de Morita-BaylisHillman. 


\section{3-REVISÃO BIBLIOGRÁFICA}

\section{1-ADUTOS DE MORITA-BAYLIS-HILLMAN}

Novas metodologias sintéticas que estejam amparadas nos princípios da Química Verde (QV) têm chamado a atenção dos químicos orgânicos sintéticos, devido à crescente preocupação com o meio ambiente. ${ }^{4}$ Assim, QV em síntese orgânica pode ser definida como a obtenção de moléculas a partir de reagentes com baixa toxicidade e reações que potencializem a economia atômica, reduzindo, deste modo, a formação de subprodutos e resíduos.

Antes mesmo dos princípios da QV surgirem, em 1968, Ken-ichi Morita e colaboradores, reagiram vários aldeídos (r.1) com olefinas (r.2) tendo um Grupo Retirador de Elétrons (GRE), acrilonitrila ou acrilato de metila, na presença de triciclohexilfosfina como catalisador e obtiveram diferentes adutos ${ }^{5}$ (produto de adição entre duas moléculas resultando em um único produto) $)^{6}, \mathbf{r . 3}$ (Esquema 4). Esta reação apresenta economia de átomos, porém utiliza um catalisador tóxico.

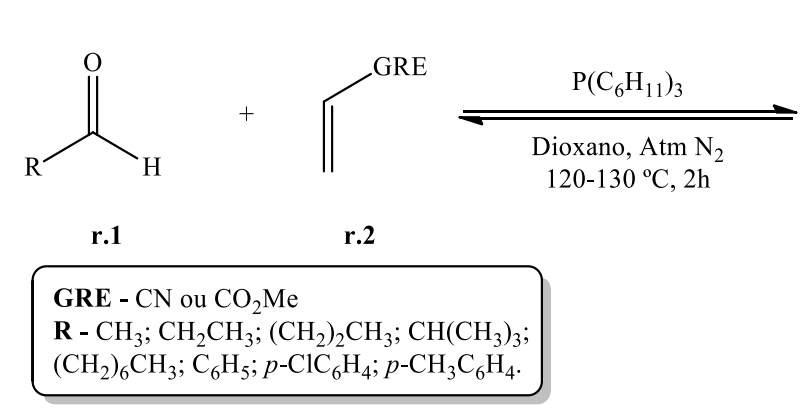<smiles>[R]C(O)C(=C)OCCO</smiles>

r.3

$70-90 \%$

Esquema 4. Reação de Ken-ichi Morita e colaboradores. ${ }^{5}$

Em 1972, A. B. Baylis e D. E. M. Hillman substituíram o catalisador utilizado por Morita, $\mathrm{P}\left(\mathrm{C}_{6} \mathrm{H}_{11}\right)_{3}$, por outra base de Lewis, o 1,4-diazobiciclo[2.2.2] octano (DABCO). Esta reação passou então a ser conhecida como reação de Morita-Baylis-Hillman. ${ }^{7}$ Os AMBH têm sido constantemente estudados, por serem intermediários em síntese orgânica que possuem alta versatilidade, pois são substâncias multifuncionalizadas. Esta característica se deve à variabilidade da estrutura do eletrófilo (r.4), do alceno ativado (r.5), e à ortogonalidade

\footnotetext{
${ }^{4}$ Lenardão, E. J.; et al. Quim. Nova. 2003, 26, 123.

${ }^{5}$ Morita, K.; Suzuki, Z.; Hirose, H. Bull. Chem. Soc. Jpn. 1968, 41, 2815.

${ }^{6}$ IUPAC. Compendium of Chemical Terminology, $2^{\mathrm{a}}$ ed. ("Livro de Ouro"). Compilado por A. D. McNaught; A. Wilkinson. Blackwell Scientific Publications, Oxford, 1997.

${ }^{7}$ Baylis, A. B.; Hillman, M. E. D.; German Patent 2155113, 1972, Chem. Abstr. 1972, 77, 34174q.
} 
observada na reatividade dos grupos funcionais presentes no produto (r.6). Estes ainda possibilitam a construção de ligações $\mathrm{C}-\mathrm{C}$ com formação de pelo menos um centro estereogênico (Esquema 5). ${ }^{8}$<smiles>[R]C([R])=[V]</smiles>

r.4<smiles>C=COc1ccccc1</smiles>

r.5

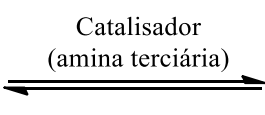

R e R' - alquil, aril, $\mathrm{CO}_{2} \mathrm{R}$

$\mathbf{X}-\mathrm{O}$ ou $\mathrm{N}\left(\stackrel{+}{\mathrm{N}} \mathrm{R}_{2}, \mathrm{NCO}_{2} \mathrm{R}, \mathrm{NTs}, \mathrm{NSO}_{2} \mathrm{Ph}\right)$

GRE - Grupo Retirador de Elétrons

\section{Esquema 5. Reação geral de Morita-Baylis-Hillman. ${ }^{8}$}

Estas reações podem demandar semanas para a sua conclusão. Assim, um número significativo de artigos vem sendo publicados visando a obtenção dos AMBH em condições reacionais com uma maior taxa de reação do produto através da utilização de baixas temperaturas, uso de quantidade subestequiométricas* ou mesmo estequiométricas de catalisador, alta pressão, uso de solventes e irradiação de microondas ou ultrassom. Dentre os insumos utilizados nesta reação, o catalisador tem recebido maior atenção, sendo que uma grande variedade de aminas terciárias tem sido utilizadas (Figura 1). ${ }^{9,} 10,11$

Morita, 1968<smiles>C1CCC(P(C2CCCCC2)C2CCCCC2)CC1</smiles>

triciclohexilfosfina
Baylis-Hillman, 1972

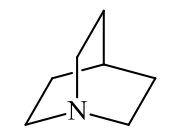

quinuclidina
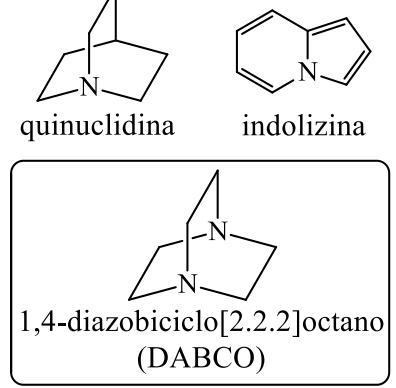

Algumas variações

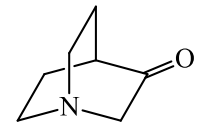

$(1 \mathrm{~S}, 4 \mathrm{~S})$-quinuclidin-3-ona

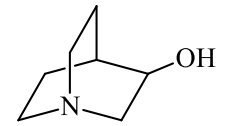

(1S, 4S) -quinuclidin-3-ol (3-QDL)

Figura 1. Alguns catalisadores utilizados nas reações de Morita-Baylis-Hillman.

A reação de MBH é uma importante reação de formação de ligação Carbono-Carbono e, atualmente, apresenta diversas propostas para o mecanismo de formação dos adutos.

\footnotetext{
${ }^{8}$ Coelho, F.; Almeida, W. P. Química Nova, 2000, 23, 98.

${ }^{9}$ Drewes, S. E.; Roos, G. H. P. Tetrahedron, 1988, 44, 4653.

${ }^{10}$ Basavaiah, D.; Reddy, B. S,; Badsara, S. S. Chem. Rev. 2010, 110, 5447.

${ }^{11}$ Wei, Y.; Shi, M. Chem. Rev. 2013, 113, 6659.
} 
Hoffmann e Rabe ${ }^{12}$ foram uns dos primeiros a propor um mecanismo para reação de MBH através da formação do aduto intermediário zwitteriônico r.9. Este, após sofrer uma $\beta$ eliminação do catalisador, leva ao AMBH. Em 1990, Hill e Issacs ${ }^{13}$ realizaram estudo cinético deste mecanismo e sugeriram que a etapa determinante da reação (etapa 2) seria a adição à carbonila (Esquema 6).

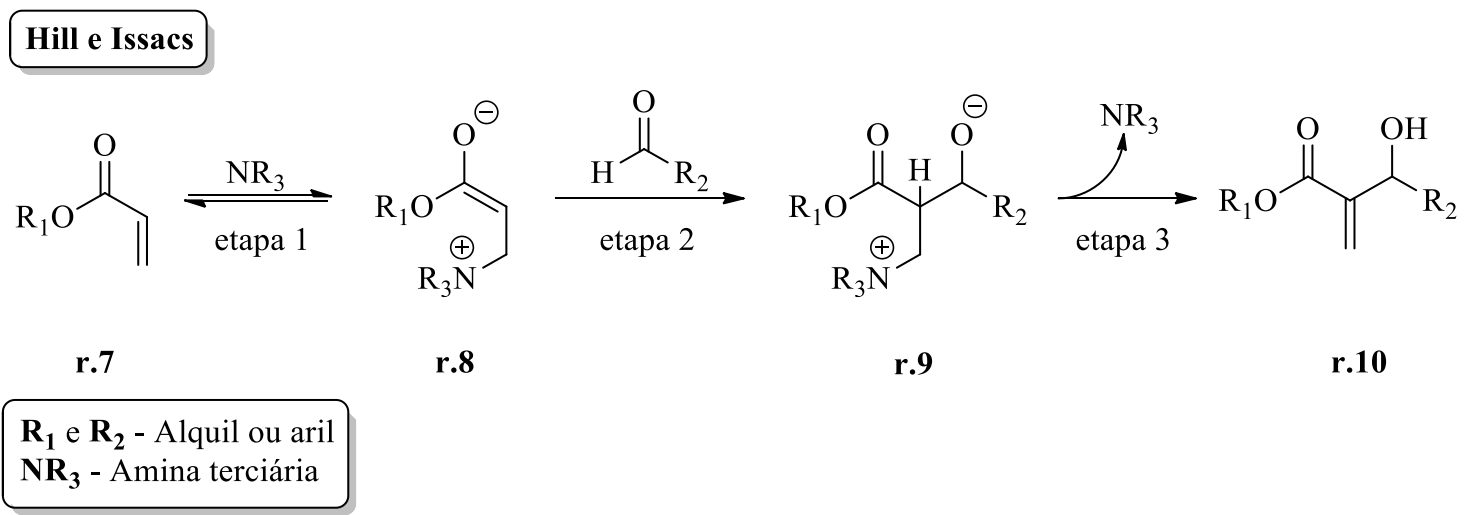

Esquema 6. Mecanismo de reação proposta por Hill e Issacs. ${ }^{13}$

Em 2005, Aggarwal ${ }^{14}$ e McQuade ${ }^{15}$ propuseram, independentemente, que a etapa determinante da reação seria uma transferência de próton. Aggarwal discute o efeito de solventes polares próticos para transferir o hidrogênio intermolecularmente, r.9'a. Por fim, McQuade propõe a formação de um hemiacetal, r.9'b, pela adição do intermediário zwitteriônico r.9, a uma segunda molécula do aldeído (Esquema 7).

\footnotetext{
${ }^{12}$ Hoffmann, H. M. R.; Rabe, J. Angew Int Ed. Engl. 1983, 22, 795.

* Quantidades subestequiometricas de catalisador inferiores a $10 \mathrm{~mol} \%$ são denominadas de quantidades catalíticas.

${ }^{13}$ Hill, J. S.; Isaacs, N. S. J. Phys. Org. Chem. 1990, 3, 285.

${ }^{14}$ Aggarwal, V. K.; Fulford, S. Y.; Lloyd-Jones, G. C. Angew. Chem. Int. Ed. 2005, 44, 1706.

${ }^{15}$ Price, K. E.; Broadwater, S. J., Walker, B. J.; McQuade, D. T. J. Org. Chem, 2005, 70, 3980.
} 


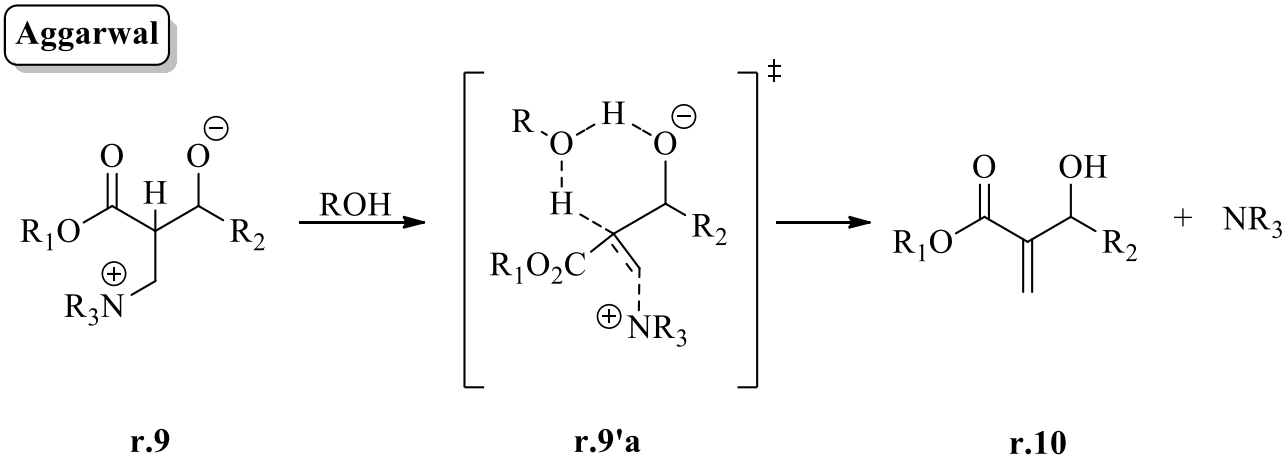

\section{McQuade}

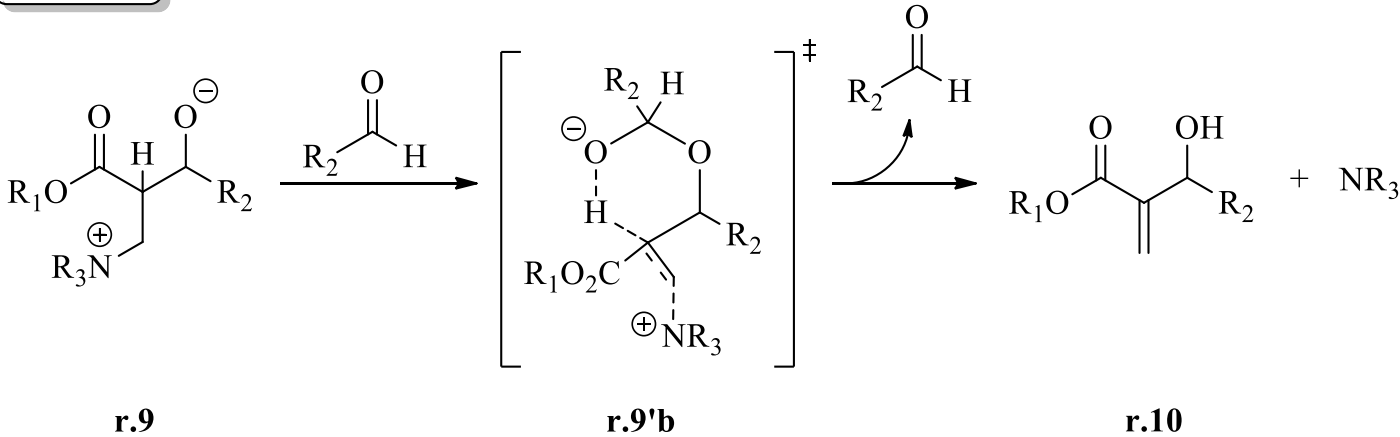

Esquema 7. Mecanismos de reação de MBH propostos por Aggarwal e McQuade. ${ }^{14,15}$

Apesar dos recentes estudos sobre o mecanismo de reação mais provável para a reação de $\mathrm{MBH}$, ainda não há uma unanimidade quanto ao caminho de reação mais concreto, pois, a reação surgiu a mais de 40 anos e estudos mecanísticos ainda estão sendo realizados. Entretanto, devemos levar em conta a diversidade de reagentes e catalisadores empregados na reação de MBH. Há de se considerar que ambas as propostas são passíveis de acontecer e estudos mecanísticos mais detalhados podem ser encontrados nos trabalhos de Robiette, Aggarwal e Harvey ${ }^{16}$, Cantillo e Kappe ${ }^{17}$, Neto e colaboradores ${ }^{18}$ e Plata e Singleton. ${ }^{19}$ Contudo, a proposta de McQuade parece ser mais promissora devido o intermediário hemiacetal, r.9’b, ter sido identificado recentemente por Coelho e colaboradores. ${ }^{20}$

\section{2-REARRANJO DE ClAisen EM ADUTOS DE MORITA-BAYLIS-HILLMAN}

A reação de $\mathrm{MBH}$ leva à formação de $\alpha$-hidroxi alquil acrilato, r.11, um álcool alílico, que em determinadas condições leva à formação de um intermediário passível de se rearranjar.

\footnotetext{
${ }^{16}$ Robiette, R.; Aggarwal, V. K.; Harvey, J. N. J. Am. Chem. Soc. 2007, 129, 15513.

${ }^{17}$ Cantillo, D. Kappe, C. O. J. Org. Chem. 2010, 75, 8615.

${ }^{18}$ Rodrigues, T. S. et al. J. Org. Chem. 2014, 79, 5239.

${ }^{19}$ Plata, R. E.; Singleton, D. A. J. Am. Chem. Soc. 2015, 137, 3811.

${ }^{20}$ Galaverna, R.; Camilo, N. S.; Godoi, M. N.; Coelho, F.; Eberlin, M. N. J. Org. Chem. 2016, 81, 1089.
} 
Assim, em 1984, Rajagopalan e colaboradores ${ }^{9,21}$ na busca de uma nova rota sintética para derivados de metileno cumarinas, perceberam que r.12, na presença de um ácido de Lewis, convertia para r.13, via rearranjo de Claisen. Este tautomerizou in situ para r.14 e após tratamento da reação, r.15 foi obtido com $76 \%$ de rendimento (Esquema 8). Apesar de não descrito pelos autores, o material de partida, r.11, pode ser obtido pela reação de MBH entre formaldeído e o acrilato de metila. ${ }^{22}$
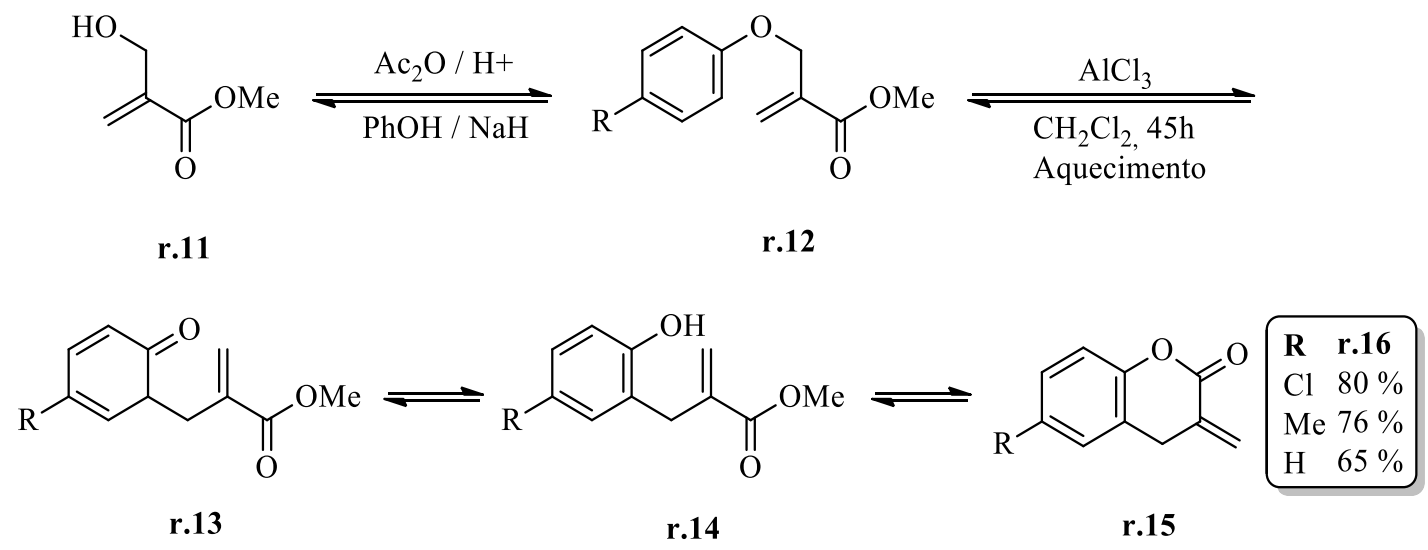

Esquema 8. Síntese da 3-metileno cumarinas via rearranjo de Claisen de adutos de MBH.

Desde a sua descoberta em 1912 por Ludwig Claisen, ${ }^{23}$ o rearranjo de Claisen, tem se destacado na formação de ligação Carbono-Carbono. O rearranjo sigmatrópico [3,3] acontece por meio de um estado de transição cíclico, concertado e não sincronizado de seis membros e é classificado como termicamente permitido pela teoria de Orbitais Moleculares de Fronteira $(\mathrm{OMF})$. Este ocorre pela quebra da ligação sigma $(\delta)$ entre os átomos $\mathrm{C} 1$ e $\mathrm{O} 1$ ' e a formação de uma nova ligação $\delta$ entre C3 e C3', concomitantemente com migração de duas ligações $\pi$, anteriormente entre os carbonos C2-C3 e C2'-C3', para C1 e C2, bem como, para a formação do grupo carbonila $\gamma, \delta$-insaturado entre $\mathrm{C}^{\prime}$ ' e $\mathrm{O} 1$ ', respectivamente (Esquema 9).

\footnotetext{
${ }^{21}$ Sunith, K.; Balasubramanian, K. K.; Rajagopalan, K. Tetrahedron Lett. 1984, 25, 3125.

${ }^{22}$ Solano, L. N.; et al. Bioorganic \& Medicinal Chemistry Lett. 2015, 25, 5777.

${ }^{23}$ Claisen, L. Chem. Ber. 1912, 45, 3157.
} 


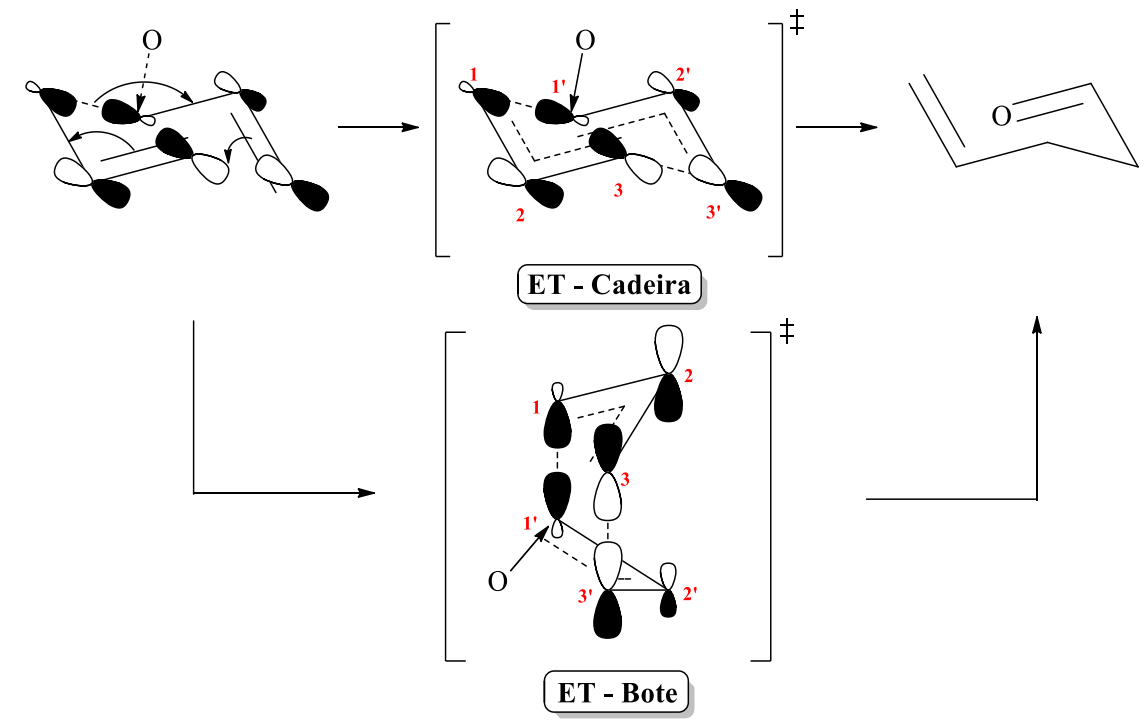

Esquema 9. Estados de transição e OMF envolvidos no rearranjo de Claisen.

A modificação do alil vinil éter pode ocorrer através de três possíveis estados de transição (ET): aromático, radicalar ou par iônico. Houk e colaboradores realizaram estudo teórico da estrutura do ET para os rearranjos de Cope e Claisen. Os dados sugerem que o ET é aromático e a conformação cadeira é 5,0-6,0 $\mathrm{kcal} \mathrm{mol}^{-1}$ mais estável que a conformação tipo bote, onde as interações secundárias dos orbitais desestabilizam este ET. ${ }^{24}$ Em 2013, Iwakura e colaboradores ratificaram, através dos dados de espectroscopia vibracional, a hipótese de que o rearranjo de Claisen ocorre por um ET aromático, concertado e assíncrono. ${ }^{25}$

Estas características do ET do rearranjo de Claisen permitem prever o curso estereoquímico da reação, e consequentemente, a configuração dos centros estereogênicos formados, bem como, a geometria da ligação dupla resultante. Haja vista que as informações de estereoquímica absoluta e/ou relativa são transferidas para o produto estereoespecificamente. ${ }^{26}$ A associação de olefinas $\boldsymbol{E} / \boldsymbol{Z}$ no reagente conduz ao produto anti (equação E-I) e a combinação $\boldsymbol{Z} / \boldsymbol{Z}$ ou $\boldsymbol{E} / \boldsymbol{E}$ ao produto syn (equação E-II). Outra consequência é que há perda de informações de quiralidade no centro estereogênico (equação E-III), porém há formação preferencial do aldeído com ligação dupla trans ao grupo R (Esquema 10). ${ }^{27}$

\footnotetext{
24 (a) Wiest, O.; Black, K. A.; Houk, K. N. J. Am. Chem. Soc. 1994, 116, 10336. (b) Yoo, H. Y.; Houk, K. N. J. Am. Chem. Soc. 1994, 116, 12047.

${ }^{25}$ Iwakura, I.; Kaneko, Y.; Hayashi, S.; Yabushita, A.; Kobayashi, T. Molecules, 2013, 18, 1995.

${ }^{26}$ Ziegler, F. E.; Acc. Chem. Res. 1977, 10, 227.

${ }^{27}$ Hiesermann, M.; Nubbemeyer, U. The Claisen Rearrangment: Methods and Applications. Wiley: Weinheim, 2007, p. 5354.
} 


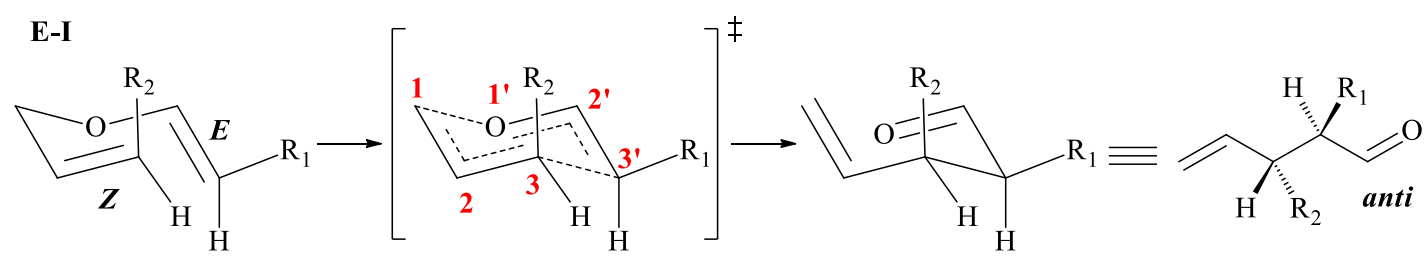

E-II

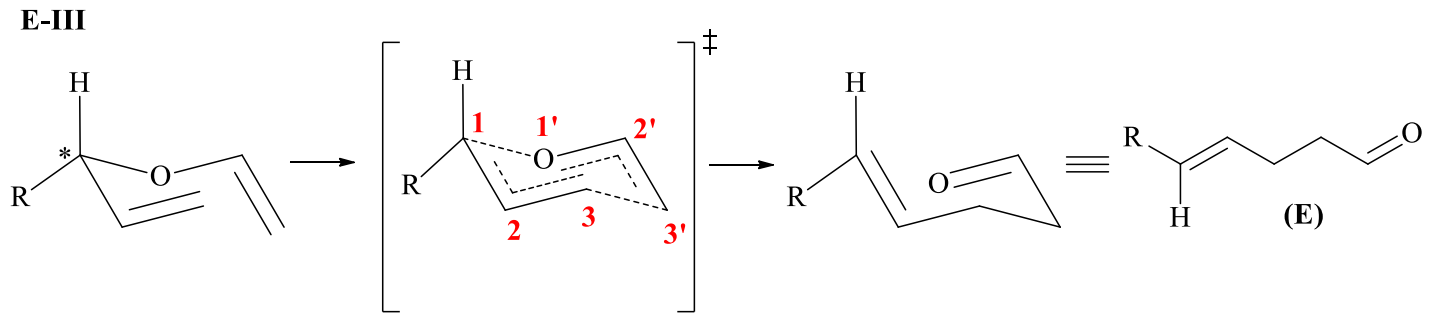

E-I: $(Z, E)$ ou $(E, Z), \mathbf{E}$-II: $(E, E)$ ou $(Z, Z), \mathbf{E}-\mathbf{I I I}: \mathrm{R}$ - alquil ou aril.

Esquema 10. Diastereosseletividade simples no rearranjo de Claisen.

Outro exemplo de rearranjo de Claisen em AMBH descrito na literatura, encontra-se no trabalho de George Büchi e colaboradores na síntese da (+)-Pilocarpina (r.21), um agente terapêutico utilizado no tratamento de glaucoma. Partindo de r.16 o álcool alílico r.17 é obtido após quatro etapas. Este é tratado com etil vinil éter na presença de acetato de mercúrio a $140^{\circ} \mathrm{C}$ levando ao intermediário r.18, que se rearranja para os produtos r.19a e r.19b numa proporção $\boldsymbol{Z}: \boldsymbol{E}$ de 2:1. Após introdução do centro estereogênico o isômero $\boldsymbol{Z}$ foi submetido à reação de hidrogenação, obtendo r.20, que foi submetido a mais duas etapas reacionais para formação do anel $N$-metil imidazólico, concluindo a síntese da (+)-Pilocarpina (r.21) (Esquema 11). ${ }^{28}$

${ }^{28}$ Horne, A. D.; Fugmann, B.; Yakushijin, K.; Buchi, G. J. Org. Chem. 1993, 58, 62. 
1. $\mathrm{NaH}, \mathrm{THF}, 0^{\circ} \mathrm{C}$ pentano, $\mathrm{PhSeCl}, 1 \mathrm{~h}$<smiles>CC(=O)C1CCOC1=O</smiles>

2. Ciclopentadieno, $\mathrm{CH}_{2} \mathrm{Cl}_{2}, \mathrm{H}_{2} \mathrm{O}_{2}, 0^{\circ} \mathrm{C}, 5 \mathrm{~h}$

3. Destilação, Pirólise, $425^{\circ} \mathrm{C}$

4. $(+)-\mathrm{Ipc}_{2} \mathrm{BCl}, \mathrm{THF}$,

r.16 $\operatorname{Ar}(\mathrm{g}),-30^{\circ} \mathrm{C}, 5$ dias<smiles>C[C@H](O)C1=CCOC1=O</smiles><smiles>CC=COCC</smiles>

r.17

$60 \%$<smiles>CC1=C2C(=O)OCC2=CCO1</smiles>

r.18<smiles>CC=C1C(=O)OC[C@@H]1CC=O</smiles>

r.19a $48 \%$<smiles>CC[C@H]1C(=O)OC[C@@H]1CC=O</smiles>

r.20<smiles>C/C=C1/C(=O)OC[C@H]1CC=O</smiles>

r.19b

$23 \%$

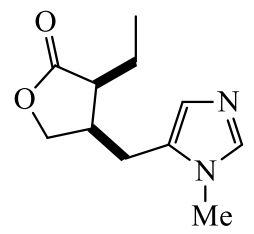

r.21 $61 \%$ r.19a
$48 \%$

Esquema 11. Síntese da (+)-Pilocarpina (r.21).

O rearranjo de Claisen em adutos de Morita-Baylis-Hillman ainda é pouco explorado em síntese de produtos naturais com atividade biológica. Contudo, algumas variações do rearranjo sigmatrópico $[3,3]$ do tipo Claisen (Esquema 12) ${ }^{29}$ com destaque para o rearranjo de Johnson-Claisen e Eschenmoser-Claisen têm sido explorado na formação de substâncias orgânicas de interesse, tendo como material de partida um AMBH. 


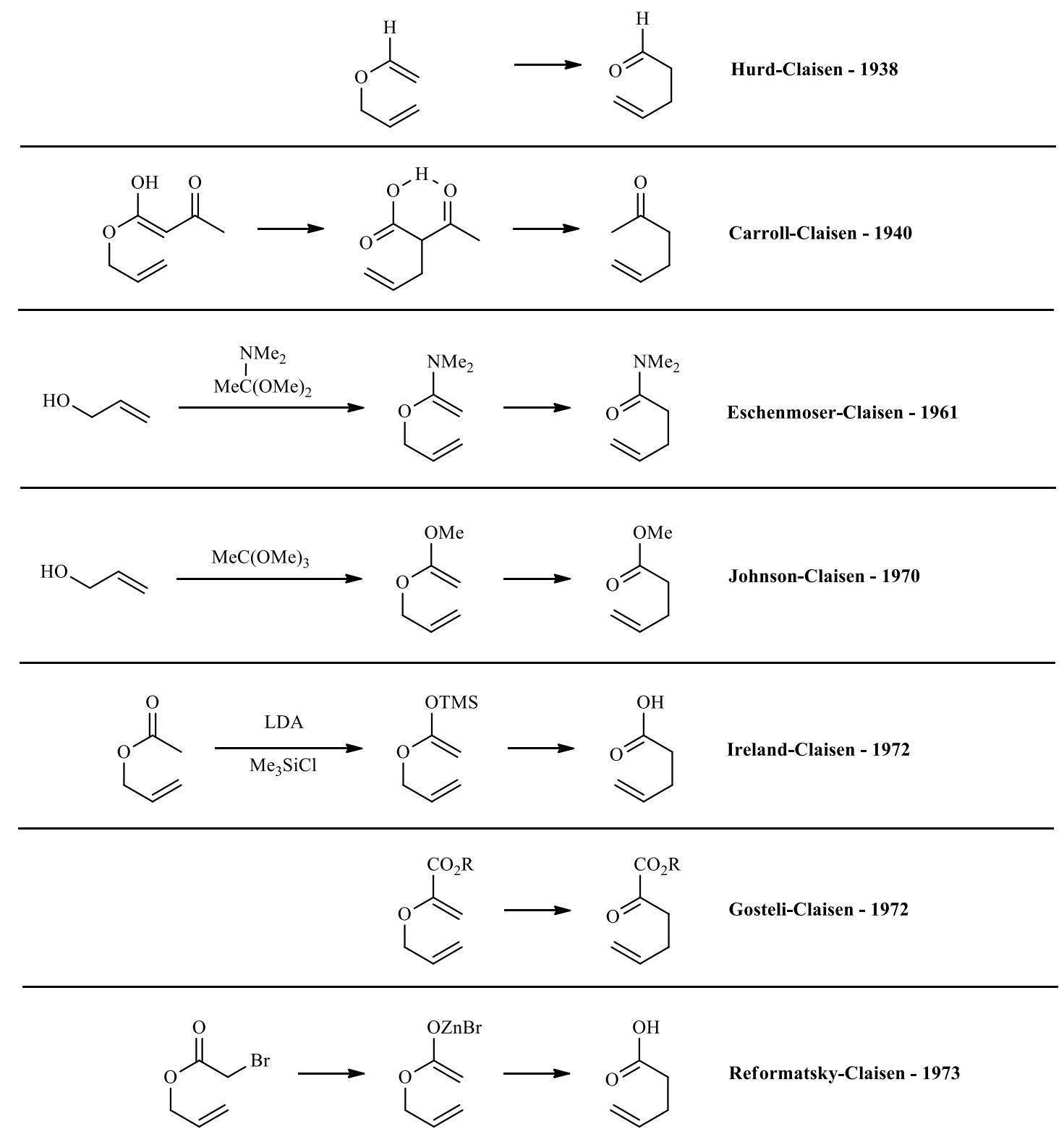

Esquema 12. Algumas variações do rearranjo de Claisen.

Essas variações do rearranjo de Claisen correlacionam-se ao efeito dos substituintes no carbono 2 do alil vinil éter (Figura 2). Contudo, a presença de Grupos Doadores de Elétrons (GDE) ou Grupos Retiradores de Elétrons (GRE), em determinadas posições, conduz a condições reacionais mais brandas e com maior taxa de reação. Os trabalhos de Schulear, Carpenter e Houk, ${ }^{30}$ contribuíram para estudo do efeito dos substituintes no alil vinil éter, no rearranjo sigmatrópico [3,3].

${ }^{30}$ (a) Schuler, F. W.; Murphy, G. W. J. Am. Chem. Soc. 1950, 72, 3155. (b) Burrows, C. J.; Carpenter, B. K. J. Am. Chem. Soc. 1981, 103, 6983. (c) Yoo, H. Y.; Houk, K. N. J. Am. Chem. Soc. 1997, 119, 2877. (d) Aviyente, V.; Yoo, H. Y.; Houk, K. N. J. Am. Chem. Soc. 1997, 119, 6121. 


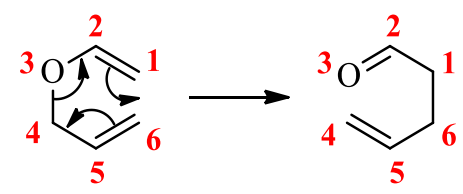

Figura 2. Estrutura do alil vinil éter.

Em uma previsão qualitativa, a presença de GDE nas posições 1, 2, 4 e 6 diminui a energia de ativação e, consequentemente, conduz a uma maior taxa de reação, porém na posição 5 este efeito é contrário. Os GRE nas posições 2, 4 e 5 proporcionam menor energia de ativação e, por conseguinte, aumentam a velocidade da reação, mas GRE nas posições 1 e 6 possui efeito contrário. $^{29 \mathrm{a}}$

Além dos efeitos doadores e retiradores de elétrons em diferentes posições do alil vinil éter também há de se considerar outros efeitos estabilizantes que conduzem a uma menor ou maior taxa de reação. Outra característica do efeito dos substituintes é que estes podem também conduzir ao aumento da diastereosseletividade no rearranjo de Claisen. Em 1969, Perrin e Faulkner publicaram um artigo descrevendo o efeito dos substituintes no estado de transição. ${ }^{31}$ Os autores sugerem que a interação estérea provocada pelos substituintes pode aumentar a estereosseletividade (Figura 3).

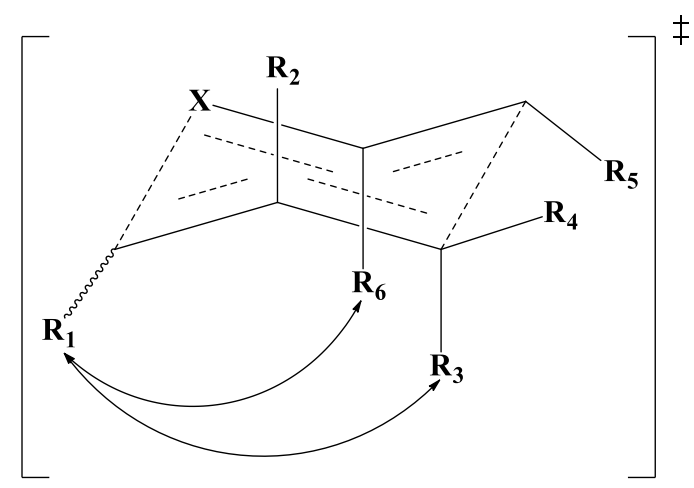

Figura 3. ET proposto por Perrin e Faulkner, baseado na interação syn-axial.

Neste mesmo ano, Faulkner e Petersen relataram uma rota sintética para olefinas trissubstituídas com diastereosseletividade para o isômero $\boldsymbol{E}$ (equação R-I). Além disso, introduzindo um substituinte volumoso no carbono 2 , os autores também realizaram uma rota 
sintética para formação de uma amida e uma cetona $\gamma, \delta$-insaturado (equações R-II e R-III), com alta seletividade para o produto $\boldsymbol{E}$ (Esquema 13). ${ }^{32}$

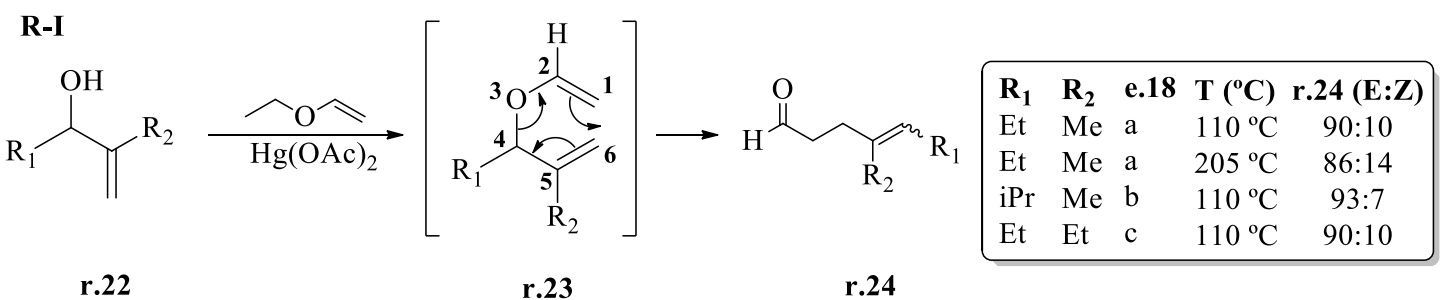

R-II

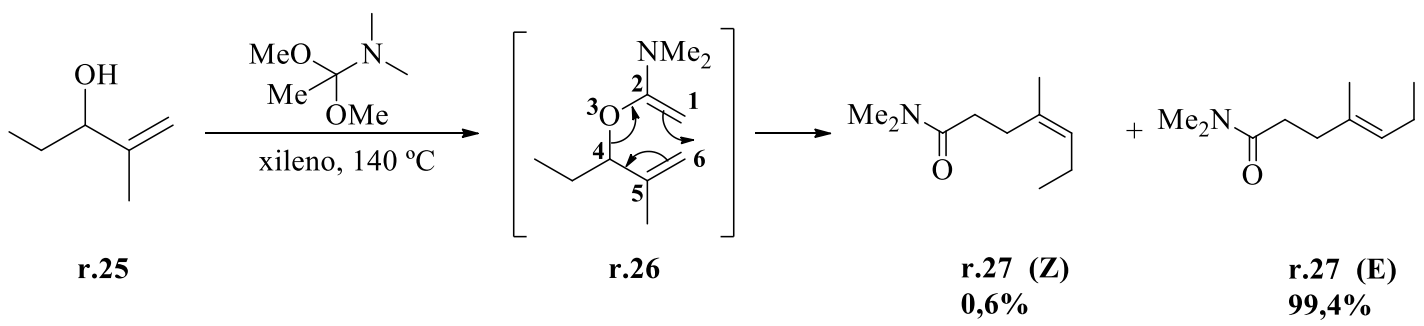

R-III

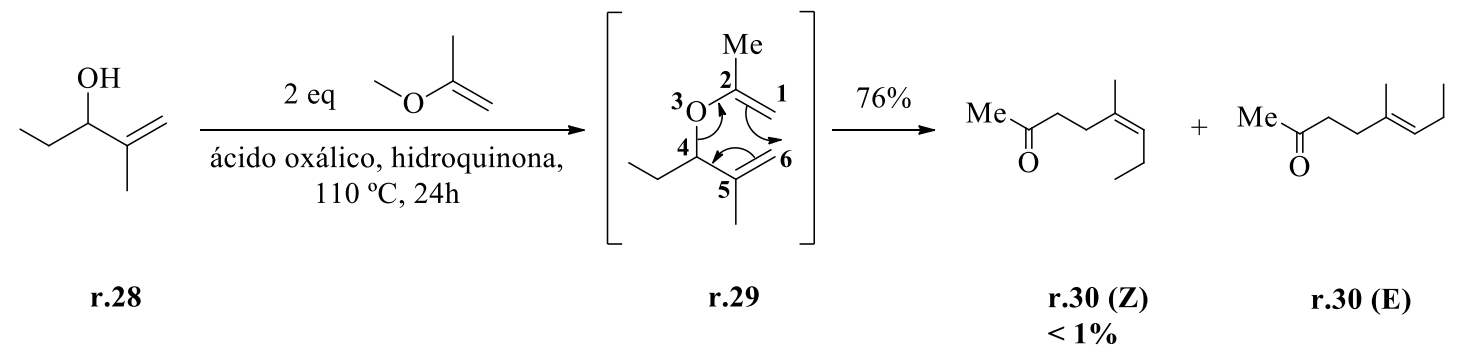

Esquema 13. Síntese de olefinas trissubstituídas com diastereosseletividade $\boldsymbol{E}$.

Os autores justificam o aumento da seletividade para o produto de rearranjo com ligação dupla $\boldsymbol{E}$ devido à tensão 1,3-diaxial entre o $\mathrm{NMe}_{2}$ ou $\mathrm{Me}$ com o grupo Etila do centro estereogênico, que pode se acomodar na posição pseudo axial ou pseudo equatorial (Figura 4).

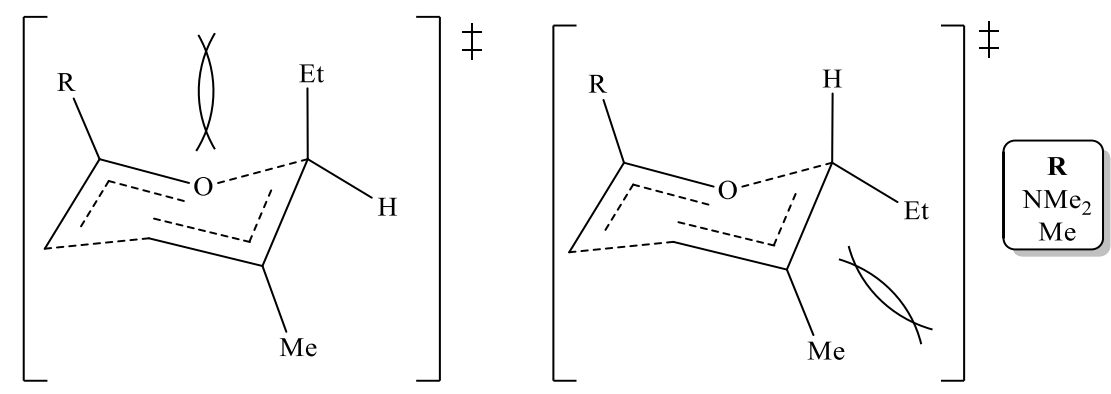

Figura 4. ET de Faulkner e Petersen para explicar a seletividade $\boldsymbol{E}$. Baseado na tensão 1,3diaxial clássica. 
A reação R-II no Esquema 13, rearranjo de Eschenmoser-Claisen, foi primeiramente publicada em 1964. Na primeira versão desta reação, um álcool alílico é tratado com $N, N$ dimetilacetamida dimetil acetal, na presença de xileno a $150^{\circ} \mathrm{C}$, conduzindo a um intermediário similar a r.26, que sobre rearranjo sigmatrópico [3,3] para viabilizar uma amida $\gamma, \delta$ insaturada. ${ }^{33}$

Seguindo a mesma lógica para se obter olefinas trissubstituidas, William S. Johnson e colaboradores $^{34}$ relataram a reação do álcool alílico r.31, na presença de ortoacetato de etila em meio ácido, obtendo éster $\gamma, \delta$-insaturada $\mathbf{r . 3 4}$, também com alta seletividade para o isômero $\boldsymbol{E}$ (Esquema 14).

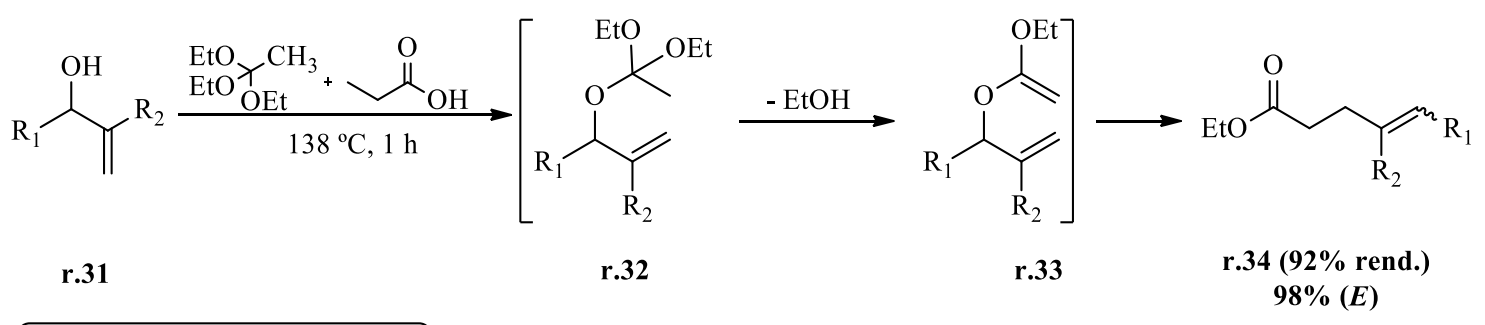

$\mathbf{R}_{1}-\mathrm{CH}_{2} \mathrm{CH}_{2} \mathrm{C}(\mathrm{Me}) \mathrm{CH}_{2} \mathbf{R}_{2}-\mathrm{Me}$

Esquema 14. Reação de Johnson-Claisen, com formação de éster $\gamma, \delta$-insaturada.

Em 1990, Drewes e colaboradores ${ }^{35}$ publicaram o primeiro relato da utilização de adutos de $\mathrm{MBH}$ em um rearranjo de Johnson-Claisen. Olefinas trissubstituidas foram obtidas como produto desta reação, tendo o isômero geométrico $\boldsymbol{Z}$ como isômero majoritário (Esquema 15).

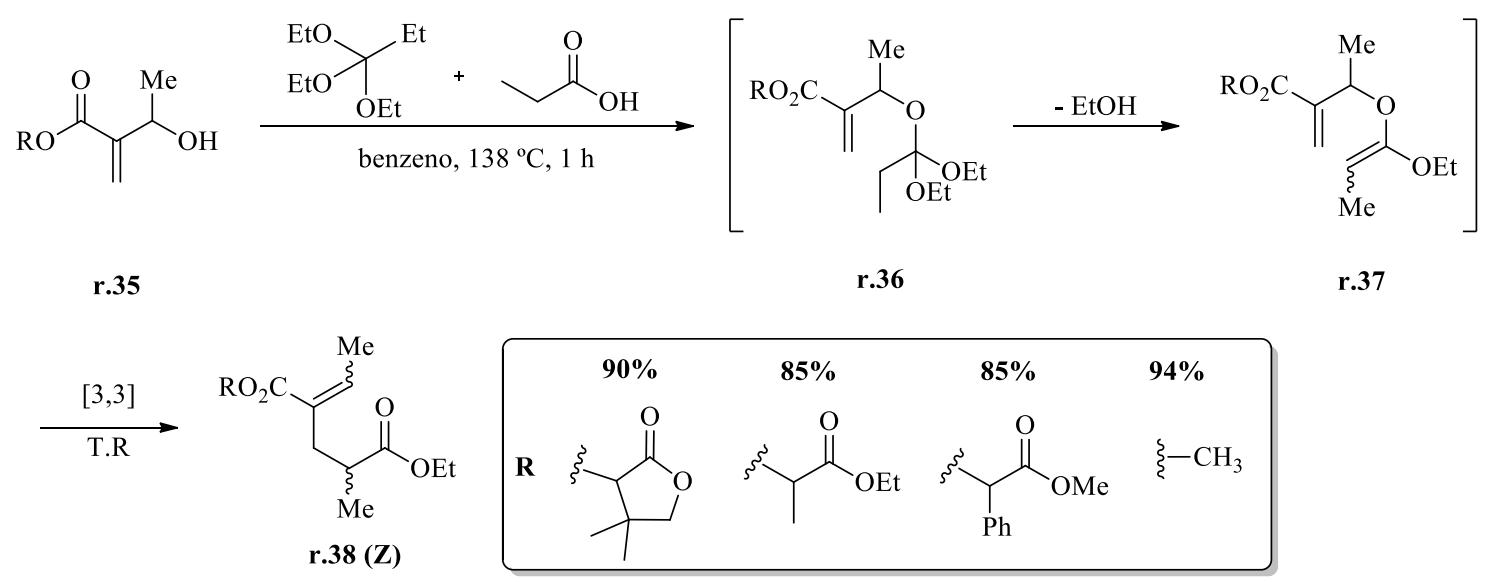

Esquema 15. Síntese de éster $\gamma, \delta$-insaturada a partir de alquil 3-hidroxi-2-metil butanoato.

\footnotetext{
${ }^{33}$ Wick, A. E.; Felix, D.; Steen, K.; Eschenmoser, A. Helv. Chim. Acta, 1964, 47, 2425.

${ }^{34}$ Johnson, W. S.; et al. J. Am. Chem. Soc. 1970, 92, 741.

${ }^{35}$ Drewes, S. E.; Emslie, N. D.; Karodia, N.; Loizou, G. Synthetic Commun, 1990, 20, 1437.
} 
Em 1995, D. Basavaiah e Pandiaraju realizaram o rearranjo de Johnson-Claisen em AMBH obtidos a partir da reação de vários aldeídos com o grupo nitrila como GRE no alceno. ${ }^{36}$ Independentemente do grupo $\mathbf{R}$ do aldeído que originou o aduto a seletividade do produto de rearranjo foi exclusivamente $\boldsymbol{Z}$. No ano seguinte, D. Basavaiah e colaboradores realizaram novamente rearranjo de Johnson-Claisen em AMBH entretanto, o grupo de D. Basavaiah substitui o GRE por um éster. ${ }^{37}$ Variando o grupo $\alpha$ à hidroxila no aduto, r.39, os autores obtiveram diastereosseletividade $\boldsymbol{Z}$ para $\mathbf{R}$ alifático e $\boldsymbol{E}$ para $\mathbf{R}$ aromático (Tabela 1).

Tabela 1. Resultados de D. Basavaiah para estereosseletividade em AMBH.

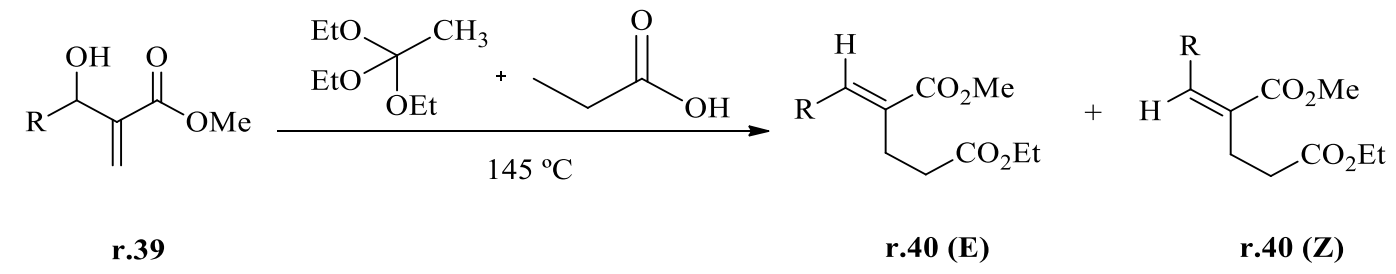

\begin{tabular}{cccc}
\hline R & Tempo & Rendimento $(\%)$ & $\boldsymbol{Z}: \boldsymbol{E}$ \\
\hline$n$-propila & 2,0 & 70 & $74: 26$ \\
$i$-propila & 2,0 & 85 & $80: 20$ \\
$n$-butila & 2,5 & 84 & $75: 25$ \\
$n$-hexila & 3,0 & 83 & $78: 22$ \\
\hline fenila & 1,5 & 78 & $20: 80$ \\
$p$-tolila & 2,0 & 87 & $25: 75$ \\
$p$-clorofenila & 1,5 & 85 & $27: 73$ \\
1-naftila & 2,5 & 82 & $26: 74$ \\
\hline
\end{tabular}

Utilizando o modelo de estado de transição de seis átomos na conformação cadeira, os autores justificaram a estereosseletividade baseado na preferência do grupo $\mathbf{R}$ em adotar a orientação pseudo axial ou pseudo equatorial, devido à interação 1,2-trans estar competindo com a clássica interação 1,3-diaxial. Além disso, a nuvem eletrônica do anel aromático, segundo os autores, causa maior repulsão com grupo éster na posição pseudo equatorial (Figura $5)$.

\footnotetext{
${ }^{36}$ Basavaiah, D.; Pandiaraju, S. Tetrahedron Lett. 1995, 36, 757.

${ }^{37}$ Basavaiah, D.; Pandiaraju, S.; Krishnamacharyulu, M. Synlett. 1996, 747.
} 


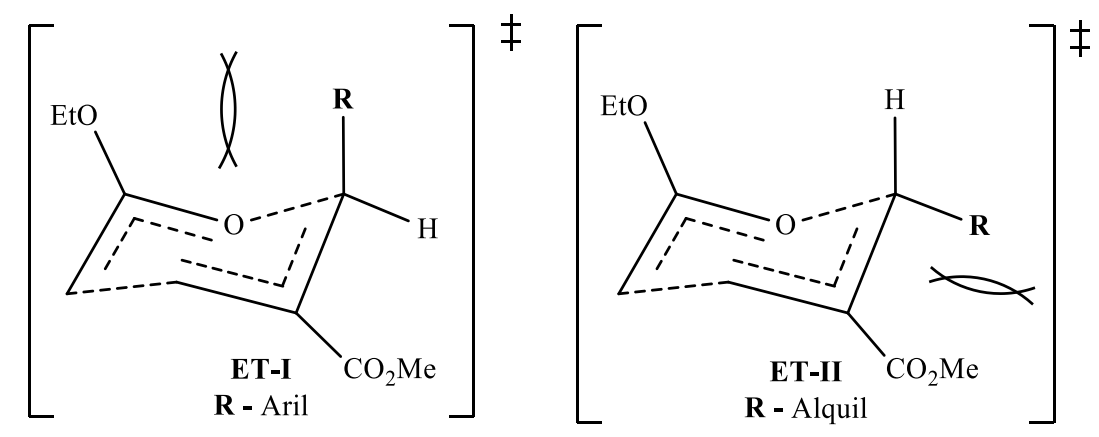

Figura 5. ET proposto por D. Basavaiah e colaboradores para explicar a estereosseletividade do rearranjo de Johnson-Claisen em AMBH.

Outra possibilidade explanada pelos autores para explicar a alteração na seletividade é que ambas as reações estariam ocorrendo via ET-I (tensão 1,3-diaxial) e a isomerização de $\boldsymbol{Z}$ conduziria ao produto $\boldsymbol{E}$. Os autores isolaram o isômero $\boldsymbol{Z}$ com $\mathbf{R}$ sendo fenil e $p$-clorofenil e os submeteram às mesmas condições reacionais (ortoacetato de trietila na presença do ácido propanóico durante 1,5 horas a $145^{\circ} \mathrm{C}$ ). Entretanto, apenas o isômero $\boldsymbol{Z}$ foi recuperado e a hipótese de isomerização foi descartada.

Em 2009, o mesmo grupo de pesquisa de D. Basavaiah utilizou o rearranjo de Claisen de orto éster, para síntese de piperidina-2,6-diona (r.43), heterocíclicos importantes biologicamente (Esquema 16). ${ }^{38}$

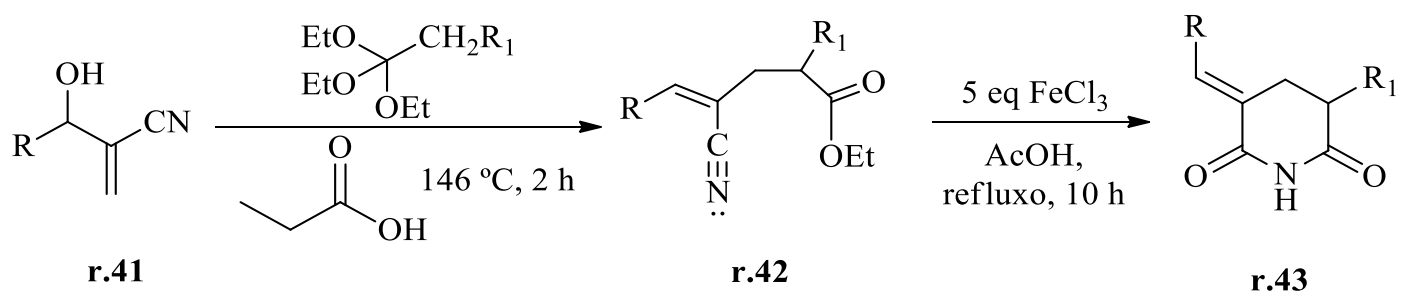

Esquema 16. Síntese de piperidina-2,6-dionas, realizada por D. Basavaiah. ${ }^{38}$

A síntese em quatro etapas reacionais (one-pot) iniciou-se pelo álcool alílico r.41 (obtido pela reação de $\mathrm{MBH}$ entre o respectivo aldeído com acrilonitrila). Após o rearranjo e a hidrólise parcial do grupo nitrila, uma imida foi obtida, por conseguinte, a isomerização altera a geometria da ligação dupla $\boldsymbol{Z}$ para isômero geométrico $\boldsymbol{E}, \mathbf{r . 4 3}$. Variando os substituintes $\mathbf{R}$ e $\mathbf{R}_{\mathbf{1}}$ as piperidina-2,6-dionas $\mathbf{1 - 9}$ foram obtidas seletivamente, isômero $\boldsymbol{E}$, (Tabela 2).

\footnotetext{
${ }^{38}$ Basavaiah, D.; Lenin, D. V.; Devendar, B. Tetrahedron Lett. 2009, 50, 3538.
} 
Tabela 2. Resultados obtidos por D. Basavaiah e colaboradores para síntese de r.43.

\begin{tabular}{|c|c|c|c|c|}
\hline & $\mathbf{R}$ & $\mathbf{R}_{1}$ & Produto & Rendimento (\%) \\
\hline 1 & $\mathrm{C}_{6} \mathrm{H}_{5}$ & $\mathrm{H}$ & \multirow{9}{*}{ 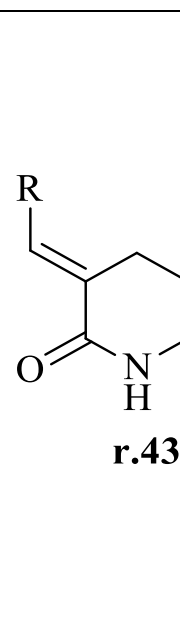 } & 84 \\
\hline 2 & $3-\mathrm{ClC}_{6} \mathrm{H}_{4}$ & $\mathrm{H}$ & & 67 \\
\hline 3 & $4-\mathrm{ClC}_{6} \mathrm{H}_{4}$ & $\mathrm{H}$ & & 71 \\
\hline 4 & $4-\mathrm{MeC}_{6} \mathrm{H}_{4}$ & $\mathrm{H}$ & & 77 \\
\hline 5 & $\mathrm{C}_{6} \mathrm{H}_{5} \mathrm{CH}_{2} \mathrm{CH}_{2}$ & $\mathrm{H}$ & & 73 \\
\hline 6 & $\mathrm{C}_{7} \mathrm{H}_{15}$ & $\mathrm{H}$ & & 75 \\
\hline 7 & $\mathrm{C}_{5} \mathrm{H}_{11}$ & $\mathrm{H}$ & & 81 \\
\hline 8 & $\mathrm{C}_{6} \mathrm{H}_{5}$ & $\mathrm{Me}$ & & 76 \\
\hline 9 & $\mathrm{C}_{6} \mathrm{H}_{5} \mathrm{CH}_{2} \mathrm{CH}_{2}$ & $\mathrm{Me}$ & & 67 \\
\hline
\end{tabular}

Os autores sugerem dois mecanismos para formação de $\mathbf{r . 4 3}$, onde a isomerização pode ocorrer antes ou depois da cíclização (Esquema 17).

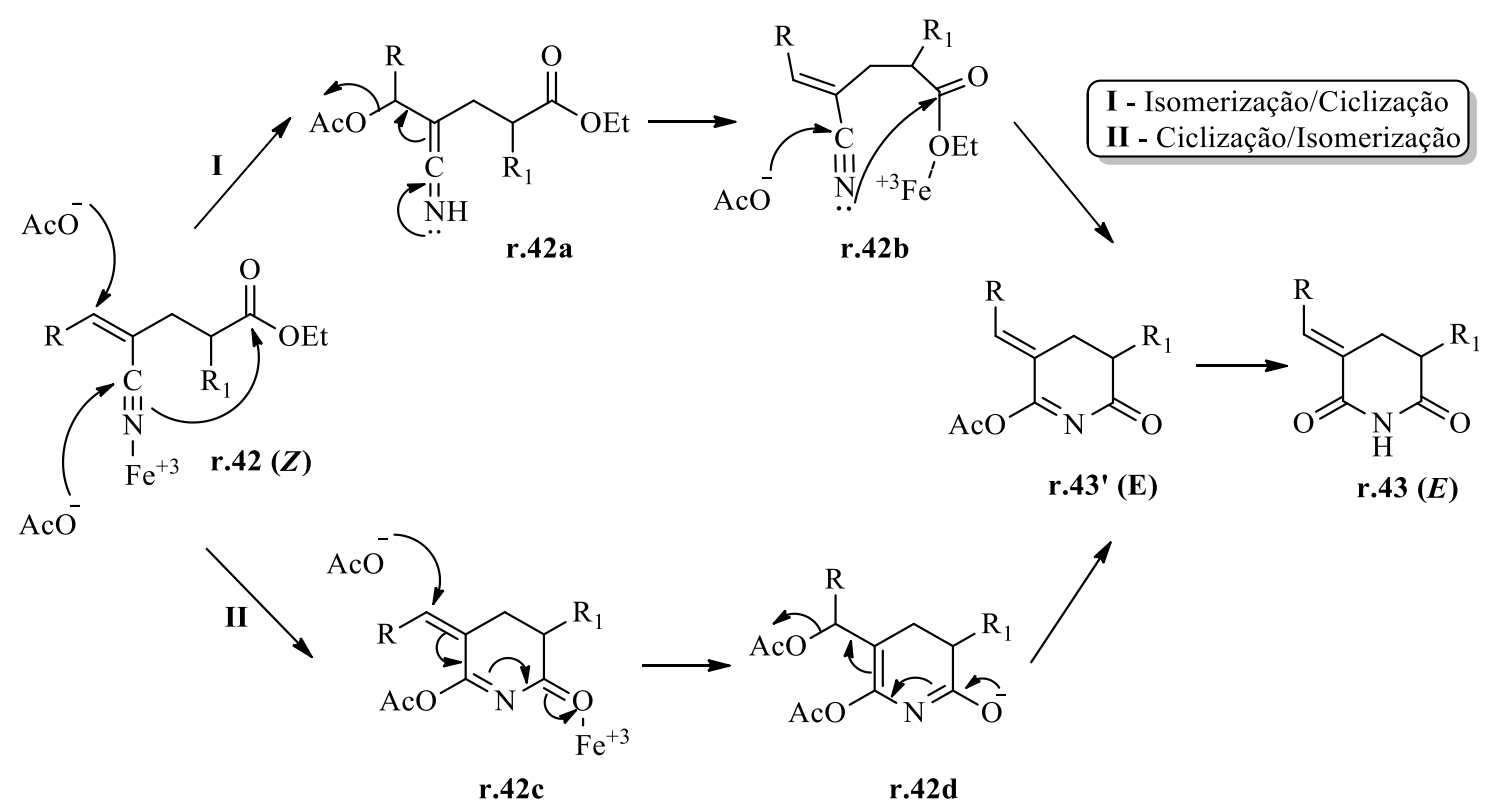

Esquema 17. Mecanismos propostos por D. Basavaiah e colaboradores para formar as piperidina-2,6-dionas $(\boldsymbol{E}){ }^{38}$

No ano seguinte, o mesmo grupo de pesquisa de D. Basavaiah utilizou novamente o rearranjo de Claisen de orto éster para síntese de piperidin-2-onas. ${ }^{39}$ A redução prévia do grupo

\footnotetext{
${ }^{39}$ Basavaiah, D.; Reddy, R. J.; Lenin, D. V. Helv. Chim. Acta. 2010, 93, 1180.
} 
nitrila conduziu à amina $\mathbf{r . 4 5}$ que realiza substituição nucleofílica ao carbono carbonílico do éster, promovendo a ciclização para r.46 (Esquema 18).

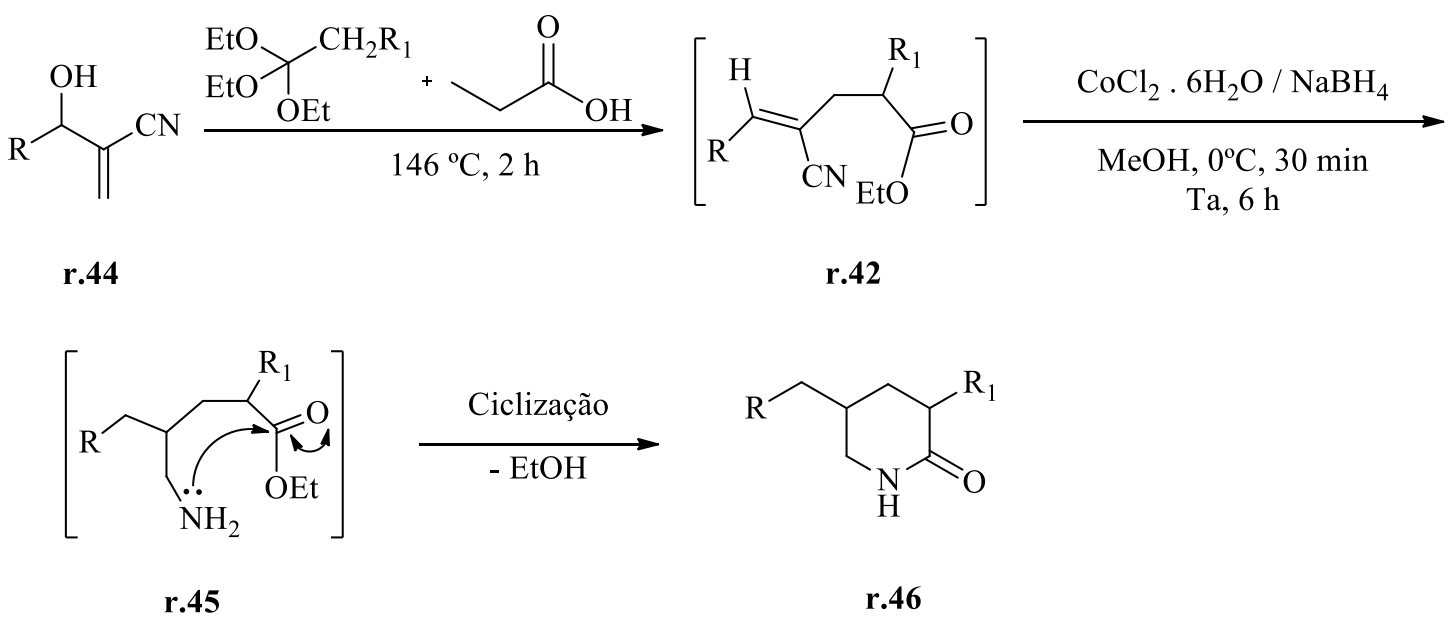

Esquema 18. Síntese de piperidin-2-onas, realizada por D. Basavaiah e colaboradores. ${ }^{39}$

Variando os substituintes $\mathbf{R}$, as piperidin-2-onas $\mathbf{r . 4 6}$ foram obtidas, porém quando $\mathbf{R}_{\mathbf{1}}$ é diferente de $\mathrm{H}$, uma piperidin-2-onas 3,5 dissubstituídas (9) é obtida na proporção de 1:1 (Tabela 3).

Tabela 3. Resultados obtidos por D. Basavaiah e colaboradores para Síntese de r.46.

\begin{tabular}{ccccc}
\hline & $\mathbf{R}$ & $\mathbf{R}_{1}$ & Produto & Rendimento (\%) \\
\hline $\mathbf{1}$ & $\mathrm{C}_{6} \mathrm{H}_{5}$ & $\mathrm{H}$ & & 60 \\
$\mathbf{2}$ & $2-\mathrm{MeC}_{6} \mathrm{H}_{4}$ & $\mathrm{H}$ & & 58 \\
$\mathbf{3}$ & $4-\mathrm{MeC}_{6} \mathrm{H}_{4}$ & $\mathrm{H}$ & $\mathrm{H}$ & 56 \\
$\mathbf{4}$ & $4-(\mathrm{iPr}) \mathrm{C}_{6} \mathrm{H}_{4}$ & $\mathrm{H}$ & 53 \\
$\mathbf{5}$ & $2-\mathrm{ClC}_{6} \mathrm{H}_{4}$ & $\mathrm{H}$ & & 59 \\
$\mathbf{6}$ & $4-\mathrm{ClC}_{6} \mathrm{H}_{4}$ & $\mathrm{H}$ & & 65 \\
$\mathbf{7}$ & $\mathrm{C}_{6} \mathrm{H}_{5} \mathrm{CH}_{2} \mathrm{CH}_{2}$ & $\mathrm{H}$ & & 61 \\
$\mathbf{9}$ & $\mathrm{CH}_{3}\left(\mathrm{CH}_{2}\right)_{5} \mathrm{CH}_{2}$ & $\mathrm{H}$ & & \\
\hline
\end{tabular}

No ano de 2010, D. Basavaiah e Reddy utilizaram a mesma proposta de rearranjo de Johnson-Claisen em AMBH para síntese (one-pot) de heterociclos tri e tetracíclicos que possuem o fragmento estrutural $[1,8]$ naftiridina-2-ona, presente em diversas estruturas com 
atividades biológicas importantes como anti-inflamatórios, anti-bacterianos, anti-tumorais e antialérgicos (Esquema 19). ${ }^{40}$

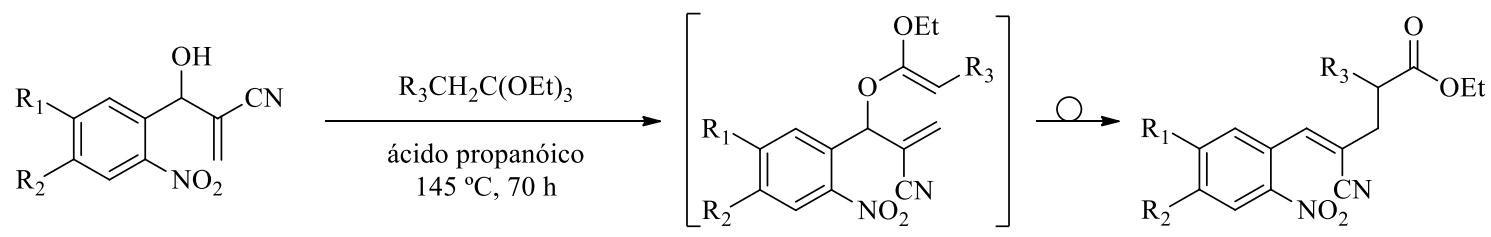

r.47

r.48

r.49

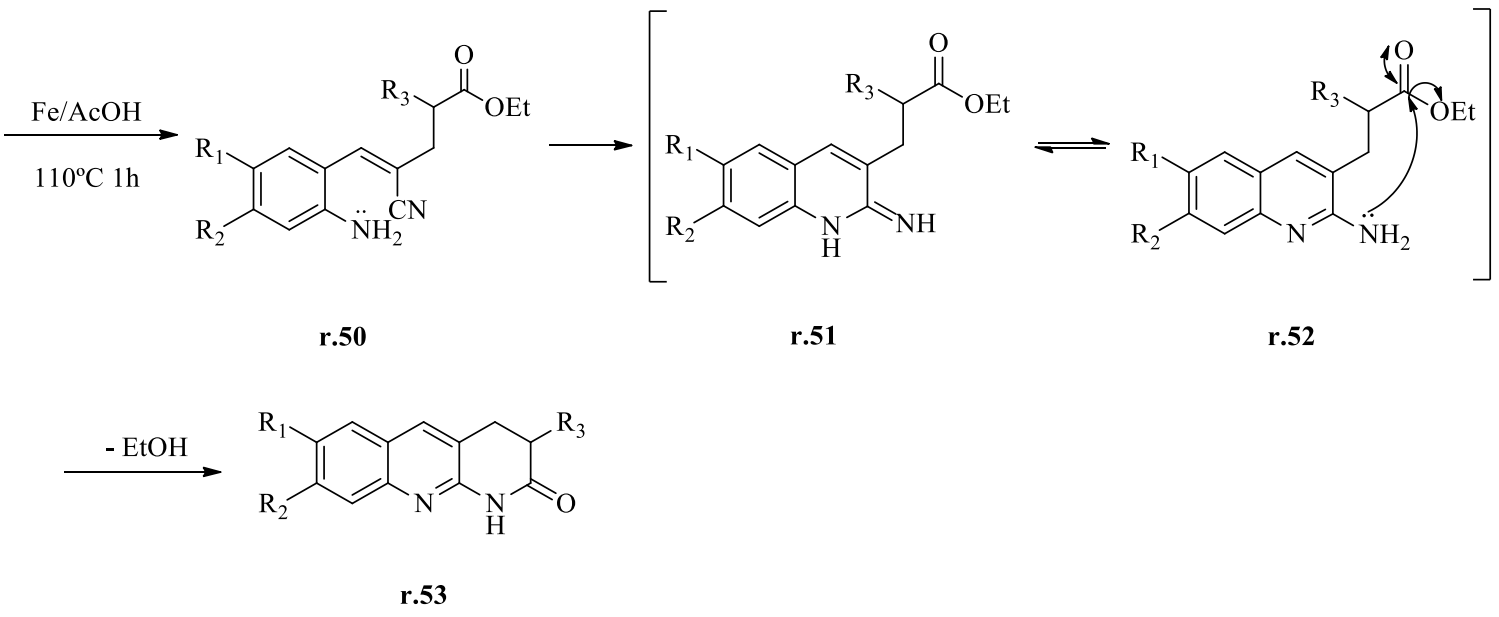

Esquema 19. Síntese do fragmento estrutural [1,8] naftiridina-2-ona.

Partindo do aduto de MBH r.47, após o longo período de 70 horas, este se rearranjou para r.49 com formação exclusiva do isômero $\boldsymbol{Z}$. No mesmo frasco reacional foi realizada a redução do grupo nitro com $\mathrm{Fe}(0)$ na presença de ácido acético à amina r.50. Sequencialmente, a adição do par de elétrons da amina ao carbono da nitrila leva à formação do heterociclo intermediário r.51. Subsequentemente, a amina r.52 adiciona-se ao grupo éster para promover a ciclização que conduz ao produto r.53. Variando os substituintes $\mathbf{R}_{1}, \mathbf{R}_{\mathbf{2}}$ e $\mathbf{R}_{\mathbf{3}}$, foram obtidas 10 naftiridina-2-onas e 2 tetraciclos (Tabela 4).

${ }^{40}$ Basavaiah, D.; Reddy, K. R. Tetrahedron, 2010, 66, 1215. 
Tabela 4. Resultados obtidos por D. Basavaiah e Reddy para síntese de r.53 e tetraciclos.

\begin{tabular}{|c|c|c|c|}
\hline $\mathbf{R}_{1}$ & $\mathbf{R}_{2}$ & $\mathbf{R}_{3}$ & Rendimento (\%) \\
\hline $\mathrm{H}$ & $\mathrm{H}$ & $\mathrm{Me}$ & 69 \\
\hline $\mathrm{H}$ & $\mathrm{H}$ & $\mathrm{H}$ & 55 \\
\hline $\mathrm{Br}$ & $\mathrm{H}$ & $\mathrm{Me}$ & 56 \\
\hline $\mathrm{Br}$ & $\mathrm{H}$ & $\mathrm{H}$ & 45 \\
\hline $\mathrm{Cl}$ & $\mathrm{H}$ & $\mathrm{Me}$ & 63 \\
\hline $\mathrm{Cl}$ & $\mathrm{H}$ & $\mathrm{H}$ & 58 \\
\hline $\mathrm{OMe}$ & $\mathrm{OMe}$ & $\mathrm{Me}$ & 60 \\
\hline $\mathrm{OMe}$ & $\mathrm{OMe}$ & $\mathrm{H}$ & 48 \\
\hline $\mathrm{OMe}$ & OEt & $\mathrm{Me}$ & 56 \\
\hline \multirow[t]{3}{*}{$\mathrm{OMe}$} & OEt & $\mathrm{H}$ & 49 \\
\hline & 8 & $\mathrm{Me}$ & 59 \\
\hline & & $\mathrm{H}$ & 51 \\
\hline
\end{tabular}

Continuando o trabalho de se obter estereosseletivamente alcenos trissubstituídos, Das e colaboradores realizaram um estudo de catálise heterogênea no rearranjo de Johnson-Claisen em AMBH. ${ }^{41}$ Dentre os catalisadores testados $\left(\mathrm{HClO}_{4}-\mathrm{SiO}_{2}, \mathrm{NaHSO}_{4}-\mathrm{SiO}_{2}\right.$ e I $\left.\mathrm{I}_{2}-\mathrm{SiO}_{2}\right)$ o iodo molecular adsorvido em sílica demonstrou ser a melhor condição, sendo necessário apenas 30 minutos de reação para se obter bons rendimentos e seletividade (Tabela 5).

Para ambos os catalisadores há formação de um sistema heterogêneo e o catalisador pode ser facilmente removido por uma filtração simples. Além disso, após determinar o melhor catalisador, $\mathrm{I}_{2}-\mathrm{SiO}_{2}$, os autores testaram a reação na sua ausência, obtendo cerca de apenas $25 \%$ de conversão. Utilizando apenas sílica, não houve conversão do substrato em produto.

O rearranjo de $\mathrm{AMBH}$, com grupo nitrila, teve somente o produto $\boldsymbol{Z}$, sendo a seletividade independente do grupo R. Quando o GRE é um éster, a seletividade foi dependente do grupo $\mathbf{R}$, para alifáticos o produto é $\boldsymbol{Z}$-seletiva, porém para aromáticos a diastereosseletividade é $\boldsymbol{E}$.

${ }^{41}$ (a) Das, B.; Majhi, A.; Banerjee, J. Tetrahedron Lett. 2006, 47, 7619. (b) Das, B.; Majhi, A.; Reddy, K. R.; Venkateswarly, K. J. Mol. Cat. 2007, 263, 273. 
Tabela 5. Resultados obtidos por Das e colaboradores alterando o substrato.

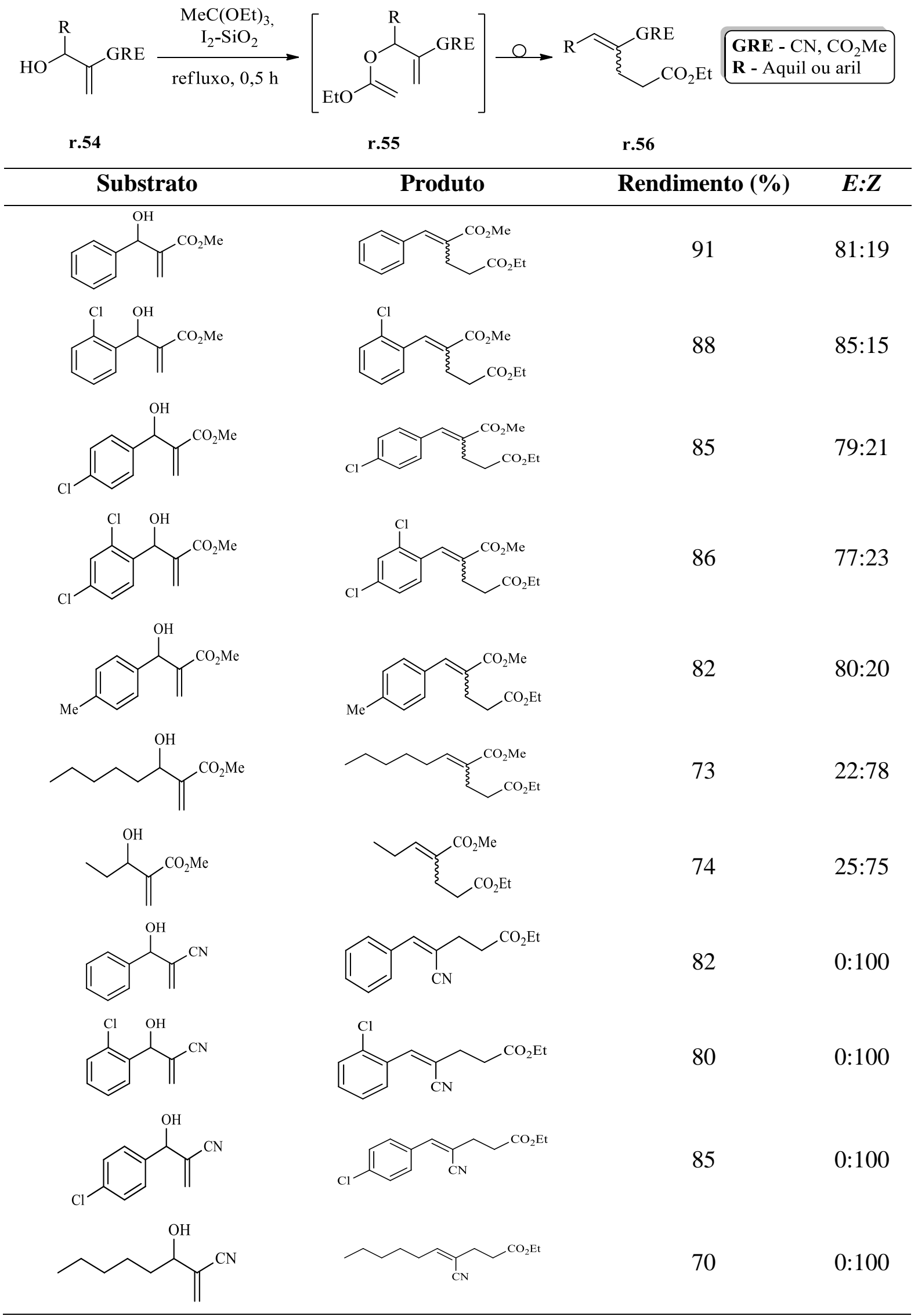


No ano de 2005, Christian Chapuis e colaboradores utilizaram o rearranjo de JohnsonClaisen em AMBH para síntese da cis-Hediona e do jasmonato de metila, substâncias importantes na indústria de fragrância. ${ }^{42}$ A síntese da cis-Hediona foi realizada em seis etapas, sendo duas delas a proteção e desproteção do grupo carbonila para obtenção do álcool alílico r.58, que foi submetido ao rearranjo de Johnson-Claisen para obter $\mathbf{r . 6 0}$ em $88 \%$ de rendimento, com razão isomérica de 7:3 (E:Z). Após hidrogenação catalítica uma mistura contendo a cisHediona (r.61a) e seu diastereoisômero (r.61b) em uma razão de 62:38 (cis:trans) foi obtida em $98 \%$ de rendimento (Esquema 20).

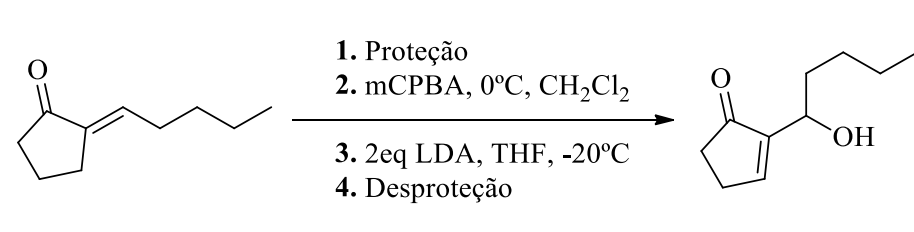

$\mathbf{r . 5 7}$ r.58 $94 \%$

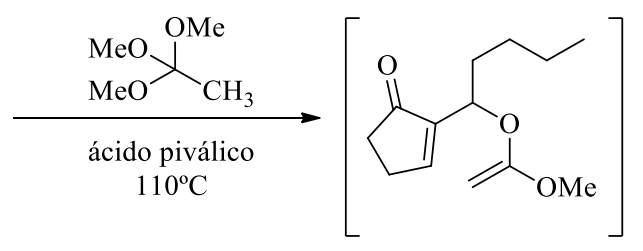

r.59

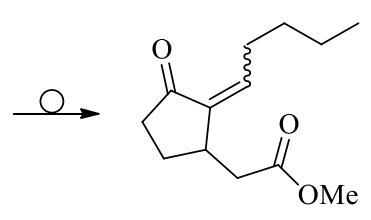

r.60 $88 \%$ 7:3 (E:Z)
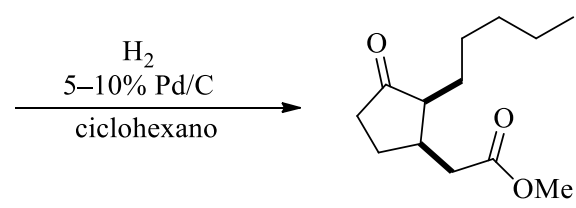

r.61a $61 \%$ (+)-cis-Hediona

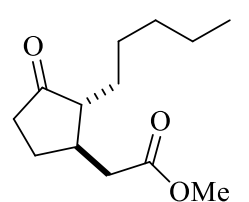

r.61b $37 \%$

1. etilenoglicol, ciclohexano, ácido fumárico (55\%) - 2. $93 \%$ - 3. $66 \%$ - 4. piridida, TsOH, acetona/ $\mathrm{H}_{2} \mathrm{O}(94 \%)$.

Esquema 20. Síntese total da (+)-cis-Hediona. ${ }^{42}$

A rota de síntese utilizada para o $( \pm)$-jasmonato de metila empregou a reação de $\mathrm{MBH}$ para obtenção do álcool alílico r.63, levando a uma redução de três etapas reacionais quando comparada com a síntese total da cis-Hediona. O AMBH na presença de ortoacetato de trietila, ácido piválico a $110^{\circ} \mathrm{C}$, conduziu ao rearranjo $[3,3]$ para forma $\mathbf{r . 6 5}$ em ótimo rendimento $(96 \%)$ com razão $\boldsymbol{Z}: \boldsymbol{E}$ de 2:3. Posteriormente, a reação de hidrogenação seguida da hidrólise do acetal com ácido acético em água forneceu o aldeído r.67 com $83 \%$ de rendimento, sem alteração da razão trans:cis. Por fim, a reação de Wittig, com ilídio de fósforo, conduziu à olefina dissubstituída r.68, na proporção trans:cis de 9:1 e razão $\boldsymbol{Z}: \boldsymbol{E}$ de 95:5 (Esquema 21).

\footnotetext{
${ }^{42}$ Chapuis, C.; Buchi, G. H.; Wuest, H. Helv. Chim. Acta. 2005, 88, 3069.
} 

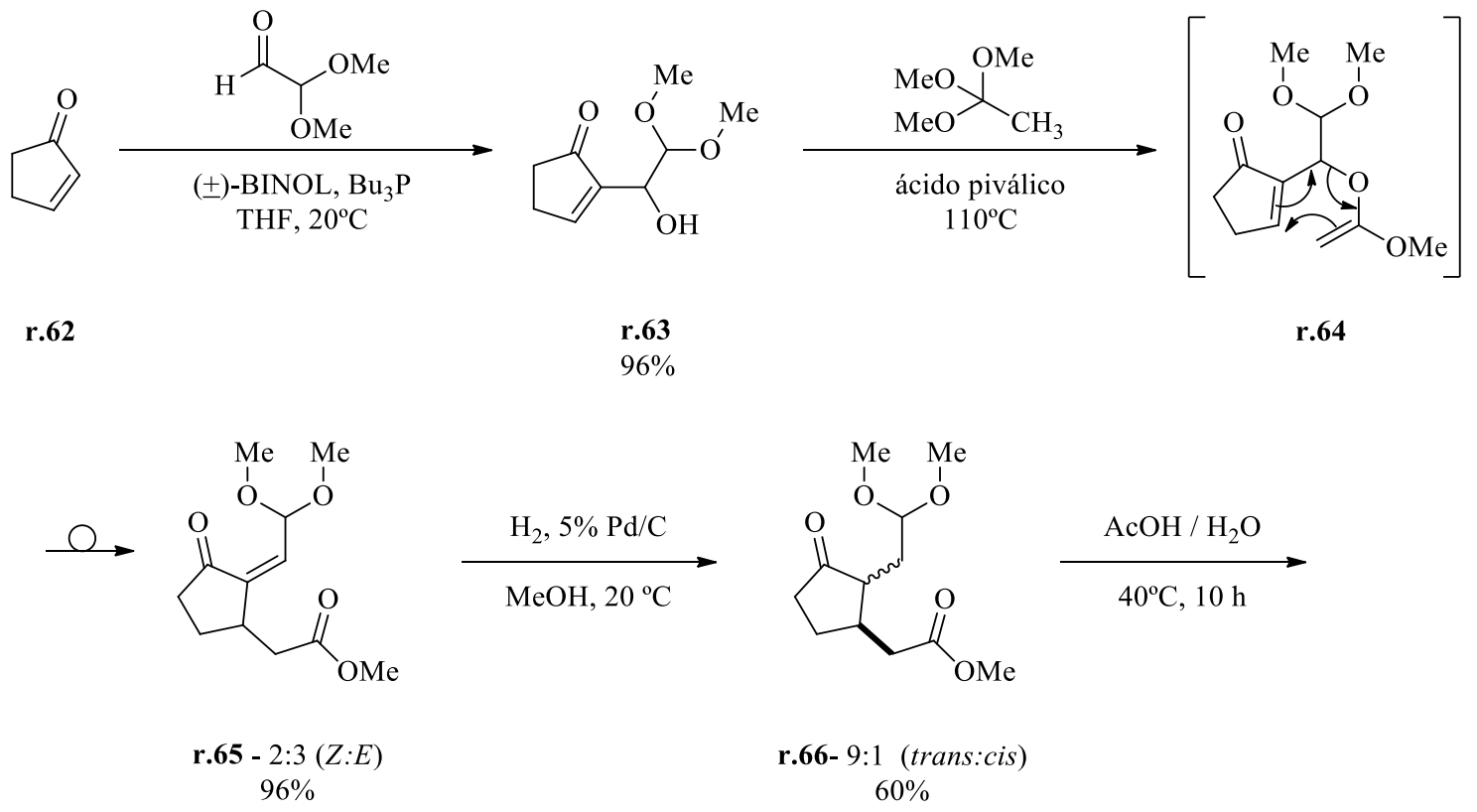<smiles>COC(=O)CC1CCC(=O)[C@H]1CC=O</smiles>

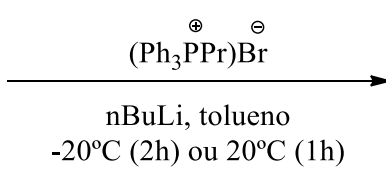

r.67 - 9:1 (trans:cis) $83 \%$

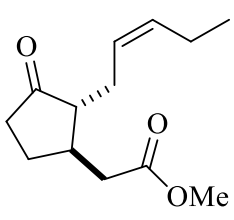

$( \pm)$-jasmonato de metila

9:1 trans:cis 95:5 Z:E

Esquema 21. Síntese do $( \pm)$-jasmonato de metila a partir do rearranjo de Johnson-Claisen em

$$
\mathrm{AMBH}^{42}
$$

Em 2007, Kim e colaboradores apresentaram o primeiro relato de rearranjo de Eschenmoser-Claisen em adutos de $\mathrm{MBH} .{ }^{43}$ Como no rearranjo de Johnson-Claisen em AMBH a configuração relativa foi dependente do GRE. O produto de rearranjo em adutos tendo o grupo nitrila como GRE foi exclusivo para o isômero com configuração $\boldsymbol{Z}$. Contudo, quando o GRE é um éster os dois isômeros foram obtidos, porém o produto majoritário foi o isômero $\boldsymbol{E}$ (Tabela $6)$.

\footnotetext{
${ }^{43}$ Kim, J. M.; Kim, S. H.; Kim, J. N. Bull. Korean Chem. Soc. 2007, 28, 2093.
} 
Tabela 6. Resultados obtidos por Kim e colaboradores alterando o substrato.

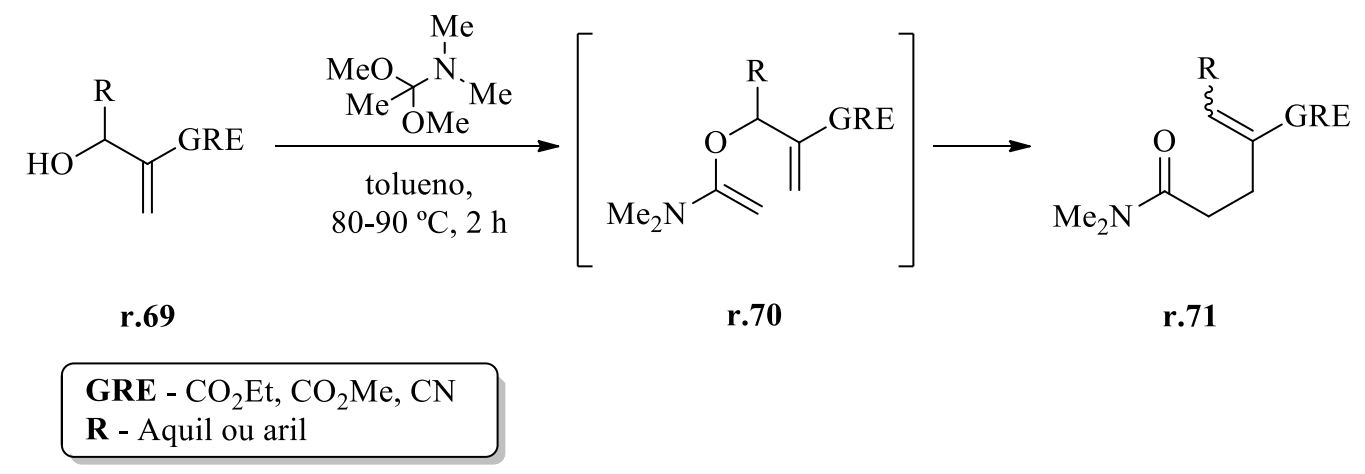

Rendimento (\%)

Apesar das variações de Eschenmoser-Claisen e Johnson-Claisen terem sido bem exploradas, há apenas um exemplo do uso da variação de Hurd-Claisen no rearranjo de AMBH, aquele utilizado por Büchi para a síntese da (+)-pilocarpina (Esquema 11) ${ }^{28}$. Isso levou nosso grupo de pesquisas a estudar esta variante do rearranjo de Claisen em AMBH oriundos de aldeídos alifáticos e aromáticos.

Assim, Rodrigues iniciou o estudo da estereosseletividade do rearranjo de Hurd-Claisen em AMBH empregando como modelo adutos provenientes de acrilato de etila. Estes conduziram preferencialmente ao produto de rearranjo r.74 $(\boldsymbol{E})$, sendo que adutos com grupo $\mathbf{R}$ alifáticos apresentaram razões diasteroisoméricas inferiores a 3,5:1, enquanto AMBH com 
grupo $\mathbf{R}$ aromáticos levaram à razões $\boldsymbol{E}: \boldsymbol{Z}$ maiores que 14:1, sugerindo um forte influência da natureza química do grupo $\mathbf{R}$ na estereosseletividade observada (Esquema 22). ${ }^{3}$

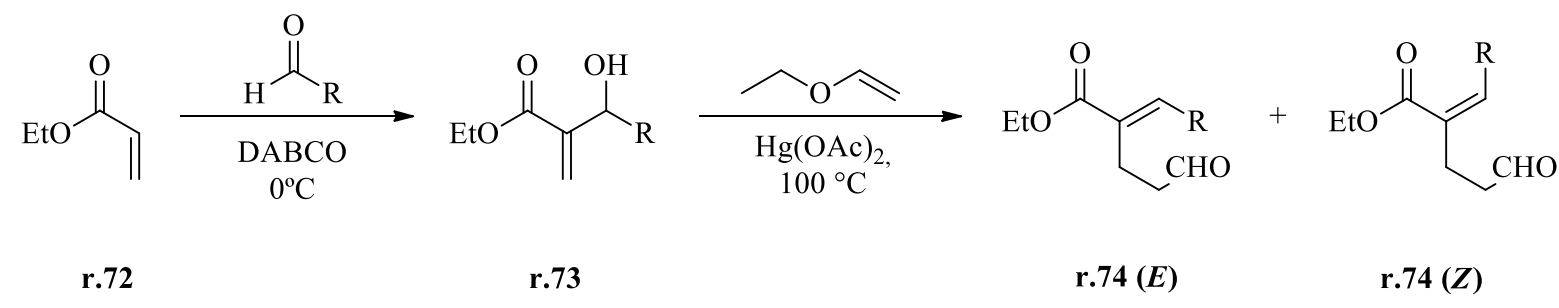

Esquema 22. Resultados preliminares do rearranjo de Hurd-Claisen em AMBH obtidos por Rodrigues. ${ }^{3}$

O entendimento de como a natureza química dos grupos funcionais presentes nos AMBH influência na estereosseletividade desta reação é de suma importância e tem o potencial de permitir a obtenção dos produtos de rearranjo com elevado controle na razão $\boldsymbol{E}: \boldsymbol{Z}$. Deste modo, a análise do modelo de ET (Esquema 1) proposto por Rodrigues precisa ser ampliada a outros grupos funcionais. 


\section{4-RESULTADOS E DISCUSSÃO}

\section{1-SÍNTESE DOS ADUTOS DE MBH AROMÁTICOS}

Os AMBH aromáticos 3a-e foram sintetizados conforme metodologia descrita por Vasconcelos e colaboradores, ${ }^{44}$ sendo que o respectivo aldeído foi posto para reagir com acrilato de terc-butila por um período de 6 a 21 dias (Tabela 7).

Tabela 7. Rendimentos obtidos para adutos de MBH aromáticos.<smiles>C=CC(=O)OC(C)(C)C</smiles>

1<smiles>[R]C=O</smiles>

\begin{tabular}{cc} 
Rendimento (\%) \\
\hline (1II
\end{tabular}

I - t.a, 1,0 equivalente de DABCO e sem solvente;

II - t.a, 0,5 equivalentes de DABCO e sem solvente;

III $-0^{\circ} \mathrm{C}, 1,0$ equivalente de $\mathrm{DABCO}$ e $0,5 \mathrm{ml} / \mathrm{mmol}$ de metanol;

IV - Ultrassom, $30-40{ }^{\circ} \mathrm{C}$ e $0,75 \mathrm{ml} / \mathrm{mmol}$ de metanol.

${ }^{44}$ Junior, C. G. L.; et al. J. Braz Chem. Soc. 2011, 22, 11, 2220. 
A primeira tentativa de sintetizar os adutos de $\mathrm{MBH}$ aromáticos foi realizada com $\mathrm{m}$ nitrobenzaldeído (AMBH-3d). Utilizando 1,0 equivalente de DABCO, temperatura ambiente e sem adição de solvente (condição de reação I) obtivemos $81 \%$ de rendimento em um tempo de reação de 9 dias. Na tentativa de reduzir o tempo de reação e melhorar o rendimento reduzimos a quantidade de catalisador (DABCO) pela metade e mantivemos o demais parâmetros de reação inalterados (condição de reação II).

A redução do catalisador tornou a mistura reacional mais homogênea. Uma vez que na condição de reação I foi observado grande quantidade de sólido não solubilizado, possivelmente do catalisador. A condição II reduziu a quantidade de sólido não solubilizado e promoveu uma melhoria no rendimento de $16 \%$. Uma possível explicação é devido à maior disponibilidade do catalisador em concentrações menores. Haja vista, que o acrilato de terc-butila, utilizado como reagente e solvente (condições I e II), não solubiliza totalmente o DABCO.

As condições I e II apesar de apresentarem um tempo de reação elevado exibem bons rendimento. Entretanto, quando estas metodologias foram testadas na síntese do aduto 3c oriundo do $p$-clorobenzaldeído foi observado um tempo de reação ainda maior, 20 e 21 dias respectivamente. Assim, uma terceira condição de reação foi testada sendo:1,0 equivalentes de $\mathrm{DABCO}, 0^{\circ} \mathrm{C}$ e com metanol. Os resultados da síntese do $\mathrm{AMBH}-3 \mathbf{c}$, nas condições de reação I, II e III estão racionalizados na Tabela 8. A adição de metanol conduziu a um menor tempo reacional e será discutido a seguir.

Tabela 8. Resultados obtidos para o AMBH-3c.

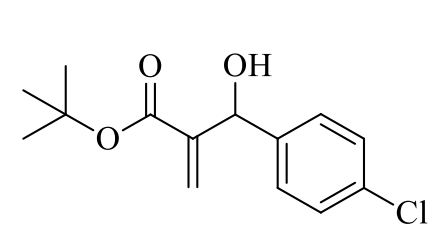

\begin{tabular}{ccc}
$\begin{array}{c}\text { Tempo } \\
\text { (dias) }\end{array}$ & $\begin{array}{c}\text { Rendimento } \\
(\%)\end{array}$ & Condição \\
\hline 20 & 72 & I \\
21 & 80 & II \\
10 & 88 & III
\end{tabular}

Como observado na síntese do AMBH-3d a redução do catalisador (condição II) promove um aumento de $8 \%$ no rendimento, porém o tempo reacional ainda é elevado. A adição de metanol (condição III) promoveu uma redução para metade do tempo reacional, dois fatores podem ter contribuído. O primeiro correlaciona-se à melhor solubilização do DABCO, tornando o catalisador mais disponível para a primeira etapa da reação, adição conjugada. $\mathrm{O}$ segundo fator pode estar associado à proposta mecanística de Aggarwal e colaboradores, na qual a adição solventes polar prótico na reação, neste caso metanol, possibilita a estabilização 
do estado de transição na etapa de formação do segundo intermediário zwitteriônico, r.9'a, facilitando a transferência de próton intermolecular, através de um estado de transição cíclico de seis membros, conforme Esquema $7^{14}$ apresentado no referencial teórico deste trabalho.

Com exceção do aduto $\mathbf{3 f}$ e $\mathbf{3 g}$, todas as moléculas são conhecidas, portanto foram caracterizadas por RMN de ${ }^{1} \mathrm{H}$ e ${ }^{13} \mathrm{C}$, e consequentemente comparados com os dados já descritos na literatura. $\mathrm{O}$ aduto 3a é o mais simples dos $\mathrm{AMBH}$ aromáticos sintetizados neste trabalho, por não apresentar substituintes no anel aromático, servindo como padrão para análise dos demais espectros de RMN de ${ }^{1} \mathrm{He}^{13} \mathrm{C}$ (Tabela 9).

Tabela 9. Dados Espectroscópicos de $\mathrm{RMN}$ de ${ }^{1} \mathrm{H}$ e ${ }^{13} \mathrm{C}$ para o $\mathrm{AMBH}-3 \mathbf{a}$.

2-(hidroxi(fenil)metil) acrilato de terc-butila (3a)

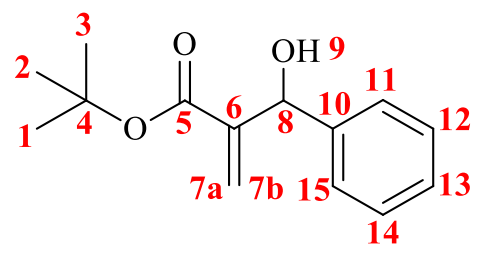

\begin{tabular}{ccccc}
\hline $\mathbf{N}^{\mathbf{0}}$ & $\mathbf{\delta}(\mathbf{p p m})$ & $\begin{array}{c}\text { RMN de }{ }^{\mathbf{H}} \\
\text { Multiplicidade, } \mathbf{J}(\mathbf{H z})\end{array}$ & $\begin{array}{c}\text { RMN de }{ }^{\mathbf{1 3}} \mathbf{C} \\
\text { Integração }\end{array}$ & $\boldsymbol{\delta}(\mathbf{p p m})$ \\
\hline $\mathbf{1 - 2 - 3}$ & 1,39 & Simpleto & 9 & 27,9 \\
$\mathbf{4}$ & - & - & - & 81,6 \\
$\mathbf{5}$ & - & - & - & 165,7 \\
$\mathbf{6}$ & - & - & - & 127,6 \\
$\mathbf{7 a}$ & 5,72 & Tripleto aparente, $J=1,2 \mathrm{~Hz}$ & 1 & 143,4 \\
$\mathbf{7 b}$ & 6,25 & Multipleto & 1 & 73,5 \\
$\mathbf{8}$ & 5,50 & Dupleto, $J=6,0 \mathrm{~Hz}$ & 1 & - \\
$\mathbf{9}$ & 3,11 & Dupleto, $J=6,0 \mathrm{~Hz}$ & 1 & 141,6 \\
$\mathbf{1 0}$ & - & - & - & 127,6 \\
$\mathbf{1 3}$ & 7,27 & Multipleto & 1 & 125,3 \\
$\mathbf{1 1}$ & & & & 128,3 \\
$\mathbf{1 2}$ & 7,35 & Multipleto & 4 & 128,3 \\
$\mathbf{1 4}$ & & & & 126,5 \\
$\mathbf{1 5}$ & & & & \\
\hline
\end{tabular}

$\mathrm{O}$ espectro de $\mathrm{RMN}$ de ${ }^{1} \mathrm{H}$ apresenta seis sinais (Figura 6). O primeiro deles, que corresponde ao grupo terc-butila é um simpleto com deslocamento químico de 1,39 ppm, integrando para 9 hidrogênios. Em 3,11 ppm observa-se um dupleto largo com $J$ de 6,0 Hz, 
atribuído ao hidrogênio da hidroxila, integrando para 1 hidrogênio. Continuando, em 5,50 ppm, encontra-se outro dupleto largo com constante de acoplamento de 6,0 Hz, atribuído ao hidrogênio carbinólico (8), integrando para 1 hidrogênio, sinal característico de formação do aduto. Os hidrogênios vinílicos são observados em 5,72 ppm e 6,25 ppm, um tripleto aparente, com $J$ de $1,2 \mathrm{~Hz}$ e um multipleto respectivamente, ambos integrando para 1 hidrogênio.
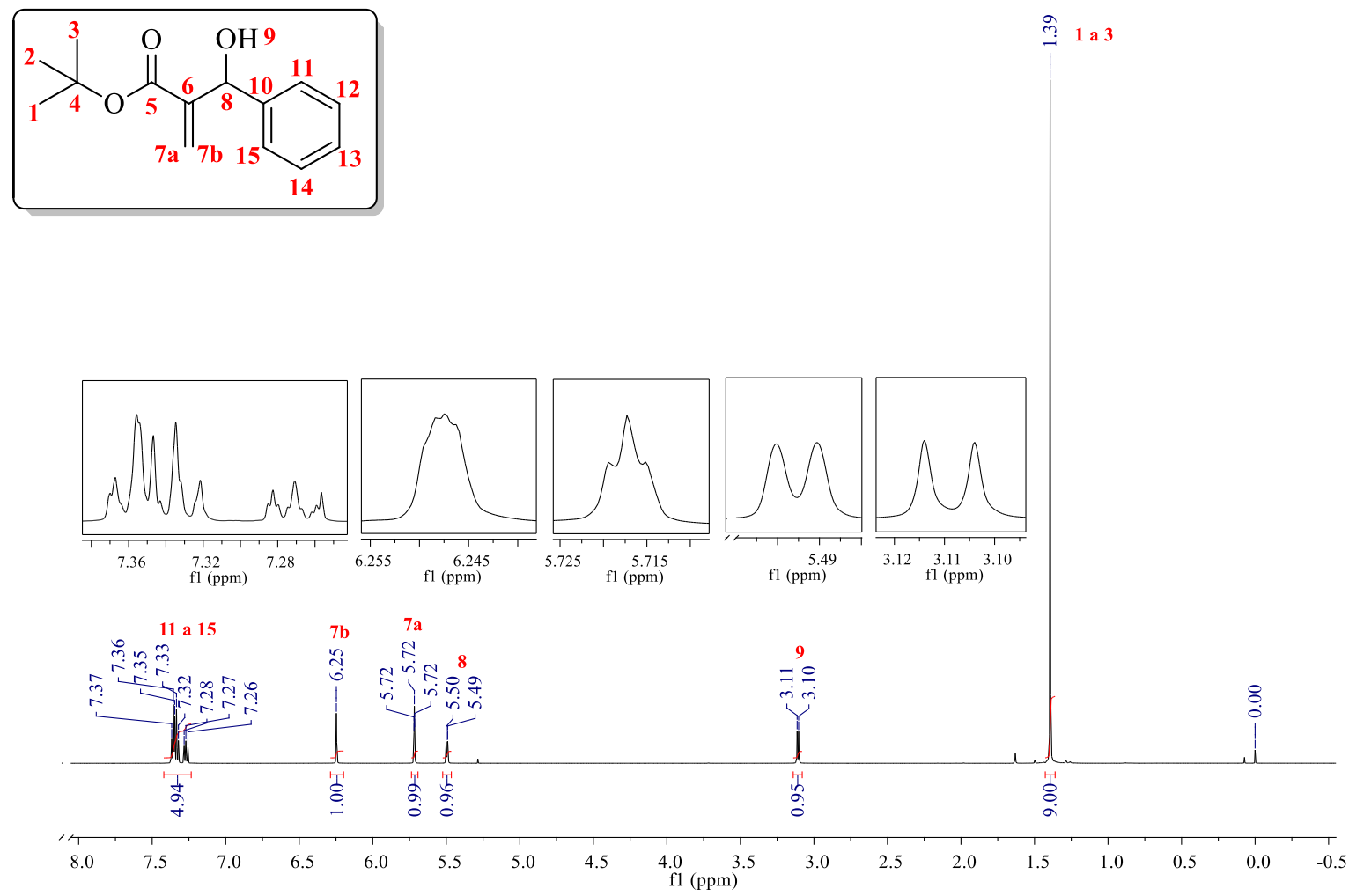

Figura 6. Espectro de $\mathrm{RMN}$ de ${ }^{1} \mathrm{H}\left(600 \mathrm{MHz}, \mathrm{CDCl}_{3}\right)$ - $\mathrm{AMBH}-3 \mathbf{a}$.

A diferença na multiplicidade dos hidrogênios vinílicos correlaciona-se ao acoplamento diferenciado com hidrogênio carbinólico. No hidrogênio 7a há o acoplamento com o hidrogênio geminal e o acoplamento com o hidrogênio carbinólico, porém este último acoplamento, ${ }^{4} \mathrm{~J}$ trans, não pode ser observado. Deste modo, há uma sobreposição dos sinais, formando um tripleto aparente. Para o hidrogênio 7b ocorre os mesmos acoplamentos entretanto, o acoplamento ${ }^{4} \mathrm{~J}$ agora é $c i s$, acoplamento a longa distância $c i s$ são ainda mais difíceis de serem observados. Neste último caso tanto a multiplicidade quanto $J$ não puderam ser determinadas, pois o sinal apresenta-se como um multipleto. Os dois últimos sinais em 7,27 ppm e 7,35 ppm, diz respeito aos sinais dos hidrogênios aromáticos, dois multipletos integrando para 1 e 4 hidrogênios respectivamente. 
O espectro de RMN de ${ }^{13} \mathrm{C}$ apresenta dez sinais (Figura 7). Os sinais em 27,9 ppm, referentes às metilas, e 81,6 ppm, carbono quaternário, correspondem aos carbonos do grupo terc-butila. O sinal em 73,5 ppm refere-se ao carbono do centro estereogênico (8). Os sinais em 127,6 ppm e 143,4 ppm pertencem aos carbonos da ligação dupla. Dos seis sinais entre 125,3 a 143,4 somente dois deles, 127,6 ppm e 143,4 ppm, são referentes aos carbonos da ligação dupla, os demais são pertencentes ao anel aromático. Por fim, o pico mais desblindado, 165,7 ppm é do carbono carbonílico. Os dados de ${ }^{13} \mathrm{C}$ confirmaram os 14 carbonos e consequentemente a estrutura do aduto $\mathbf{3 a}$.
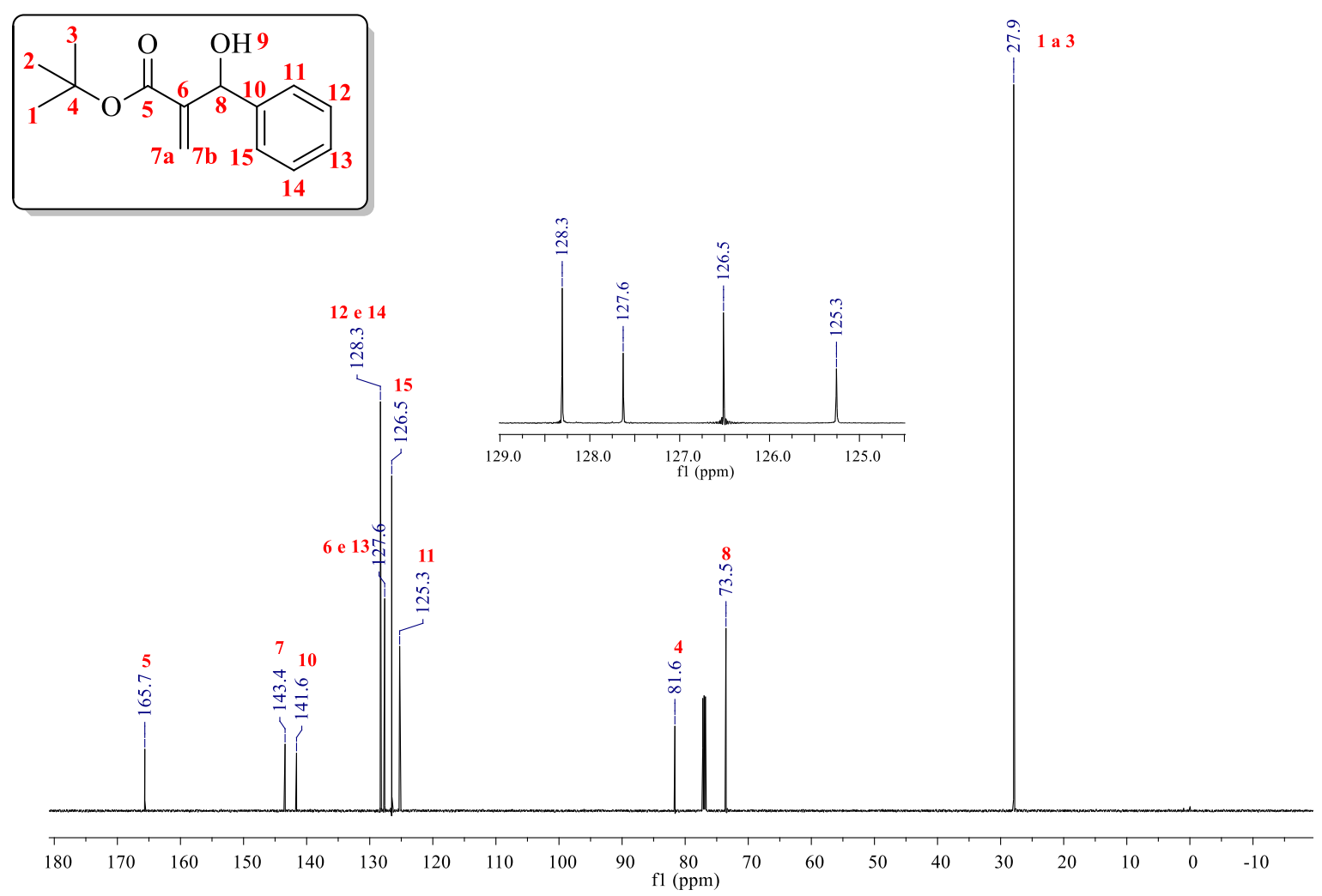

Figura 7. Espectro de $\mathrm{RMN}$ de ${ }^{13} \mathrm{C}\left(150 \mathrm{MHz}, \mathrm{CDCl}_{3}\right)-\mathrm{AMBH}-3 \mathbf{a}$.

O espectro de massa do AMBH 3a (Figura 8) não apresentou o íon molecular (M =234). Contudo, o espectro apresentou o pico 217 (M-17), atribuído ao íon fragmento devido à perda do radical $\mathrm{HO}^{*}$, formando uma cátion alílico e benzílico. Os dois picos mais intensos de massa 57 (pico base) e 105 correspondem aos cátions terc-butila e benzilidineoxônio respectivamente. 


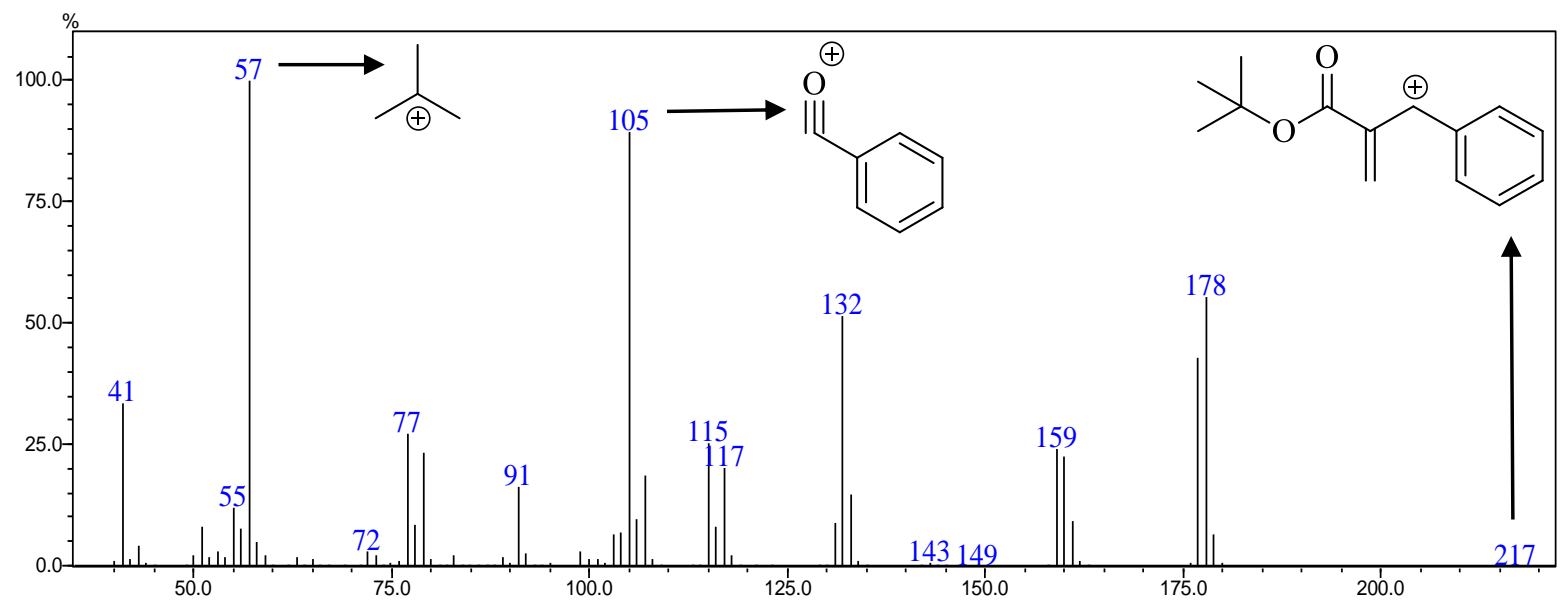

Figura 8. Espectro de massas do 2-(hidroxi(fenil)metil) acrilato de terc-butila - AMBH 3a.

Tentativas de sintetizar os adutos $\mathbf{3 f}$ e $\mathbf{3 g}$ conforme metodologia descrita por Vasconcellos colaboradores não demonstraram ser eficiente tanto com a adição de metanol tanto com a mistura de DMF: $\mathrm{H}_{2} \mathrm{O}$ como solvente, proposta originalmente pelos autores. Os AMBH $3 f$ e $3 g$ foram preparados seguindo a metodologia descrita por Coelho e colaboradores. ${ }^{45}$ Neste trabalho, aldeídos com grupos doadores são postos a reagir sob efeito de ultrassom e apresentam bons rendimentos em um menor tempo reacional. Apesar de seguir a metodologia descrita, os adutos $\mathbf{3 f}$ e $\mathbf{3 g}$, foram obtidos em baixos rendimentos, 14 e $15 \%$ respectivamente.

\section{2-SÍNTESE DOS ADUTOS DE MBH ALIFÁTICOS}

Os AMBH alifáticos $\mathbf{3 h}-\mathbf{k}$ foram sintetizados conforme metodologia descrita por Coelho e colaboradores ${ }^{45}$, sendo que os respectivos aldeídos foram postos para reagir com acrilato de terc-butila por um período de 96 horas (Tabela 10).

\footnotetext{
${ }^{45}$ Coelho, F.; et al. Tetrahedron, 2002, 58, 7437.
} 
Tabela 10. Rendimentos obtidos para os adutos de MBH alifáticos.

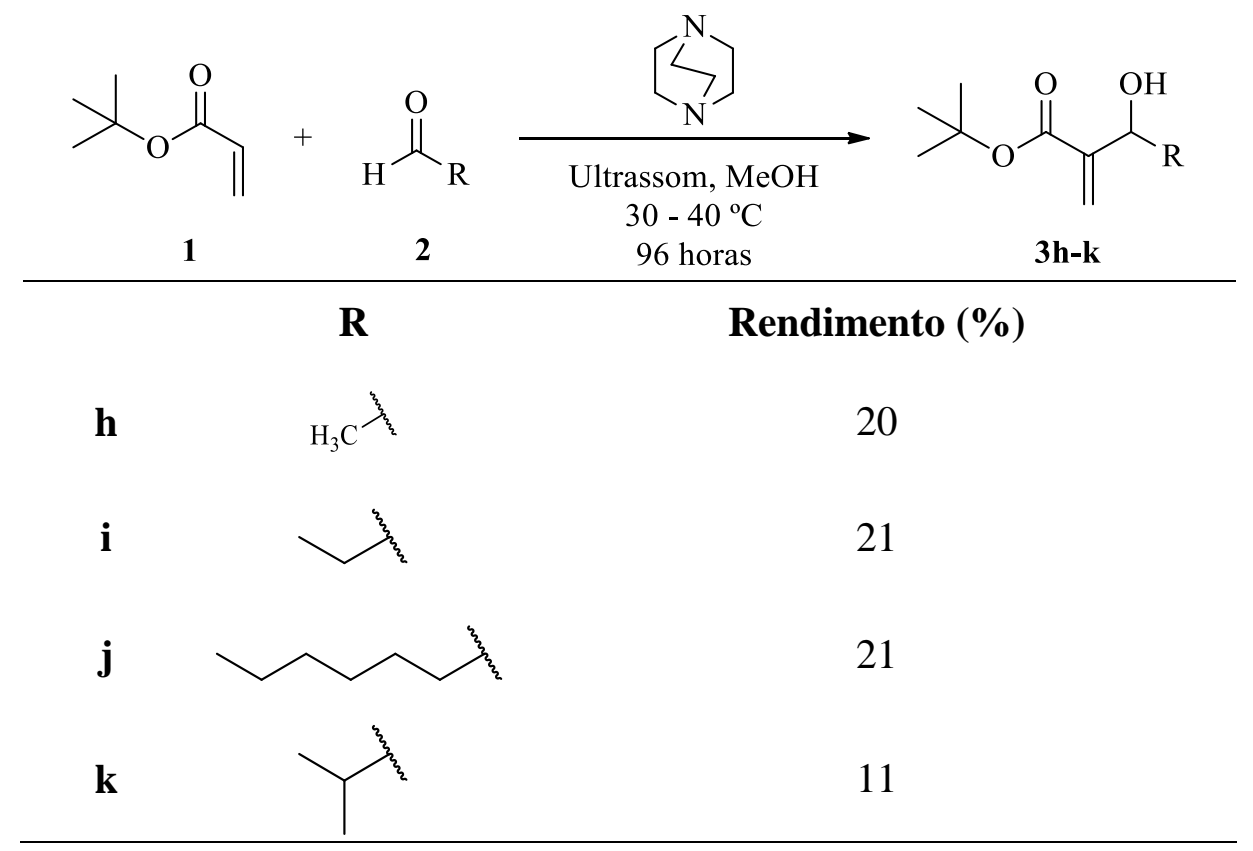

$\mathrm{O}$ aduto 3h é o mais simples dos AMBH alifáticos sintetizados neste trabalho, este servirá como padrão para análise dos demais espectros de $\mathrm{RMN} \mathrm{de}{ }^{1} \mathrm{H}$ e ${ }^{13} \mathrm{C}$ (Tabela 11).

Tabela 11. Dados Espectroscópicos de RMN de ${ }^{1} \mathrm{H}$ e ${ }^{13} \mathrm{C}$ para o $\mathrm{AMBH}-3 \mathbf{h}$.

3-hidróxi-2-metilenobutanoato de terc-butila (3h)

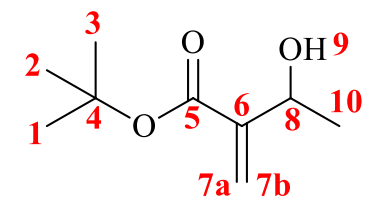

\begin{tabular}{|c|c|c|c|c|}
\hline \multirow{2}{*}{$\mathbf{N}^{\mathbf{o}}$} & \multicolumn{3}{|c|}{ RMN de ${ }^{1} H$} & \multirow{2}{*}{$\begin{array}{c}\text { RMN de }{ }^{13} \mathrm{C} \\
\delta(\mathrm{ppm})\end{array}$} \\
\hline & $\delta(\mathbf{p p m})$ & Multiplicidade, J (Hz) & Integração H & \\
\hline $1-2-3$ & 1,52 & Simpleto & 9 & 28,0 \\
\hline 4 & - & - & - & 81,4 \\
\hline 5 & - & - & - & 166,0 \\
\hline 6 & - & - & - & 144,8 \\
\hline $7 \mathbf{a}$ & 5,73 & Tripleto, $J=1,2 \mathrm{~Hz}$ & 1 & \multirow{2}{*}{123,1} \\
\hline $7 \mathrm{~b}$ & 6,11 & Multipleto & 1 & \\
\hline 8 & 4,58 & Quarteto, $J=6,3$ & 1 & 67,3 \\
\hline 9 & 2,90 & Simpleto largo & 1 & - \\
\hline 10 & 1,38 & Dupleto, $J=6,3 \mathrm{~Hz}$ & 3 & 21,9 \\
\hline
\end{tabular}


$\mathrm{O}$ espectro de $\mathrm{RMN}$ de ${ }^{1} \mathrm{H}$ apresenta seis sinais (Figura 9). O dupleto em 1,38 ppm corresponde ao grupo metila (10) acoplando com o hidrogênio carbinólico (8) com $J$ de $6,3 \mathrm{~Hz}$ e integrando para 3 hidrogênios. A ressonância dos hidrogênios do grupo terc-butila encontrase em 1,52 ppm como um simpleto integrando para 9 hidrogênios. Em 2,90 ppm temos simpleto largo do hidrogênio da hidroxila, integrando para 1 hidrogênio. O quarteto com $\delta$ de 4,58 ppm, que está acoplando com os hidrogênios da metila (10) com a mesma constante de acoplamento de $6,3 \mathrm{~Hz}$, pertence ao hidrogênio carbinólico (8), integrando para 1 hidrogênio, sinal característico da formação do aduto.
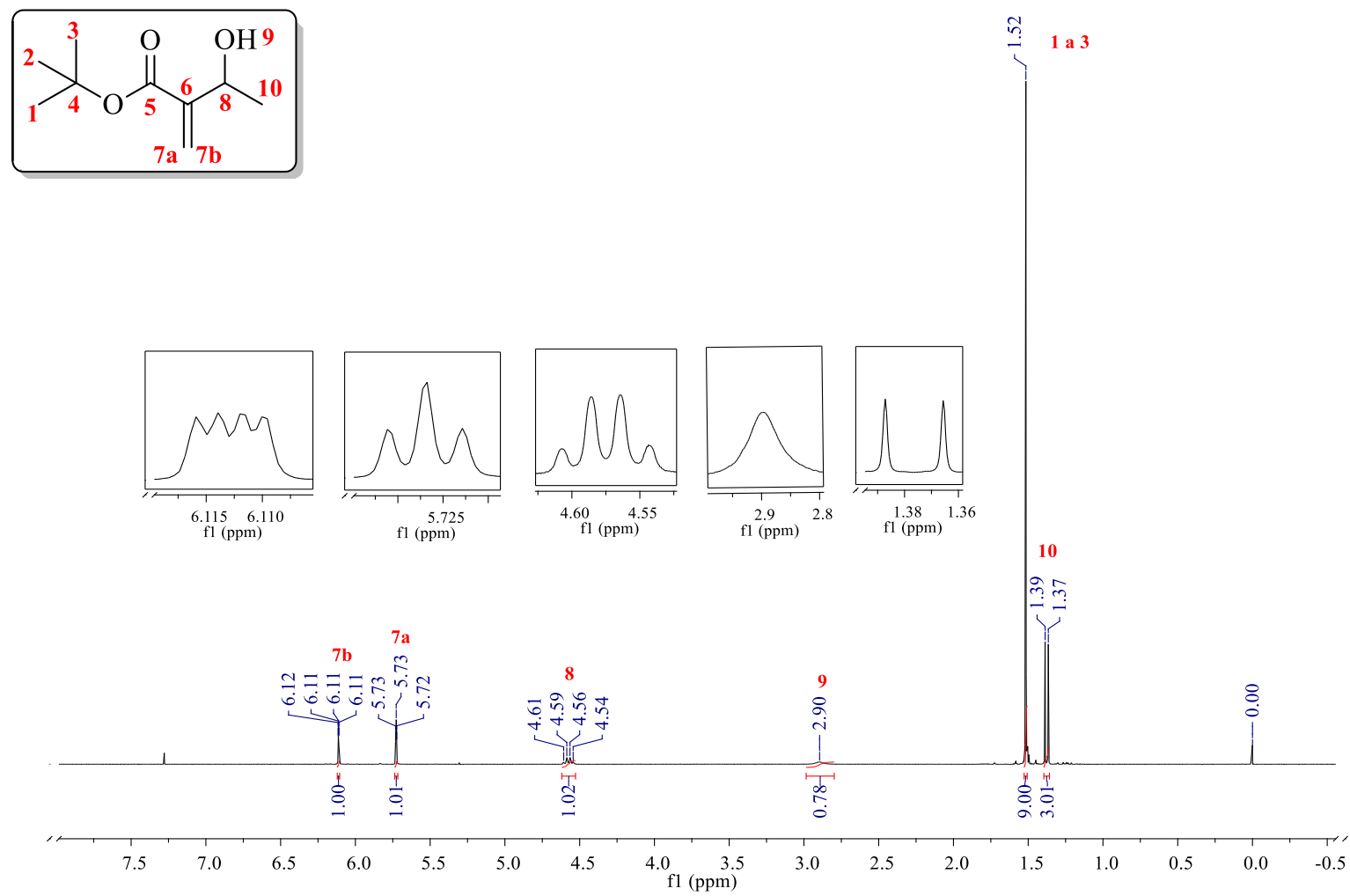

Figura 9. Espectro de RMN de ${ }^{1} \mathrm{H}\left(300 \mathrm{MHz}, \mathrm{CDCl}_{3}\right)$ - AMBH-3h.

Os hidrogênios vinílicos aparecem em 5,73 ppm e 6,11 ppm. No hidrogênio vinílico 7a há o acoplamento com o hidrogênio geminal com um $J$ de 1,2 Hz e um acoplamento de longa distância, ${ }^{4} \mathrm{~J}$ trans, com o hidrogênio carbinólico, porém este último acoplamento não pode ser observado. Deste modo, há uma sobreposição dos sinais para formar um tripleto aparente com $J$ de $1,2 \mathrm{~Hz}$. No hidrogênio $7 \mathrm{~b}$ ocorre os mesmos acoplamentos entretanto, o ${ }^{4} J$ agora é cis, e acoplamentos cis geralmente não são observados. Neste caso o hidrogênio $7 \mathrm{~b}$ apresenta-se com um multipleto. Ambos os hidrogênios $7 \mathrm{a}$ e $7 \mathrm{~b}$ integrando para 1 hidrogênio. $\mathrm{O}$ acoplamento 
geminal dos hidrogênios 7 a e $7 \mathrm{~b}$ encontra-se na faixa de acoplamento de duas ligações $\left({ }^{2} J\right)$ para hidrogênios vinílicos (0 a $2 \mathrm{~Hz})$.

O espectro de RMN de ${ }^{13} \mathrm{C}$ apresenta sete sinais (Figura 10). O primeiro sinal, 21,9 ppm, corresponde ao carbono do grupo metila (10). Os sinais em 28,0 ppm e 81,4 ppm correspondem ao grupo terc-butila. O sinal em 67,3 ppm refere-se ao carbono do centro estereogênico. Os dois sinais em 123,1ppm e 144,8 ppm são referentes aos carbonos da ligação dupla. Por fim, o sinal mais desblindado, 166,0 ppm, é do carbono carbonílico. Os dados de ${ }^{13} \mathrm{C}$ confirmaram os 9 carbonos, e consequentemente, a estrutura do aduto $\mathbf{3 h}$, este servirá como padrão para análise dos demais espectros de $\mathrm{RMN}$ de ${ }^{1} \mathrm{H}$ e ${ }^{13} \mathrm{C}$ dos adutos alifáticos.
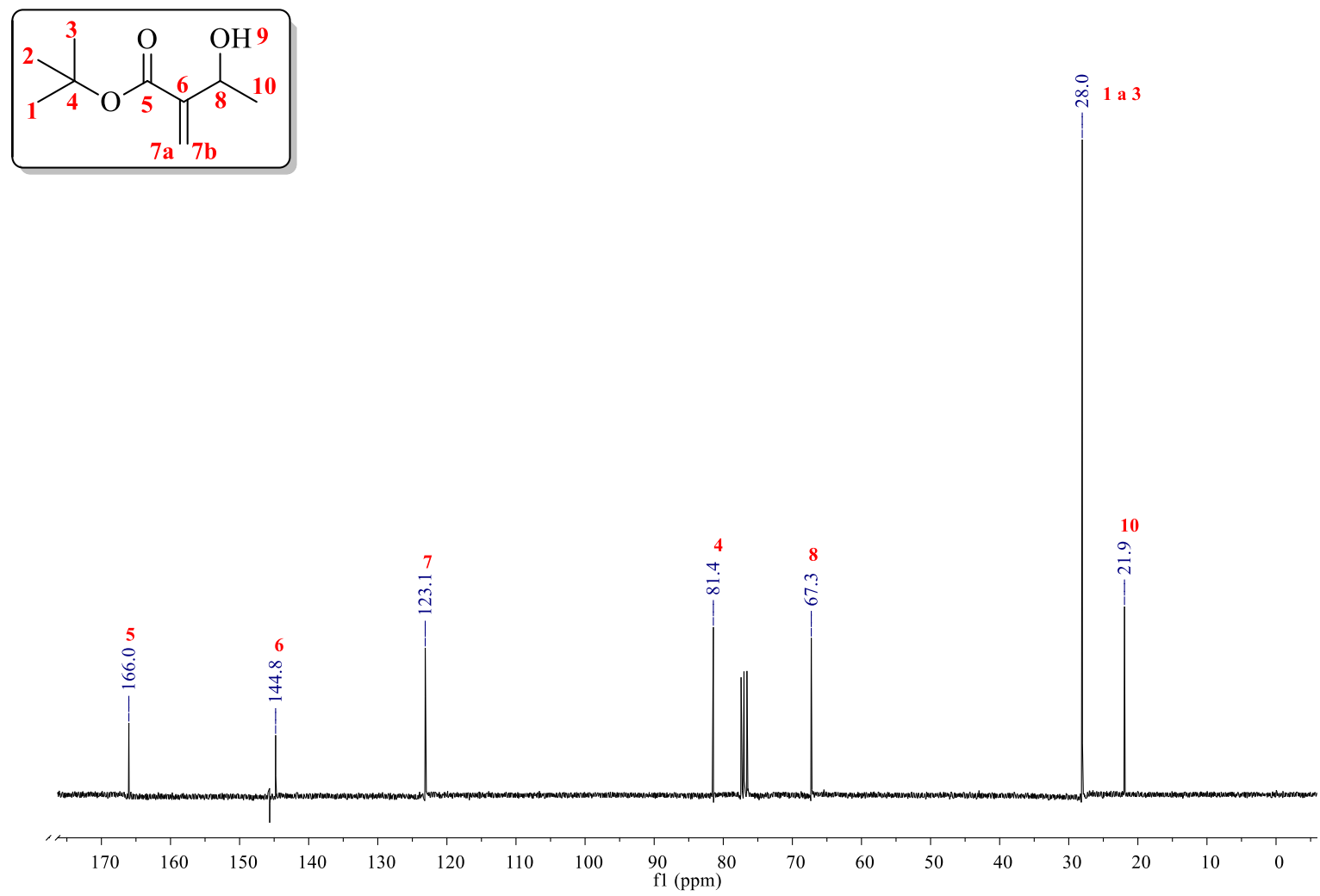

Figura 10. Espectro de $\mathrm{RMN}$ de ${ }^{13} \mathrm{C}\left(75 \mathrm{MHz}, \mathrm{CDCl}_{3}\right)-\mathrm{AMBH}-3 \mathbf{h}$.

O espectro de massa do AMBH 3h (Figura 11) não apresentou o íon molecular (M =172). Contudo, o espectro apresentou o pico 157 (M-15), atribuído ao íon fragmento devido à perda do radical $\mathrm{CH}_{3}{ }^{\circ}$. O pico mais intenso de massa 57 (pico base) corresponde ao cátion tercbutila. 


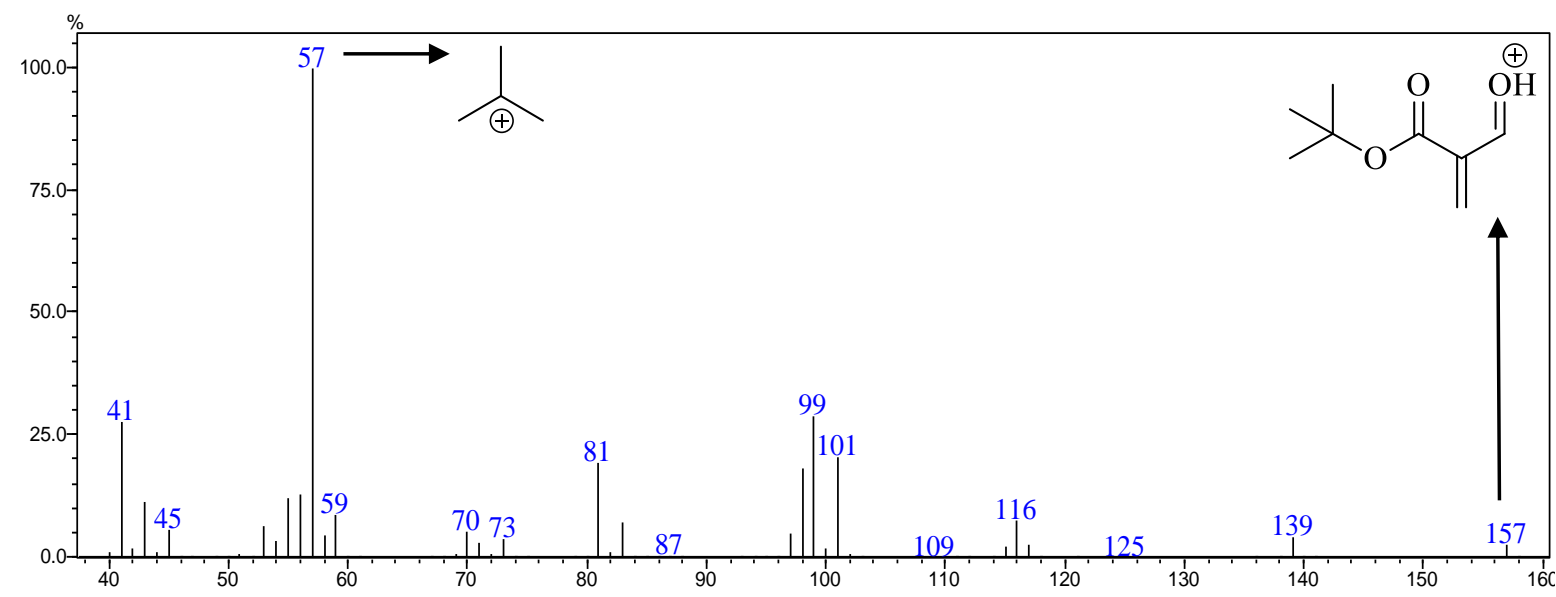

Figura 11. Espectro de massa do 3-hidróxi-2-metilenobutanoato de terc-butila AMBH $3 \mathbf{h}$.

\section{3-REARRANJO DE HURD-CLAISEN EM AMBH}

\subsection{1-OTIMIZAÇÃo DO REARRANJo DE HuRd-Claisen EM AdUTOS DE MoRitA- BAYLIS-HILLMAN}

A realização do estudo sistemático sobre as condições de reação do rearranjo de HurdClaisen em AMBH sob aquecimento convencional pela ação de acetato de mercúrio (II) e etil vinil éter (EVE) foi iniciada pelos adutos de MBH 3a e 3c (aromáticos) e 3h (alifático). Três parâmetros de reação foram elencados como importantes: temperatura, quantidade de catalisador e tempo reacional. O rearranjo de Hurd-Claisen foi realizado com base nas condições experimentais investigadas por Rodrigues ${ }^{3}$, propostas a partir do trabalho de Srikrishna e colaboradores. ${ }^{46}$

Uma observação importante se refere à necessidade de destilar previamente o EVE. Quando este foi utilizado sem a prévia destilação, não houve conversão do substrato. Para que haja a transformação desejada, o EVE deve ser destilado e dopado com 0,1\% (m/v) de hidróxido de potássio. Uma vez tratado desta forma, o EVE foi armazenado por um período de 7 dias e, durante este período, este reagente pode ser utilizado sem prejuízo para o resultado da reação.

Para avaliar o desempenho dos experimentos realizados, uma amostra do bruto reacional foi analisada por RMN ${ }^{1} \mathrm{H}$ (Figura 12) e a partir da integração de alguns sinais, tidos por nós como diagnóstico, da presença do $\mathrm{AMBH}-3 \mathbf{a}$, dos produtos isoméricos de rearranjo 4a e do

${ }^{46}$ Srikrishna, A.; Yelamaggad, C. V.; Kumar, P. P. J. Chem. Soc. Perkin Trans. 1 1999, 2877. 
acetal $\mathbf{5 a},{ }^{47}$ foi calculada a conversão (equação 1), seletividade (equação 2), razão $\boldsymbol{E}: \boldsymbol{Z}$ (equação 3) e rendimento esperado (equação 4) deste experimento.

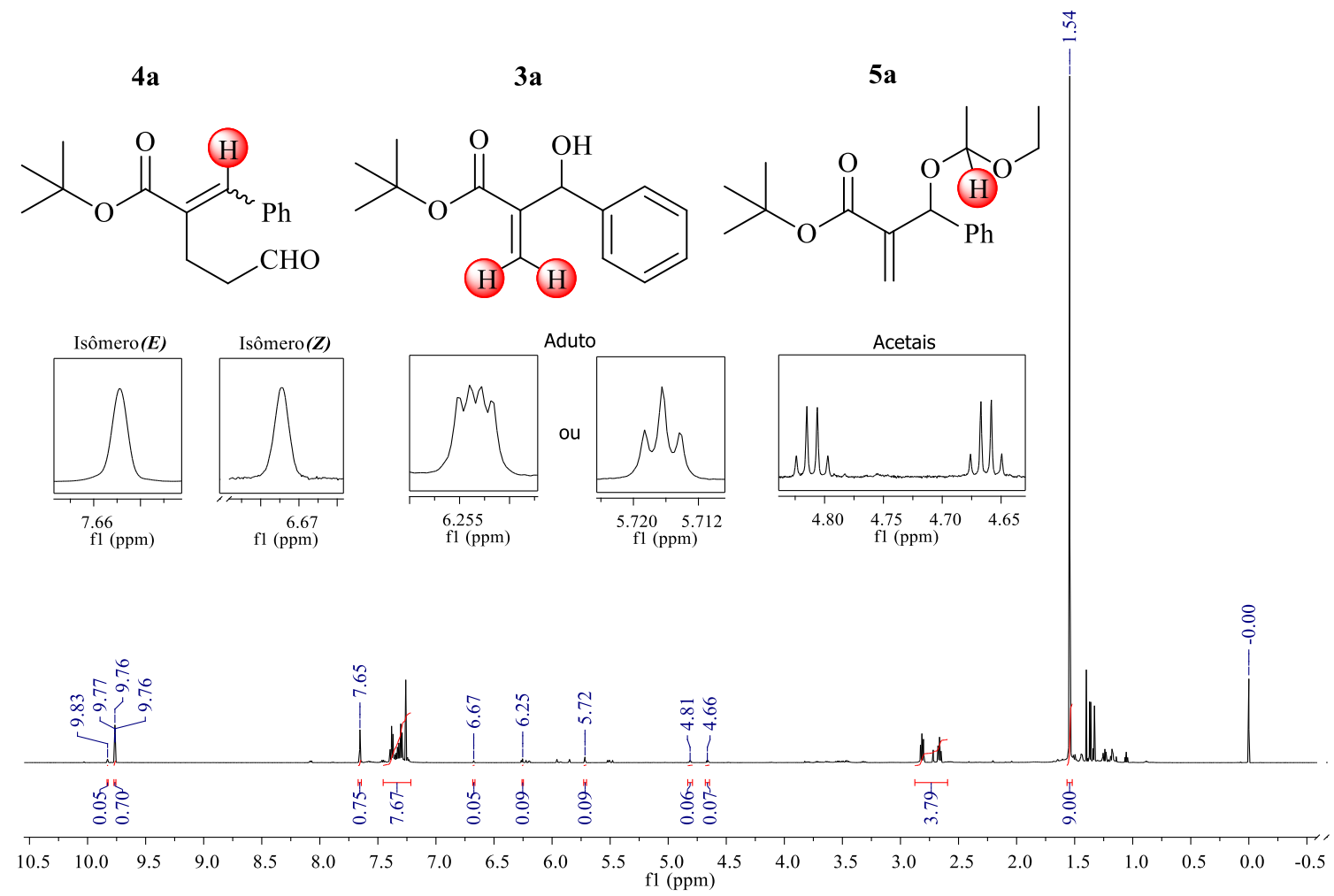

Figura 12. Espectro de RMN de ${ }^{1} \mathrm{H}(600 \mathrm{MHz})$ do bruto de reação do rearranjo de HurdClaisen com 18 horas.

A conversão (Equação 1) se refere à quantidade de aduto de $\mathrm{MBH}$ que foi convertido nos produtos desejados $4 \mathbf{a}$ e nos acetais indesejados 5a. A seletividade (Equação 2) se refere à quimiosseletividade da reação no que diz respeito à formação dos produtos $\mathbf{4 a}$ formados com relação à quantidade formada da mistura diastereoisomérica dos acetais 5a. A razão $\boldsymbol{E}: \boldsymbol{Z}$ (Equação 3) se refere à diastereosseletividade do rearranjo.

O produto entre a conversão e a seletividade (Equação 4) é o rendimento que a reação deveria fornecer caso não houvesse perdas durante a finalização da reação e a purificação dos produtos 4a. Todos os sinais diagnósticos utilizados nestas equações correspondem a um hidrogênio na estrutura química destas substâncias. Portanto, não é necessário aplicar nenhum fator de correção nas equações empregadas para estes cálculos.

${ }^{47}$ Este subproduto da reação foi previamente relatado, para outros álcoois alílicos, por Wei, X.; et al. J. Org. Chem. 2007, 72, 4250. 
Conversão $=\frac{E+Z+\text { Acetais }}{E+Z+\text { Aduto }+ \text { Acetais }} x \mathbf{1 0 0}$

$$
\text { Seletividade }=\frac{E+Z}{E+Z+\text { Acetais }} x \mathbf{1 0 0}
$$

$$
\operatorname{Razão}_{E: Z}=\frac{E}{Z}
$$

Rend. esperado $=$ conversão $\mathrm{x}$ seletividade
Equação 1

Equação 2

Equação 3

\section{Equação 4}

Em que:

$E=$ área do sinal em 7,65 ppm (hidrogênio vinílico, isômero $\boldsymbol{E}$ do produto de rearranjo)

$Z$ = área do sinal em 6,67 ppm (hidrogênio vinílico, isômero $\boldsymbol{Z}$ do produto de rearranjo)

Acetais (mistura diastereoisomérica) = soma das áreas dos sinais em 4,66 ppm e 4,81 ppm

(hidrogênio do carbono anomérico)

Aduto = área do sinal em 5,71 ppm ou 6,25 ppm (hidrogênios vinílicos)

$\mathrm{O}$ primeiro parâmetro estudado foi o tempo reacional. Fixando a temperatura em $100^{\circ} \mathrm{C}$ e a quantidade de catalisador em $2,5 \mathrm{~mol} \%$, a reação foi realizada em três diferentes tempos reacionais: 18, 24 e 30 horas (Tabela 12). Destes, o tempo de 24 horas demonstrou ser o melhor com uma conversão de $99 \%$, seletividade de $84 \%$, razão $\boldsymbol{E}: \boldsymbol{Z}$ de 15:1 e rendimento esperado de 83\%. De posse destes resultados, os parâmetros temperatura e concentração do catalisador igualmente foram investigados. Todos os resultados obtidos estão apresentados na Tabela 12.

Apesar da conversão ser superior a 90\% para todos os experimentos, percebe-se que a variação de temperatura e catalisador interferem significativamente na seletividade do produto de rearranjo. Analisando a variação de temperatura $\left(80\right.$ e $\left.120^{\circ} \mathrm{C}\right)$ a conversão foi similar, 95 e 97\% respectivamente. Entretanto, a razão entre os isômeros geométricos $(\boldsymbol{E}: \boldsymbol{Z})$ sofre uma variação, $19: 1\left(80^{\circ} \mathrm{C}\right), 15: 1\left(100^{\circ} \mathrm{C}\right)$ e $12: 1\left(120^{\circ} \mathrm{C}\right)$. 
Tabela 12. Resultados obtidos para otimização do rearranjo de Hurd-Claisen variando os parâmetros reacionais.

\begin{tabular}{|c|c|c|c|c|c|c|c|}
\hline Exp. & $\begin{array}{l}\text { Tempo } \\
\text { (horas) }\end{array}$ & $\begin{array}{l}\text { Temp. } \\
\left({ }^{\circ} \mathrm{C}\right)\end{array}$ & $\begin{array}{c}\mathrm{Hg}(\mathrm{OAc})_{2} \\
(\mathrm{~mol} \mathrm{\%})\end{array}$ & $\begin{array}{c}\text { Razão } \\
E: Z\end{array}$ & $\begin{array}{c}\text { Conversão } \\
(\%)\end{array}$ & $\begin{array}{c}\text { Seletividade } \\
(\%)\end{array}$ & $\begin{array}{c}\text { Rendimento } \\
(\%)^{*}\end{array}$ \\
\hline 1 & 18 & & & $15: 1$ & 91 & 86 & 78 \\
\hline 2 & 24 & 100 & 2,5 & $15: 1$ & 99 & 84 & 83 \\
\hline 3 & 30 & & & $13: 1$ & 99 & 77 & 76 \\
\hline 4 & & 80 & & $19: 1$ & 95 & 81 & 77 \\
\hline 5 & 24 & 120 & 2,5 & $12: 1$ & 97 & 68 & 66 \\
\hline 6 & & & 1,0 & $17: 1$ & 97 & 43 & 41 \\
\hline 7 & 24 & 100 & 5,0 & $13: 1$ & 98 & 80 & 78 \\
\hline 8 & & & 10 & $10: 1$ & 97 & 82 & 80 \\
\hline
\end{tabular}

Outro resultado importante foi que o aumento de temperatura para $120^{\circ} \mathrm{C}$ reduz a seletividade em aproximadamente $16 \%$, quando comparada à observada para o experimento realizado na temperatura de $100^{\circ} \mathrm{C}$. Uma explicação possível e que traços de água levaria a protonação do EVE, conduzindo ao intermediário 6 que pode sofrer adição do AMBH, levando à formação do subproduto acetal ou mesmo à polimerização do EVE, conforme sugere o mecanismo apresentado no Esquema 23.

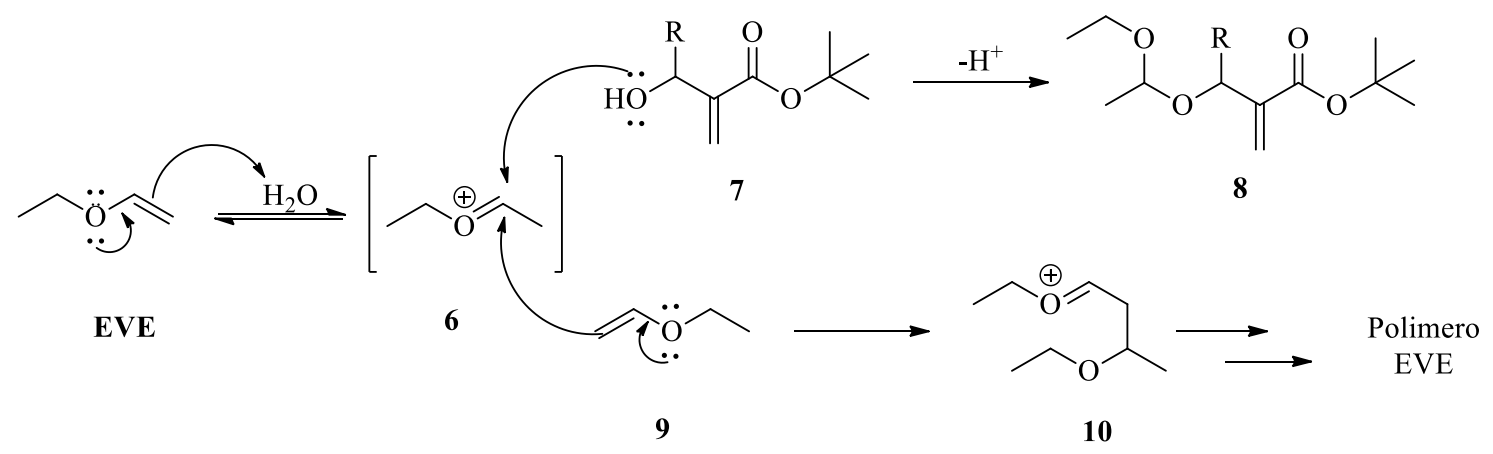

Esquema 23. Mecanismos proposto para formação do subproduto acetal e do polímero de EVE.

Esta hipótese é reforçada pela observação de vários sinais na região 3,00 $<\delta<4,00$. Tanto o acetal quanto o polímero de EVE, teriam sinais no espectro de $\mathrm{RMN}{ }^{1} \mathrm{H}$ com deslocamento químico nesta região, o que explicaria a complexidade dos sinais ali observados. 
Antes de realizar a comparação entre os espectros de $\mathrm{RMN}$ de ${ }^{1} \mathrm{H}$ do bruto de reação do rearranjo do AMBH-3a realizados nas temperatura de $80{ }^{\circ} \mathrm{C}, 100^{\circ} \mathrm{C}$ a $120^{\circ} \mathrm{C}$ (Figura 13) adotamos o sinal da terc-butila em 1,54 ppm como referência para padronizar a intensidade dos espectros. Deste modo, o sinal em 1,54 ppm tem a mesma intensidade em ambos os espectros. Assim, a região em destaque evidencia a presença dos sinais do acetal e do polímero de EVE em concentrações que variam com a temperatura. Contudo, a análise por $\mathrm{RMN}{ }^{1} \mathrm{H}$ dos experimentos realizados nas temperaturas de $80^{\circ} \mathrm{C}$ e $100^{\circ} \mathrm{C}$ apresentam menor concentração destas espécies quando comparados com o resultado do experimento a $120^{\circ} \mathrm{C}$.

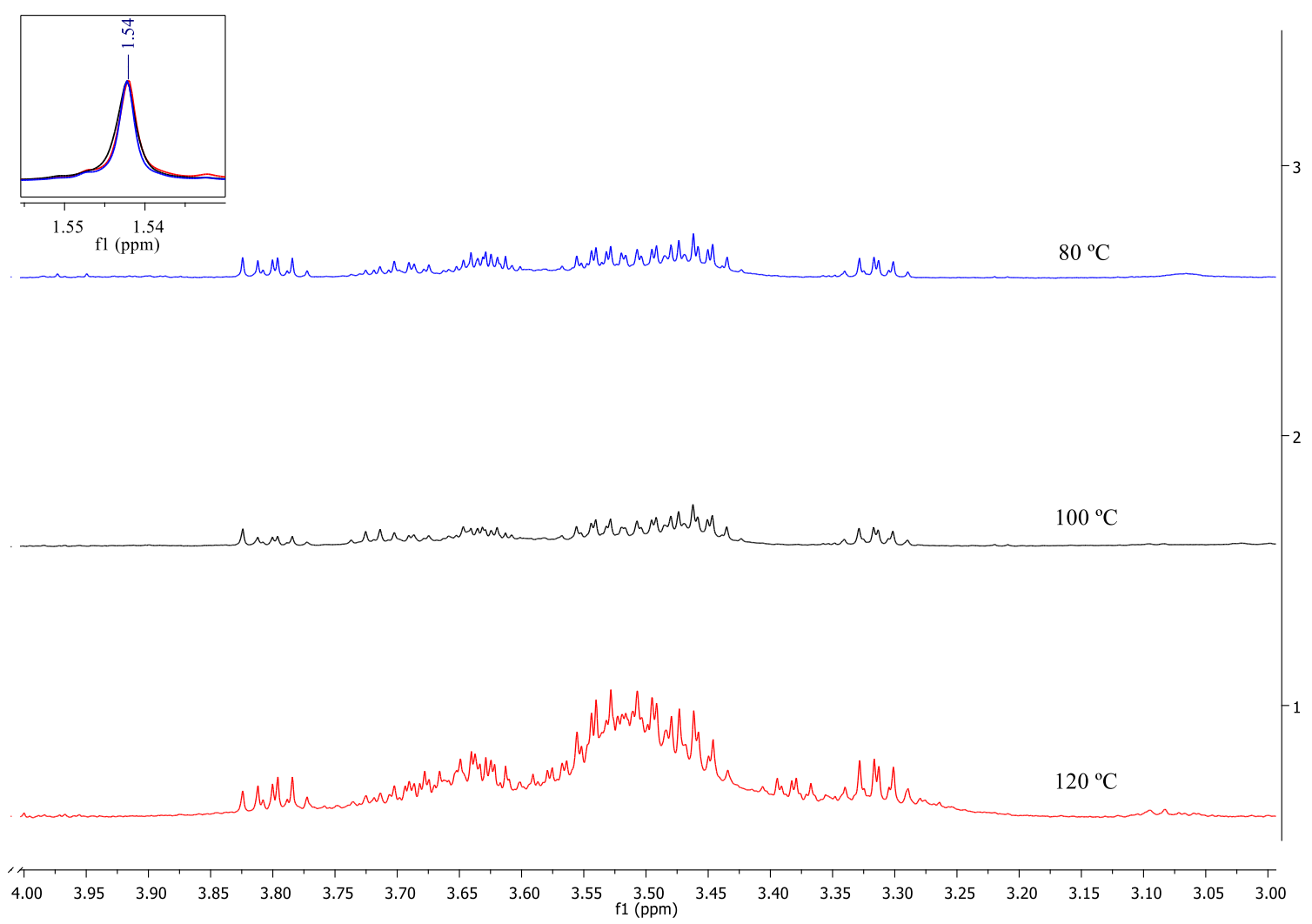

Figura 13. Sobreposição dos espectros de $\mathrm{RMN}{ }^{1} \mathrm{H}$ do bruto de reação do rearranjo de HurdClaisen do AMBH-3a nas temperatura de 120,100 e $80^{\circ} \mathrm{C}$.

A concentração de $\mathrm{Hg}(\mathrm{OAc})_{2}$ foi o parâmetro que promoveu maior alteração na razão $\boldsymbol{E}: \boldsymbol{Z}$ e na seletividade da reação. Em relação à seletividade, o $\mathrm{Hg}$ (II) é determinante para a formação do produto de rearranjo. Sendo que, em quantidades inferiores, a seletividade é ruim, apenas $43 \%$ de seletividade para formação do produto de rearranjo de Hurd-Claisen, quando a reação foi submetida a $1,0 \mathrm{~mol} \%$ de $\mathrm{Hg}(\mathrm{OAc})_{2}$. Na ausência do catalisador a reação além de não converter totalmente o AMBH (87\% de conversão), o acetal é formado como o produto majoritário (seletividade de $93 \%$ em seu favor). O espectro de $\mathrm{RMN}{ }^{1} \mathrm{H}$ do bruto de reação do 
rearranjo de Hurd-Claisen (Figura 14) realizado sem catalisador evidência além da formação do produto de acetal, a presença de alguns subprodutos advindos do EVE, como o polímero e acetaldeído.

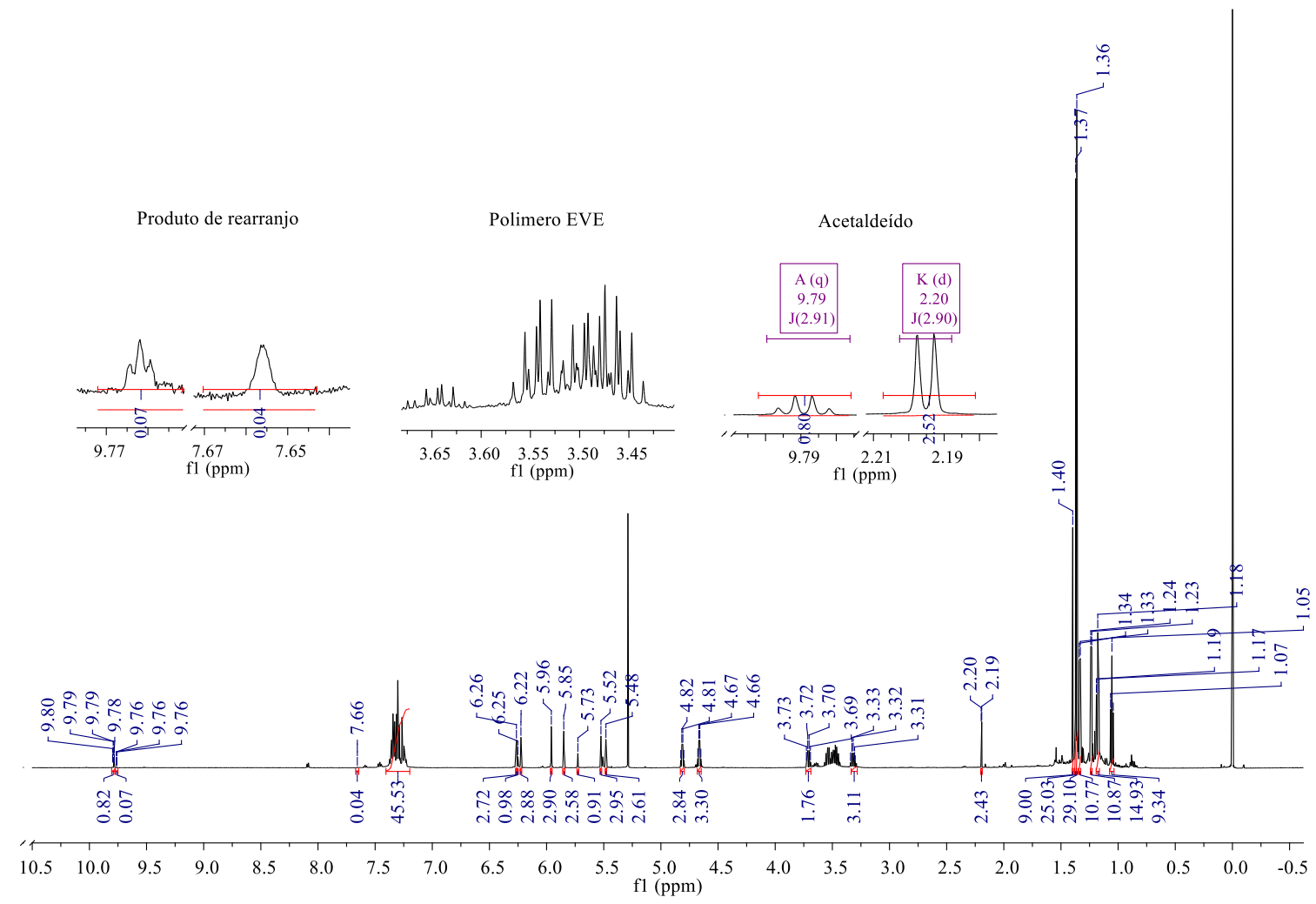

Figura 14. Espectro de RMN de ${ }^{1} \mathrm{H}(600 \mathrm{MHz})$ do bruto de reação do rearranjo de HurdClaisen realizado sem $\mathrm{Hg}(\mathrm{OAc})_{2}$.

Novamente a presença de vários sinais sobrepostos na região 3,00< $\delta<4,00$ ppm reforça a formação do polímero do agente de vinilação (EVE). A formação de acetaldeído pode ser constatada no espectro de RMN de ${ }^{1} \mathrm{H}$ da Figura 14 devido ao dupleto em 2,20 ppm estar acoplando com o quarteto em 9,79 ppm com $J$ de 2,9 Hz. A combinação destes sinais e suas respectivas integrações, 3 e 1 hidrogênio, nos permite detectar a formação de acetaldeído.

Apesar da formação seletiva do produto de acetal, que será discutido a seguir, é possível perceber uma pequena formação do produto de rearranjo devido a presença de dois sinais diagnósticos, o simpleto largo em 7,66 ppm e o tripleto em 9,76 ppm com $J$ de 1,5 Hz. A ampliação das regiões mencionadas anteriormente pode ser visualizada na Figura 14.

Por fim, o espectro de RMN de ${ }^{1} \mathrm{H}$ da Figura 14 possui oito pares de sinais de igual multiplicidade, este sinais encontram-se ampliando na Figura 15 para melhor discussão e 
caracterização do subproduto acetal (5a). O primeiro par de sinais encontra-se entre 1,00 ppm a 1,20 ppm, dois tripletos com constante de acoplamento de 7,1 Hz atribuído aos hidrogênios da metila (12) que estão acoplando com os hidrogênios metilênicos (11), estes integram para 3 hidrogênios. Os hidrogênios metilênicos que estão acoplando com a metila encontra-se entre 3,20 ppm a 3,80 ppm, dois quartetos com $J$ de 7,1 Hz integrando para 2 hidrogênios. O par de sinais presente entre 1,23 ppm a 1,34 ppm, dois dupletos com $J$ de 5,3 Hz são das metilas (10) acoplando com centro estereogênico do carbono anomérico (9), estes sinais integram para 3 hidrogênios. O par de sinais do centro estereogênico 9 está localizado entre 4,65 ppm a 4,83 ppm, dois quartetos com mesma constante de acoplamento $(J=5,3 \mathrm{~Hz})$ e integração para 1 hidrogênio.
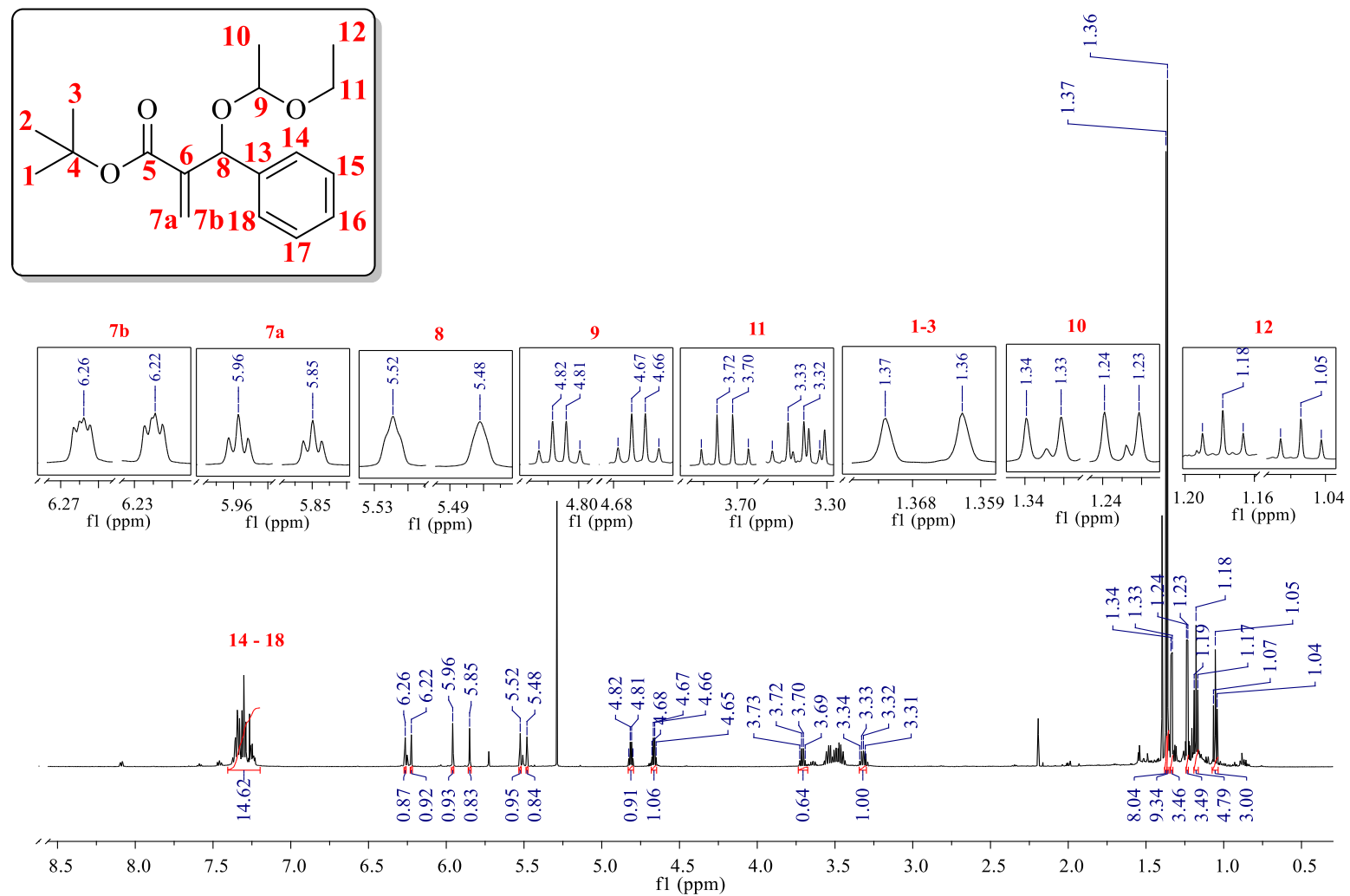

Figura 15. Espectro de RMN de ${ }^{1} \mathrm{H}(600 \mathrm{MHz})$ do bruto de reação do rearranjo de Hurd-

Claisen realizado sem $\mathrm{Hg}(\mathrm{OAc})_{2}$ com respectivas ampliações dos sinais dos acetais.

Continuando, os dois simpletos em 1,36 ppm e 1,37 ppm são referentes aos hidrogênios da terc-butila, ambos integram para 9 hidrogênios. O par de sinais do centro estereogênico (8) situa-se em 5,48 ppm e 5,52 ppm, dois simpletos aparente integrando para 1 hidrogênio. A região entre 5,80 ppm a 6,30 ppm possui dois pares de sinais que são referentes aos hidrogênios vinílicos com constante de acoplamento geminal de 1,6 Hz, o primeiro par de sinais é um 
tripleto aparente e o segundo um multipleto. A diferença na multiplicidade é a mesma explicação sugerida para o AMBH-3a. Na região entre 7,20 ppm a 7,40 ppm encontra-se os hidrogênios do anel aromático de ambos os acetais.

$\mathrm{O}$ espectro de $\mathrm{RMN}$ de ${ }^{13} \mathrm{C}$ apresenta 14 pares de sinais (Figura 16). O primeiro par com deslocamento químico de $15,1 \mathrm{ppm}$ e $15,3 \mathrm{ppm}$ corresponde a metila (12) vizinha ao carbono metilênico. Os carbonos metilênicos (11) estão localizados em 59,9 ppm e 60,3 ppm. O par de sinais em 20,2 ppm e 20,3 ppm, são referentes a metila (10) vizinha ao centro estereogênico 9. Os sinais em 27,9 ppm são dos carbonos do grupo terc-butila de ambos os isômeros. Em 80,9 ppm e 81,0 ppm correspondem ao carbono quaternário (4) do grupo terc-butila. Os carbonos dos dois centros estereogênicos estão em 74,5 ppm e 75,9 ppm e 97,8 ppm e 99,1 ppm, o primeiro par $(74,5$ e 75,9$)$ é do carbono 8 e o segundo par $(97,8$ e 99,1) são do centro estereogênico 9, carbono anomérico.
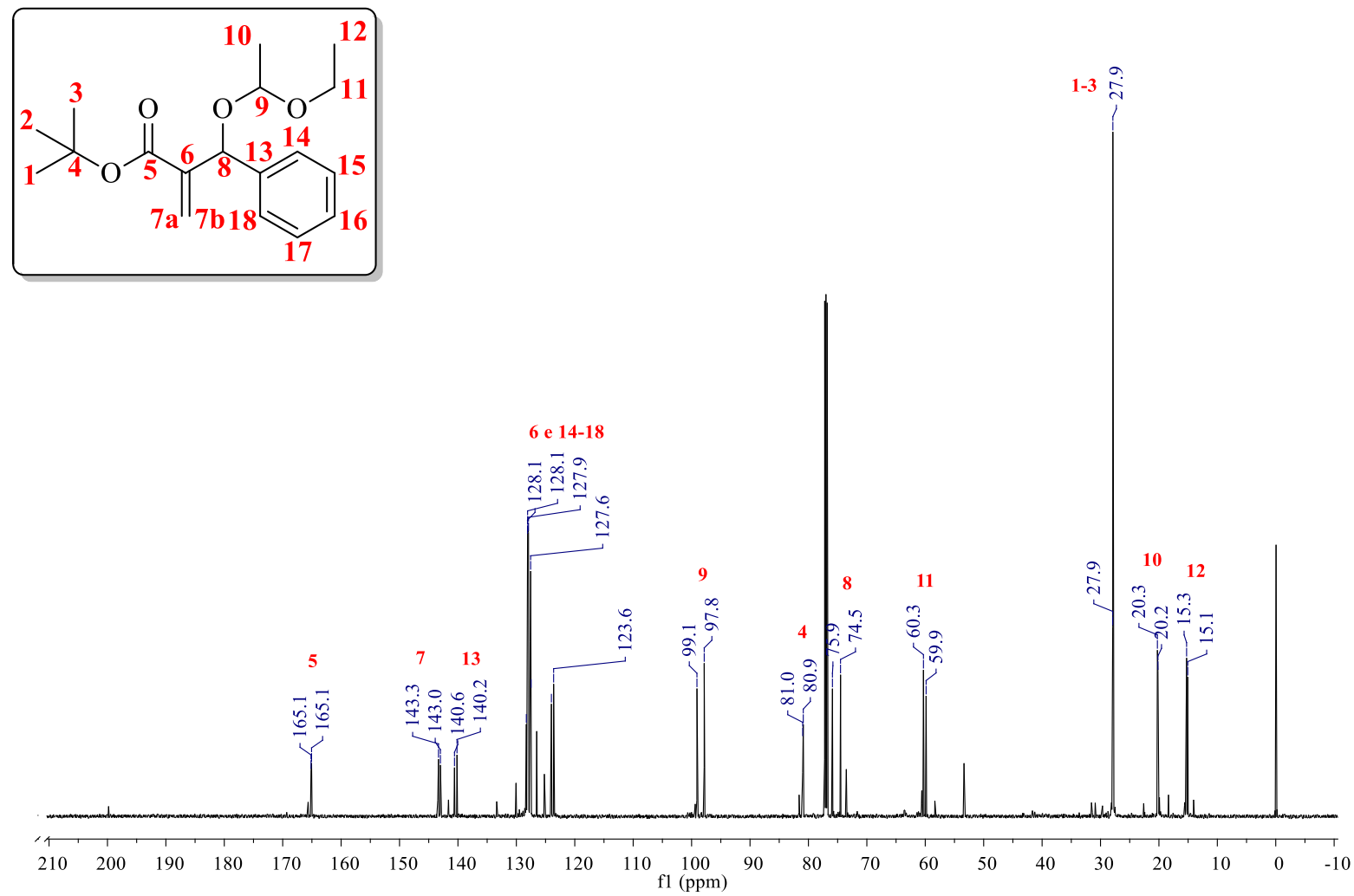

Figura 16. Espectro de RMN de ${ }^{13} \mathrm{C}(150 \mathrm{MHz})$ bruto de reação do rearranjo de Hurd-Claisen realizado sem $\mathrm{Hg}(\mathrm{OAc})_{2}$.

Os pares de sinais entre 120 ppm e 145 ppm são referentes aos carbonos da ligação dupla e do anel aromático. Por fim, o par de sinais mais desblindado, em 166,5 ppm (E) e166,9 
$\operatorname{ppm}(\boldsymbol{Z})$ pertence ao carbono carbonílico do éster. Os dados de ${ }^{13} \mathrm{C}$ confirmaram os 18 carbonos e consequentemente a estrutura dos acetais, 5a.

A sobreposição dos espectros de RMN de ${ }^{1} \mathrm{H}$ do bruto de reação do rearranjo do AMBH 3a (Figura 17), obtidos através da variação da concentração de mercúrio (1,0 a 10 mol\%), demonstra um decréscimo na intensidade do quarteto do centro estereogênico da função química acetal, com deslocamento químico em 4,66 ppm e 4,81 ppm. Cabe ressaltar que a mesma padronização da intensidade do sinal da terc-butila, realizada na Figura 13, foi aplicada a sobreposição dos espectros da Figura 17. A realização do rearranjo com $2,5 \mathrm{~mol} \%$ de $\mathrm{Hg}(\mathrm{OAc})_{2}$ apresenta intensidade do sinal do acetal similar ao espectro obtido com 5,0 mol\% de catalisador. Contudo, é necessário uma quantidade menor de mercúrio para obter uma boa seletividade $(83 \%)$ para o produto de rearranjo de Hurd-Claisen. A variação da quantidade de catalisador permitiu avaliar a formação do subproduto acetal.

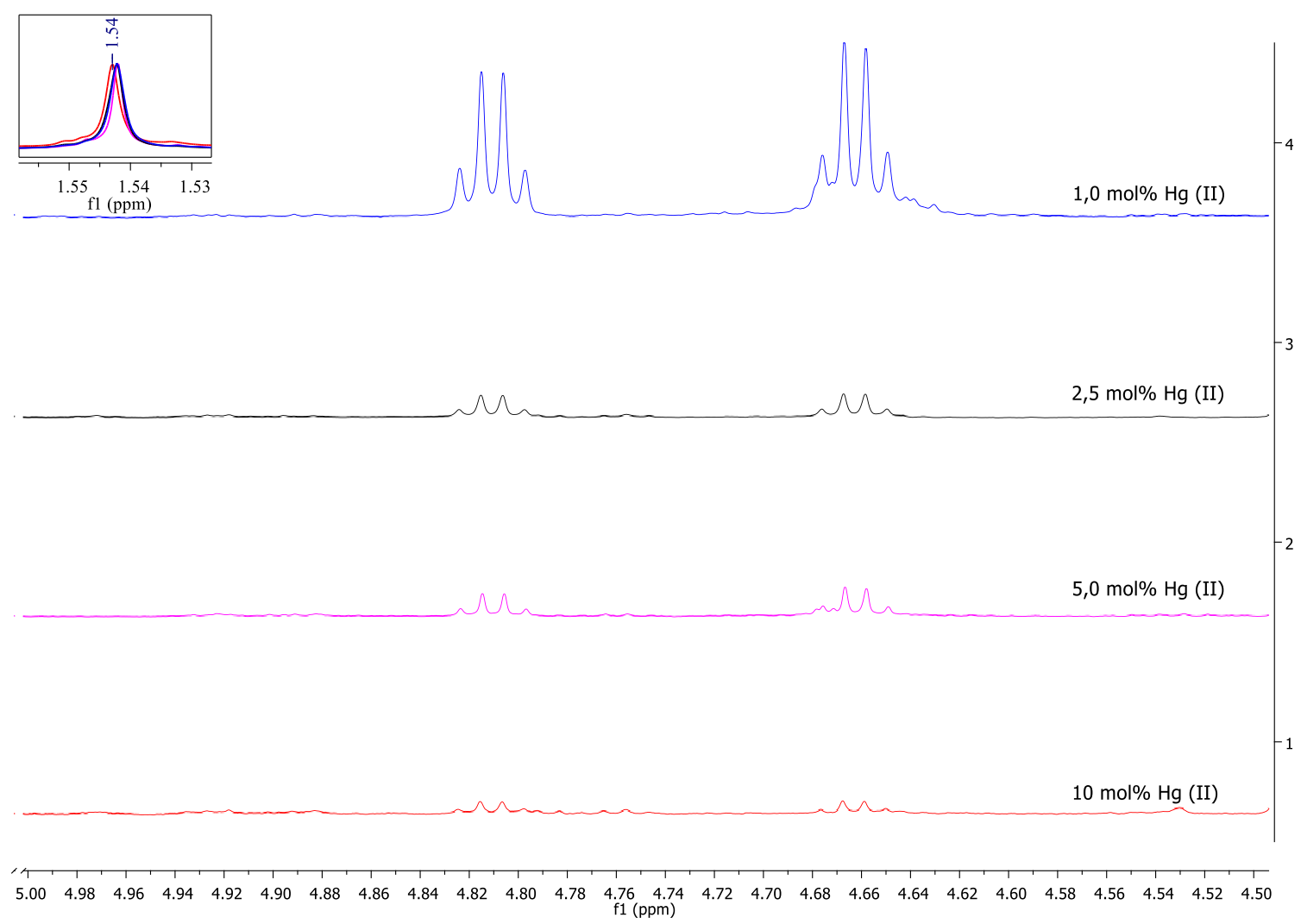

Figura 17. Sobreposição dos espectros de $\mathrm{RMN}{ }^{1} \mathrm{H}$ do bruto de reação do rearranjo de HurdClaisen do $\mathrm{AMBH}$ 3a variando a concentração de $\mathrm{Hg}(\mathrm{OAc})_{2}$.

Ainda analisando a influência da concentração do catalisador na reação, pode-se observar que há uma relação entre a concentração de acetato de mercúrio e a razão $\boldsymbol{E}: \boldsymbol{Z}$ (Gráfico 
1). Quanto maior a concentração do catalisador, menor é o valor de $\boldsymbol{E}: \boldsymbol{Z}$. Deste modo, algumas hipóteses sobre como o mercúrio poderia, além de catalisar a etapa de formação do alil vinil éter, estar influenciando na razão $\boldsymbol{E}: \boldsymbol{Z}$ foram levantadas.

\section{Influência da concentração de Hg na razão $E: Z$}

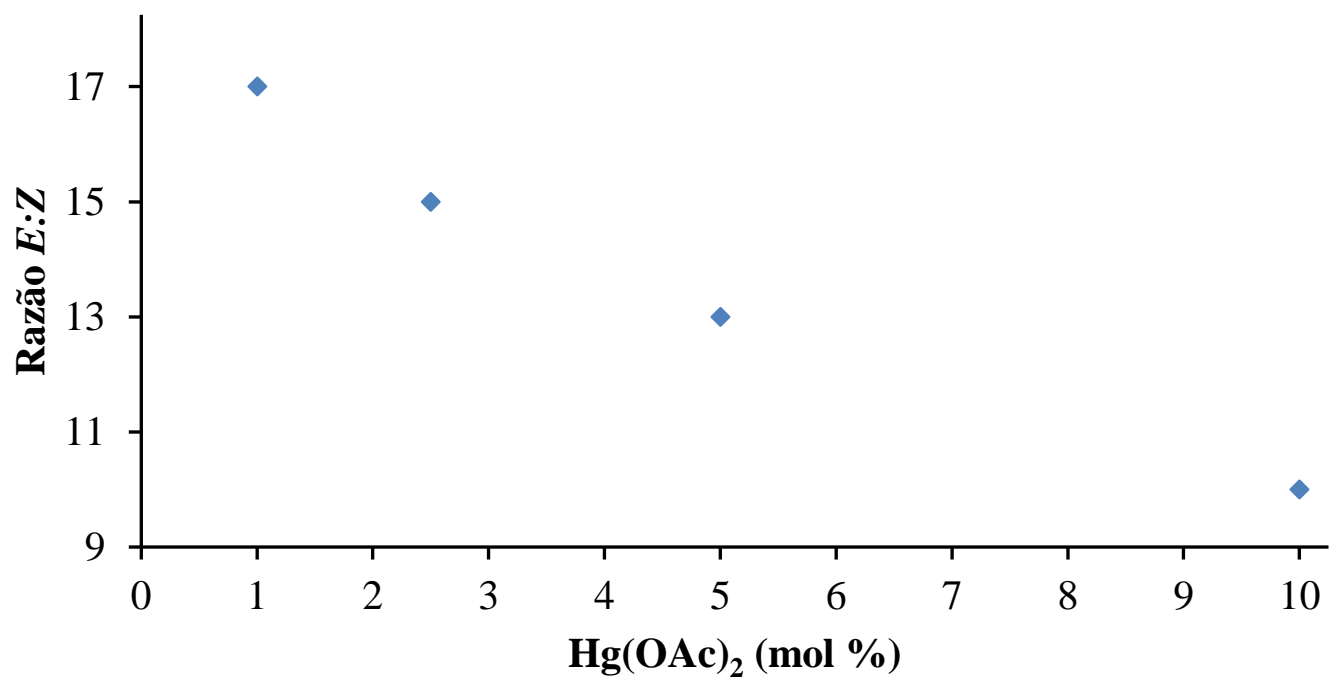

Gráfico 1. Concentração de acetato de mercúrio pela razão $\boldsymbol{E}: \boldsymbol{Z}$.

A primeira hipótese seria uma possível isomerização $(\boldsymbol{E} \rightarrow \boldsymbol{Z})$ do produto de rearranjo devido a deslocalização dos elétrons $\pi$ pela complexação do mercúrio com os oxigênios carbonílicos permitindo a rotação da ligação para formação do isômero $\boldsymbol{Z}$. Deste modo a diminuição da concentração de mercúrio $(1,0 \mathrm{~mol} \%)$ aumentaria a proporção do isômero $\boldsymbol{E}$ na mistura reacional contendo os dois isômeros.

Para avaliar a extensão de isomerização causada pelo catalisador no produto da reação, foi realizado um experimento complementar no qual o isômero $\boldsymbol{E}$ puro foi submetido à melhor condição de reacional (24 horas, $2,5 \mathrm{~mol} \%$ de $\mathrm{Hg}(\mathrm{OAc})_{2}$ e $100^{\circ} \mathrm{C}$ ). $\mathrm{O}$ espectro de $\mathrm{RMN}{ }^{1} \mathrm{H}$ (Figura 18) não evidenciou o surgimento do simpleto largo em 6,67 ppm, sinal característico do isômero $\boldsymbol{Z}$, excluindo a hipótese de isomerização. 


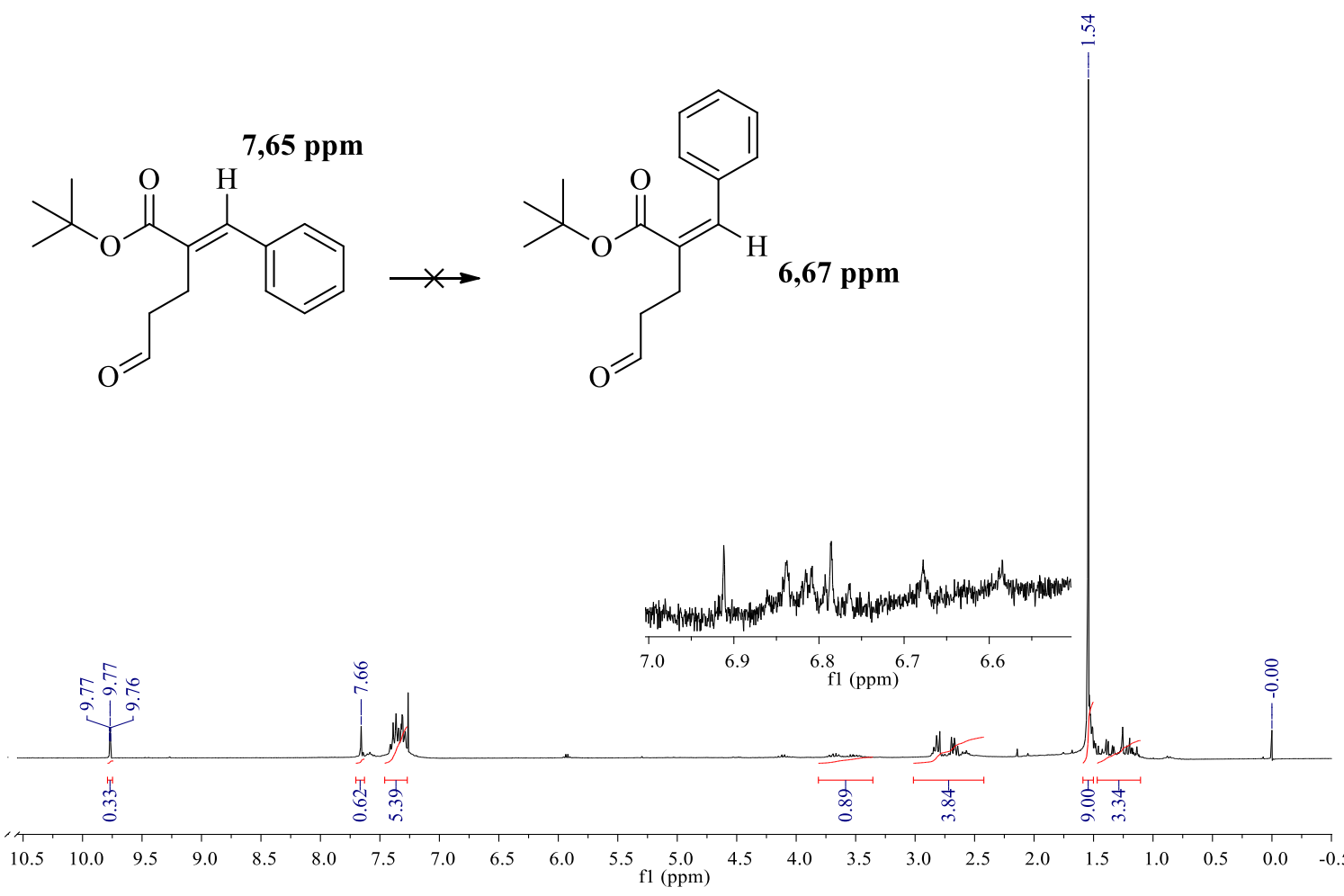

Figura 18. Espectro de RMN 1H (600 MHz) do bruto da tentativa de isomerização do produto de rearranjo $\boldsymbol{E}$ quando submetido a aquecimento em etil vinil éter, $100^{\circ} \mathrm{C}$, na presença de $\mathrm{Hg}(\mathrm{OAc})_{2}{ }^{48}$

Um segunda hipótese está relacionada à participação de $\mathrm{Hg}(\mathrm{II})$ nos estados de transição diastereisoméricos que conduzem aos produtos de rearranjo $\boldsymbol{E}: Z$. Quando a reação é realizada com baixas concentrações de catalisador, este pode influenciar nestes estados de transição, favorecendo a formação do produto $\boldsymbol{E}$ em detrimento do $\boldsymbol{Z}$. Quando a concentração de catalisador é elevada, ocorre a formação de nanopartículas de mercúrio que levaria à uma redução da concentração de $\mathrm{Hg}(\mathrm{II})$. Isso promoveria a redução da influência do catalisador na diastereosseletividade da reação, devido à sua baixa disponibilidade.

Esta hipótese se baseia na observação de mercúrio metálico quando a reação ocorre com $10 \mathrm{~mol} \%$ de catalisador. Para avaliar esta hipótese foi realizado um estudo cinético para analisar o perfil reacional na ausência e presença de mercúrio metálico, pois a baixa disponibilidade de catalisador levaria, também, à redução da taxa de reação. Como resultado, ambos experimentos apresentaram o mesmo perfil cinético (Gráfico 2). Isso sugere que não há a supressão de catalisador pela presença de mercúrio metálico, como preconiza a hipótese em

${ }^{48}$ Dos $54 \mathrm{mg}$ do isômero $\boldsymbol{E}$ puro utilizadas para tentativa de isomerização foi recuperado, após tratamento da reação, $47 \mathrm{mg}$ do produto não isomerizado. 
questão. Até o presente momento, não foi possível formular uma hipótese que explique a relação entre concentração de catalisador e a razão $\boldsymbol{E}: \boldsymbol{Z}$. Estudos envolvendo a modelagem molecular dos caminhos de reação que conduzem aos produtos de rearranjo encontra-se em andamento numa colaboração de nosso grupo de pesquisas com aquele coordenado pelo professor Heibbe C. B. Oliveira do IQ/UnB.

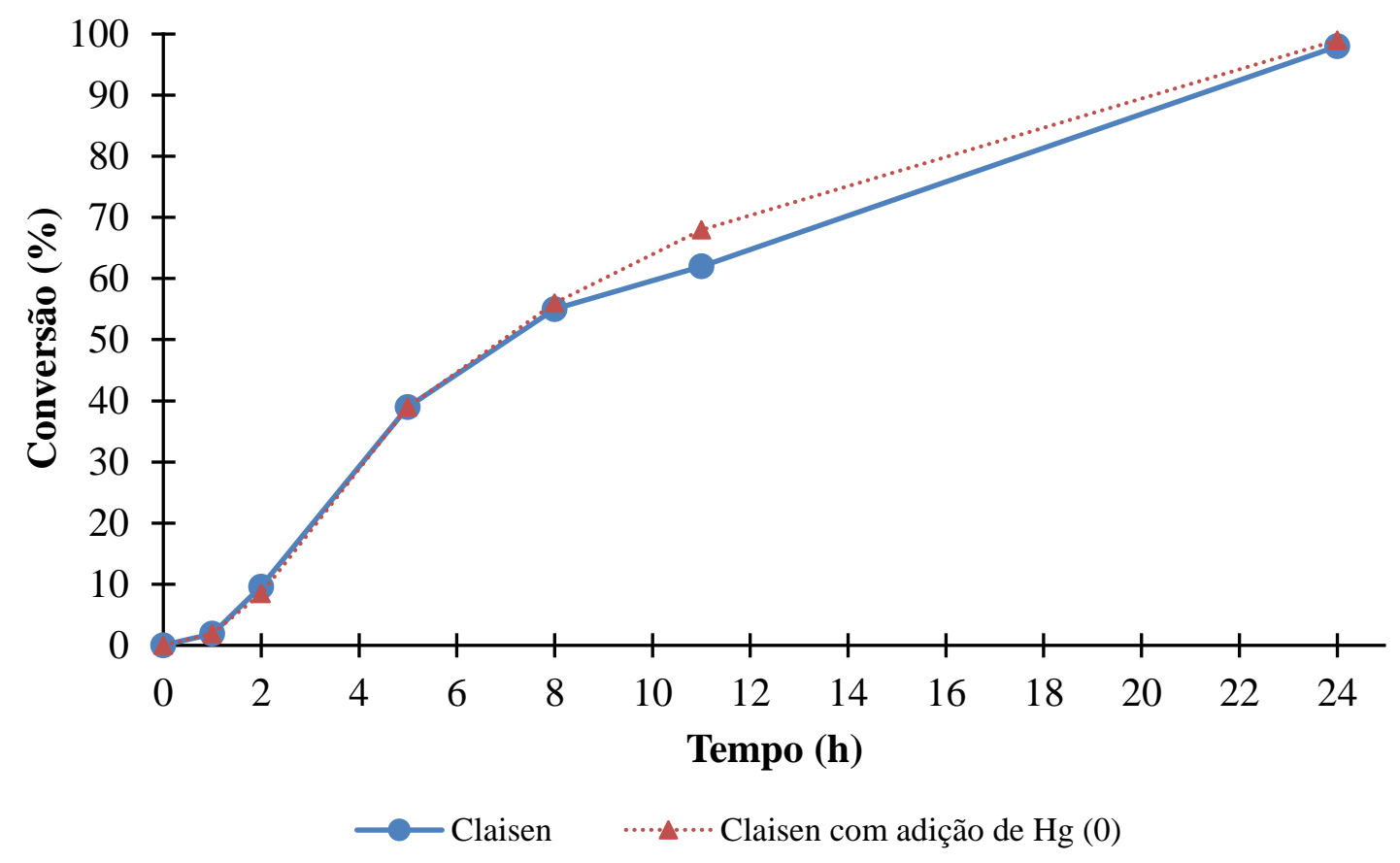

Gráfico 2. Estudo Cinético e tentativa de cessar a reação com adição de $\mathrm{Hg}(0){ }^{49}$

De posse dos resultados do rearranjo de Hurd-Claisen no AMBH-3a, que não possui substituinte no anel aromático. Foi realizado um breve estudo de otimização da reação utilizando um substrato com um cloro na posição para do anel aromático (AMBH-3c). A priori não sabemos se substituintes no anel podem influenciar na conversão, seletividade, razão $\boldsymbol{E}: \boldsymbol{Z}$ e no rendimento esperado da reação, conduzindo deste modo a um processo de otimização da reação equivocado.

Tendo como ponto de partida a condição já otimizada, foram elencados dois tempos reacionais, 24 e 48 horas. Deste modo, pode-se confirmar se a metodologia é reprodutiva para

\footnotetext{
49 O estudo cinético da reação de Hurd-Claisen foi realizado em um tubo de ensaio de $10 \mathrm{~mm}$ x $100 \mathrm{~mm}$ pyrex com tampa. Foram adicionados 0,63 mmol do AMBH-3a, 3,13 mmol de etil vinil éter $(0,3 \mathrm{~mL})$ e $106 \mathrm{mmol}$ de acetado de mercúrio $\left(\mathrm{Hg}(\mathrm{OAc})_{2}, 5,0 \mathrm{mg}\right.$. Após uma hora de reação a mistura reacional foi dividida igualmente em dois tubos. Em um dois tubos foi adicionado 100 equivalente de $\mathrm{Hg}(0)$.
} 
substratos contendo anel aromático e se tempos superiores a 24 horas são necessários para completa conversão do substrato. $\mathrm{O}$ aduto $\mathbf{3 h}$, substrato alifático, também foi submetido a diferentes tempos reacionais, 24, 30 e 48 horas. Os resultados destes experimentos estão racionalizados na Tabela 13.

Tabela 13. Rendimentos obtidos para rearranjo de Hurd-Claisen dos AMBH 3c e $\mathbf{3 h}$.

\begin{tabular}{cccccc}
\hline Produto & $\begin{array}{c}\text { Tempo } \\
\text { (horas) }\end{array}$ & $\begin{array}{c}\text { Conversão } \\
(\%)\end{array}$ & $\begin{array}{c}\text { Seletividade } \\
(\%)\end{array}$ & $\boldsymbol{E}: \boldsymbol{Z}$ & $\begin{array}{c}\text { Rendimento } \\
(\boldsymbol{\%})\end{array}$ \\
\hline 24 & 91 & 93 & $12: 1$ & 85 \\
\hline
\end{tabular}

* rendimento esperado, obtido pelo produto entre conversão e seletividade (equação 4).

Tempo de reação superiores a 24 horas não são necessários para ótima conversão de substratos aromáticos no produto de rearranjo. Com 48 horas, a reação de 3c apresenta essencialmente os mesmo resultados que os obtidos com 24 horas.

Para o substrato alifático (AMBH-3h) os sinais diagnósticos utilizados para os cálculos de conversão, seletividade, razão $\boldsymbol{E}: \boldsymbol{Z}$ e rendimento esperado com seus respectivos deslocamentos químicos, bem como os valores de integração da mistura contendo os dois isômeros, 4h $(\boldsymbol{E})$ e $4 \mathbf{h}(\boldsymbol{Z})$, são exemplificados na Figura 19. 

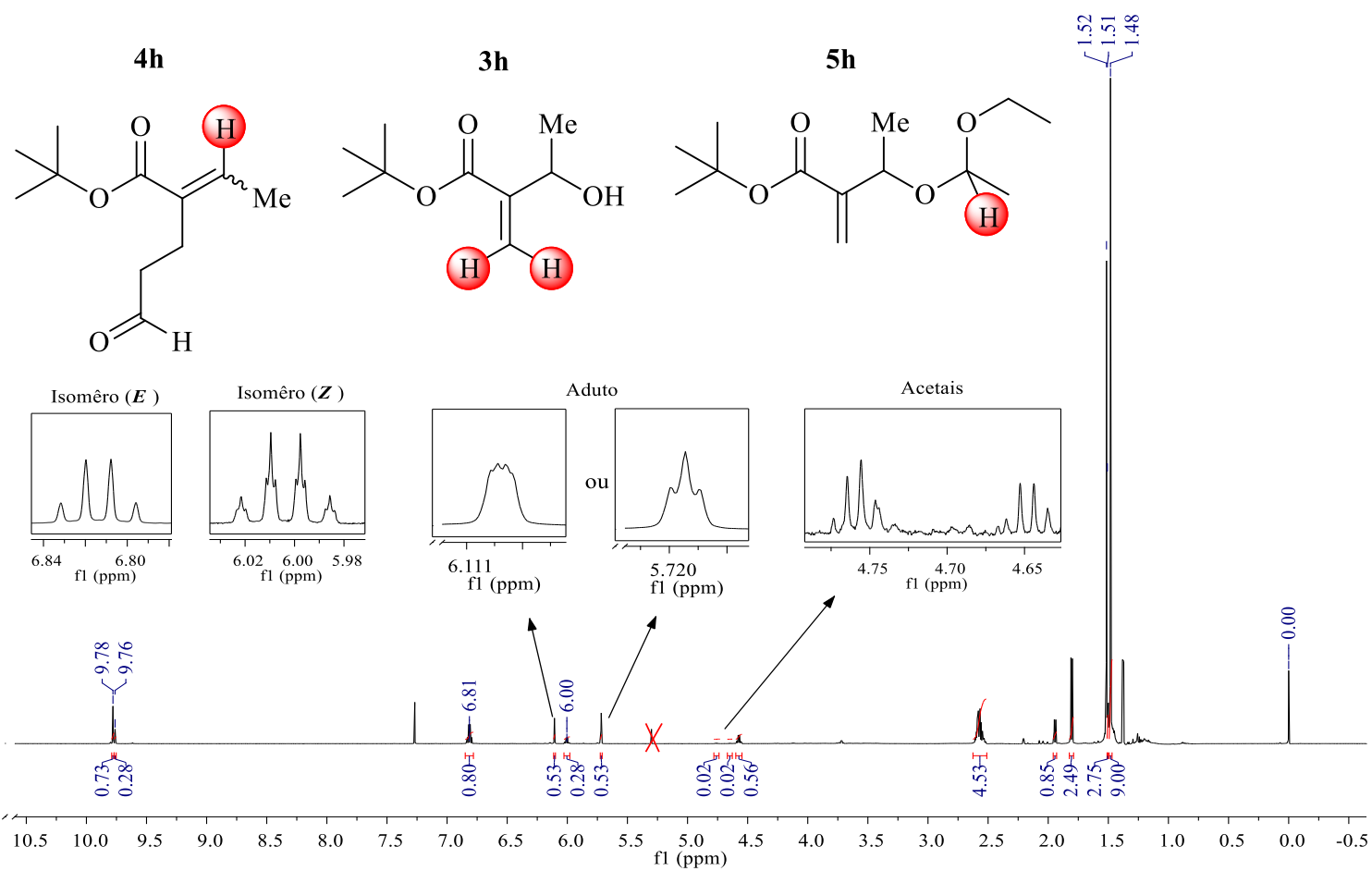

Figura 19. Espectro de RMN de ${ }^{1} \mathrm{H}(600 \mathrm{MHz})$ do bruto de reação do rearranjo de HurdClaisen de 24 horas com os isômeros $4 \mathbf{h}(\boldsymbol{E})$ e $\mathbf{4 h}(\boldsymbol{Z})$.

O rearranjo do AMBH 3h na condição reacional otimizada para o aduto 3a (24 horas, $2,5 \mathrm{~mol} \%$ de catalisador e $100^{\circ} \mathrm{C}$ ) não demonstrou ser tão eficiente. Utilizando as mesmas equações 1 a 4 foi possível calcular, a partir do espectro de $\mathrm{RMN}{ }^{1} \mathrm{H}$ do bruto de reação (Figura 19) uma conversão de $68 \%$, seletividade de $96 \%$ é uma razão $\boldsymbol{E}: \boldsymbol{Z}$ de 2,9:1 (Tabela 13). Aproximadamente $30 \%$ do aduto $\mathbf{3 h}$ foi recuperado. Para substratos alifáticos, mantivemos a concentração de catalisador e a temperatura, porém foi preciso elevar o tempo reacional para 30 horas para maximizar a conversão do substrato. A realização do rearranjo com o tempo reacional de 48 horas apresentou resultados similares aos obtidos com 30 horas.

Todo este trabalho baseado na análise de brutos reacionais por $\mathrm{RMN}{ }^{1} \mathrm{H}$ para alcançar a melhor condução reacional (Esquema 24), foi possível pois os produtos de rearranjo e os correspondentes acetais foram devidamente purificados e caracterizados espectroscopicamente. A seguir será apresentada a discussão desses dados para os produtos de rearranjo os aldeídos 4a ( $\mathrm{R}$ - fenila) e 4h (R - metila). Esta discussão serviu de base para a caracterização espectroscópica de todos os produtos de rearranjo preparados neste trabalho de dissertação. Todos os produtos de rearranjo de Hurd-Claisen são inéditos. 
<smiles>[R]C(O)C(=C)C(=O)OC(C)(C)C</smiles>

3a-k

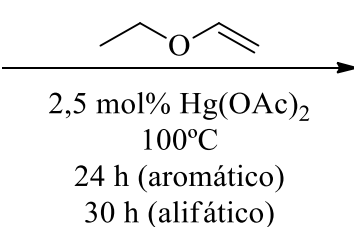

30 h (alifático)<smiles>[R]C=C(CCC=O)C(=O)OC(C)(C)C</smiles>

4a-k<smiles>[R]C(OC(C)OCC)C(=C)C(=O)OC(C)(C)C</smiles>

5a-k acetal

Esquema 24. Condição de reação otimizada para o rearranjo de Hurd-Claisen em adutos de MBH.

Para o produto de rearranjo aromático, 4a, foi possível obter uma amostra pura do isômero $\boldsymbol{E}$. Seu espectro de RMN de ${ }^{1} \mathrm{H}$ possui sete sinais (Figura 20). O primeiro sinal em 1,54 ppm, corresponde ao grupo terc-butila, um simpleto integrando para 9 hidrogênios. Os dois multipletos, 2,66 ppm e 2,81 ppm, ambos integrando para 2 hidrogênios, foram atribuídos aos hidrogênios metilênicos 7 e 8. Em 7,32 ppm e 7,38 ppm, encontram-se dois multipletos integrando para 3 e 2 hidrogênios respectivamente, que foram atribuídos aos hidrogênios do anel aromático. O simpleto largo em 7,58 ppm integrando para 1 hidrogênio, foi atribuído ao hidrogênio vinílico 10 que caracteriza o isômero $\boldsymbol{E}$. O sinal mais desblindado, 9,76 ppm, um tripleto com constante de acoplamento de $1,5 \mathrm{~Hz}$, integrando para 1 hidrogênio, diz respeito ao hidrogênio 9 do aldeído $\gamma, \delta$-insaturado.
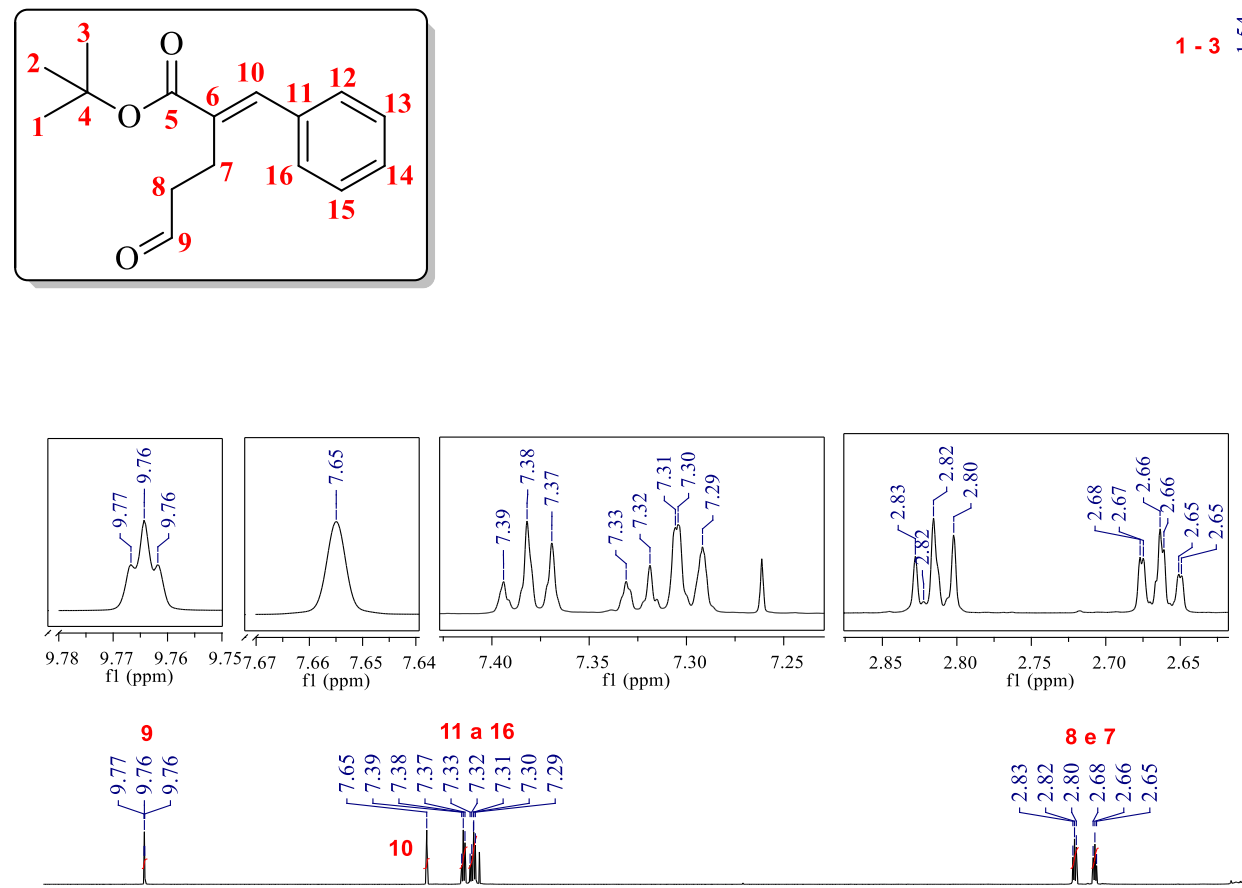

8 e 7

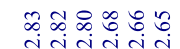

ìi $i$ is
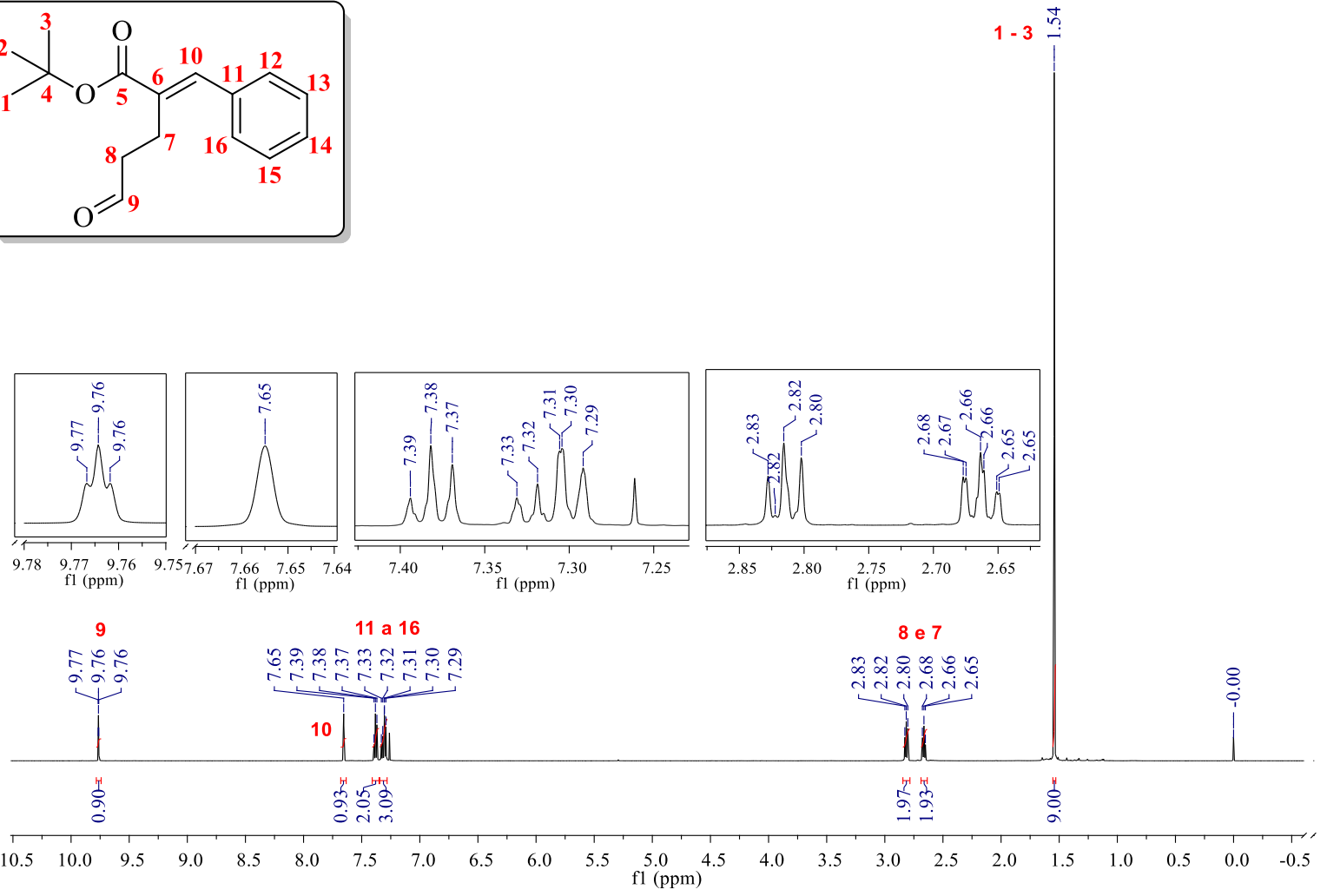

Figura 20. Espectro de $\mathrm{RMN}$ de ${ }^{1} \mathrm{H}\left(600 \mathrm{MHz}, \mathrm{CDCl}_{3}\right)$ do rearranjo de Hurd-Claisen $4 \mathbf{a}(\boldsymbol{E})$. 
$\mathrm{O}$ espectro de $\mathrm{RMN}$ de ${ }^{13} \mathrm{C}$ apresenta 12 sinais (Figura 21). O primeiro com deslocamento químico em 20,3 ppm, juntamente com o sinal em 43,3 ppm, foram atribuídos aos carbonos metilênicos 7 e 8 . Os sinais em 28,1 ppm e 81,1 ppm correspondem aos carbonos 1-4 presentes no grupo terc-butila. Dos seis sinais entre 128,4 ppm e 139,4 ppm, dois deles, 132,8 e 139,4, são referentes aos carbonos da ligação dupla, 10 e 6 respectivamente. Os quatros sinais restantes foram atribuídos aos carbonos do anel aromático. Por fim, o sinal em 166,9 ppm pertence ao carbono carbonílico (5) do éster e o sinal em 201,4 ppm pertence ao carbono carbonílico (9) do aldeído. Os dados de ${ }^{13} \mathrm{C}$ confirmaram os 16 carbonos e consequentemente a estrutura do isômero $\mathbf{4 a}(\boldsymbol{E})$.
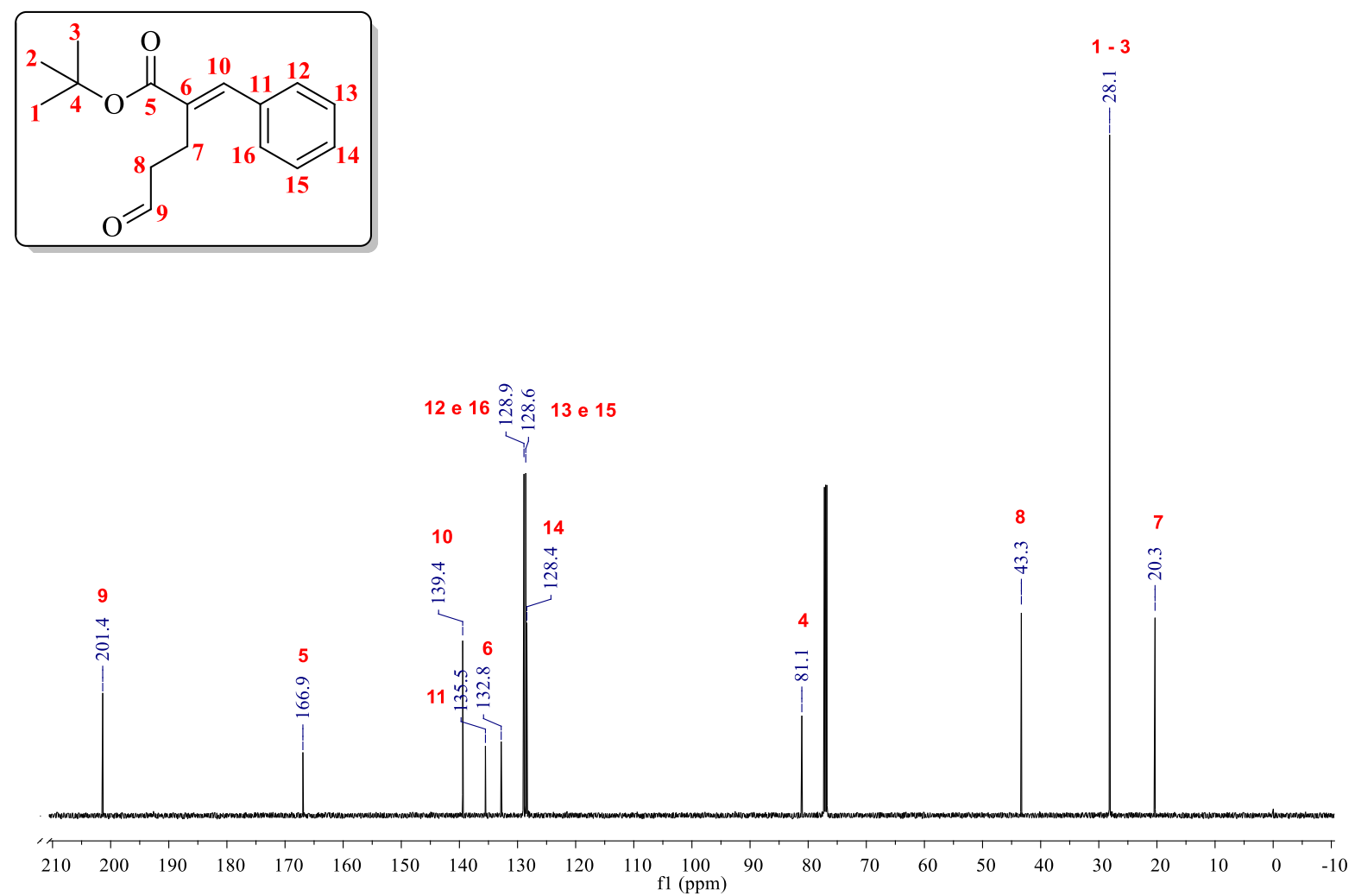

Figura 21. Espectro de $\mathrm{RMN}$ de ${ }^{13} \mathrm{C}\left(150 \mathrm{MHz}, \mathrm{CDCl}_{3}\right)$ do rearranjo de Hurd-Claisen $4 \mathbf{a}(\boldsymbol{E})$.

A atribuição dos sinais dos espectros de $\mathrm{RMN}$ de ${ }^{1} \mathrm{H}$ e ${ }^{13} \mathrm{C}$ encontra-se resumida na Tabela 14. Para os demais produtos de rearranjo aromáticos obtidos neste trabalho, há uma pequena variação no deslocamento químico devido à presença dos grupos substituintes no anel aromático. 
Tabela 14. Dados Espectroscópicos de $\mathrm{RMN}$ de ${ }^{1} \mathrm{He}{ }^{13} \mathrm{C}$ para o rearranjo de Hurd-Claisen $4 \mathbf{a}$.

2-benzidileno-5-oxopentanoato de de terc-butila (4a-E)

\begin{tabular}{|c|c|c|c|c|}
\hline \multirow{2}{*}{$\mathbf{N}^{\mathbf{o}}$} & \multicolumn{3}{|c|}{ RMN de ${ }^{1} H$} & \multirow{2}{*}{$\begin{array}{c}\text { RMN de }{ }^{13} \mathrm{C} \\
\delta(\mathrm{ppm})\end{array}$} \\
\hline & $\delta(p p m$ & Multiplicidade, J (Hz) & Integração & \\
\hline $1-2-3$ & 1,54 & Simpleto & 9 & 28,1 \\
\hline 4 & & & & 81,1 \\
\hline 5 & - & - & - & 166,9 \\
\hline 6 & & & & 132,8 \\
\hline 7 & 266 & Multipleto & 2 & 20,3 \\
\hline 8 & 2,81 & Multipleto & 2 & 43,3 \\
\hline 9 & 9,76 & Tripleto, $J=1,5 \mathrm{~Hz}$ & 1 & 201,4 \\
\hline 10 & 7,65 & Simpleto largo & 1 & 139,4 \\
\hline 11 & & & & 135,5 \\
\hline 12 & 732 & & & 128,9 \\
\hline 13 & & Daio multinlato & 5 & 128,6 \\
\hline 14 & & DOAs muitiptetus & $J$ & 128,4 \\
\hline 15 & 7,38 & & & 128,6 \\
\hline 16 & & & & 128,9 \\
\hline
\end{tabular}

Para confirmação da estereoquímica relativa foi realizado experimento de espectroscopia diferencial de Efeito Nuclear Overhauser - NOE (Figura 22). Ao irradiar o hidrogênio vinílico do isômero $\boldsymbol{E}$, sinal em 7,65 ppm, foi observado incremento em alguns sinais da região entre 7,25 ppm a 7,45 ppm. Os sinais presentes nesta região são referentes aos hidrogênios orto do anel aromático, que estão espacialmente próximos ao hidrogênio vinílico irradiado. Outro sinal que apresentou incremento no espectro de NOE foi o atribuído às metilas do grupo terc-butila que, na conformação 4a-I, permite a interação com o hidrogênio do isômero $\boldsymbol{E}$. Esta última observação e a ausência de incremento de NOE no sinal atribuído aos hidrogênios metilenos 7 e 8 sugerem que este isômero se trata do produto $4 \mathbf{a}$ com configuração E. 


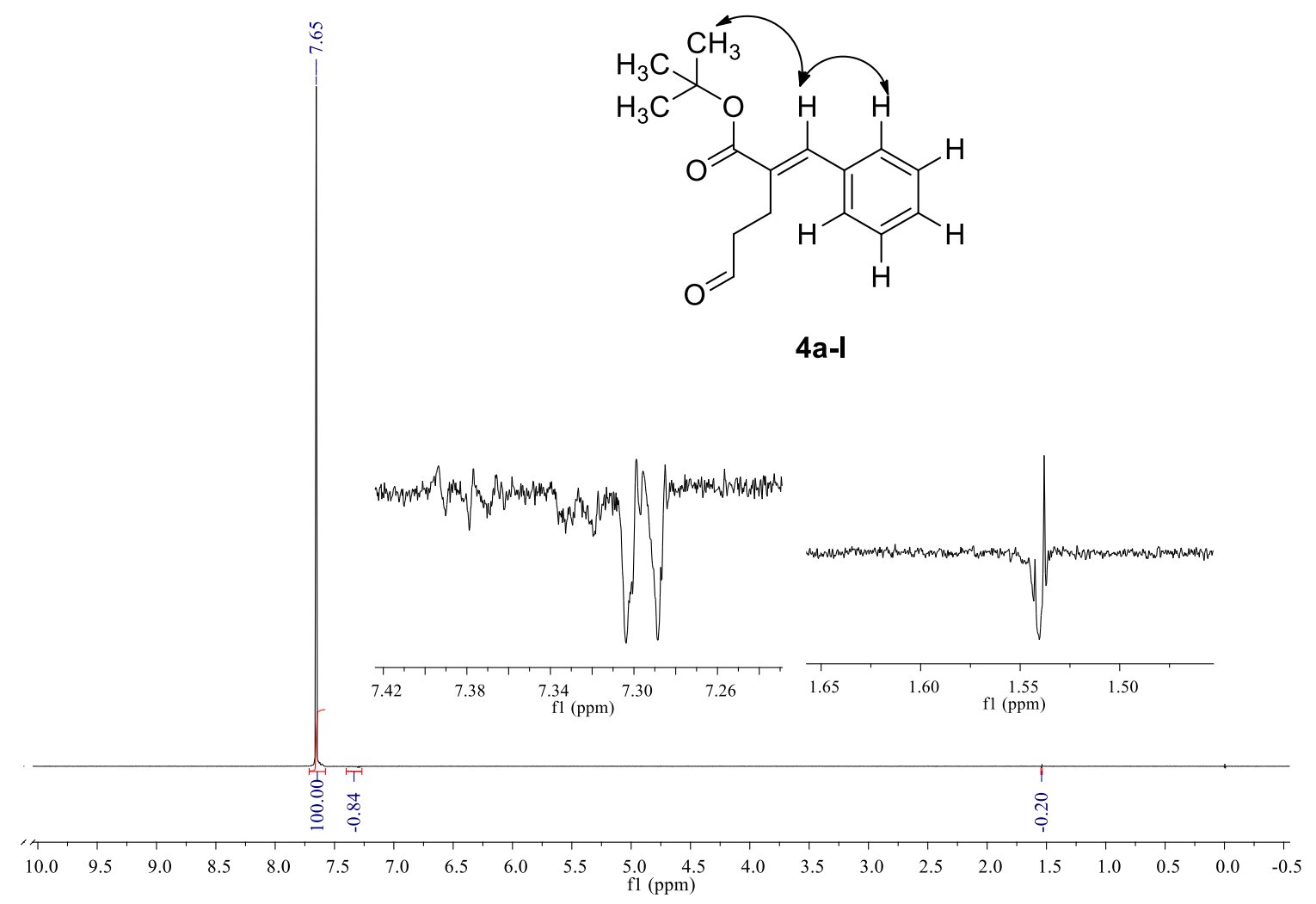

Figura 22. Espectro de NOE do produto de rearranjo do isômero $4 \mathbf{a} \boldsymbol{E}$ puro.

Para o produto de rearranjo alifático, $\mathbf{4 h}$, não foi possível separar os dois isômeros durante o processo de purificação. Esta mistura foi analisada por de $\mathrm{RMN}$ de ${ }^{1} \mathrm{H} \mathrm{e}{ }^{13} \mathrm{C}$ e, como consequência disto, estes espectros apresentaram duplicidade de sinais. A Tabela 15 resume a atribuição feita nos espectros de RMN. 
Tabela 15. Dados Espectroscópicos de $\mathrm{RMN}$ de ${ }^{1} \mathrm{H}$ e ${ }^{13} \mathrm{C}$ para o rearranjo de Hurd-Claisen $\mathbf{4 h}$ (E) e 4h (Z).

2-etilideno-5-oxopentanoato de terc-butila 4 h $(E)$ e 4 h $(Z)$<smiles>CC=CC(CC=O)C(=O)OC(C)(C)I</smiles>

\begin{tabular}{|c|c|c|c|c|}
\hline \multirow{2}{*}{$\mathbf{N}^{\mathbf{o}}$} & \multicolumn{3}{|c|}{ RMN de ${ }^{1} \mathbf{H}$} & \multirow{2}{*}{$\begin{array}{c}\text { RMN de }{ }^{13} \mathrm{C} \\
\delta(\mathbf{p p m})\end{array}$} \\
\hline & $\delta(\mathbf{p p m})$ & Multiplicidade, J (Hz) & Integração & \\
\hline \multirow{2}{*}{$1-2-3$} & $1,48^{E}$ & \multirow{2}{*}{ Simpleto } & \multirow{2}{*}{9} & $28,1^{E}$ \\
\hline & $1,51^{Z}$ & & & $28,2^{Z}$ \\
\hline 4 & \multirow{3}{*}{-} & \multirow{3}{*}{-} & \multirow{3}{*}{-} & $80,4^{E}-80,8^{Z}$ \\
\hline 5 & & & & $166,5^{E}-166,9^{Z}$ \\
\hline 6 & & & & $132,4^{Z}-132,7^{E}$ \\
\hline 7 & \multirow{2}{*}{$2,57^{E-Z}$} & \multirow{2}{*}{ Multipleto } & \multirow{2}{*}{2} & $19,3^{E}-27,5^{Z}$ \\
\hline 8 & & & & $43,1^{E}-43,4^{Z}$ \\
\hline \multirow{2}{*}{9} & $9,76^{Z}$ & Tripleto, $J=1,6$ & \multirow{2}{*}{1} & $201,8^{Z}$ \\
\hline & $9,78^{E}$ & Tripleto, $J=1,5$ & & $201,7^{E}$ \\
\hline \multirow{2}{*}{10} & $6,00^{Z}$ & Quarteto de tripleto, $J=7,2 ; 1,0 \mathrm{~Hz}$ & \multirow{2}{*}{1} & $137,5^{E}$ \\
\hline & $6,81^{E}$ & Quarteto, $J=7,2 \mathrm{~Hz}$ & & $136,6^{Z}$ \\
\hline \multirow{2}{*}{11} & $1,80^{E}$ & Dupleto, $J=7,2 \mathrm{~Hz}$ & \multirow{2}{*}{3} & $14,2^{E}$ \\
\hline & $1,94^{Z}$ & Dupleto de tripleto, $J=7,2 ; 1,0 \mathrm{~Hz}$ & & $15,6^{Z}$ \\
\hline
\end{tabular}

O espectro de RMN de ${ }^{1} \mathrm{H}$ possui nove sinais (Figura 23). Os dois primeiros, 1,48 ppm (Z) e 1,51 ppm $(\boldsymbol{E})$, correspondem aos hidrogênios do grupo terc-butila, simpletos integrando 9 hidrogênios. Os sinais em 1,80 ppm e 1,94 ppm referem-se à metila vinílica $\boldsymbol{E}$ e $\boldsymbol{Z}$ respectivamente. Ambas metilas vinílicas acoplam com o hidrogênio vinílico, desdobrando o sinal em dupletos com igual constante de acoplamento, 7,2 Hz. Entretanto, na metila referente ao isômero $\boldsymbol{Z}$ é possível verificar um acoplamento com hidrogênio metilênico mais próximo com ${ }^{5} \mathrm{~J}$ de $1,0 \mathrm{~Hz}$. Este se encontra trans, acoplamentos deste tipo são mais fáceis de serem observados que num arranjo cis (presente no isômero $\boldsymbol{E}$ ). Desta forma, a metila do isômero $\boldsymbol{Z}$ apresenta-se como um dupleto de tripleto com $J=7,2$ e 1,0 Hz. Ao multipleto em 2,57 ppm, integrando para 4 hidrogênios, foram atribuídos aos hidrogênios metilênicos de ambos os isômeros. 


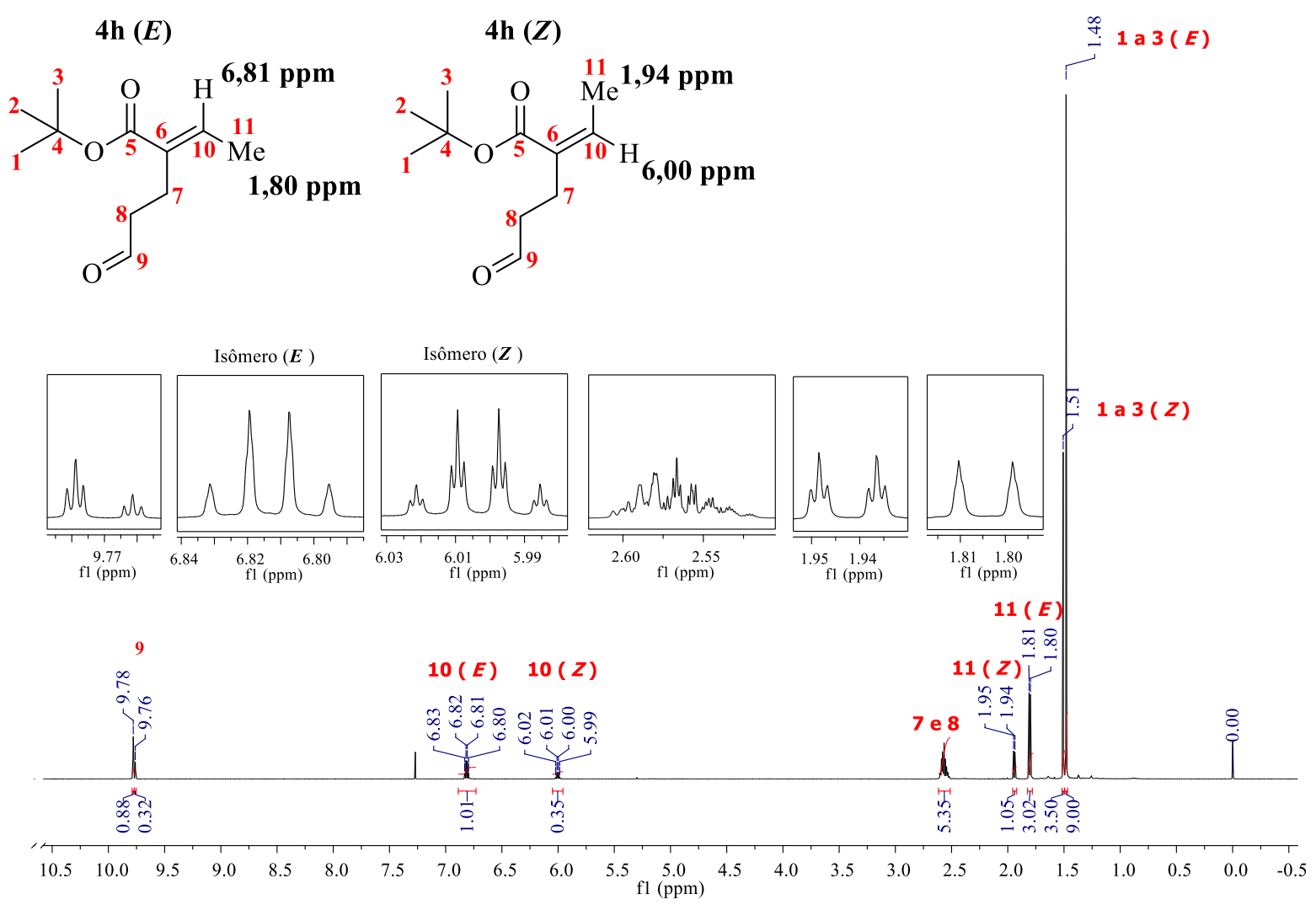

Figura 23. Espectro de $\mathrm{RMN}$ de ${ }^{1} \mathrm{H}\left(600 \mathrm{MHz}, \mathrm{CDCl}_{3}\right)$ do rearranjo de Hurd-Claisen $4 \mathbf{h}$.

O quarteto de tripleto em 6,00 ppm caracteriza o isômero $\boldsymbol{Z}$, e o quarteto em 6,81 ppm pertence ao isômero $\boldsymbol{E}$, ambos integrando para 1 hidrogênio. $\mathrm{O}$ isômero $\boldsymbol{Z}$ se desdobra em um quarteto de tripleto devido ao acoplamento com os hidrogênios da metila, ${ }^{3} J(7,2 \mathrm{~Hz})$, e o acoplamento com hidrogênio metilênico, ${ }^{5} \mathrm{~J}$ trans $(1,0 \mathrm{~Hz})$. O mesmo ${ }^{5} \mathrm{~J}$ encontra-se cis no isômero $\boldsymbol{E}$, não sendo observado. Os dois tripletos mais desblindados, em 9,76 ( $J=1,6 \mathrm{~Hz}) \mathrm{e}$ 9,78 $(J=1,5 \mathrm{~Hz})$ ppm, integrando para 1 hidrogênio, dizem respeito ao hidrogênio carbonílico do aldeído $\gamma, \delta$-insaturado, $\boldsymbol{Z}$ e $\boldsymbol{E}$ respectivamente.

$\mathrm{O}$ espectro de $\mathrm{RMN}$ de ${ }^{13} \mathrm{C}$ apresenta 9 pares de sinais (Figura 24). O primeiro par com deslocamento químico de 14,2 ppm $(\boldsymbol{E})$ e 15,6 ppm $(\boldsymbol{Z})$ corresponde à metila. Em 19,3 ppm (E) e 27,5 ppm (Z) juntamente com o sinal em 43,1 ppm (E) e 43,4 ppm (Z), foram atribuídos aos carbonos metilênicos. Os sinais em 28,1 e 80,4 ppm e 28,2 e 80,8 ppm correspondem respectivamente aos carbonos do grupo terc-butila dos isômeros $\boldsymbol{E}$ e $\boldsymbol{Z}$. Os dois pares de sinais entre 130 ppm e 140 ppm são referentes aos carbonos da ligação dupla, os sinais de maior intensidade correspondem ao isômero $\boldsymbol{E}$. Por fim, os dois pares de sinais mais desblindados, o primeiro deles em 166,5 ppm $(\boldsymbol{E})$ e 166,9 ppm $(\boldsymbol{Z})$ pertence ao carbono carbonílico do éster e o 
segundo, ambos em 201,8 ppm pertence ao carbono carbonílico do aldeído. Os dados de ${ }^{13} \mathrm{C}$ confirmaram os 11 carbonos e consequentemente a estrutura dos dois isômeros $4 h(E)$ e $4 h(Z)$.
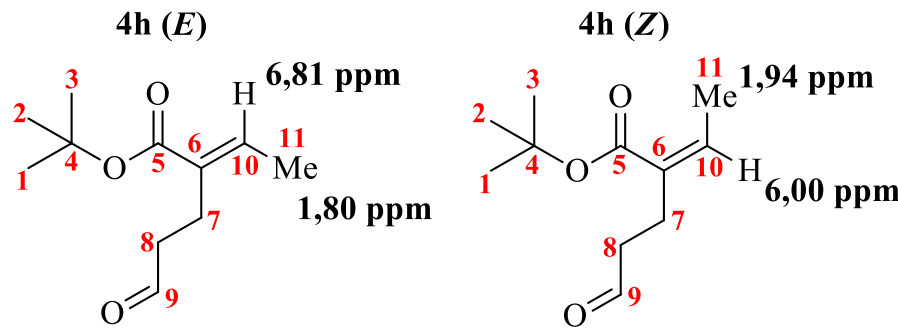

4h $(Z)$

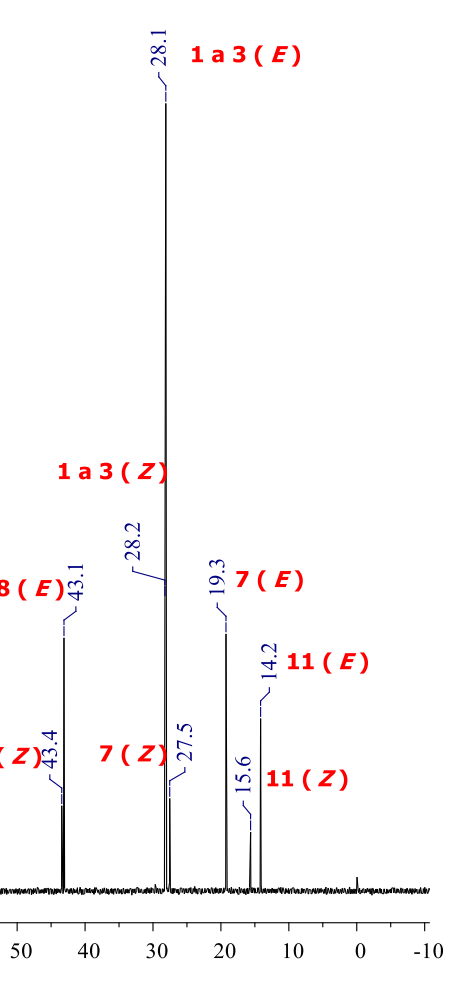

Figura 24. Espectro de $\mathrm{RMN}$ de ${ }^{13} \mathrm{C}\left(150 \mathrm{MHz}, \mathrm{CDCl}_{3}\right)$ do rearranjo de Hurd-Claisen da mistura contendo os isômeros $4 \mathrm{~h}(\boldsymbol{E})$ e $4 \mathrm{~h}(Z)$.

Mais uma vez, para confirmação da estereoquímica relativa, foram realizados experimentos de NOE (Figura 25). Ao irradiar os hidrogênios da metila vinílica, 1,81 ppm, foi observado alguns sinais na região que compreende os hidrogênios metilênicos e o hidrogênio vinílico do isômero $\boldsymbol{E}$. O incremento observado confirma que, na conformação onde o hidrogênio vinílico está cis à carbonila, os hidrogênios da metila encontram-se próximo espacialmente dos hidrogênios metilênicos. Outro sinal observado no espectro de NOE é do grupo terc-butila que, na conformação 4h-I, permite uma pequena interação com os hidrogênios da metila, porém o incremento não é tão expressivo. 


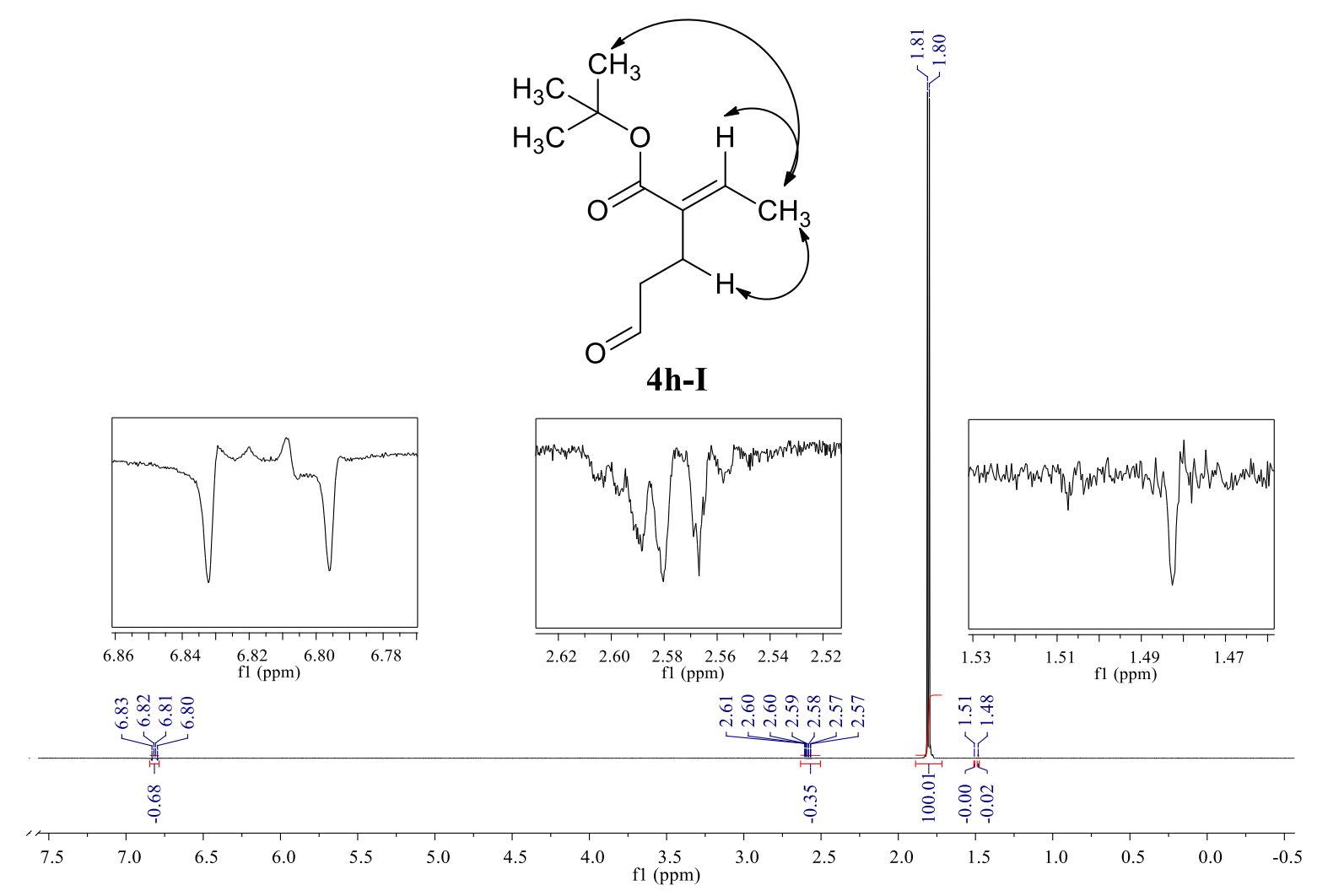

Figura 25. Espectro de NOE do produto de rearranjo de Hurd-Claisen da mistura dos isômeros $\mathbf{4 h}(\boldsymbol{E})$ e $\mathbf{4 h}(\boldsymbol{Z})$, irradiando a metila do isômero $\boldsymbol{E}(1,81 \mathrm{ppm})$.

Um segundo experimento de NOE (Figura 26) foi realizado, porém irradiando a metila referente ao isômero $\boldsymbol{Z}$, em 1,94 ppm. Foi observado incremento no hidrogênio vinílico. Entretanto, também foi observado um pequeno incremento nos hidrogênios metilênicos. Uma possível explicação pode ser devido ao acoplamento ${ }^{5} \mathrm{~J}$ trans.

Outra explicação é que o isômero $\boldsymbol{E}$ encontra-se em maior quantidade na mistura reacional analisada e pode estar interferindo no experimento de NOE para caracterização da estereoquímica do isômero $\boldsymbol{Z}$. Percebe-se que o sinal em 1,48 ppm (sinal da terc-butila do isômero $\boldsymbol{E}$ ), bem como os sinais em 2,55 ppm, não estão totalmente em fase e ambos os incrementos não são expressivos o que justifica a possibilidade de artefato advindo do isômero majoritário na mistura reacional. Haja vista que não foi possível isolar um dos isômeros para analisa-los separadamente. Outro sinal observado no espectro de NOE é do grupo terc-butila em 1,51 ppm do isômero $\boldsymbol{Z}$, este encontra-se totalmente em fase e, apesar do pequeno valor do incremento $(0,07)$ é mais provável de ocorrer pois, a conformação 4 h-II coloca a terc-butila próximo espacialmente da metila irradiada quando comparado com a conformação 4 h-I. 


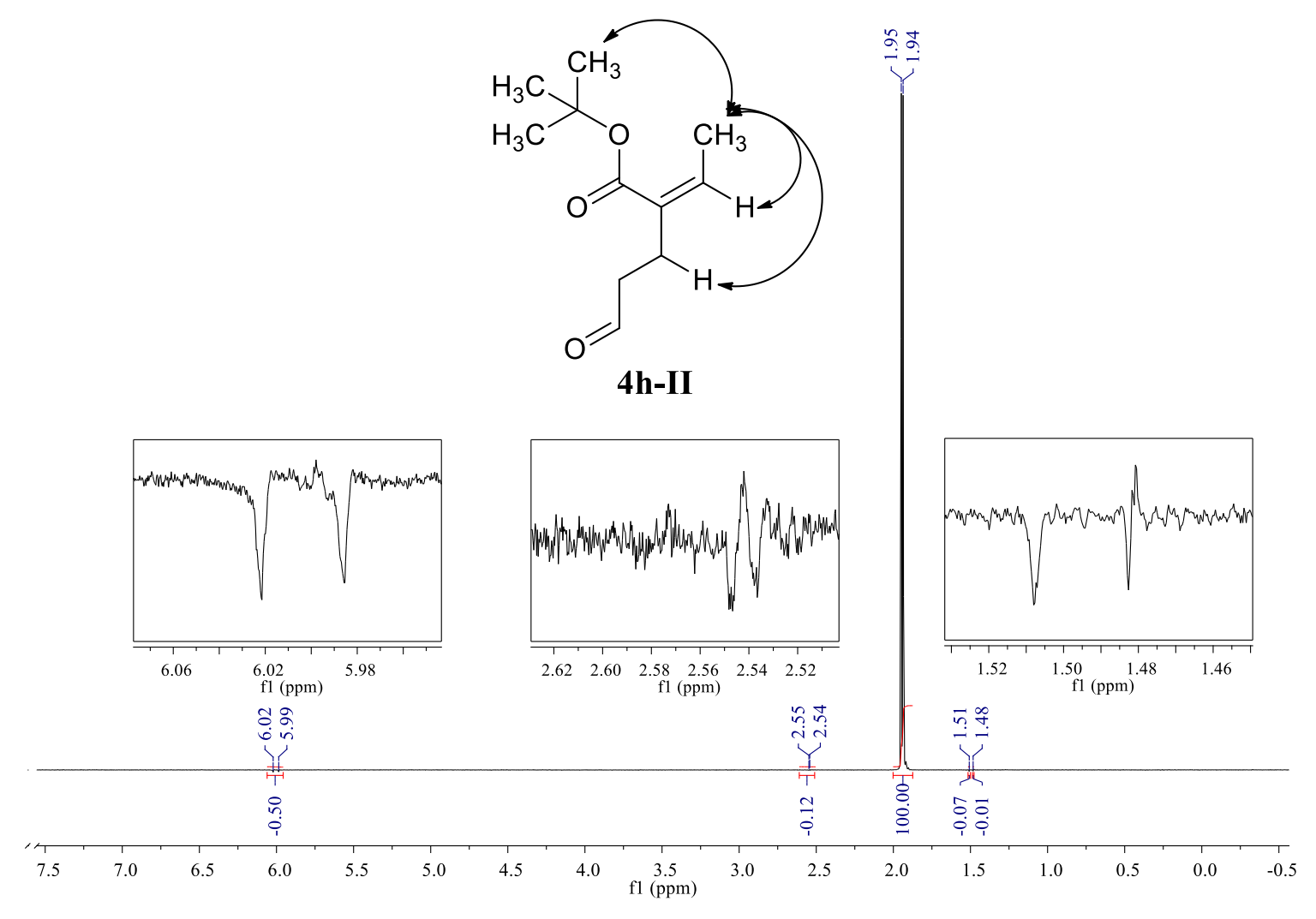

Figura 26. Espectro de NOE do produto de rearranjo de Hurd-Claisen da mistura dos isômeros $\mathbf{4 h}(\boldsymbol{E})$ e $\mathbf{4 h}(\boldsymbol{Z})$, irradiando a metila do isômero $\boldsymbol{Z}$ (1,94 ppm).

Para garantir ainda mais confiabilidade na atribuição da estereoquímica relativa por nos adotada, comparamos os resultados obtidos com os trabalhos de Basavaiah $^{37}$ e Rodrigues ${ }^{3}$ (Figura 27). Coincidentemente, os resultados deste trabalho para o rearranjo em adutos alifáticos são os mesmos obtidos por Basavaiah, 6,81 ppm $(\boldsymbol{E})$ para o hidrogênio cis ao grupo éster e 6,00 ppm $(\boldsymbol{Z})$ para isômero com hidrogênio vinílico trans.

A diferença no deslocamento químico entre $\boldsymbol{E}$ e $\boldsymbol{Z}$ é justificada por Rodrigues ${ }^{3}$ devido à anisotropia do grupo carbonila e o efeito de desblindagem que este exerce no hidrogênio vinílico. A proximidade do hidrogênio vinílico cis à carbonila, situação observada no isômero $\boldsymbol{E}$, desblinda este núcleo, uma vez que ele está fora do cone desproteção da ligação $\mathrm{C}=\mathrm{O}$, conduzindo a $\delta$ em campo mais baixo, quando comparado ao mesmo núcleo do isômero $\boldsymbol{Z}$. $\mathrm{O}$ mesmo efeito de anisotropia magnética também explica o deslocamento químico maior quando o grupo $\mathbf{R}$ aromático está trans ao éster. Entretanto, o deslocamento químico é ainda maior devido à anisotropia magnética do anel aromático (Figura 27). 
Este trabalho
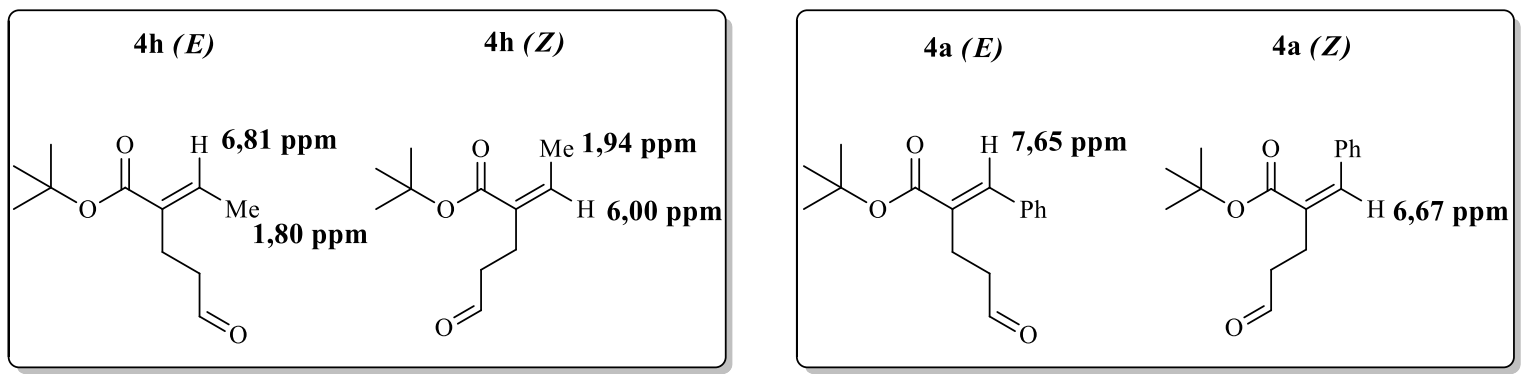

Rodrigues
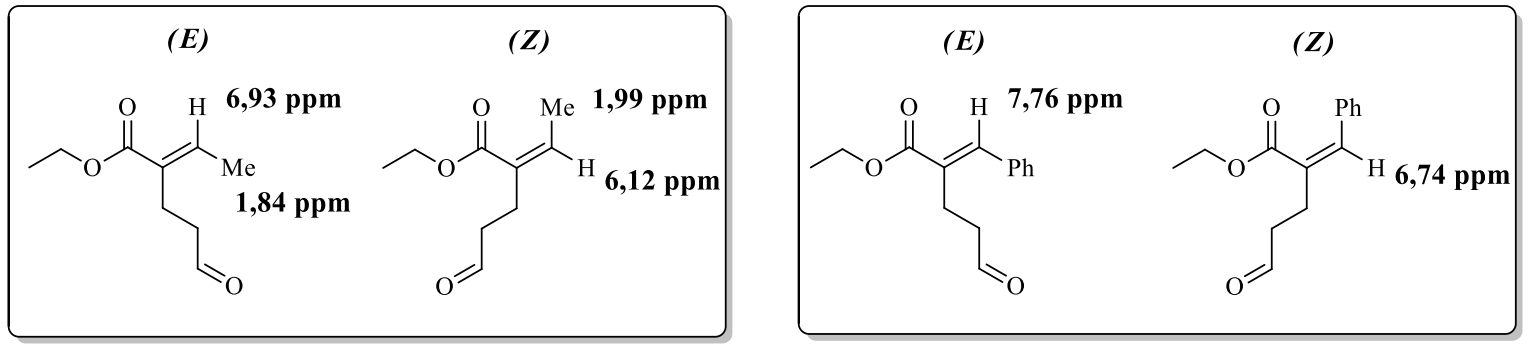

Basavaiah
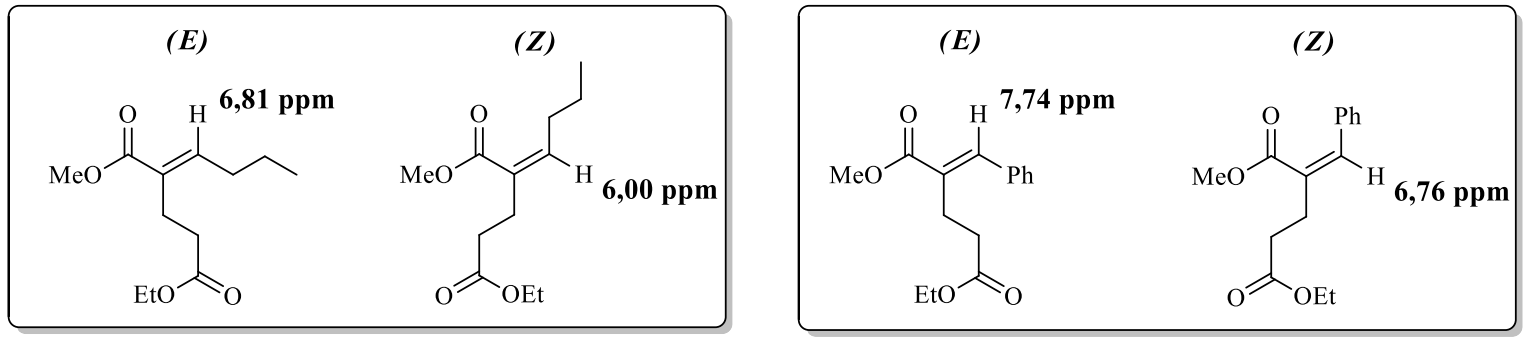

Figura 27. Dados apresentados por Rodrigues e Basavaiah e colaboradores.

\subsection{2-ESTEREOSSELETIVIDADE DO REARRANJO DE HURD-ClaisEN EM ADUTOS DE MORITA-BAYLIS-HILLMAN}

Utilizando a condição de reação otimizada para o substrato 3a (Esquema 24) realizamos o rearranjo de Hurd-Claisen com todos AMBH aromáticos, 3b-g. As conversões, seletividades, as razões entre os isômeros $(\boldsymbol{E}: \boldsymbol{Z})$ e o rendimento esperado, bem como o rendimento obtido estão ilustrados na Tabela 16. As conversões e as seletividades foram superiores a $79 \%$ e $83 \%$ respectivamente. Entretanto, a razão entre os isômeros varia conforme os substituintes no anel aromático. Porém, a diastereosseletividade dos produtos de rearranjo de Hurd-Claisen, 4a-g, foi sempre seletiva ao isômero $\boldsymbol{E}$. 
Tabela 16. Resultados obtidos para o rearranjo de Hurd-Claisen em AMBH aromáticos 3a-g.

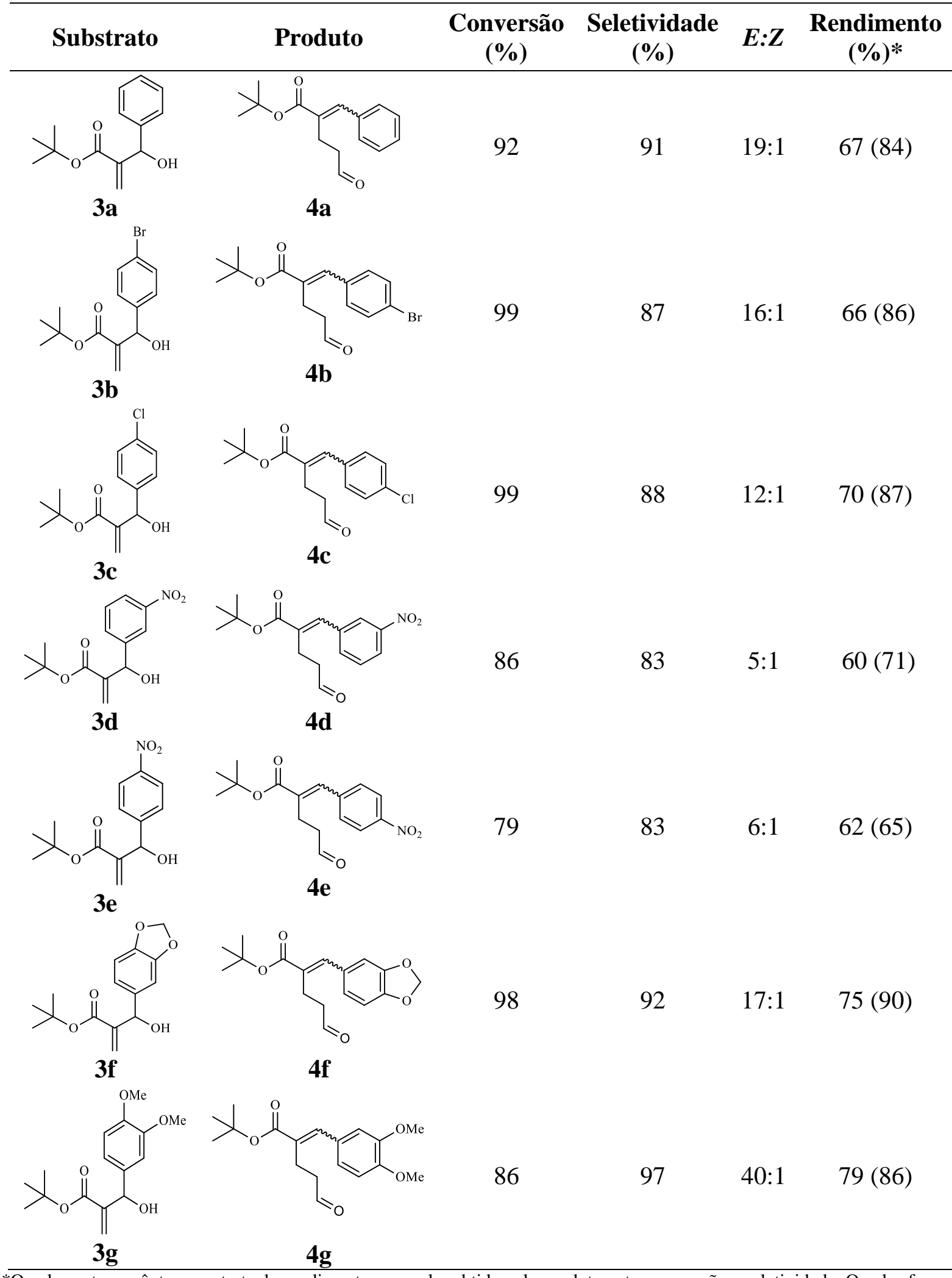

*O valor entre parênteses se trata do rendimento esperado, obtido pelo produto entre conversão e seletividade. $\mathrm{O}$ valor fora dos parênteses são os rendimentos obtidos após purificação cromatrográfica. 
Foram obtidos rendimentos superiores a $60 \%$ para os produtos de rearranjo. Com exceção dos produtos de rearranjo com o grupo nitro, $\mathbf{4 d}$ e $\mathbf{4 e}$, todas as reações forneceram razão $\boldsymbol{E}: \boldsymbol{Z}$ superiores a 10:1. Todos os resultados obtidos estão de acordo com os dados de Basavaiah $^{37}$ e Rodrigues ${ }^{3}$, onde rearranjo de Johnson-Claisen e Hurd-Claisen em adutos de MBH aromáticos favorecem o isômero $\boldsymbol{E}$.

Para o rearranjo dos AMBH oriundo de aldeídos alifáticos, o isômero $\boldsymbol{E}$ ainda é majoritário, sendo que a maior razão foi de 5:1 do aldeído $\mathbf{4 k}$, apesar de as razões $\boldsymbol{E}: \boldsymbol{Z}$ serem inferiores às observadas para os adutos oriundos de aldeídos aromáticos. Devido à volatilidade dos aldeídos de Hurd-Claisen, os rendimentos foram inferiores aos observados para os aromáticos, porém superiores a 56\%. Foi observada ótima conversão para todos os substratos, sendo que a menor foi de 94\%, AMBH-3j, e seletividade acima de 75\% (Tabela 17).

Tabela 17. Resultados obtidos para o rearranjo de Hurd-Claisen em AMBH alifáticos 3h-k.

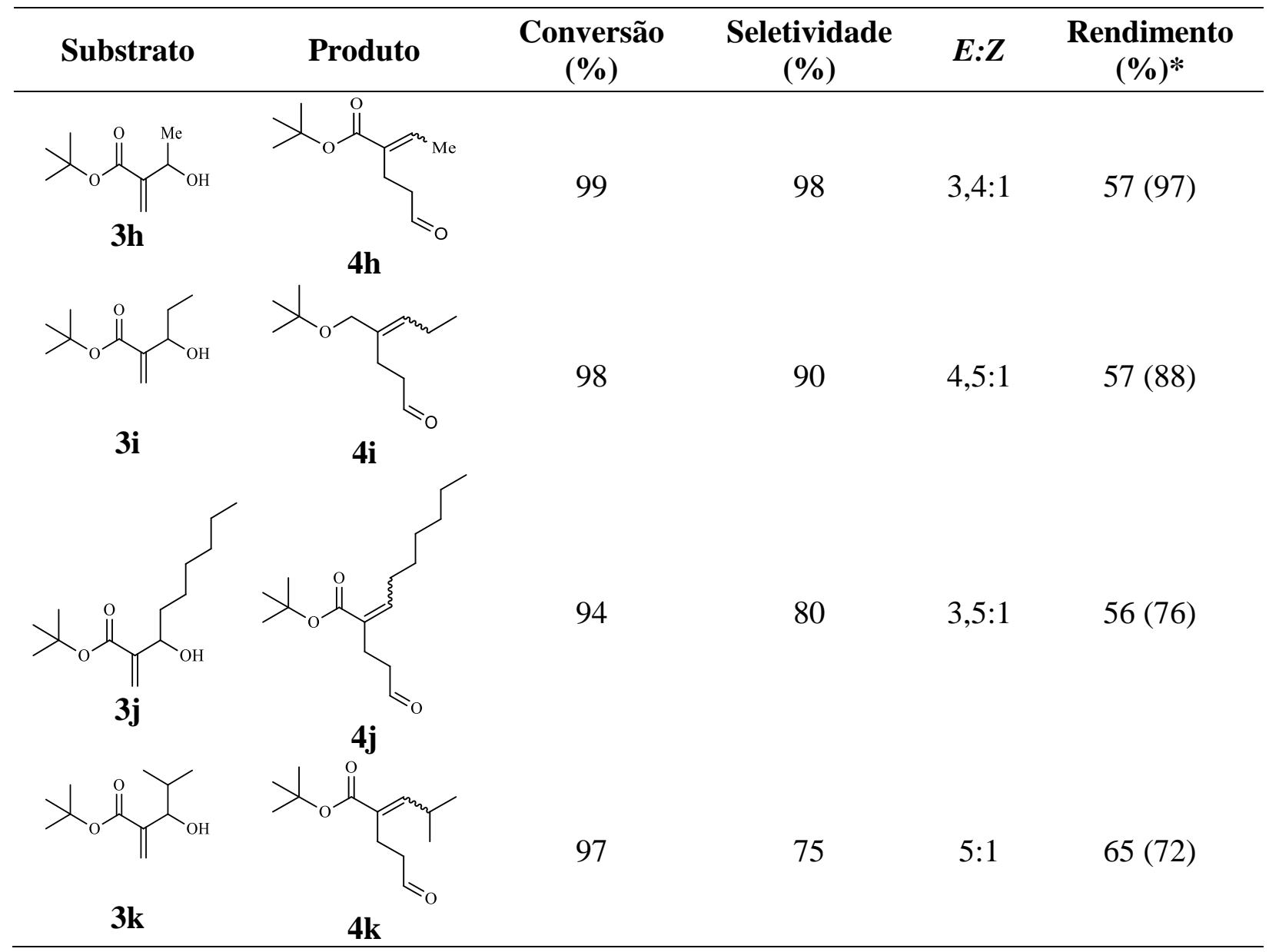

*O valor entre parênteses se trata do rendimento esperado, obtido pelo produto entre conversão e seletividade. O valor fora dos parênteses são os rendimentos obtidos após purificação cromatrográfica. 


\subsection{3-JustificAtiva PARA EstereosseletividAde DO REARRANJO DE HuRD- Claisen Em adutos De Morita-BAYlis-HiLlman}

O modelo de estado de transição proposto por Rodrigues ${ }^{3}$, com base no trabalho de Basavaiah $^{37}$, se baseia no efeito estéreo do grupo éster, oriundo do acrilato de etila e no caráter doador no $\rightarrow \sigma^{*} \mathrm{C}$-Ar, sendo que, este último, estabiliza o ET-cadeira que leva ao produto majoritário $\boldsymbol{E}$. A análise deste modelo sugere que a substituição do grupo etila do éster por um grupo mais volumoso deve levar a uma interação estérea desfavorável entre a terc-butila e o grupo $\mathbf{R}$, tensão alílica $\mathrm{A}^{1,3}$, fato que desestabilizaria o estado de transição que leva à formação do produto $\boldsymbol{Z}$, favorecendo o aumento na razão $\boldsymbol{E}: \boldsymbol{Z}$ (Esquema 25).
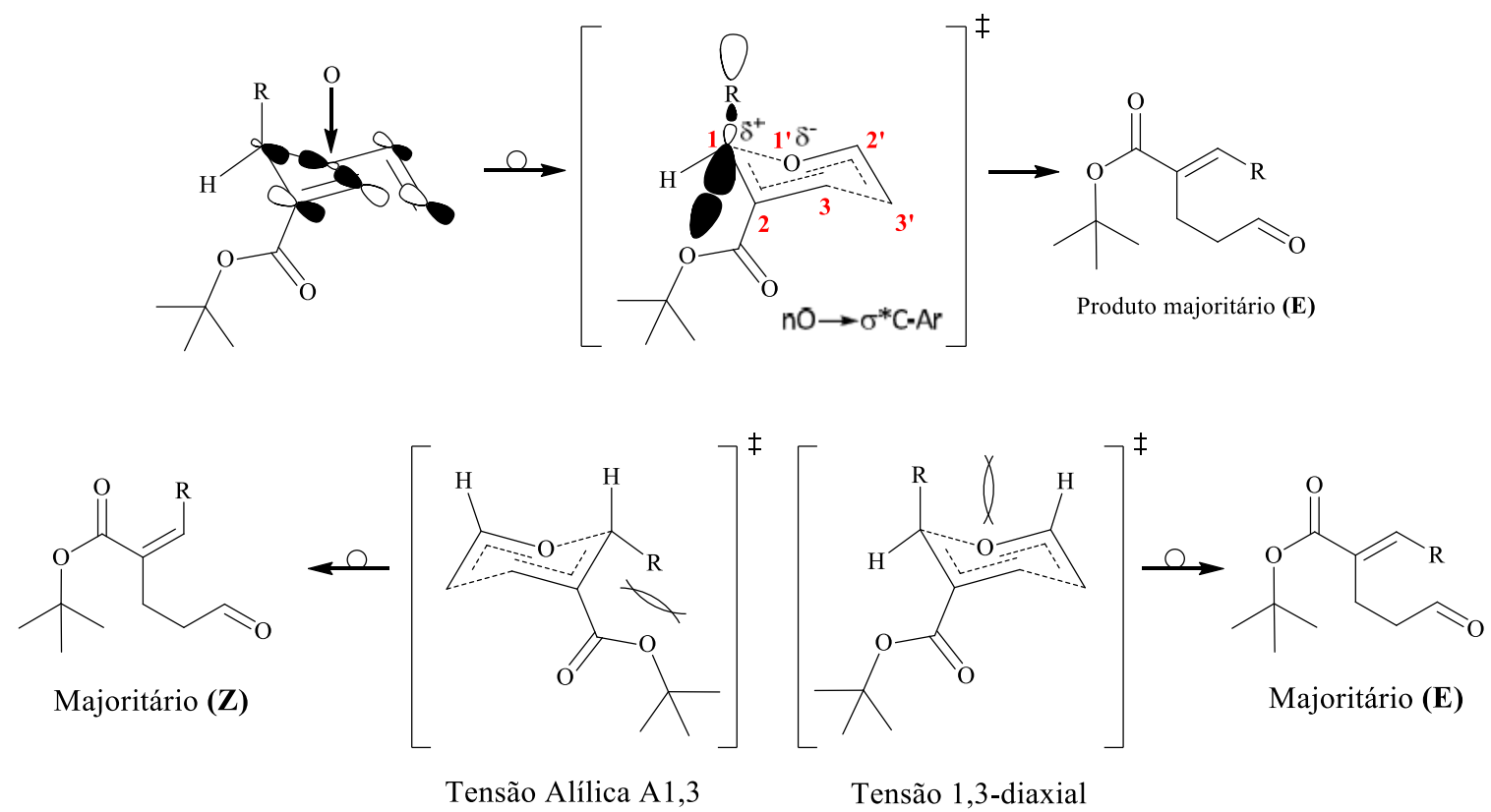

Esquema 25. Modelo de ET proposto por Rodrigues baseado em efeito anomérico e na competição entre tensão alílica $\mathrm{A}^{1,3}$ versus tensão 1,3-diaxial aplicado ao rearranjo de HurdClaisen de adutos oriundos do acrilato de terc-butila.

Ao se comparar os resultados desta dissertação com aqueles relatados por Rodrigues (Tabela 18), para rearranjo de Hurd-Claisen com os mesmos grupos $\mathbf{R}$ em adutos oriundos de aldeídos alifáticos ou aromáticos, pode-se observar que para o rearranjo do aduto oriundo do acrilato de terc-butila, uma razão $\boldsymbol{E}: \boldsymbol{Z}$ de 3,4:1, muito semelhante à observada por Rodrigues (3:1), para o grupo $\mathbf{R}$ sendo uma metila. Para os AMBH aromáticos oriundos do acrilato de terc-butila, foi observada uma razão $\boldsymbol{E}: \boldsymbol{Z}$ 19:1 ( $\mathbf{R}$ - fenila), também na mesma ordem de grandeza observada por Rodrigues (21:1). Estes resultados sugerem que o aumento do volume 
do grupo alcóxido do éster, e consequente desenvolvimento da tensão alílica $\mathrm{A}^{1,3}$, não influência significativamente na diferenciação entre os estados de transição diastereoisoméricos que conduzem aos isômeros geométricos $\boldsymbol{E}$ e $\boldsymbol{Z}$, em linha com o resultado observado por Drew e colaboradores ${ }^{35}$.

Tabela 18. Comparação entre as razões $\boldsymbol{E}: Z$ para o rearranjo de Hurd-Claisen em AMBH com diferentes substituintes R e R'.

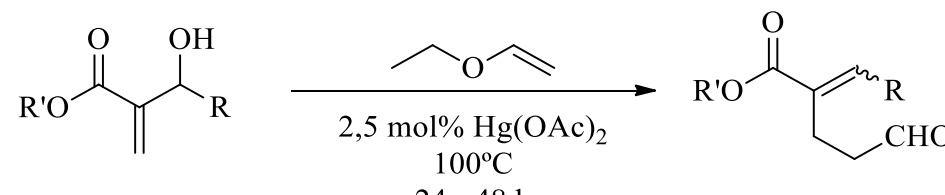

$24-48 \mathrm{~h}$

\begin{tabular}{c|cccccccc} 
& \multicolumn{7}{|c}{$\mathbf{R}$} \\
\hline R' & Me & Et & ${ }^{i} \mathrm{Pr}$ & $\mathrm{Ph}$ & $p$-ClPh & $p$-BrPh & $m-\mathrm{NO}_{2} \mathrm{Ph}$ & $\mathrm{MDF}^{*}$ \\
$\mathrm{Et}$ & $3: 1$ & $3: 1$ & $3,5: 1$ & $21: 1$ & $17: 1$ & $17: 1$ & $24: 1$ & $14: 1$ \\
${ }^{t} \mathrm{Bu}$ & $3,4: 1$ & $4,5: 1$ & $5: 1$ & $19: 1$ & $12: 1$ & $16: 1$ & $5: 1$ & $17: 1$ \\
\hline
\end{tabular}

Outra observação importante se refere ao fato de que, independentemente do tamanho do grupo R', a razão $\boldsymbol{E}: \boldsymbol{Z}$ do rearranjo de Hurd-Claisen de AMBH é cerca de 4-6 vezes maior quando $\mathrm{R}$ é aromático, excetuando-se, apenas, $\mathrm{R}=p-\mathrm{NO}_{2} \mathrm{Ph}$ e $m-\mathrm{NO}_{2} \mathrm{Ph}$. $\mathrm{O}$ modelo de estado de transição baseado em tensões estéreas, proposto por Basavaiah e colaboradores, sugere que a presença de um substituinte $\mathbf{R}$ volumoso na posição pseudo-equatorial desestabiliza o estado de transição que conduz ao produto $\boldsymbol{Z} \cdot{ }^{37}$ Como no rearranjo de Hurd-Claisen a tensão 1,3 diaxial, proposta neste modelo, é diminuída pela presença do hidrogênio, quando comparada às reação de Johnson-Claisen e Eschenmoser-Claisen, esta característica estrutural, somada ao alívio da tensão $\mathrm{A}^{1,3}$ observada no ET que leva ao produto $\boldsymbol{Z}$, explicaria a preferência pela formação do produto de rearranjo com geometria $\boldsymbol{E}$, com aumento da razão $\boldsymbol{E}: \boldsymbol{Z}$ dependente do aumento do tamanho do grupo $\mathbf{R}$, tanto para adutos com $\mathbf{R}$ aromático quanto para AMBH com $\mathbf{R}$ alifático.

Contudo, o volume hidrodinâmico do substituinte isopropila é comparável ao de um grupo fenila e, por esta razão, era de se esperar que, com base no modelo de Basavaiah, a diastereosseletividade dos rearranjos de Hurd-Claisen desses AMBH fossem semelhantes. Isto 
sugere que outra causa se soma ao efeito estéreo na determinação da diastereosseletividade desta reação.

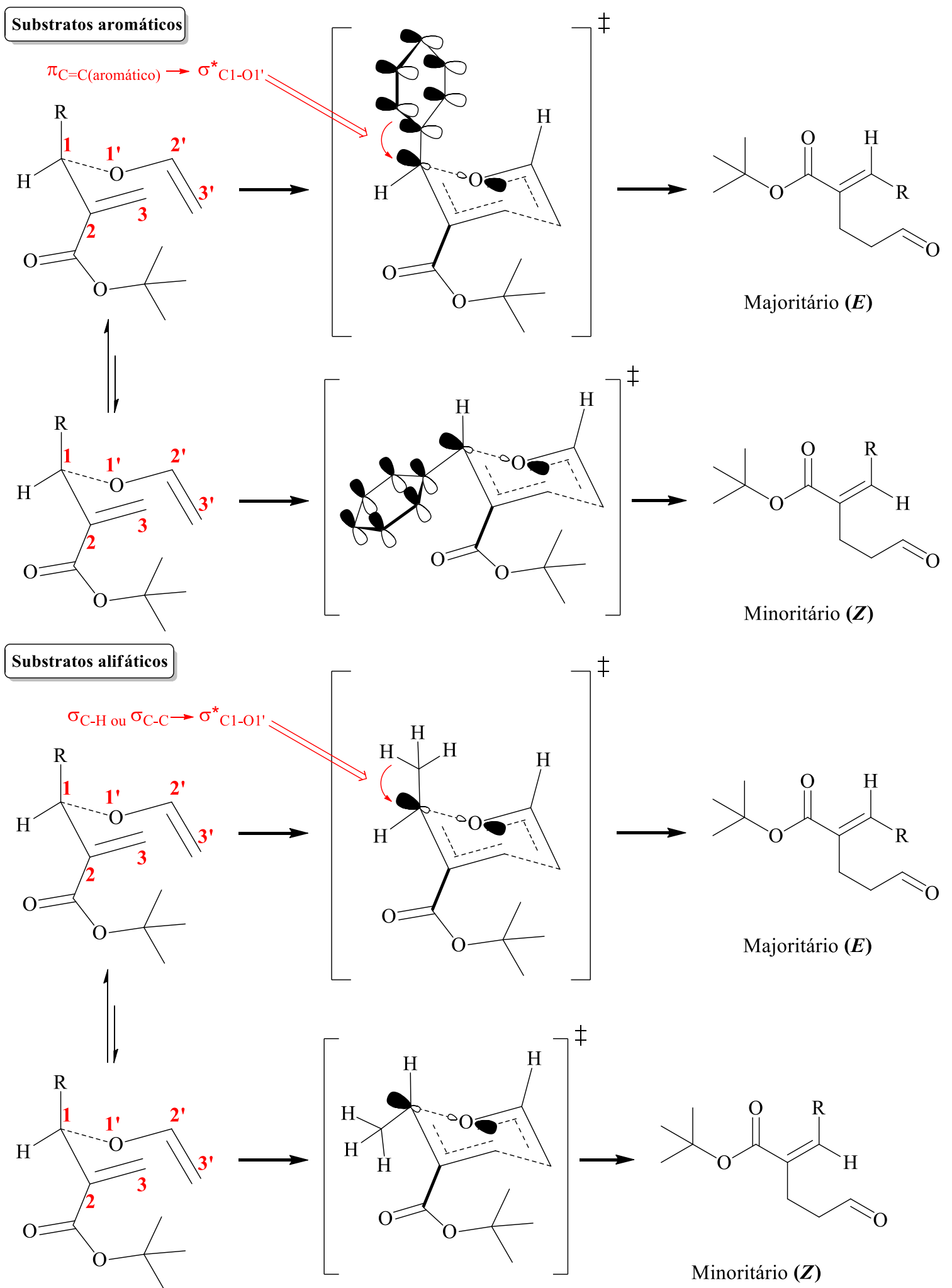

Esquema 26. Interações orbitalres proposta para explicar a diastereosseletividade $\boldsymbol{E}$ no produto de rearranjo de Hurd-Claisen e Johnson-Claisen em adutos MBH. 
No nosso entender, esta observação pode ser compreendida à luz do efeito estereoeletrônico oriundo da doação da densidade eletrônica do sistema aromático para o orbital antiligante da ligação C1-O1' que se rompe no desenvolvimento do estado de transição, $\left(\pi_{\mathrm{C}=\mathrm{C}(\text { aromático })} \rightarrow \sigma^{*} \mathrm{C1-O1}\right)$. Quando o anel aromático se encontra na posição pseudo axial, situação que leva à formação do produto $\boldsymbol{E}$, os orbitais envolvidos nesta interação apresentam melhor alinhamento, quando comparado ao ET que leva ao produto $Z$, que tem o anel aromático na posição pseudo equatorial. Isto promove uma maior estabilização da carga positiva parcial que se estabelece em $\mathrm{C} 1$ no desenvolvimento do estado de transição, como consequência da quebra da ligação C1-O1'. Assim, o ET que conduz a formação do isômero $\boldsymbol{E}$ é favorecido em detrimento daquele que produz o isômero $\boldsymbol{Z}$. Outra consequência destas interações de orbitais é a preferência do isômero $\boldsymbol{E}$ ser inferior quando o grupo $\mathbf{R}$ é alquílico devido à ausência da nuvem $\pi_{\mathrm{C}-\mathrm{C}}($ Esquema 26$)$.

Entretanto, o caráter doador $\pi_{\mathrm{C}=\mathrm{C}}$ é influenciado pelos grupos presentes no anel aromático, grupos doadores estabilizam melhor o $\delta^{+}$, aumentando a diastereosseletividade. Este aumento é observado no produto de rearranjo 4g, onde obtivemos uma razão de 40:1 devido ao caráter doador dos dois grupos metoxila. O mesmo também deveria ocorre com produto $4 \mathbf{f}$ que possui o grupo 2,3-metilenodioxifenila, contudo, a razão obtida foi de 17:1. Talvez o anel 2,3metilenodioxifenila assume uma conformação rígida e como consequência o grupo 2,3metilenodioxifenila possivelmente apresente um caráter aromático semelhante ao do grupo naftila (Figura 28). Este possível caráter aromático reduziria a capacidade doadora $\pi_{\mathrm{C}=\mathrm{C}}$, e consequentemente a razão $\boldsymbol{E}: \boldsymbol{Z}$.

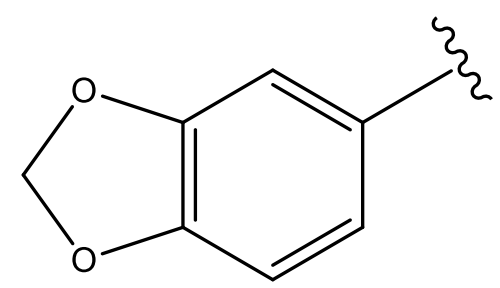

2,3-metilenodioxifenila

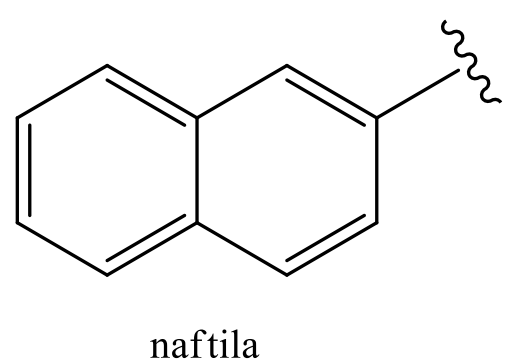

naftila

Figura 28. Similaridade do caráter aromático do grupo $\mathbf{R}$ presente no rearranjo de HurdClaisen-4f com o grupo naftila.

A presença de um GRE, seja por efeito indutivo (4b e $4 \mathbf{c}$ ) ou por ressonância (4d e 4e), também diminui o efeito estereoeletrônico $\quad \pi_{\mathrm{C}=\mathrm{C}(\text { aromático }) \rightarrow \sigma^{*} \mathrm{Cl}-\mathrm{O} 1}$ e conduz $\quad$ a estereosseletividades mais discretas. GRE por ressonância reduz drasticamente a 
diastereosseletividade, $\mathbf{4 d}(5: 1)$ e $\mathbf{4 e}(6: 1)$, aproximando-se até mesmo dos valores obtidos com substituintes alifáticos, onde a maior razão foi de 5:1 (4i). Porém, GRE por efeito indutivo, 4b e 4c, não promove um alteração expressiva na diastereosseletividade quando comparado com um anel aromático sem substituinte, grupo fenila (4a).

A estabilidade do estado de transição e consequentemente a formação preferencial do

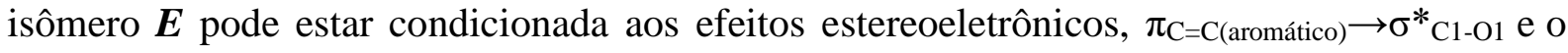
efeito anomérico exercido pelos pares de elétrons não ligantes do oxigênio 1', que melhor estabilize o $\delta^{+}$no carbono anomérico. A presenta de GRE reduz a capacidade doadora do anel aromático, porém favorece o efeito anomérico, mas GDE promovem efeito contrário. Um consequência do efeito anomérico seria uma ET tardio, o que levaria uma menor conversão e razão $\boldsymbol{E}: \boldsymbol{Z}$, como observado no rearranjo dos adutos 3d e 3e. Entretanto, GDE aumentam a capacidade doadora $\pi_{\mathrm{C}=\mathrm{C}(\text { aromático) }}$ conduzindo maior razão $\boldsymbol{E}: \boldsymbol{Z}$, como constatado no produto $\mathbf{4 g}$. 


\section{5-CONCLUSÕES}

Os adutos de Morita-Baylis-Hillman juntamente com o rearranjo de Hurd-Claisen, ambos estudados neste trabalho, permeiam os princípios de química verde, no que tange à economia de átomos. Contudo, tentativas para melhorar os rendimentos dos adutos com grupos doadores, $\mathbf{3 f}$ e $\mathbf{3 g}$, bem como os AMBH alifáticos foram frustradas e merecem ser revisitadas, pois ambos foram inferiores a $20 \%$.

O estudo do efeito estéreo no rearranjo do Hurd-Claisen em adutos de MBH corrobora com o modelo de estado de transição propostos por Basavaiah ${ }^{37}$ e estão em linha com os resultados obtidos por Rodrigues ${ }^{3}$, pois todos os resultados favorecem a formação do isômero $\boldsymbol{E}$. Para adutos com grupo $\mathbf{R}$ aromáticos a conversão e seletividade foram superiores a 79\% e $83 \%$ respectivamente. Utilizando o mesmo tempo reacional, 24 horas, a conversão para adutos com $\mathbf{R}$ alifático foi moderada, $67 \%$, porém a seletividade é ótima $96 \%$. Entretanto, com o tempo reacional de 30 horas foi possível maximizar a conversão dos substratos alifáticos, onde foram obtidas conversões superiores as $94 \%$ e seletividade acima de $80 \%$.

Apesar do aumento do grupo alcóxido do éster, não houve desestabilização do ET que leva ao produto $\mathbf{Z}$, uma vez que lá, na Johnson-Claisen, ele permanece como o majoritário, quando o grupo $\mathbf{R}$ é alifático. Assim, a troca do grupo alcóxido (OEt) por uma grupo mais volumoso $(\mathrm{Ot}-\mathrm{Bu})$ não promoveu uma modificação muito expressiva da razão $\boldsymbol{E}: \boldsymbol{Z}$.

O estudo de otimização realizado variando os parâmetros reacionais, principalmente variando os fatores temperatura e quantidade de catalisador, possibilitou maximizar a seletividade da reação, sendo dispensado o uso de uma base para impedir a formação do subproduto acetal, diminuindo o número de resíduos gerados, o que aproxima essa metodologia de uma síntese verde. Além disso, a análise destes parâmetros reacionais auxiliou no entendimento da razão $\boldsymbol{E}: \boldsymbol{Z}$ e, por conseguinte, na proposta de novas interações de orbitais que favorecem o estado de transição diastereoisomérico que conduz ao produto majoritário $\boldsymbol{E}$.

Em se tratando do rendimento da reação de rearranjo de Hurd-Claisen em AMBH, foram obtidos rendimentos superiores a $60 \%$ em substratos aromáticos e acima de 56\% para alifáticos. Cabe ressaltar que na grande maioria dos produtos de rearranjo aromáticos apenas o isômero $\boldsymbol{E}$ foi obtido. 
O rearranjo sigmatrópico $[3,3]$ do tipo Hurd-Claisen demonstrou ser uma metodologia viável para síntese de compostos carbonílicos $\gamma, \delta$-insaturados. Além disso, a análise por espectroscopia de RMN de ${ }^{1} \mathrm{H}$ possibilitou determinar a conversão, seletividade, razão $\boldsymbol{E}: \boldsymbol{Z}$ e rendimento esperado. A análise complementar de NOE auxiliou na determinação da configuração relativa, confirmando a seletividade para o isômero $\boldsymbol{E}$.

Contudo, a obtenção dos aldeídos de Claisen não permeia uma síntese orgânica verde, portanto, a substituição do mercúrio por um metal de menor toxicidade bem como a redução ou eliminação do uso de solventes conduziria essa metodologia para o caminho de uma síntese orgânica verde.

O efeito dos substituintes interfere significativamente no modelo de estado de transição que conduz a diastereosseletividade preferencia $\boldsymbol{E}$. As interações de orbitais moleculares propostas nesta dissertação não só pode como precisa ser ampliada a outros grupos alcóxidos de cadeias longas ou mais volumosos. Além disso, a presença de outros grupos doadores de elétrons pode aumentar consideravelmente a seletividade $\boldsymbol{E}$ e talvez grupos retiradores de elétrons possa inverter a seletividade de $\boldsymbol{E}$ para $\boldsymbol{Z}$.

Além disso, entender o mecanismo da reação de Claisen e como o mercúrio participa tanto na formação do alil vinil éter quanto nos estados de transição diastereoisoméricos pode auxiliar na compreensão da diastereosseletividade preferencial pelo isômero $\boldsymbol{E}$ no rearranjo de Claisen em adutos de $\mathrm{MBH}$. 


\section{6-PARTE EXPERIMENTAL}

\section{1-MATERIAIS E MÉTODOS}

Todos os aldeídos alifáticos, bem como o benzaldeído foram purificados antes da sua utilização. O etil vinil éter (EVE) e o acrilato de terc-butila (utilizado sem prévia purificação) foram adquiridos da Sigma Aldrich. O EVE foi destilado e armazenado em frasco âmbar por 7 dias, sendo utilizado sem prejuízo para a reação de Claisen.

O acompanhamento da reação e as análises preliminares de impurezas foram realizadas por cromatografia em camada delgada em cromatoplacas de alumínio revestida de sílica gel 60 F 254 (Fluka $\left.{ }^{\circledR}\right)$ irradiadas com luz ultravioleta de 254 nm (UV-C GERMICIDA, BOITTON Instrumentos) e/ou reveladas com solução alcoólica de 5\% de ácido fosfomolibídico seguido de aquecimento. A purificação dos $\mathrm{AMBH}$ e dos rearranjos de Claisen foram realizadas por cromatografia em coluna utilizando sílica gel (70-230 mesh) e como eluente foi utilizado acetato de etila:hexano em diferentes proporções, com exceção dos adutos oriundo do Piperonal (3f) e do 3,4-Dimetoxbenzaldeído (3g) o qual foi utilizado acetado de etila:diclorometano.

As reações sob irradiação ultrassom foram realizadas com ultrassom da marca Branson, modelo Bransonic cleanear 1210R-DTH, com frequência de $50 / 60 \mathrm{kHz}$ e potência de 80 Watts.

Os espectros de $\mathrm{RMN}{ }^{1} \mathrm{H}$ e ${ }^{13} \mathrm{C}$ foram adquiridos no aparelho Varian Mercury Plus 7,04 $\mathrm{T}\left(300 \mathrm{MHz}\right.$ para ${ }^{1} \mathrm{H}$ e $75 \mathrm{MHz}$ para ${ }^{13} \mathrm{C}$ ) e Bruker Ascend 14,1 T (600 MHz para ${ }^{1} \mathrm{H} 150 \mathrm{e}$ $\mathrm{MHz}$ para ${ }^{13} \mathrm{C}$ ). Os deslocamentos químicos $(\delta)$ estão em partes por milhão (ppm). Como referência nos espectros de ${ }^{1} \mathrm{H}(0,00 \mathrm{ppm})$ foi utilizado trimetilsilano (TMS) e para ${ }^{13} \mathrm{C}(77,0$ $\mathrm{ppm})$, clorofórmio deuterado $\left(\mathrm{CDCl}_{3}\right)$. Os espectros foram processados no programa MestReNova versão 6.0.2.

As multiplicidades das emissões nos espectros de $\mathrm{RMN}$ de ${ }^{1} \mathrm{H}$ são expressas seguindo a convenção: simpleto (s), dupleto (d), duplo dupleto (dd), duplo duplo dupleto (ddd), dupleto de tripleto $(\mathrm{dt})$, tripleto $(\mathrm{t})$, tripleto de tripleto $(\mathrm{tt})$, quadrupleto $(\mathrm{q})$, quadrupleto de tripleto $(\mathrm{qt})$, octeto (oct) e multipleto (m). 
Os espectros de infravermelho foram obtidos no espectrofotômetro Varian FT 640-IR empregando pastilhas de brometo de potássio (KBr) ou por refletância total atenuada (ATR) e $\mathrm{cm}^{-1}$ como unidade de frequência.

A pureza, bem como os espectros de massa foram obtidos em cromatógrafo gasoso acoplado à espectrometria de massa (GCMS) Shimadzu modelo GCMS-QP2010 Plus. Coluna capilar de 5\%-fenil-95\%-metilsiloxano (HP5, $30 \mathrm{~mm}$ x 0,32 $\mathrm{mm}$ x 0,25 $\mu \mathrm{m}$ ) e hélio como gás de arraste $(1,0 \mu \mathrm{m} / \mathrm{min})$ foram utilizados. A rampa de temperatura do forno foi programada de 100 a $200^{\circ} \mathrm{C}$, com uma taxa de aquecimento de $3{ }^{\circ} \mathrm{C} / \mathrm{min}$. A amostra foi preparada dissolvendo um miligrama do respectivo produto em $1,5 \mathrm{~mL}$ de acetonitrila ou metanol e 1,0 $\mu \mathrm{L}$ da solução foi injetada. Os dados foram analisados usando o software GCMSsolution.

Os solventes foram evaporados em evaporador rotatório (Fisatom) sob temperatura controlada e consequentemente a pressão reduzida em bomba a vácuo (Welch ${ }^{\circledR} 1376$, DuoSeal ${ }^{\circledR}$ VACUUM PUMP).

A atribuição do nome das moléculas foi realizada pelo programa ChemDraw Ultra 12,0. 


\section{2-FormaÇão dOS AdUTOS DE MORITA-BAYLIS-HILlMAN AROMÁticos}<smiles>[R]c1ccc(C=O)cc1</smiles><smiles>CC(=O)N1CCN2CCC1C2</smiles><smiles>[R]c1ccc(C(O)C(=C)C(=O)OC(C)(C)C)cc1</smiles>

Em um balão de 50,0 $\mathrm{mL}$ foram adicionados 1,93 mmol do respectivo aldeído, 1,93 mmol de 1,4-diazobiciclo[2.2.2] octano (108 mg), 20,5 mmol de acrilato de terc-butila (3,0 mL) e 1,0 mL de metanol. A reação foi acompanhada por análise em CCD e após o período de 10 dias a reação não apresentou evolução, sendo então finalizada. Pela concentração da mistura reacional em evaporador rotatório, a fim de se retirar o acrilato de terc-butila remanescente e o metanol. Nos casos onde a análise preliminar por CCD apresentou aldeído residual ou impurezas, o produto foi purificado por cromatografia em coluna utilizado acetato de etila:hexano (10:90) como eluente. Caso contrário, o produto foi utilizado sem purificação adicional.

\section{2-(hidroxi(fenil)metil) acrilato de terc-butila (3a)}

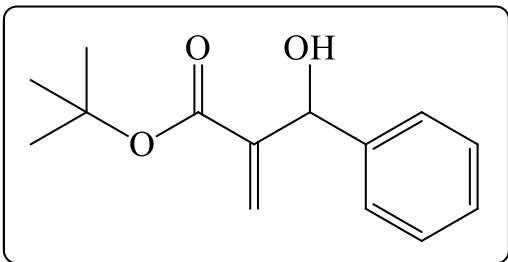

Característica: Óleo viscoso incolor

Rendimento: $98 \%$

Pureza: 99\%

\section{Dados Espectroscópicos}

RMN de ${ }^{1} \mathbf{H}\left(600 \mathrm{MHz}, \mathbf{C D C l}_{3}\right): 1,39$ (s, 9H); 3,11 (d, $\left.J=6,0 \mathrm{~Hz}, 1 \mathrm{H}\right) ; 5,50$ (d, $J=5,8 \mathrm{~Hz}$, $1 \mathrm{H}) ; 5,72(\mathrm{t}, J=1,2 \mathrm{~Hz}, 1 \mathrm{H}) ; 6,25(\mathrm{~m}, 1 \mathrm{H}) ; 7,27(\mathrm{~m}, 1 \mathrm{H}) ; 7,35(\mathrm{~m}, 4 \mathrm{H})$.

RMN de ${ }^{13} \mathbf{C}(150$ MHz, CDCl 3$): 27,9 ; 73,5 ; 81,6 ; 125,3 ; 126,5 ; 127,6 ; 128,3 ; 141,6$; 143,$4 ; 165,7$.

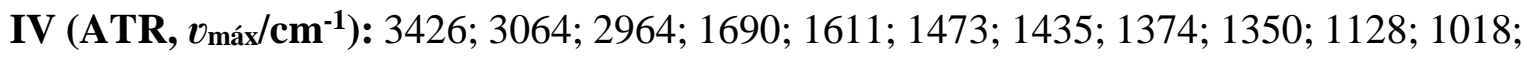
829.

EM (70 eV) m/z: 234 (M-17), 57 (100) 
<smiles>C=C(C(=O)OC(C)(C)C)C(O)c1ccc(Br)cc1</smiles>

Característica: sólido branco

Rendimento: $94 \%$

P.F: $65-70^{\circ} \mathrm{C}$

Pureza: $99 \%$

\section{Dados Espectroscópicos}

RMN de ${ }^{1} \mathbf{H}(\mathbf{6 0 0}$ MHz, CDCl 3$): 1,42$ (s, 9H); 3, 19 (d, $\left.J=5,9 \mathrm{~Hz} ; 1 \mathrm{H}\right) ; 5,45$ (d, $J=4,9$ $\mathrm{Hz} ; 1 \mathrm{H}) ; 5,70$ (t, $J=1,1 \mathrm{~Hz} ; 1 \mathrm{H}) ; 6,25(\mathrm{~m}, 1 \mathrm{H}) ; 7,25$ (m, 2H); 7,47 (m, 2H).

RMN de ${ }^{13} \mathbf{C}$ (150 MHz, CDCl 3$): 28,0 ; 73,1 ; 81,9 ; 121,6 ; 125,7 ; 128,2 ; 131,4 ; 140,7$; 143,$0 ; 165,5$.

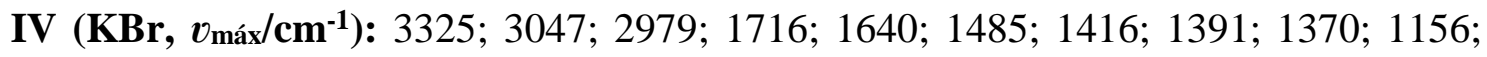
$1071 ; 1028 ; 826$.

EM (70 eV) m/z: 313 (M-57), 57 (100).

2-((4-bromofenil(hidroxi)metil) acrilato de terc-butila (3c)

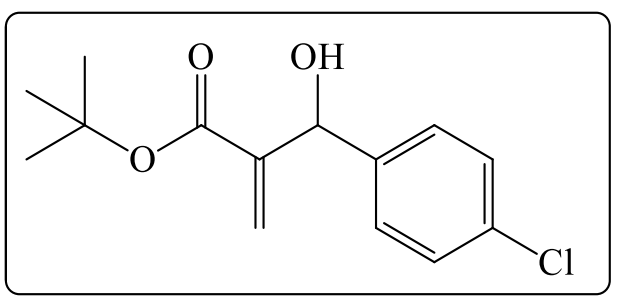

Característica: sólido branco

Rendimento: $88 \%$

P.F: $73-75^{\circ} \mathrm{C}$

Pureza: 99\%

\section{Dados Espectroscópicos}

RMN de ${ }^{1} \mathbf{H}(300$ MHz, CDCl3): 1,41 (s, 9H); 3,23 (d, $J=6,1 \mathrm{~Hz} ; 1 \mathrm{H}) ; 5,46$ (d, $J=5,8$ $\mathrm{Hz} ; 1 \mathrm{H}) ; 5,71$ (t, $J=1,2 \mathrm{~Hz} ; 1 \mathrm{H}) ; 6,25$ (dd, $J=1,1 ; 0,6 \mathrm{~Hz} ; 1 \mathrm{H}) ; 7,31$ (s, 4H).

RMN de ${ }^{13} \mathbf{C}$ (75 MHz, CDCl3): 27,9; 73,0; 81,9; 125,7; 127,9; 128,4; 133,4; 140,1; 142,$9 ; 165,5$.

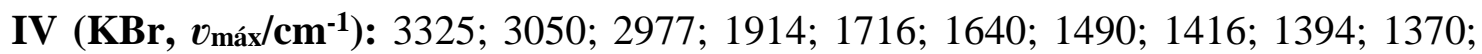
$1157 ; 1090 ; 1026 ; 828$.

EM (70 eV) m/z: 268 (M-17), 57 (100). 


\subsection{1-FORMAÇÃO DO 2-(HIDROXI(3-NITROFENIL)METIL) ACRILATO DE TERC-BUTILA}

E 2-(HIDROXI(4-NITROFENIL)METIL) ACRILATO DE TERC-BUTILA

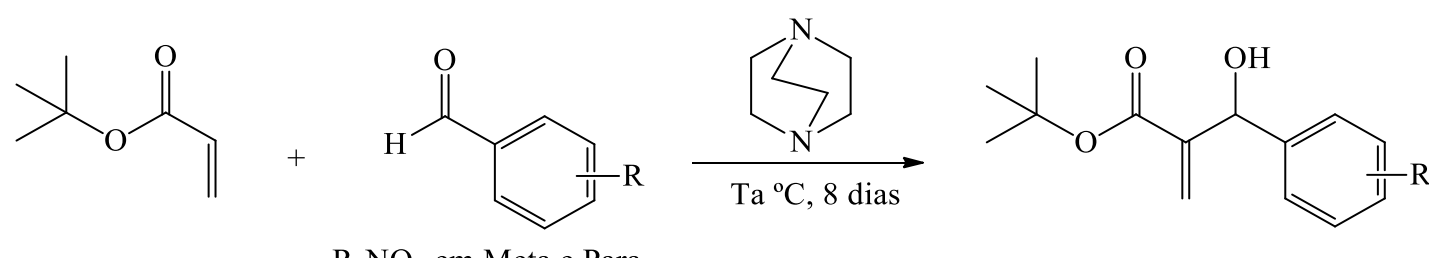

Em um balão de 50,0 $\mathrm{mL}$ foram adicionados 1,93 mmol do respectivo aldeído, 1,93 mmol de 1,4-diazobiciclo[2.2.2]octano $(108 \mathrm{mg})$ e $20,5 \mathrm{mmol}$ de acrilato de terc-butila $(3,0$ mL). A reação foi acompanhada por análise em CCD e após o período de 8 dias a reação não apresentou aldeído, sendo então finalizada. Pela concentração da mistura reacional em evaporador rotatório, a fim de se retirar o acrilato de terc-butila remanescente. O produto obtido foi filtrado em funil de placa de sinterizada utilizando sílica gel e acetato de etila:hexano (30:70) como eluente. Nos casos onde a análise preliminar por CCD apresentou aldeído residual ou impurezas, o produto foi purificado por cromatografia em coluna utilizado acetato de etila:hexano (10:90) como eluente. Caso contrário, o produto foi utilizado sem purificação adicional.

2-(hidroxi)(3-nitrofenil)metil) acrilato de terc-butila (3d)

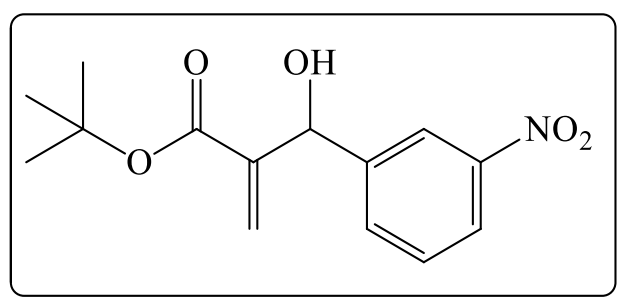

Característica: óleo viscoso amarelado

Rendimento: $96 \%$

Pureza: 99\%

\section{Dados Espectroscópicos}

RMN de ${ }^{1} \mathbf{H}(300$ MHz, CDCl 3$): 1,43$ (s, 9H); 3,41 (d, $\left.J=6,1 \mathrm{~Hz} ; 1 \mathrm{H}\right) ; 5,58(\mathrm{~d}, J=5,6 \mathrm{~Hz}$; $1 \mathrm{H}) ; 5,79(\mathrm{t}, J=1,0 \mathrm{~Hz} ; 1 \mathrm{H}) ; 6,32(\mathrm{~m}, 1 \mathrm{H}) ; 7,53(\mathrm{t}, J=7,9 \mathrm{~Hz} ; 1 \mathrm{H}) ; 7,74(\mathrm{~d}, J=7,7 \mathrm{~Hz} ; 1 \mathrm{H})$; $8,15$ (ddd, $J=8,2 ; 2,3 ; 1,1 \mathrm{~Hz} ; 1 \mathrm{H}) ; 8,26(\mathrm{t}, J=2,0 \mathrm{~Hz} ; 1 \mathrm{H})$.

RMN de ${ }^{13} \mathbf{C}$ (75 MHz, CDCl3): 28,0; 73,0; 82,3; 121,5; 122,6; 126,4; 129,3; 132,5; 142,4; 144,$0 ; 148,3 ; 165,3$.

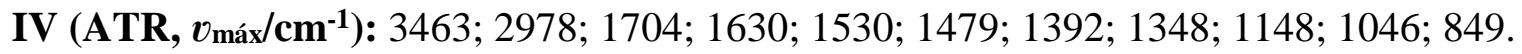

EM (70 eV) m/z: 279 (M-30), 57 (100). 
2-(hidroxi)(4-nitrofenil)metil) acrilato de terc-butila (3e)

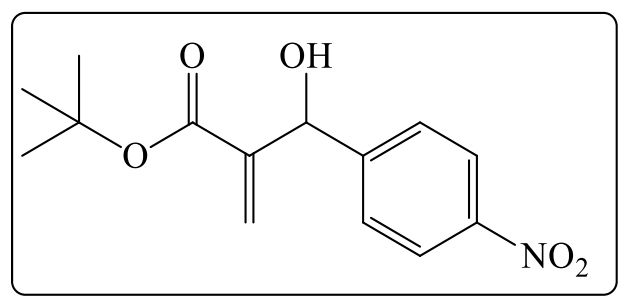

Característica: sólido levemente amarelado

Rendimento: $86 \%$

P.F: $85-90^{\circ} \mathrm{C}$

Pureza: 99\%

\section{Dados Espectroscópicos}

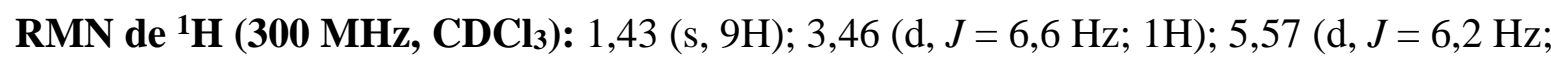
$1 \mathrm{H}) ; 5,75(\mathrm{t}, J=1,0 \mathrm{~Hz} ; 1 \mathrm{H}) ; 6,31(\mathrm{dd}, J=0,8 ; 0,4 \mathrm{~Hz} ; 1 \mathrm{H}) ; 7,57(\mathrm{dd}, J=9,0 ; 0,6 \mathrm{~Hz} ; 2 \mathrm{H})$; $8,21(\mathrm{~d}, J=8,8 \mathrm{~Hz} ; 2 \mathrm{H})$.

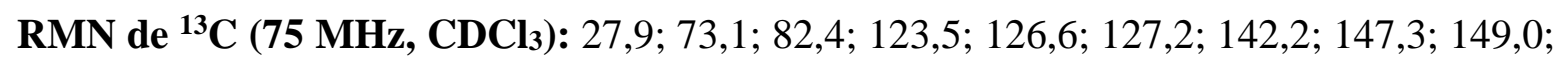
165,3 .

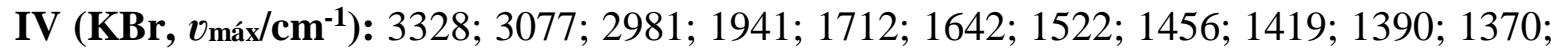
$1353 ; 1156 ; 1024 ; 832$.

EM (70 eV) m/z: 279 (M-33), 57 (100). 


\subsection{2-FormaÇÃO dOS ADUTOS DE MoRita-BAylis-Hillman AROMÁticos SOB IRRADIAÇÃO ULTRASSOM}

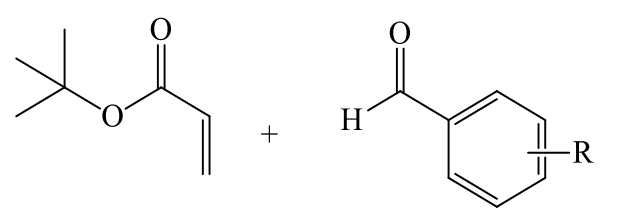

3,4-Dimetoxbenzaldeído Piperonal

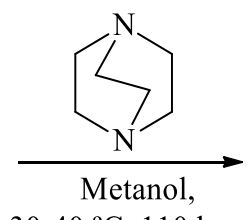

$30-40{ }^{\circ} \mathrm{C}, 110$ horas<smiles>[R][X]c1ccc(C(O)C(=C)C(=O)OC(C)(C)C)cc1</smiles>

Em um tubo de ensaio de $10 \mathrm{~mm} \times 100 \mathrm{~mm}$ pyrex com tampa foram adicionados 5,25 mmol do respectivo aldeído, 3,41 mmol de 1,4-diazobiciclo[2.2.2]octano (383 mg), 6,83 mmol de acrilato de terc-butila $(1,0 \mathrm{~mL})$ e $3,95 \mathrm{~mL}$ de metanol. A mistura reacional foi colocada em ultrassom e a temperatura foi constantemente monitorada, entre 30 e $40{ }^{\circ} \mathrm{C}$, sendo adicionado gelo para estabilizar a temperatura. A reação foi acompanhada por análise em CCD e após o período de 110 horas a reação não apresentou evolução, sendo então finalizada. A mistura reacional foi transferida para um balão de $25 \mathrm{~mL}$ e concentrada em evaporador rotatório, a fim de se retirar o acrilato de terc-butila remanescente e o metanol. A análise preliminar por CCD apresentou aldeído residual e impurezas, sendo então o produto purificado por cromatografia em coluna utilizando acetato de etila:diclometano (5:95) como eluente.

\section{2-((benzo[d][1,3]dioxol-5-il)(hidróxi)metil) acrilato de terc-butila (3f)}

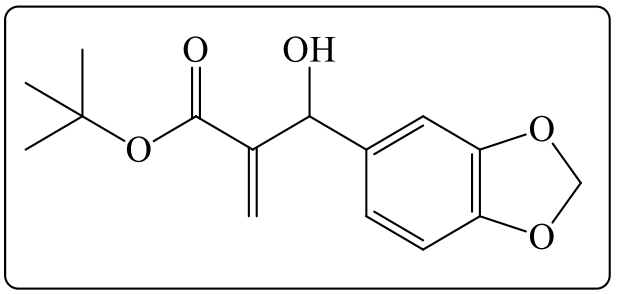

Característica: óleo viscoso amarelado

Rendimento: $14 \%$

Pureza: $98 \%$

\section{Dados Espectroscópicos}

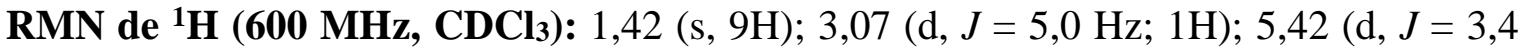
$\mathrm{Hz} ; 1 \mathrm{H}) ; 5,73$ (t, $J=1,3 \mathrm{~Hz} ; 1 \mathrm{H}) ; 5,95$ (s, 2H); 6,24 (dd, $J=1,3 ; 0,8 \mathrm{~Hz} ; 1 \mathrm{H}) ; 6,77$ (dd, $J=$ 7,9; 0,3 Hz; 1H); 6,83 (ddd, $J=8,0 ; 1,7 ; 0,6 \mathrm{~Hz} ; 1 \mathrm{H}) ; 6,87$ (dd, $J=1,3 ; 0,4 \mathrm{~Hz} ; 1 \mathrm{H})$.

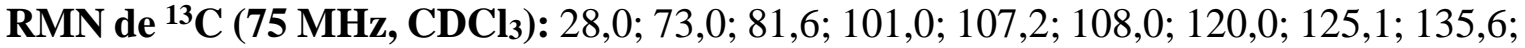
143,$3 ; 147,0 ; 147,6 ; 165,6$.

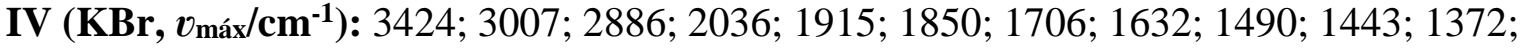
$1337 ; 1143 ; 1025 ; 884 ; 870 ; 849$.

EM (70 eV) m/z: 278, 149 (100). 
2-((3,4-dimetoxifenil)(hidróxi)metil) acrilato de terc-butila (3g)

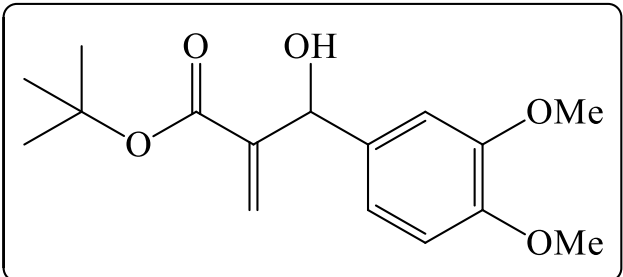

Característica: óleo viscoso amarelado

Rendimento: $14 \%$

Pureza: $98 \%$

\section{Dados Espectroscópicos}

RMN de ${ }^{1} \mathbf{H}(300$ MHz, CDCl$): 1,42$ (s, 9H); 3,17 (s, 1H); 3,87 (s, $\left.6 \mathrm{H}\right) ;$ 4,78 (s, 1H); 5,46 (s, 1H) $5,71(\mathrm{t}, J=1,3 \mathrm{~Hz} ; 1 \mathrm{H}) ; 6,24(\mathrm{~m}, 1 \mathrm{H}) ; 6,88(\mathrm{~m}, 1 \mathrm{H})$.

RMN de ${ }^{13} \mathbf{C}(\mathbf{7 5}$ MHz, CDCl 3$): 27,9 ; 55,7 ; 55,8 ; 73,2 ; 81,6 ; 109,7 ; 110,8 ; 118,9 ; 125,0$; 134,$2 ; 143,5 ; 148,4 ; 148,9 ; 165,8$.

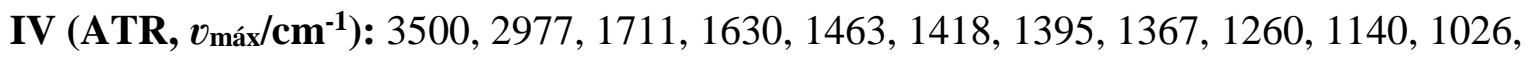
851.

EM (70 eV) m/z: 294, 165 (100). 


\section{3-FormaÇão dOS ADUTOS DE MoRITA-BAYLIS-HiLlman Alifáticos}

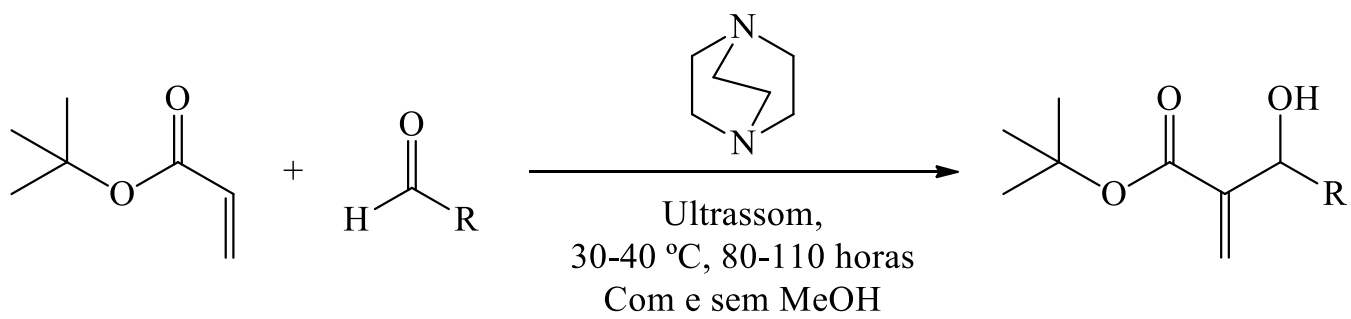

Em um tubo de ensaio de $10 \mathrm{~mm}$ x $100 \mathrm{~mm}$ pyrex com tampa foram adicionados 7,88 mmol do respectivo aldeído, 5,12 mmol de 1,4-diazobiciclo[2.2.2]octano (574 mg), 10,2 mmol de acrilato de terc-butila $(1,5 \mathrm{~mL})$. Os mesmos adutos foram realizados com e sem adição de metanol. Para as reações com adição de solvente foram necessários $6,95 \mathrm{~mL}$ de metanol. A mistura reacional foi colocada em ultrassom e a temperatura foi constantemente monitorada, entre 30 e $40^{\circ} \mathrm{C}$, sendo adicionado gelo para estabilizar a temperatura. A reação foi acompanhada por análise em CCD e após o período de 110 horas a reação não apresentou evolução, sendo então finalizada. A mistura reacional foi transferida para um balão de $25 \mathrm{~mL}$ e concentrada em evaporador rotatório, a fim de se retirar o acrilato de terc-butila remanescente e o metanol. A mistura concentrada foi diluída em $10 \mathrm{~mL}$ de acetato de etila e transferida para funil de separação onde foi lavada com solução de $\mathrm{HCl} 10 \%$ (3 x $5 \mathrm{~mL})$. A fase orgânica foi novamente extraída com água destilada $(3 \times 5 \mathrm{~mL})$ e verificado o $\mathrm{pH}$ (neutro). A mistura contendo o AMBH foi seca com $\mathrm{Na}_{2} \mathrm{SO}_{4}$, filtrada e concentrada em evaporador rotatório. Nos casos onde a análise preliminar por CCD apresentou aldeído residual ou impurezas, o produto foi purificado por cromatografia em coluna utilizado acetato de etila:hexano (20:80) como eluente.

\section{3-hidróxi-2-metilenobutanoato de terc-butila (3h)}

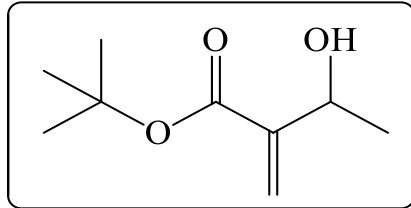

Característica: Óleo incolor

Rendimento: $20 \%$

Pureza: $98 \%$

\section{Dados Espectroscópicos}

RMN de ${ }^{1} \mathbf{H}(300$ MHz, CDCl 3$): 1,38$ (d, $\left.J=6,5 \mathrm{~Hz} ; 3 \mathrm{H}\right) ; 1,52$ (s, 9H); 2,90 (s, 1H); 4,58 (q, $J=6,3 \mathrm{~Hz} ; 1 \mathrm{H}) ; 5,73(\mathrm{t}, J=1,2 \mathrm{~Hz} ; 1 \mathrm{H}) ; 6,11(\mathrm{~m}, 1 \mathrm{H})$.

RMN de ${ }^{13}$ C (75 MHz, CDCl3): 21,9; 28,0; 67,3; 81,4; 123,1; 144,8; 166,0.

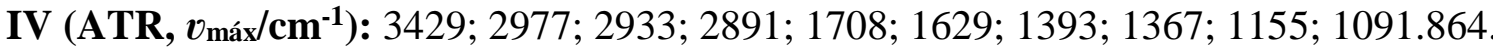

EM (70 eV) m/z:172 (M-15), 57 (100). 
3-hidróxi-2-metilenopentanoato de terc-butila (3i)

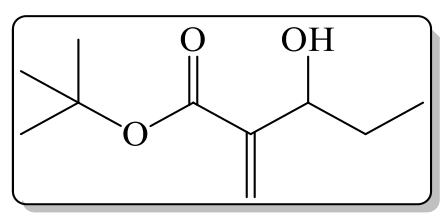

Característica: Óleo incolor

Rendimento: $21 \%$

Pureza: 99\%

Dados Espectroscópicos

RMN de ${ }^{1} \mathbf{H}(300$ MHz, CDCl3): 0,95 (t, $J=7,4 \mathrm{~Hz}, 3 \mathrm{H}) ; 1,51$ (s, 9H); 1,68 (m, 2H); 2,71 $(\mathrm{d}, J=5,1 \mathrm{~Hz}, 1 \mathrm{H}) ; 4,27(\mathrm{~m}, 1 \mathrm{H}) ; 5,69$ (t, $J=1,3 \mathrm{~Hz}, 1 \mathrm{H}) ; 6,13(\mathrm{dd}, J=1,3 \mathrm{~Hz} ; 0,4 \mathrm{~Hz}, 1 \mathrm{H})$.

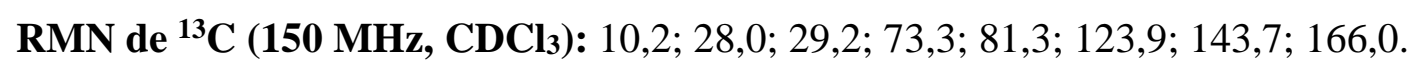

IV (ATR, v máx $\left._{\mathbf{c}} \mathbf{c m}^{-1}\right)$ : 3444, 2975, 2937, 2878, 1706, 1630, 1392, 1369, 1153, 1100, 849.

EM (70 eV) m/z:186 (M-15), 57(100).

3-hidróxi-2-metilenononanoato de terc-butila (3j)

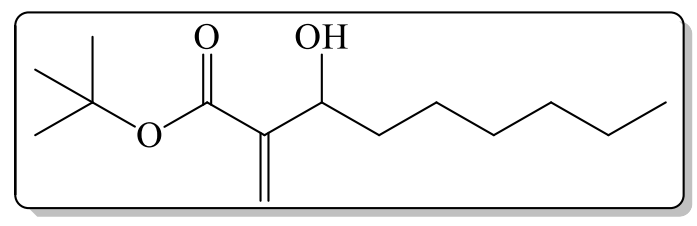

Característica: Óleo incolor

Rendimento: $21 \%$

Pureza: 99\%

Dados Espectroscópicos

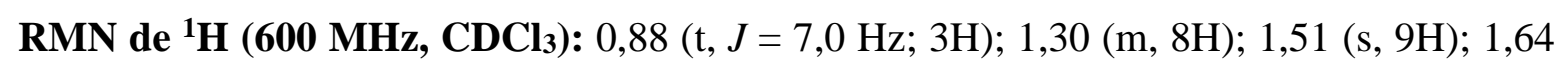
(m, 2H); 2,64 (s, 1H); 4.33 (t, $J=6,5 \mathrm{~Hz}, 1 \mathrm{H}) ; 5,68(\mathrm{t}, J=1,2 \mathrm{~Hz}, 1 \mathrm{H}) ; 6,11(\mathrm{~m}, 1 \mathrm{H})$.

RMN de ${ }^{13} \mathbf{C}$ (150 MHz, CDCl3): 14,0; 22,6; 25,8; 28,1; 29, 1; 31,8; 36,4; 72,1; 81,4; 123,8; 144,$0 ; 166,0$.

IV (ATR, $\left.v_{\text {máx }} / \mathbf{c m}^{-1}\right): 3440 ; 2958 ; 2928 ; 2854 ; 1710 ; 1630 ; 1392 ; 1368 ; 1152 ; 1065$.

EM (70 eV) m/z: 242 (M-57), 57 (100). 
3-hidróxi-4-metil-2-metilenopentanoato de terc-butila (3k)

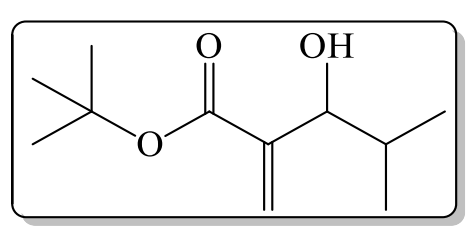

Característica: Óleo incolor

Rendimento: $11 \%$

Pureza: $88 \%$

Dados Espectroscópicos

RMN de ${ }^{1} \mathbf{H}(300$ MHz, CDCl 3$): 0,87$ (d, $\left.J=6,8 \mathrm{~Hz} ; 3 \mathrm{H}\right) ; 0,97(\mathrm{~d}, J=6,8 \mathrm{~Hz} ; 3 \mathrm{H}) ; 1,50$ (s, 9H); $1,91(\mathrm{dq}, J=13,6 ; 6,8 \mathrm{~Hz}, 1 \mathrm{H}) ; 2,62(\mathrm{~d}, J=7,7 \mathrm{~Hz} ; 1 \mathrm{H}) ; 4.01(\mathrm{t}, J=7,1 \mathrm{~Hz}, 1 \mathrm{H}) ; 5,65$ $(\mathrm{m}, 1 \mathrm{H}) ; 6,14(\mathrm{~d}, J=1,5 ; 1 \mathrm{H})$.

RMN de ${ }^{13} \mathbf{C}$ (75 MHz, CDCl3): 19,5; 19,7; 28,4; 33,2; 78,3; 81,4; 125,4; 142,7; 166,2.

IV (ATR, vmáx/cm-1): 3466; 2968; 2934; 2874; 1705; 1627; 1392; 1368; 1152; 1015.

EM (70 eV) m/z: 200 (M-43), 57 (100) 


\section{4-REARRANJo DE HuRD-Claisen EM AdUTOS DE MORITA-BAYLIS-HILLMAN}<smiles>[R]C(O)C(=C)C(=O)OC(C)(C)C</smiles>

3 a-k

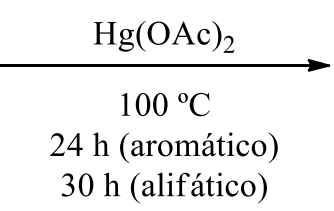

$30 \mathrm{~h}$ (alifático)<smiles>[R]C=C(CCC=O)C(=O)OC(C)(C)C</smiles>

4 a-k

Em um tubo de ensaio de $10 \mathrm{~mm} \times 100 \mathrm{~mm}$ pyrex com tampa foram adicionados 0,42 mmol do respectivo AMBH, 2,09 mmol de etil vinil éter ${ }^{50}(0,2 \mathrm{~mL})$ e $100 \mathrm{mmol}$ de acetado de mercúrio $\left(\mathrm{Hg}(\mathrm{OAc})_{2}, 3,3 \mathrm{mg}\right.$. A mistura foi colocada em banho de óleo a $100{ }^{\circ} \mathrm{C}$, sob agitação magnética. Após período determinado a mistura foi diluída em 5,0 $\mathrm{mL}$ de acetato de etila e transferida para funil de separação onde foi lavada com solução de $\mathrm{NaCl}$ saturada $(3 \times 3 \mathrm{~mL})$. A fase orgânica foi seca com $\mathrm{Na}_{2} \mathrm{SO}_{4}$, filtrada e concentrada em evaporador rotatório. Antes do produto ser purificado por cromatografia em coluna utilizando acetato de etila:hexano $(10: 90)^{51}$ como eluente, foi separada um alíquota para análise do bruto de reação por RMN ${ }^{1} \mathrm{H}$.

\section{2-benzidileno-5-oxopentanoato de terc-butila $4 a(E)$}

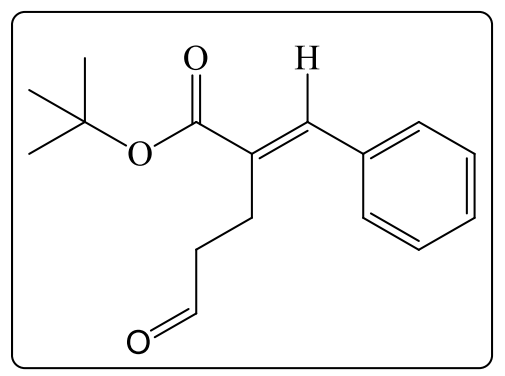

Característica: Óleo incolor

Rendimento: $67 \%(E)$

Pureza: 98\%

\section{Dados Espectroscópicos}

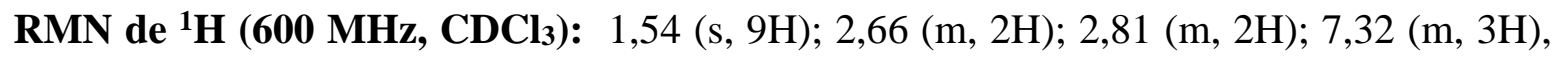
7,38 (m, 2H); 7,65 (s, 1H); 9,76 (t, $J=1,5 \mathrm{~Hz}, 1 \mathrm{H})$.

RMN de ${ }^{13}$ C (150 MHz, CDCl3): (E) 20,3; 28,1; 43,3; 81,1; 128,4; 128,6; 128,9; 132,8; 135,$5 ; 139,4 ; 166,9 ; 201,4$.

IV (ATR, $\left.v_{\text {máx }} / \mathbf{c m}^{-1}\right)$ : 2976; 2726; 1700; 1631; 1443; 1391; 1366; 1158; 846; 770; 700.

EM $(70 \mathrm{eV})$ m/z: 260 (M-54), 57 (100).

\footnotetext{
${ }^{50}$ Etil vinil éter recém destilado, vide matérias e métodos, bem como o tópico 4.3.1.

${ }^{51}$ Para os produtos de rearranjo dos AMBH 3d e 3e foi utilizado acetato de etila:hexano (20:80).
} 
2-(4-bromobenzidileno)-5-oxopentanoato de terc-butila $4 \mathrm{~b}(E)$

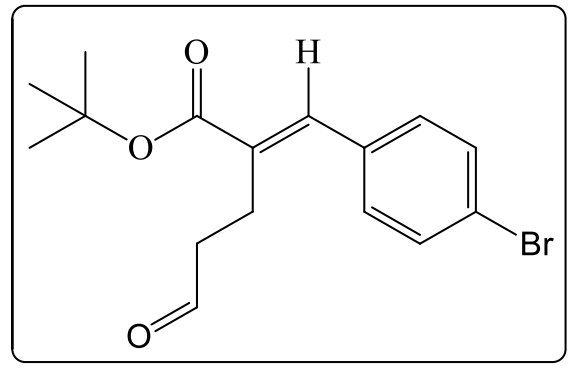

Característica: Óleo incolor

Rendimento: $66 \%(E)$

Pureza: 99\%

\section{Dados Espectroscópicos}

RMN de ${ }^{1} \mathbf{H}(600$ MHz, CDCl$): 1,54(\mathrm{~s}, 9 \mathrm{H}) ; 2,65$ (m, 2H); 2,77 (m, 2H); 7,17 (m, 2H), 7,51 (m, 2H); 7,56 (s, 1H); 9,76 (t, $J=1,5 \mathrm{~Hz}, 1 \mathrm{H})$.

RMN de ${ }^{13} \mathbf{C}(150$ MHz, CDCl 3$): ~ 20,3 ; 28,1 ; 43,1 ; 81,3 ; 122,6 ; 130,4 ; 131,8 ; 133,6 ; 134,4$; 138,$0 ; 166,6 ; 201,0$.

IV (ATR, $\left.\boldsymbol{v}_{\text {máx }} / \mathbf{c m}^{-1}\right): 2975 ; 2717 ; 1701 ; 1633 ; 1486 ; 1392 ; 1367 ; 1157 ; 1072 ; 846 ; 759 ; 720$. EM (70 eV) m/z: 338 (M-53), 57 (100).

2-(4-clorobenzidileno)-5-oxopentanoato de terc-butila $4 \mathrm{c}(E)$

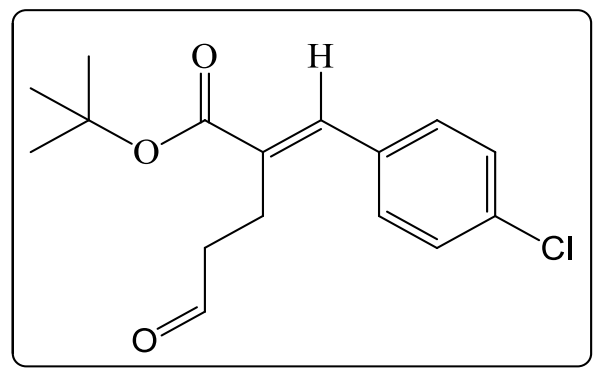

Característica: Óleo incolor

Rendimento: $70 \%(E)$

Pureza: 99\%

\section{Dados Espectroscópicos}

RMN de ${ }^{1} \mathbf{H}(600$ MHz, CDCl$): 1,54(\mathrm{~s}, 9 \mathrm{H}) ; 2,66(\mathrm{~m}, 2 \mathrm{H}) ; 2,78(\mathrm{~m}, 2 \mathrm{H}) ; 7,23(\mathrm{~m}, 2 \mathrm{H})$, 7,36 (m, 2H); 7,58 (s, 1H); 9,76 (t, $J=1,3 \mathrm{~Hz}, 1 \mathrm{H})$.

RMN de ${ }^{13} \mathbf{C}$ (150 MHz, CDCl3): 20,3; 28,1; 43,2; 81,3; 128,9; 128,6; 128,9; 130,2; 133,5; 133,$9 ; 134,4 ; 138,0 ; 166,7 ; 201,1$.

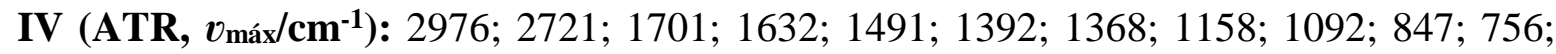
727.

EM (70 eV) m/z: 294 (M-53), 57 (100) 


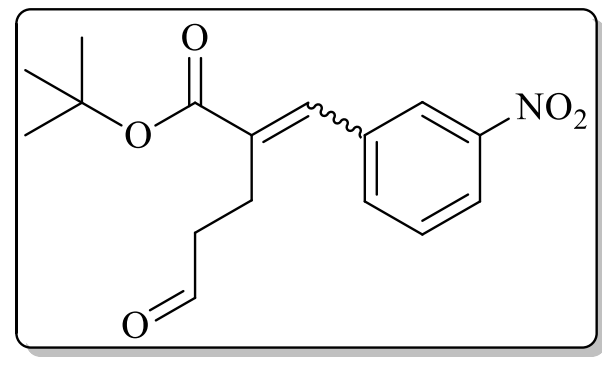

Dados Espectroscópicos
Característica: Óleo levemente amarelado

Rendimento: $60 \%(E, Z)$

Pureza: $90 \%$

RMN de ${ }^{1} \mathbf{H}(600$ MHz, CDCl 3$):(Z)$ 1,35 (s, 9H); (E) 1,56 (s, 9H); (E, Z) 2,71 (m, 2H); (Z) 6,70 (s, 1H); (E) 7,64 (s, 1H); (E, Z) 7,58 (m, 2H), (E, Z) 8,17 (m, 2H); (E) 9,78 (t, J=1,1 $\mathrm{Hz}, 1 \mathrm{H})(Z) 9,84(\mathrm{t}, J=1,0 \mathrm{~Hz}, 1 \mathrm{H})$.

RMN de ${ }^{13}$ C (150 MHz, CDCl3): (E) 20,2; 28,1; 43,0; 81,8; 123,0; 123,7; 129,5; 129,7; 134,$5 ; 136,7 ; 137,3 ; 148,4 ; 166,1 ; 200,5$. (Z) 22,$5 ; 27,8 ; 42,4 ; 81,5 ; 122,4 ; 124,0 ; 129,0$; 131,$2 ; 134,3 ; 135,7 ; 137,4 ; 148,0 ; 166,5 ; 200,6$.

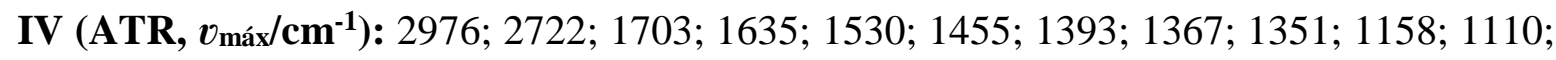
$848 ; 737 ; 676$.

EM (70 eV) m/z: 305 (M-56), 57 (100).

2-(4-nitrobenzidileno)-5-oxopentanoato de terc-butila $4 \mathrm{e}(E)$

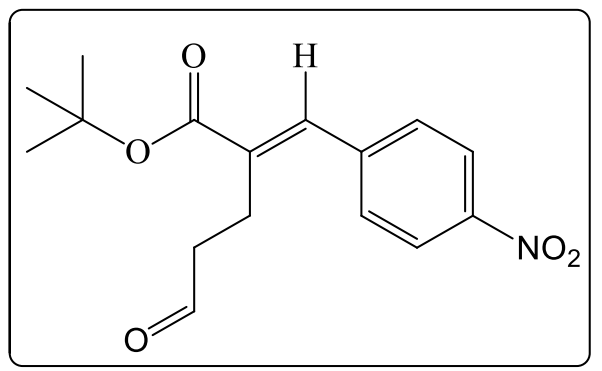

Característica: Óleo viscoso amarelado

Rendimento: $50 \%(\boldsymbol{E})$

Pureza: 99\%

Dados Espectroscópicos

RMN de ${ }^{1} \mathbf{H}(300$ MHz, CDCl 3$): 1,55$ (s, 9H); 2,73 (m, 4H); 7,50 (m, 2H), 7,64 (s, 1H); $8,25(\mathrm{~m}, 2 \mathrm{H}) ; 9,77(\mathrm{t}, J=1,2 \mathrm{~Hz}, 1 \mathrm{H})$.

RMN de ${ }^{13} \mathbf{C}(150$ MHz, CDCl 3$): ~ 20,3 ; 28,0 ; 42,9 ; 81,8 ; 123,8 ; 129,6 ; 136,2 ; 136,6 ; 142,2$; 147,$3 ; 166,0 ; 200,5$.

IV (ATR, $\left.v_{\text {máx }} / \mathbf{c m}^{-1}\right): 2969 ; 2718 ; 1624 ; 1510 ; 1455 ; 1382 ; 1358 ; 1148 ; 1100 ; 840,680$. EM (70 eV) m/z: 305 (M-56), 57 (100). 
2-((benzo[d][1,3]dioxol-5-ilmetileno)-5-oxopentanoato de terc-butila $4 \mathrm{f}(E)$

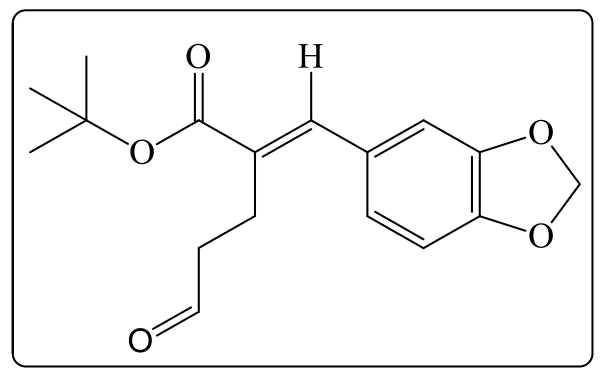

Característica: Óleo incolor

Rendimento: $75 \%$

Pureza: $99 \%$

Dados Espectroscópicos

RMN de ${ }^{1} \mathbf{H}(600$ MHz, CDCl 3$): 1,53$ (s, 9H); 2,66 (m, 2H); 2,82 (m, 2H); 5,99 (s, 1H); 6,82 (m, 3H), 7,55 (s, 1H); 9,79 (t, $J=1,5 \mathrm{~Hz}, 1 \mathrm{H})$.

RMN de ${ }^{13} \mathbf{C}$ (150 MHz, CDCl 3$): 20,3 ; 28,1 ; 43,2 ; 81,0 ; 101,3 ; 108,5 ; 109,0 ; 123,8 ; 129,4$; 131,$4 ; 139,1 ; 147,8 ; 147,9 ; 167,1 ; 201,4$.

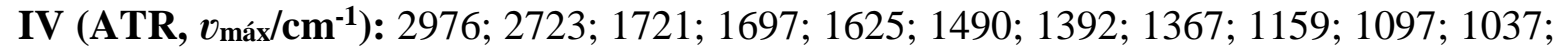
851.

EM (70 eV) m/z: 305, 57 (100).

2-(3,4-dimetoxbenzidileno)-5-oxopentanoato de terc-butila $4 \mathrm{~g}(E)$<smiles>COc1ccc(/C=C(\CCC=O)C(=O)OC(C)(C)C)cc1OC</smiles>

Característica: Óleo incolor

Rendimento: $79 \%(E)$

Pureza: $97 \%$

\section{Dados Espectroscópicos}

RMN de ${ }^{1} \mathbf{H}(300$ MHz, CDCl 3$): 1,54(\mathrm{~s}, 9 \mathrm{H}) ; 2,70$ (m, 2H); 2,86 (m, 2H); 3,88 (s, 3H); $3,91(\mathrm{~s}, 3 \mathrm{H}) ; 6,91(\mathrm{~m}, 3 \mathrm{H}) ; 7,59(\mathrm{~s}, 1 \mathrm{H}) ; 9,81(\mathrm{t}, J=1,5 \mathrm{~Hz}, 1 \mathrm{H})$.

RMN de ${ }^{13} \mathbf{C}(150$ MHz, CDCl$): 20,4 ; 28,1 ; 43,3 ; 55,9 ; 80,9 ; 111,1 ; 112,3 ; 122,3 ; 128,1$; 130,$9 ; 139,2 ; 148,8 ; 149,4 ; 167,1 ; 201,4$.

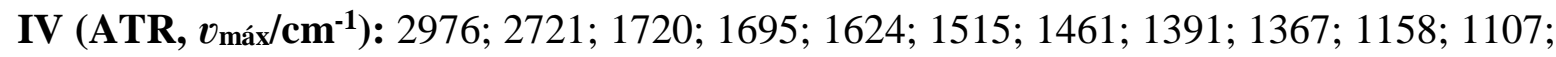
$1024 ; 850$.

EM (70 eV) m/z: 320 (M-56), 41 (100). 
2-etilideno-5-oxopentanoato de terc-butila $4 \mathrm{~h}(E)$ e $4 \mathrm{~h}(Z)$

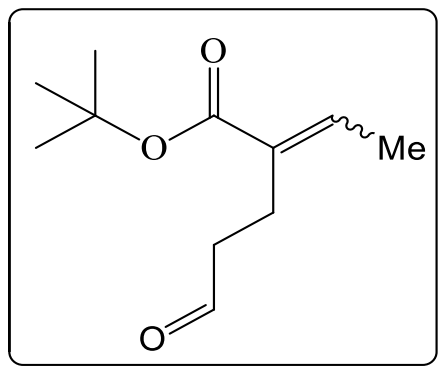

Característica: Óleo incolor

Rendimento: $57 \%$

Pureza: 99\%

Dados Espectroscópicos

RMN de ${ }^{1} \mathbf{H}$ (600 MHz, CDCl $)$ : (E) 1,48 (s, 9H); (Z) 1,51 (s, 9H); (E) 1,80 (d, J= 7,2 Hz, 2H); (Z) 1,94 (dt, $J=7,2 ; 1,0 \mathrm{~Hz}, 1 \mathrm{H}) ;(\boldsymbol{E} / \boldsymbol{Z}) 2,51$ a 2,62 (m, 2H) (Z) 6,00 (qt, $J=7,2 ; 1,0$ $\mathrm{Hz}, 1 \mathrm{H}) ;(\boldsymbol{E}) 6,81(\mathrm{q}, J=7,2 \mathrm{~Hz}, 1 \mathrm{H}) ;(\boldsymbol{Z}) 9,76(\mathrm{t}, J=1,6 \mathrm{~Hz}, 1 \mathrm{H}) ;(\boldsymbol{E})$ 9,78 (t, $J=1,5 \mathrm{~Hz}$, $1 \mathrm{H})$.

RMN de ${ }^{13}$ C (150 MHz, CDCl3): (E) 14,2; 19,3; 28,1; 43,1; 80,4; 132,7; 137,5; 166,5; 201,7.

(Z) 15,$6 ; 27,5 ; 28,2 ; 43,4 ; 80,8 ; 132,4 ; 136,6 ; 166,9 ; 201,8$.

IV (ATR, $\left.v_{\text {máx }} / \mathbf{c m}^{-1}\right):$ 2977, 2721, 1701, 1649, 1391, 1366, 1150, 850.

EM (70 eV) m/z: 198 (M-56), 57 (100).

2-(3-oxopropil)pent-2-enoato de terc-butila $4 \mathbf{i}(E)$ e $4 \mathbf{i}(Z)$

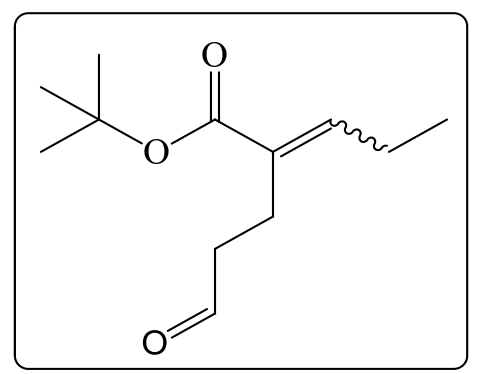

Característica: Óleo incolor

Rendimento: $57 \%$

Pureza: 99\%

\section{Dados Espectroscópicos}

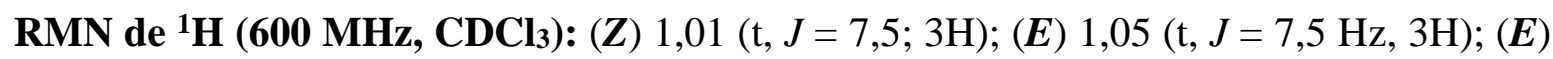
1,49 (s, 9H); (Z) 1,50 (s, 9H); (E) 2,19 (q, $J=7,5 \mathrm{~Hz}, 2 \mathrm{H}$ ); (Z) 2,40 (qt, $J=7,5 ; 0,83 \mathrm{~Hz}, 2 \mathrm{H}$ ) (E/Z) 2,56 (m, 2H) (Z) 5,86 (tt, $J=7,5 ; 0,83 \mathrm{~Hz}, 1 \mathrm{H}) ;(\boldsymbol{E}) 6,70(\mathrm{t}, J=7,5 \mathrm{~Hz}, 1 \mathrm{H}) ;(\boldsymbol{Z})$ 9,76 $(\mathrm{t}, J=1,6 \mathrm{~Hz}, 1 \mathrm{H}) ;(\boldsymbol{E}) 9,77(\mathrm{t}, J=1,4 \mathrm{~Hz}, 1 \mathrm{H})$.

RMN de ${ }^{13}$ C (150 MHz, CDCl3): (E) 13,3; 19,6; 21,9; 28, 1; 43,5; 80,5; 131,2; 144,4; 166,7; 201,8. (Z) 14,1; 22,6; 22,9; 28,2; 51,3; 80,9; 131,0; 143,6; 167,0; 201,9.

IV (ATR, $v_{\text {máx }} / \mathbf{c m}^{-1}$ ): 2974, 2720, 1702, 1643, 1393, 1367, 1143, 850.

EM (70 eV) m/z: 212 (M-56), 57 (100). 
2-(3-oxopropil)non-2-enoato de terc-butila $4 \mathbf{j}(E)$ e $4 \mathbf{j}(Z)$

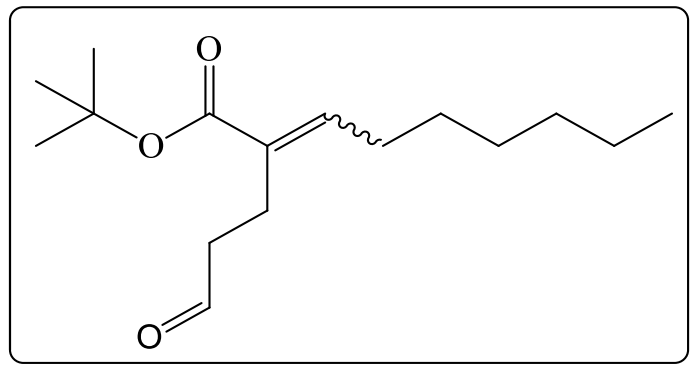

Característica: Óleo incolor

Rendimento: $56 \%$

Pureza: $98 \%$

\section{Dados Espectroscópicos}

RMN de ${ }^{1} \mathbf{H}(600$ MHz, CDCl $):(E / Z) ~ 0,89(\mathrm{~m}, 3 \mathrm{H})$; (E/Z) 1,33 (m, 8H); (E) 1,48 (s, 9H); (Z) $1,50(\mathrm{~s}, 9 \mathrm{H}) ;(\boldsymbol{E}) 2,16(\mathrm{q}, J=7,5 \mathrm{~Hz}, 2 \mathrm{H})$; (Z) 2,38 (q, $J=7,4 \mathrm{~Hz}, 2 \mathrm{H}) ;(\boldsymbol{E} / \boldsymbol{Z})$ 2,56 (m, 2H) (Z) 5,87 (t, $J=7,4,1 \mathrm{H})$; $(\boldsymbol{E}) 6,71(\mathrm{t}, J=7,5 \mathrm{~Hz}, 1 \mathrm{H})$; (Z) 9,76 (t, $J=1,6 \mathrm{~Hz}, 1 \mathrm{H})$; $(\boldsymbol{E})$ $9,78(\mathrm{t}, J=1,4 \mathrm{~Hz}, 1 \mathrm{H})$.

RMN de ${ }^{13} \mathbf{C}$ (150 MHz, CDCl3): (E) 14,0; 19,6; 22,5; 28,1; 28,6; 29, 1; 29,6; 31,6; 43,5; 80,4; 131,5; 143,2; 166,7; 201,8. (Z) 13,9; 27,6; 22,6; 28,2; 28,8; 29,0; 29,4; 31,7; 43,5; 80,8; 131,$4 ; 142,2 ; 167,0 ; 201,9$.

IV (ATR, $\left.v_{\text {máx }} / \mathbf{c m}^{-1}\right):$ 2958, 2927, 2716, 1703, 1643, 1392, 1368, 1169, 850.

EM (70 eV) m/z: 268 (M-56), 57 (100).

4-metil-2-(3-oxopropil)pent-2-enoato de terc-butila 4k $(E)$ e $4 \mathrm{k}(Z)$

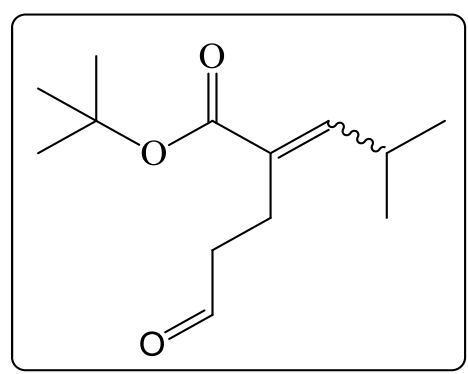

Característica: Óleo incolor

Rendimento: $65 \%$

Pureza: 99\%

\section{Dados Espectroscópicos}

RMN de ${ }^{1} \mathbf{H}\left(600 \mathrm{MHz}, \mathbf{C D C l}_{3}\right):(\boldsymbol{E})$ 1,02 (d, $\left.J=6,6 \mathrm{~Hz}, 6 \mathrm{H}\right)$; (Z) 0,98 (d, $\left.J=6,6 \mathrm{~Hz}, 6 \mathrm{H}\right)$; (E) 1,49 (s, 9H); (Z) 1,50 (s, 9H); (E/Z) 2,53 (m, 2H); (E/Z) 2,65 (m, 1H) (Z) 5,63 (d, J = 9,7; Hz, 1H); (E) 6,51 (d, $J=10 \mathrm{~Hz}, 1 \mathrm{H}) ;(\boldsymbol{Z}) 9,76(\mathrm{t}, J=1,6 \mathrm{~Hz}, 1 \mathrm{H}) ;(\boldsymbol{E})$ 9,78 (t, $J=1,3$ $\mathrm{Hz}, 1 \mathrm{H})$.

RMN de ${ }^{13}$ C (150 MHz, CDCl3): (E) 19,7; 22,3; 28, 1; 43,8; 80,5; 129,4; 149,4; 166,9; 201,7. (Z) 22,$7 ; 22,3 ; 27,9 ; 43,4 ; 80,9 ; 127,3 ; 148,3 ; 167,9 ; 201,8$.

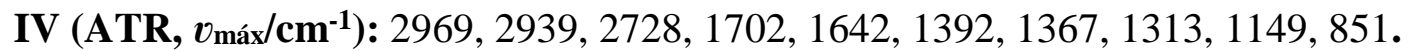

EM (70 eV) m/z: 226 (M-56), 57 (100). 


\section{7-BIBLIOGRAFIA}

1 Trost, B. M. Science. 1991, 254, 1471.

2 Trost, B. M. Science, 1983, 219, 245.

3 Rodrigues, T. C. A. F. Rearranjo de Claisen clássico em adutos de Morita-Baylis-Hillman. 2014. 128 f. Dissertação (Mestrado em Química) - Instituto de Química, Universidade de Brasília, Brasília.

4 Lenardão, E. J.; Freitag, R. A.; Dabdoub, M. J.; Batista, A. C. F.; Silveira, C. C. Quim. Nova. 2003, 26, 123.

5 Morita, K.; Suzuki, Z.; Hirose, H. Bull. Chem. Soc. Jpn. 1968, 41, 2815.

6 IUPAC. Compendium of Chemical Terminology, $2^{\mathrm{a}}$ ed. ("Livro de Ouro"). Compilado por A. D. McNaught; A. Wilkinson. Blackwell Scientific Publications, Oxford, 1997.

7 Baylis, A. B.; Hillman, M. E. D.; German Patent 2155113, 1972, Chem. Abstr. 1972, 77, 34174q.

8 Coelho, F.; Almeida, W. P. Química Nova, 2000, 23, 98.

9 Basavaiah, D.; Rao, P. D.; Hyma, R. S. Tetrahedron, 1996, 52, 8001.

10 Basavaiah, D.; Rao, A. J.; Satyanarayana, T. Chem. Rev. 2003, 103, 811.

11 Drewes, S. E.; Roos, G. H. P. Tetrahedron, 1988, 44, 4653.

12 Hoffmann, H. M. R.; Rabe, J. Angew Int Ed. Engl.1983, 22, 795.

13 Hill, J. S.; Isaacs, N. S. J. Phys. Org. Chem. 1990, 3, 285.

14 Aggarwal, V. K.; Fulford, S. Y.; Lloyd-Jones, G. C. Angew. Chem. Int. Ed. 2005, 44, 1706.

15 Price, K. E.; Broadwater, S. J., Walker, B. J.; McQuade, D. T. J. Org. Chem, 2005, 70, 3980.

16 Robiette, R.; Aggarwal, V. K.; Harvey, J. N. J. Am. Chem. Soc. 2007, 129, 15513.

17 Cantillo, D. Kappe, C. O. J. Org. Chem. 2010, 75, 8615.

18 Rodrigues, T. S.; Silva, V. H. C.; Lalli, P. M.; Oliveira, H. C. B.; Silva, W. A. Coelho, F.

Eberlin, M. N.; Neto, B. A. D. J. Org. Chem. 2014, 79, 5239.

19 Plata, R. E.; Singleton, D. A. J. Am. Chem. Soc. 2015, 137, 3811.

20 Galaverna, R.; Camilo, N. S.; Godoi, M. N.; Coelho, F.; Eberlin, M. N. J. Org. Chem. 2016, $81,1089$.

21 Sunith, K.; Balasubramanian, K. K.; Rajagopalan, K. Tetrahedron Lett. 1984, 25, 3125.

22 Solano, L. N.; Nelson, G. L.; Ronayne, C. T.; Lueth, E. A.; Foxley, M. A.; Jonnalagadda, S. K.; Gurrapu, S.; Mereddy, V. R. Bioorganic \& Medicinal Chemistry Lett. 2015, 25, 5777.

23 Claisen, L. Chem. Ber. 1912, 45, 3157.

24 (a) Wiest, O.; Black, K. A.; Houk, K. N. J. Am. Chem. Soc. 1994, 116, 10336. (b) Yoo, H. Y.; Houk, K. N. J. Am. Chem. Soc. 1994, 116, 12047. 
25 Iwakura, I.; Kaneko, Y.; Hayashi, S.; Yabushita, A.; Kobayashi, T. Molecules, 2013, 18, 1995.

26 Ziegler, F. E.; Acc. Chem. Res. 1977, 10, 227.

27 Hiesermann, M.; Nubbemeyer, U. The Claisen Rearrangment: Methods and Applications. Wiley: Weinheim, 2007, p. 53-54.

28 Horne, A. D.; Fugmann, B.; Yakushijin, K.; Buchi, G. J. Org. Chem. 1993, 58, 62.

29 (a) Castro, A. M. M. Chem. Rev. 2004, 104, 2939. (b) Rehbein, J.; Hiersemann M. Synthesis, 2013, 45, 1121.

30 (a) Schuler, F. W.; Murphy, G. W. J. Am. Chem. Soc. 1950, 72, 3155. (b) Burrows, C. J.; Carpenter, B. K. J. Am. Chem. Soc. 1981, 103, 6983. (c) Yoo, H. Y.; Houk, K. N. J. Am. Chem. Soc. 1997, 119, 2877. (d) Aviyente, V.; Yoo, H. Y.; Houk, K. N. J. Am. Chem. Soc. 1997, 119, 6121.

31 Perrin, C. L.; Faulkner, D. J. Tetrahedron Lett. 1969, 32, 2783.

32 Faulkner, D. J.; Petersen, M. R. Tetrahedron Lett. 1969, 38, 3243.

33 Wick, A. E.; Felix, D.; Steen, K.; Eschenmoser, A. Helv. Chim. Acta, 1964, 47, 2425.

34 Johnson, W. S.; Werthemann, L.; Bartlett, W. R.; Brocksom, T. J.; Li, T.-T.; Faulkner, D. J.; Petersen, M. R. J. Am. Chem. Soc. 1970, 92, 741.

35 Drewes, S. E.; Emslie, N. D.; Karodia, N.; Loizou, G. Synthetic Commun, 1990, 20, 1437.

36 Basavaiah, D.; Pandiaraju, S. Tetrahedron Lett. 1995, 36, 757.

37 Basavaiah, D.; Pandiaraju, S.; Krishnamacharyulu, M. Synlett. 1996, 747.

38 Basavaiah, D.; Lenin, D. V.; Devendar, B. Tetrahedron Lett. 2009, 50, 3538.

39 Basavaiah, D.; Reddy, R. J.; Lenin, D. V. Helv. Chim. Acta. 2010, 93, 1180.

40 Basavaiah, D.; Reddy, K. R. Tetrahedron, 2010, 66, 1215.

41 (a) Das, B.; Majhi, A.; Banerjee, J. Tetrahedron Lett. 2006, 47, 7619. (b) Das, B.; Majhi, A.; Reddy, K. R.; Venkateswarly, K. J. Mol. Cat. 2007, 263, 273.

42 Chapuis, C.; Buchi, G. H.; Wuest, H. Helv. Chim. Acta. 2005, 88, 3069.

43 Kim, J. M.; Kim, S. H.; Kim, J. N. Bull. Korean Chem. Soc. 2007, 28, 2093.

44 Junior, C. G. L.; Silva, F. P. L.; Oliveira, R. G.; Subrinho, F. L.; Andrade, N. G.; Vasconcellos, M. L. A. A. J. Braz. Chem. Soc. 2011, 22, 2220.

45 Coelho, F.; Almeida, W. P.; Veronese, D.; Mateus, C. R.; Lopes, E. C. S.; Rossi, R. C.; Silveira, G. P. C.; Pavam, C. H. Tetrahedron, 2002, 58, 7437.

46 Srikrishna, A.; Yelamaggad, C. V.; Kumar, P. P. J. Chem. Soc., Perkin Trans. 1 1999, 2877.

47 Wei, X.; Lorenz, J. C.; Kapadia, S.; Saha, A.; Haddad, N.; Busacca, C. A.; Senanayake, C. H. J. Org. Chem. 2007, 72, 4250. 
ANEXOS 


\section{2-(hidroxi(fenil)metil) acrilato de terc-butila (3a)}
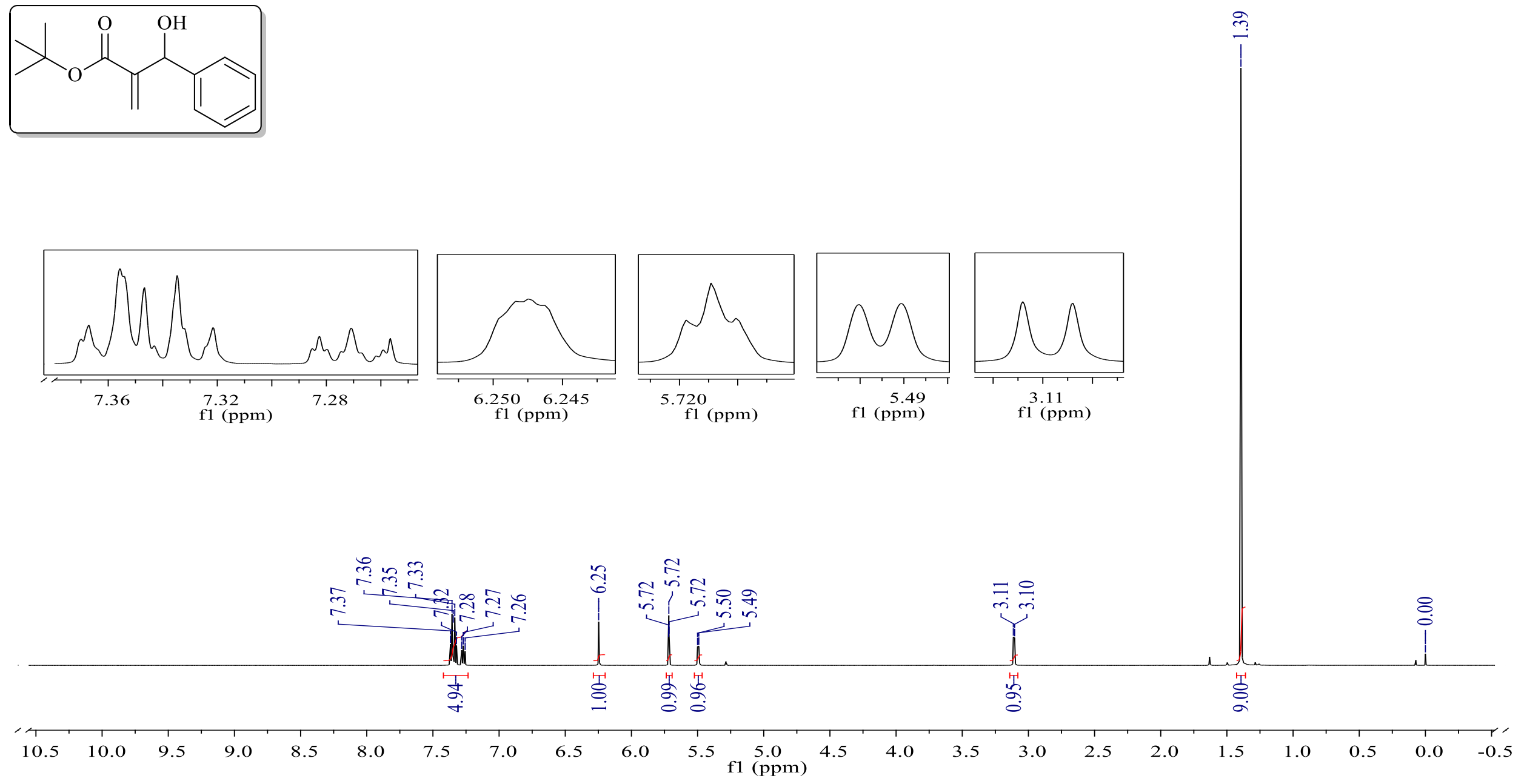

Espectro de RMN de ${ }^{1} \mathrm{H}\left(600 \mathrm{MHz}, \mathrm{CDCl}_{3}\right)$ - AMBH-3a 

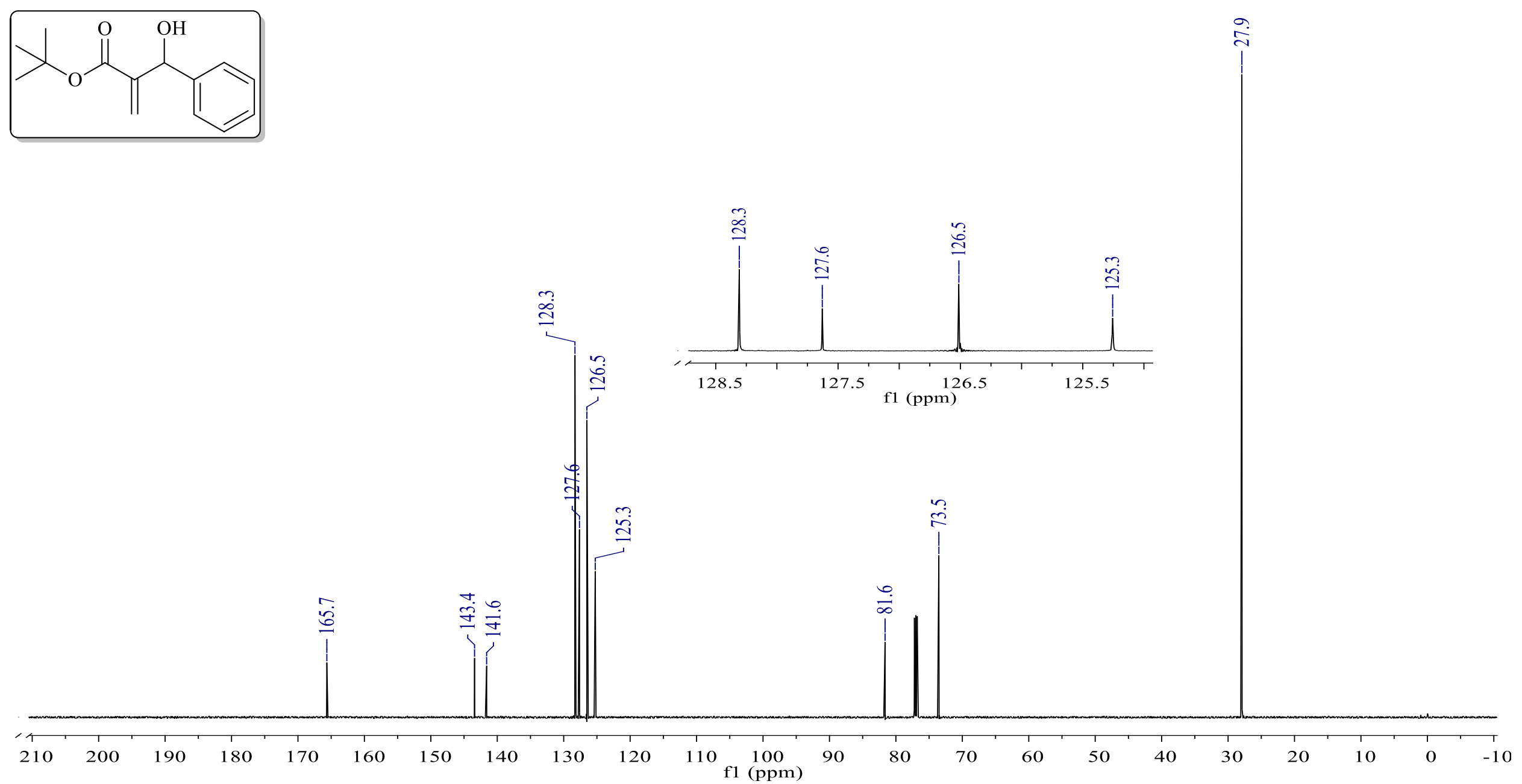

Espectro de RMN de ${ }^{13} \mathrm{C}$ (150 MHz, $\left.\mathrm{CDCl}_{3}\right)$ - AMBH-3a 


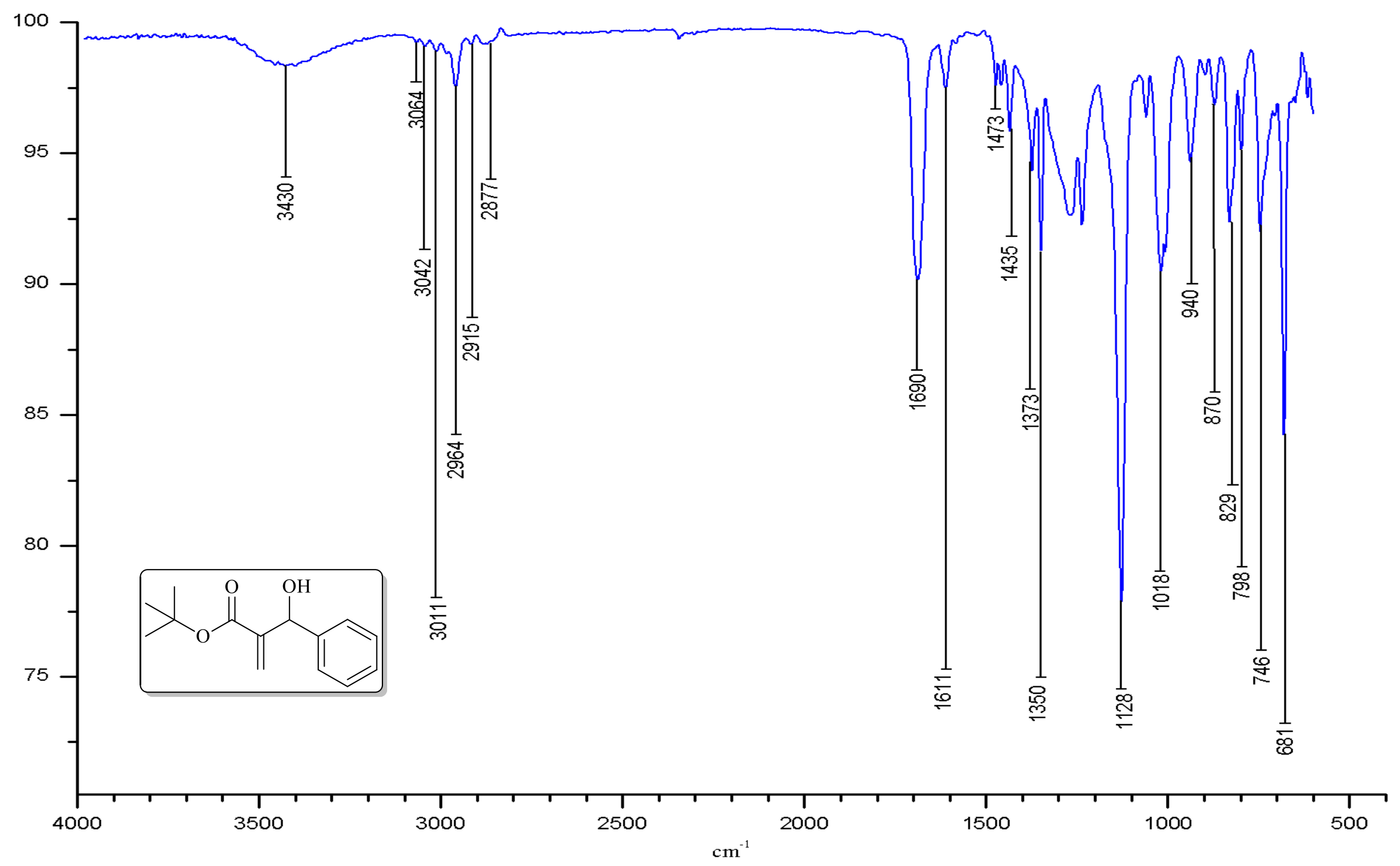

Espectro de infravermelho (ATR) - AMBH-3a 

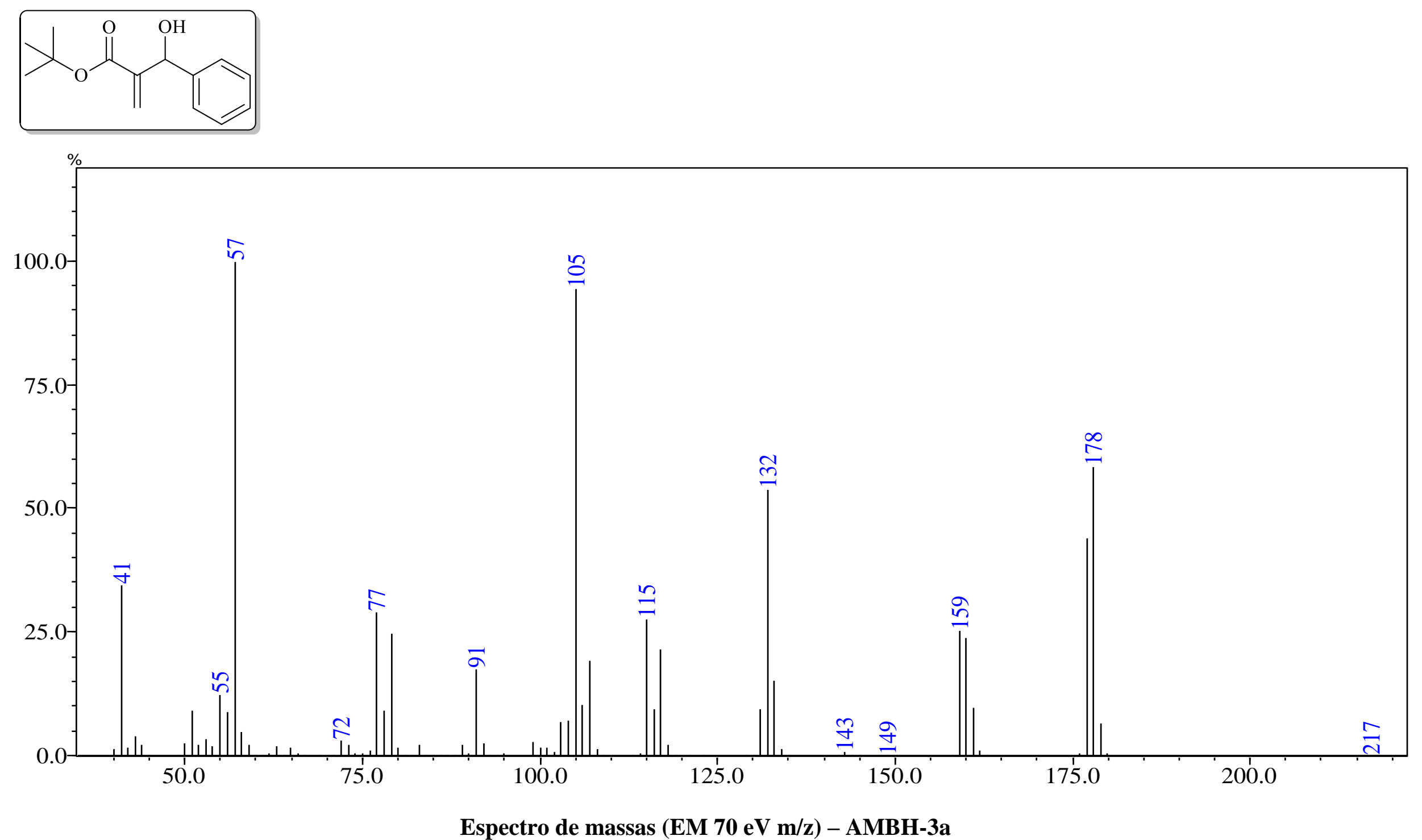
2-((4-bromofenil(hidroxi)metil) acrilato de terc-butila (3b)
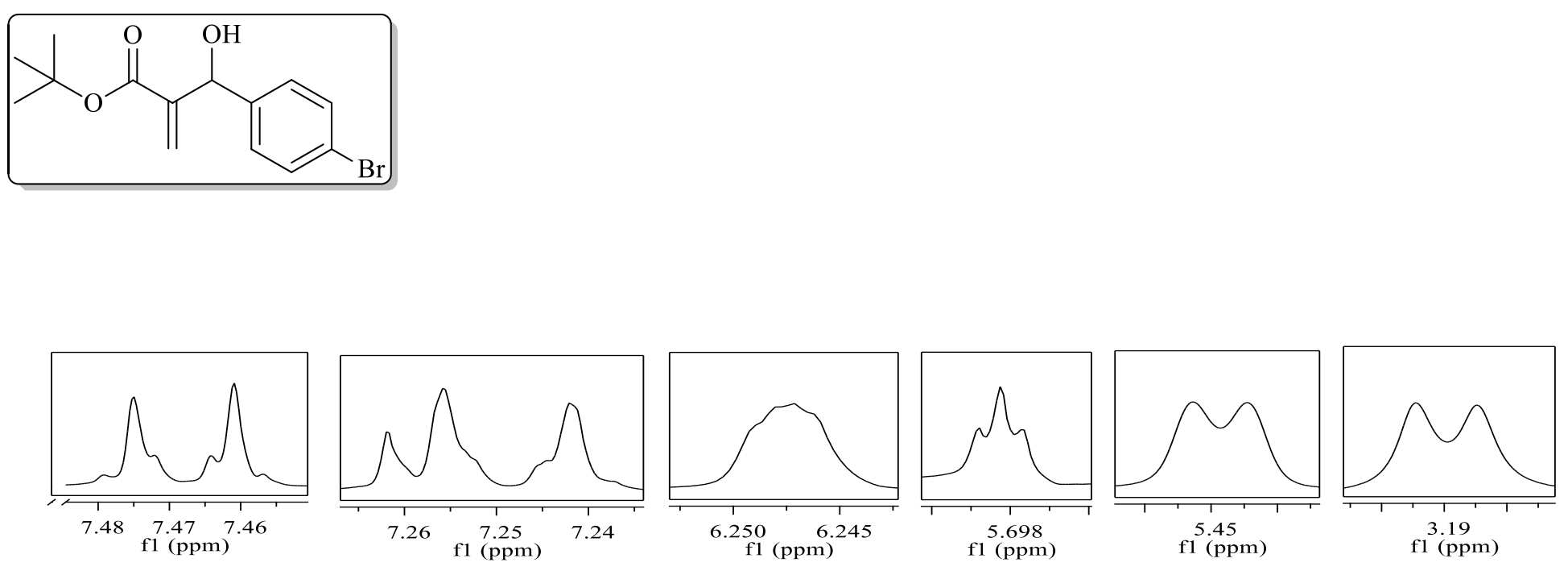

f1 (ppm)

f1 (ppm)

f1 $\begin{gathered}3.19 \\ \text { ppm }\end{gathered}$

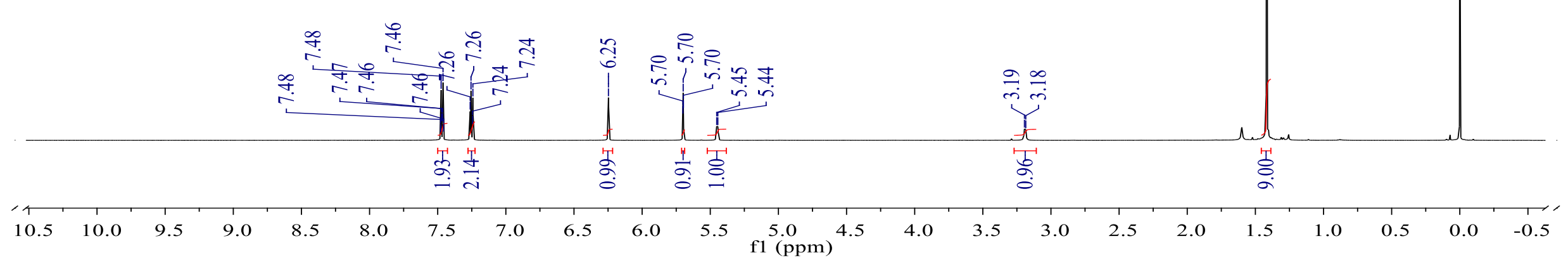

Espectro de RMN de ${ }^{1} \mathrm{H}\left(600 \mathrm{MHz}, \mathrm{CDCl}_{3}\right)-\mathrm{AMBH}-3 \mathrm{~b}$ 

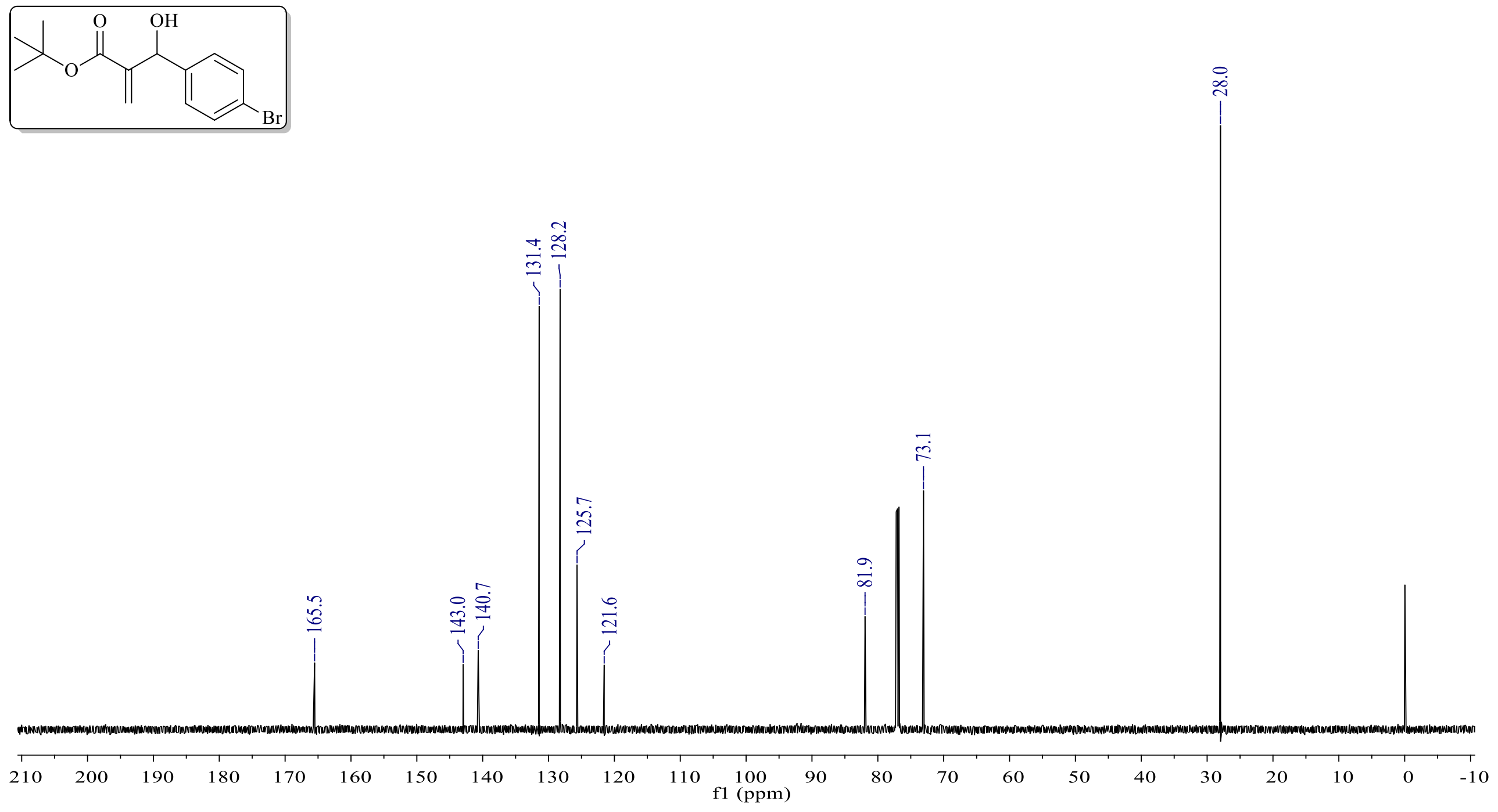

Espectro de RMN de ${ }^{13} \mathrm{C}$ (150 MHz, CDCl $)$ - AMBH-3b 


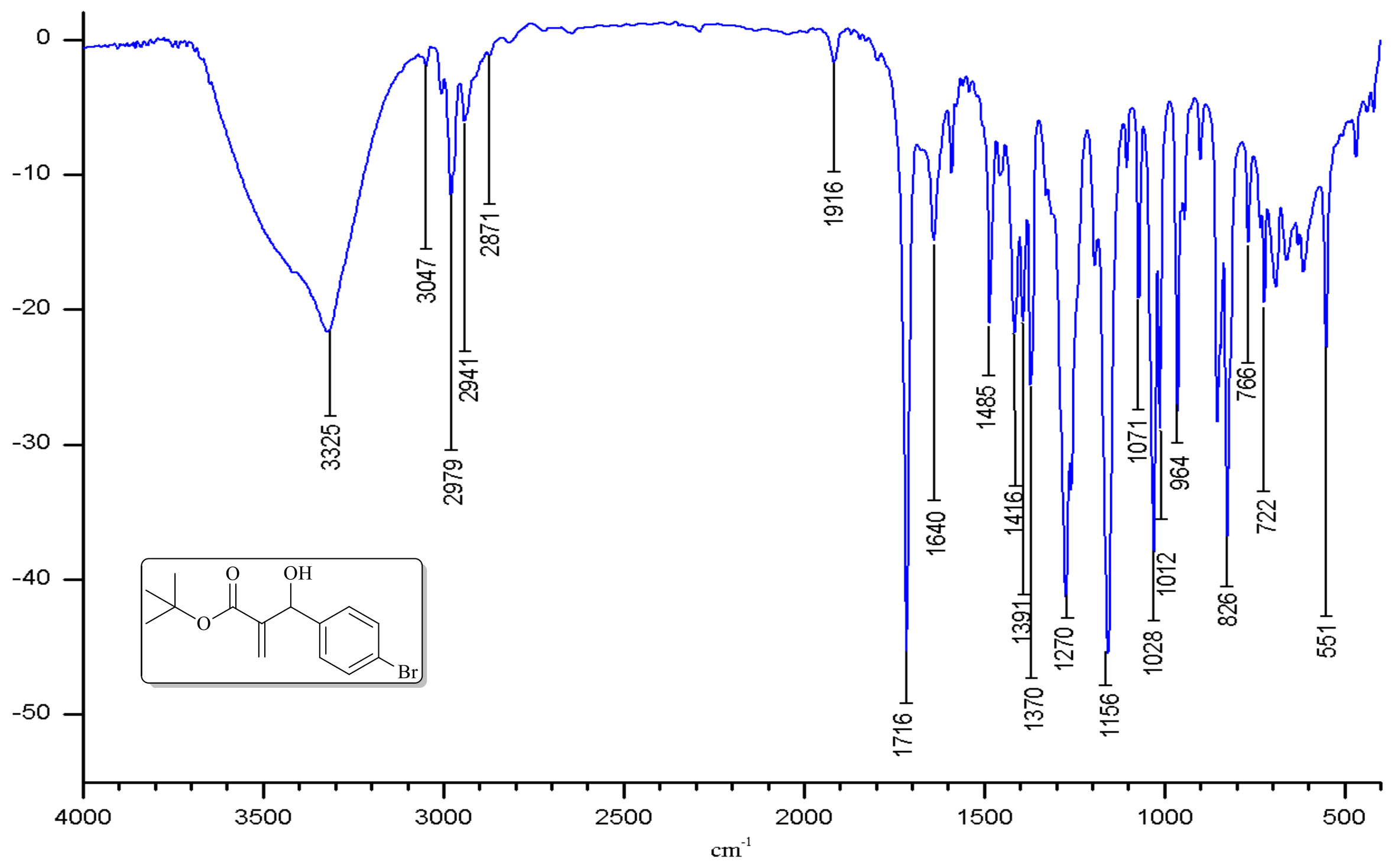

Espectro de infravermelho (KBr) - AMBH-3b 


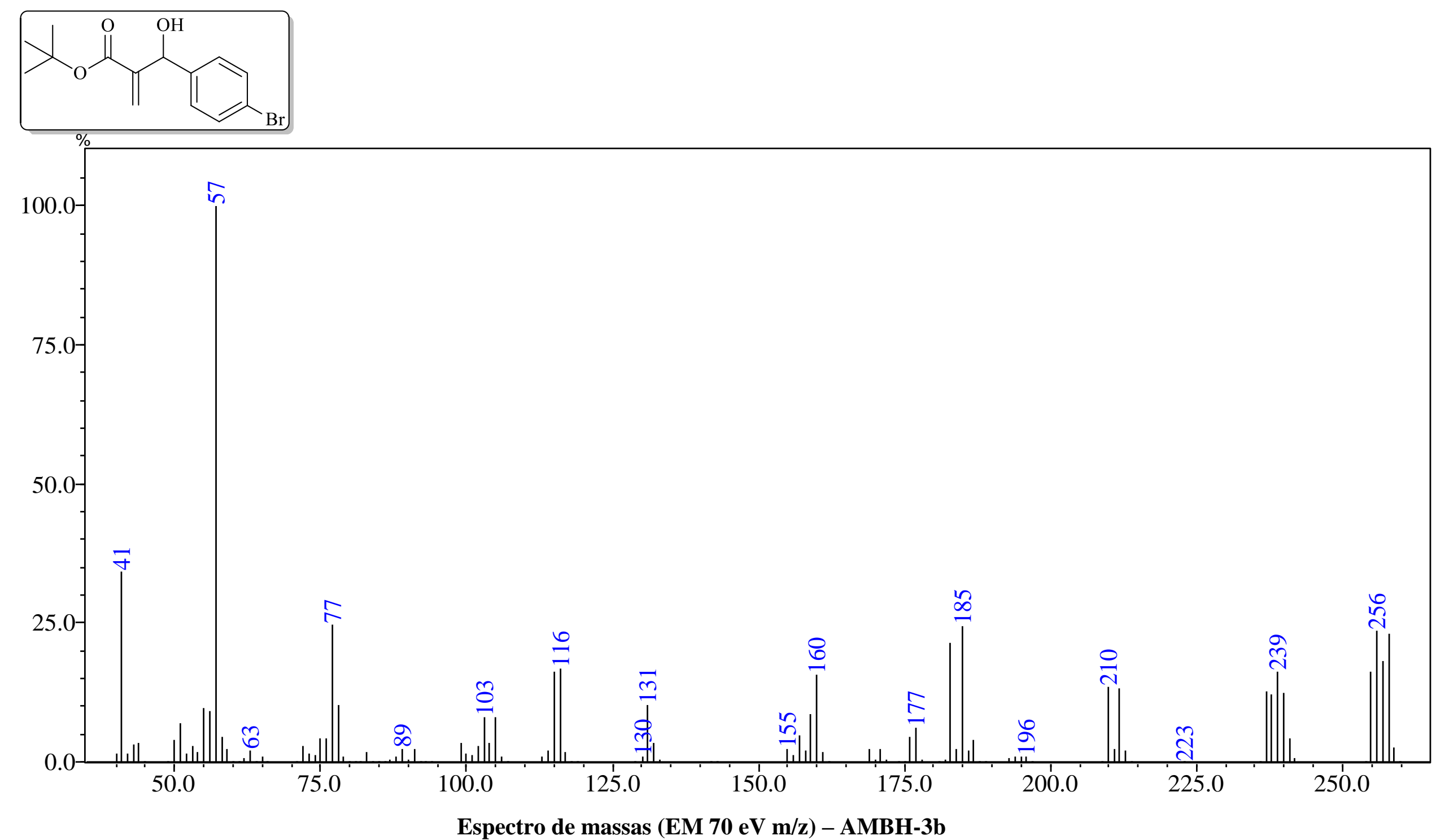


2-((4-clorofenil(hidroxi)metil) acrilato de terc-butila (3c)
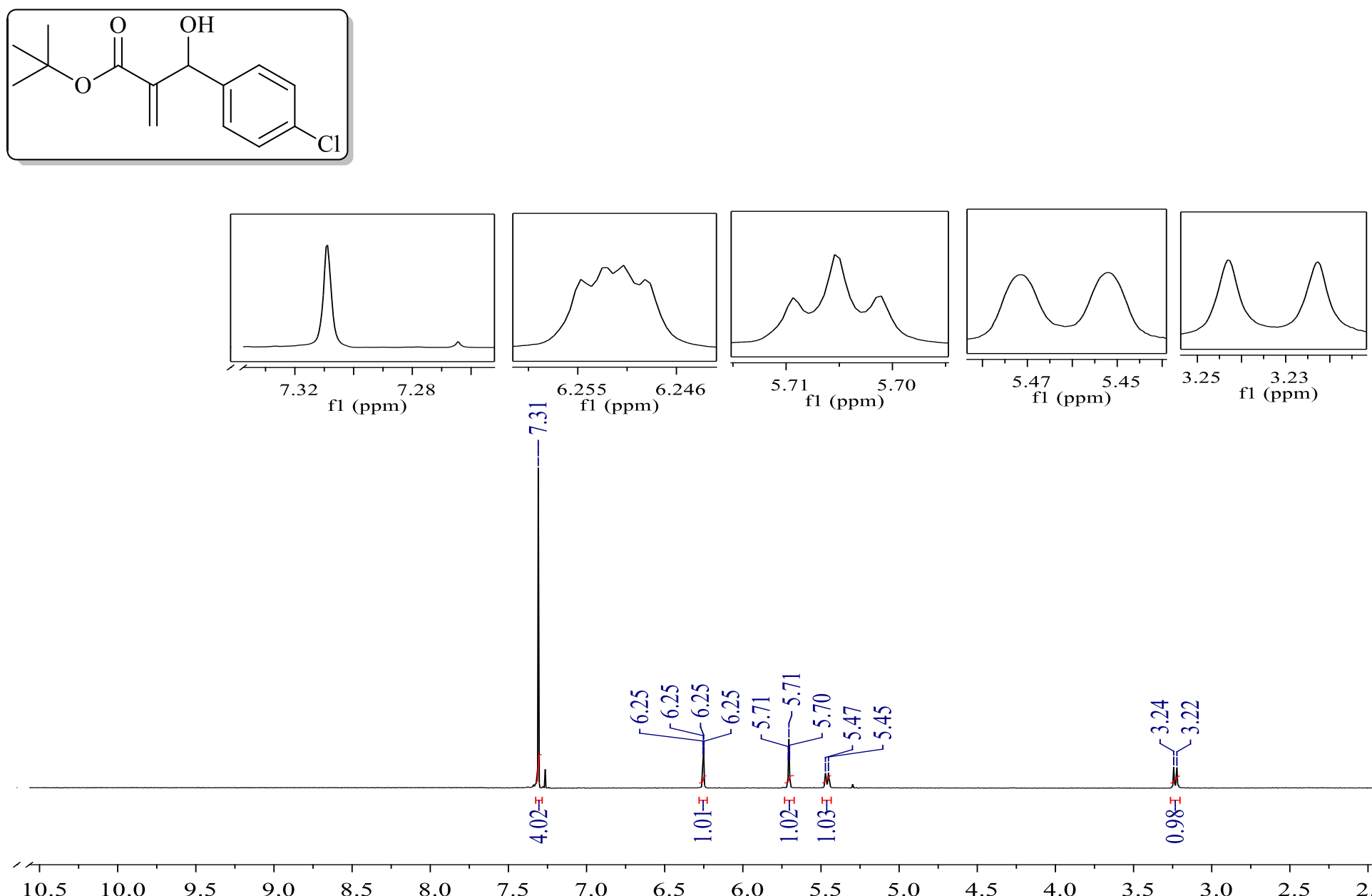

f1 (ppm)

$1(\mathrm{ppm})$

10.510 .0
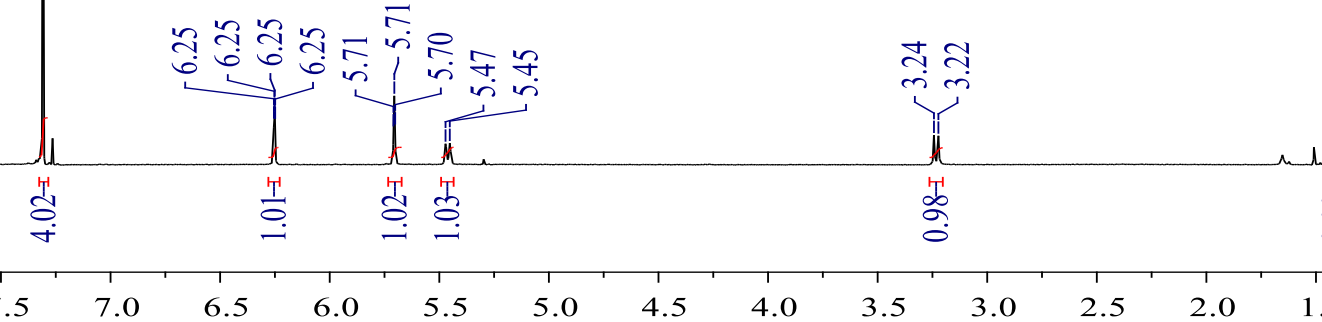

$1(\mathrm{ppm})$

Espectro de RMN de ${ }^{1} \mathbf{H}(300$ MHz, CDCl3) - AMBH-3c 

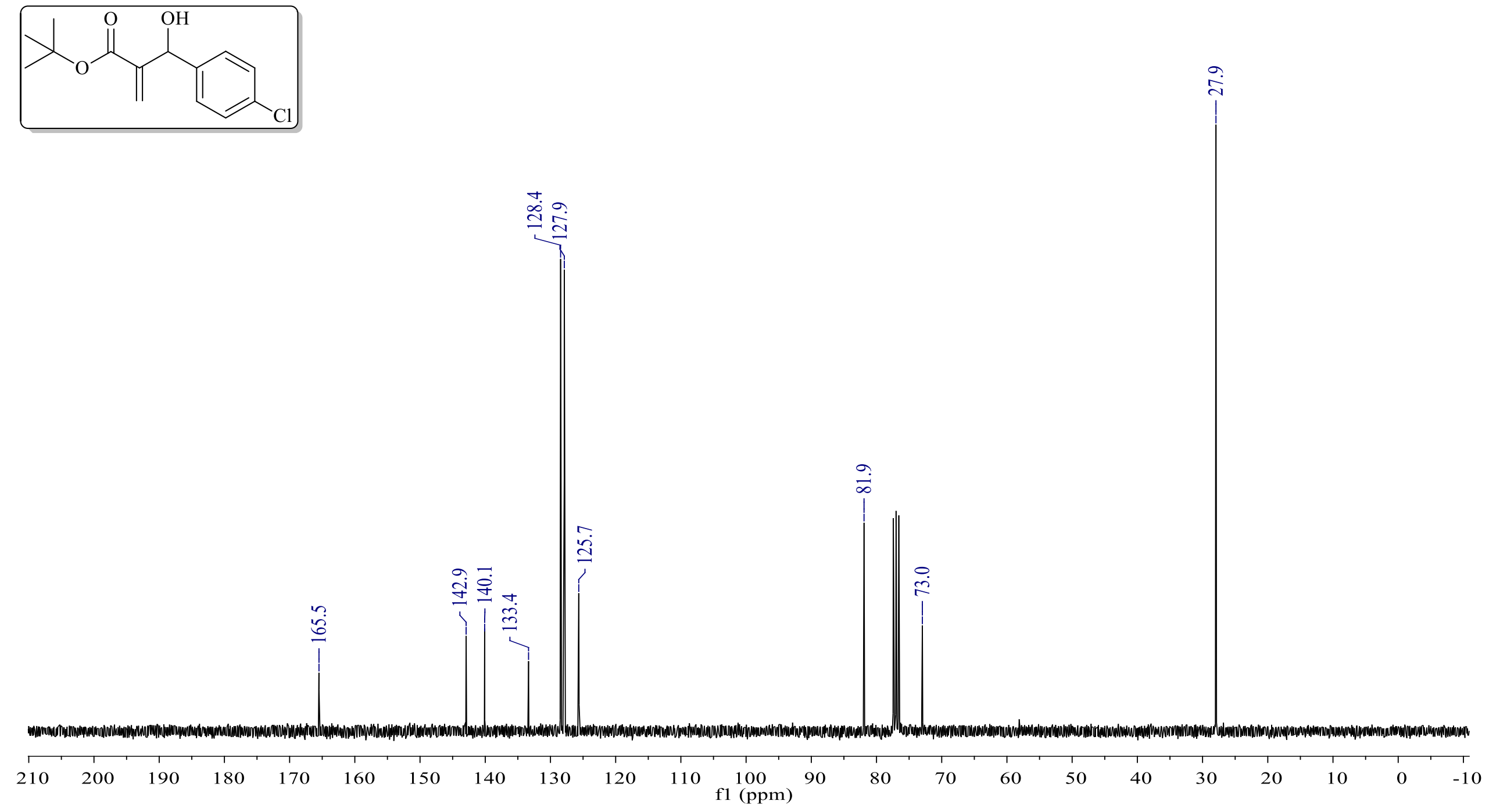

Espectro de RMN de ${ }^{13} \mathrm{C}$ (75 MHz, $\left.\mathrm{CDCl}_{3}\right)$ - AMBH-3c 


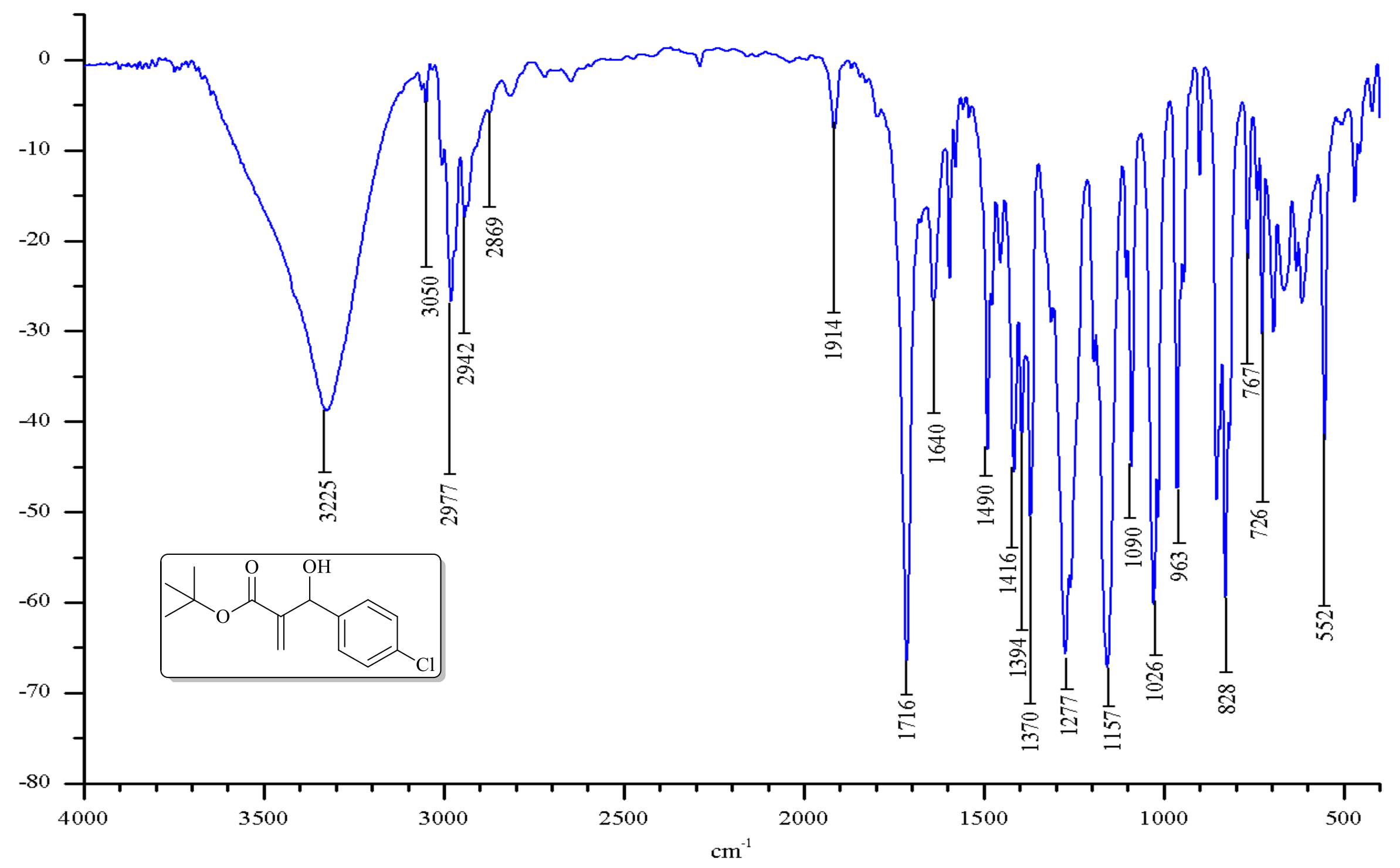

Espectro de infravermelho (KBr) - AMBH-3c 


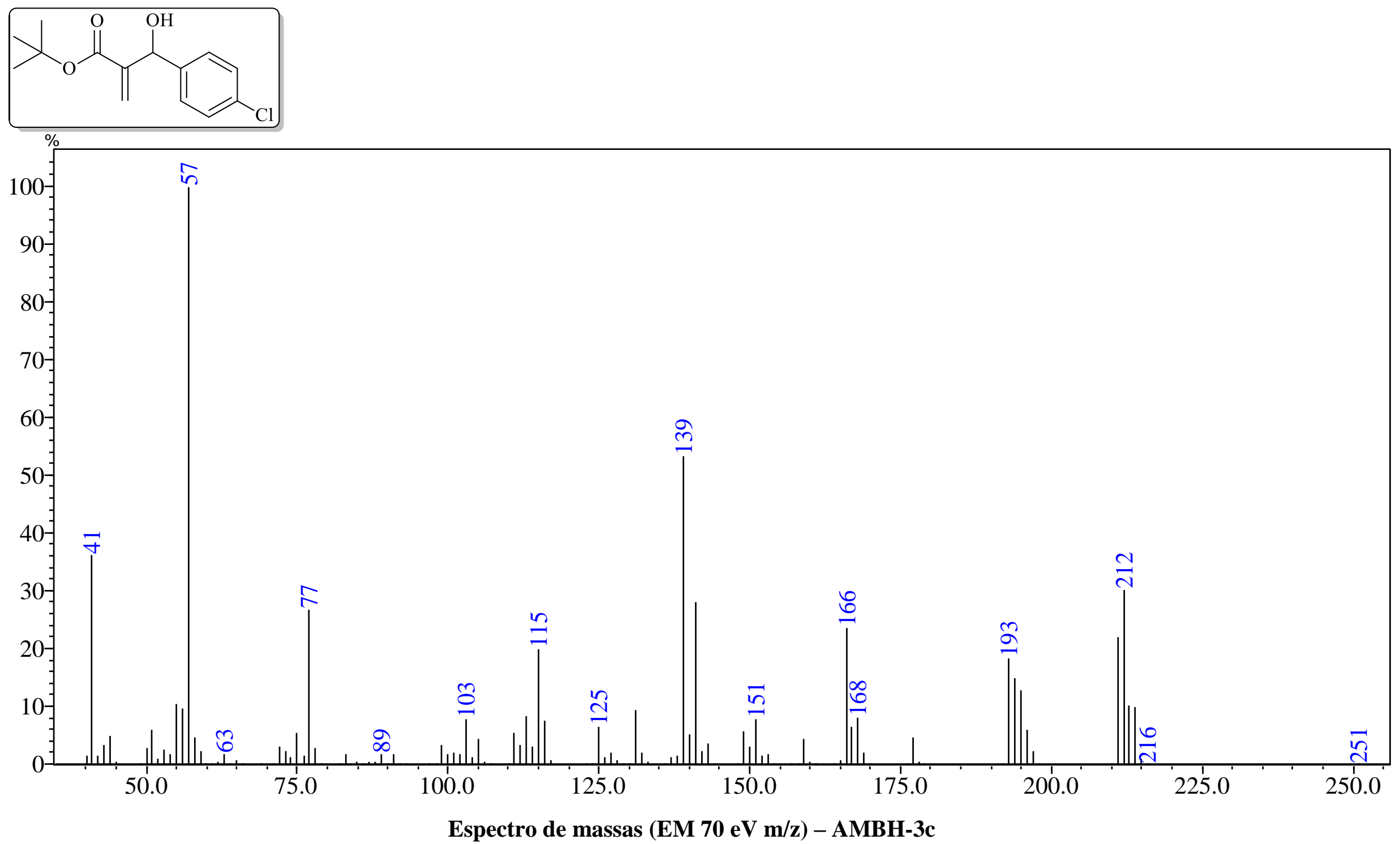

100 
2-(hidroxi)(3-nitrofenil)metil) acrilato de terc-butila (3d)
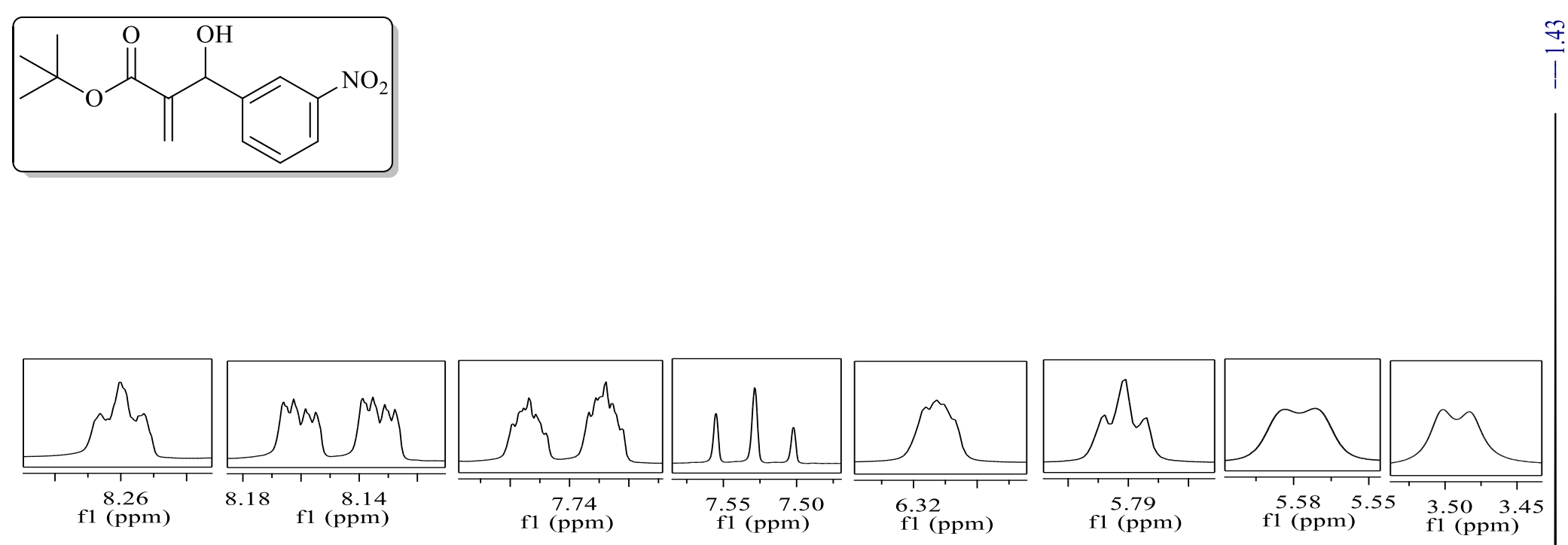

$1(\mathrm{ppm})$

$1(\mathrm{ppm})$

f1 $(\mathrm{ppm})$

f1 (ppm)

.i (ppm)

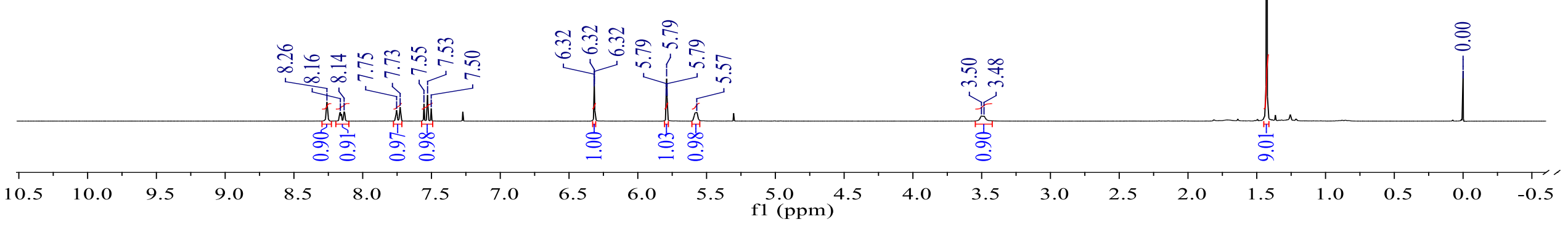

Espectro de RMN de ${ }^{1} \mathbf{H}(300 \mathrm{MHz}, \mathrm{CDCl})$ - AMBH-3d 

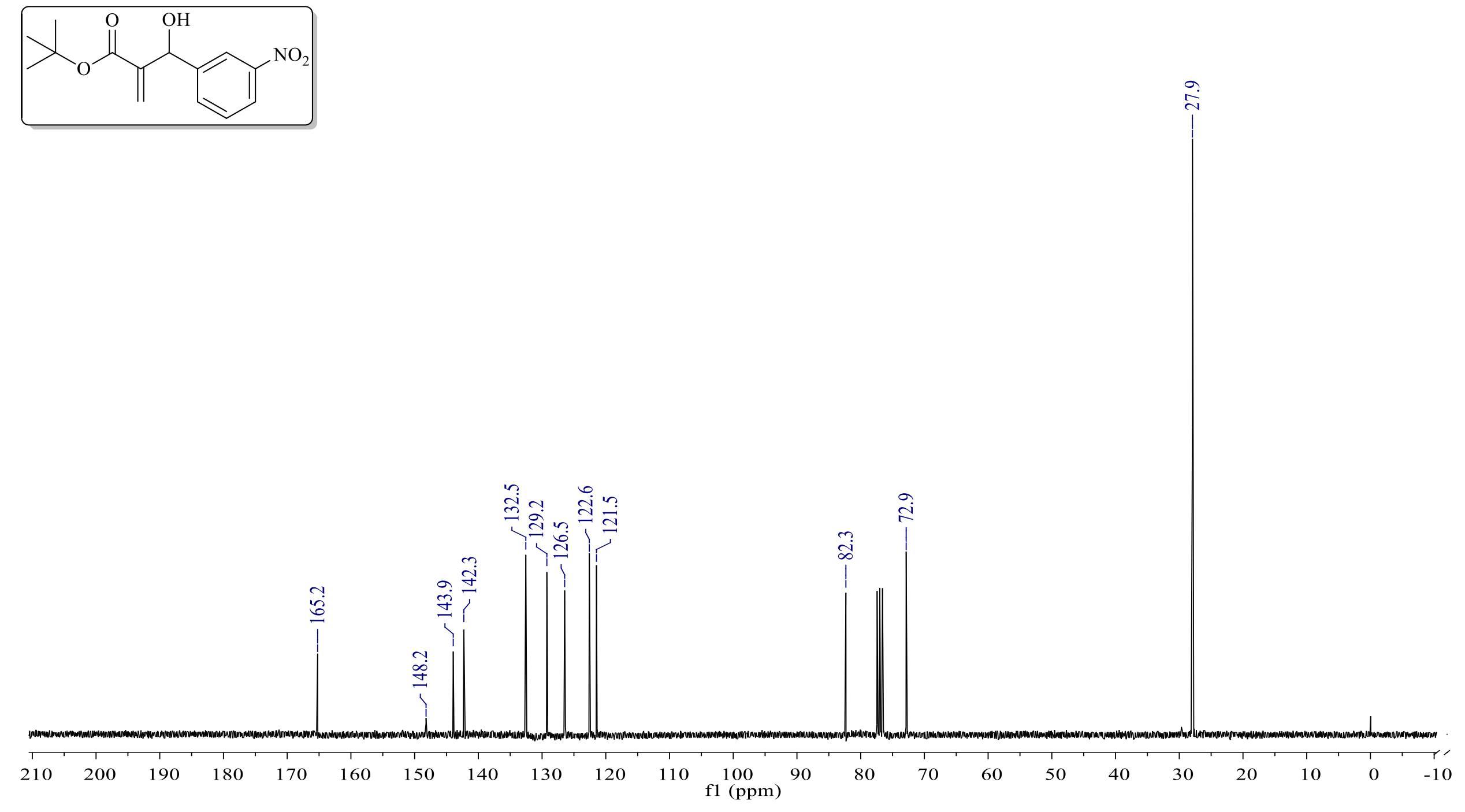

Espectro de RMN de ${ }^{13} \mathrm{C}$ (75 MHz, CDCl3) - AMBH-3d 


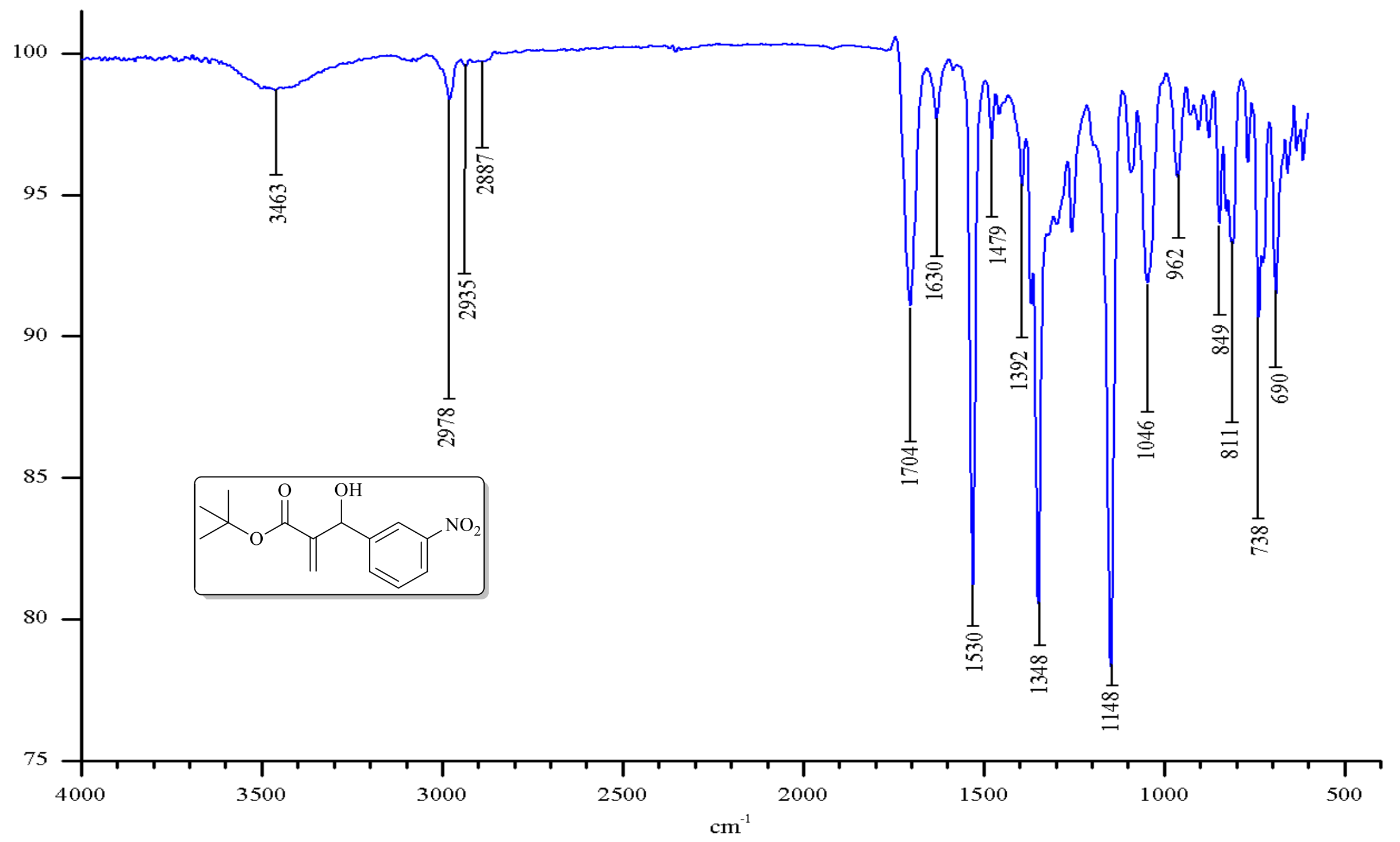

Espectro de infravermelho (ATR) - AMBH-3d 


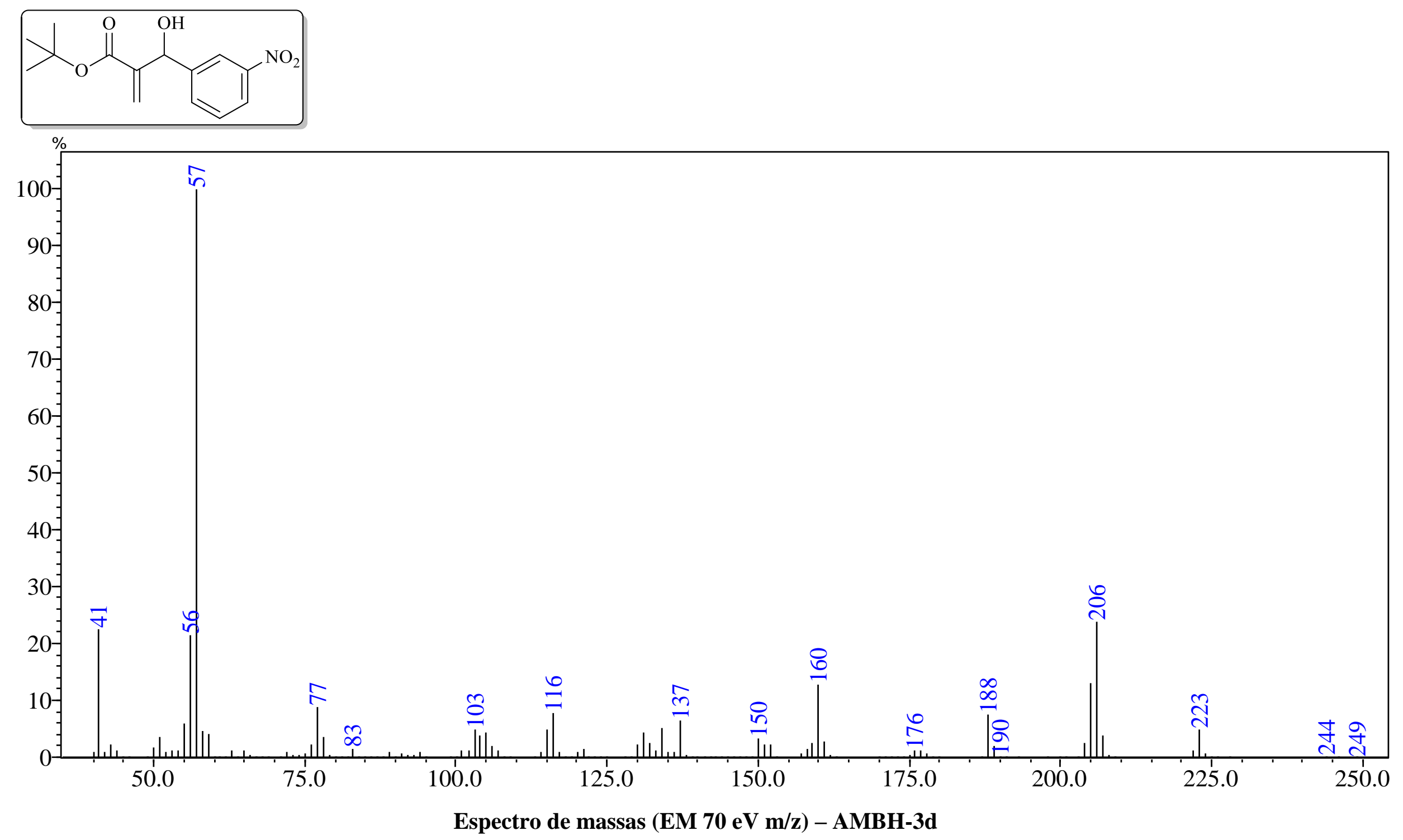


2-(hidroxi)(4-nitrofenil)metil) acrilato de terc-butila (3e)
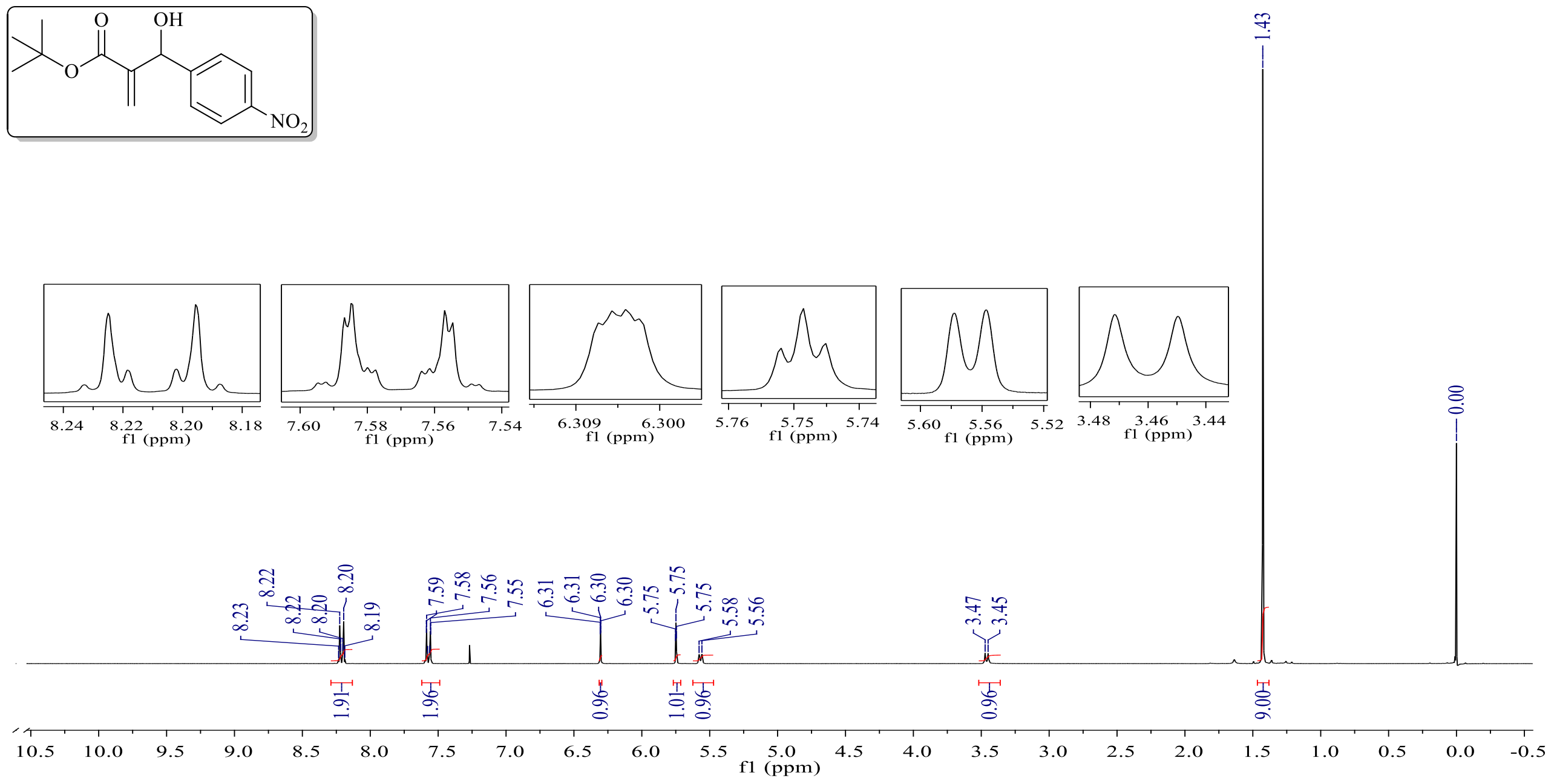

Espectro de RMN de ${ }^{1} \mathrm{H}\left(300 \mathrm{MHz}, \mathrm{CDCl}_{3}\right)$ - AMBH-3e 

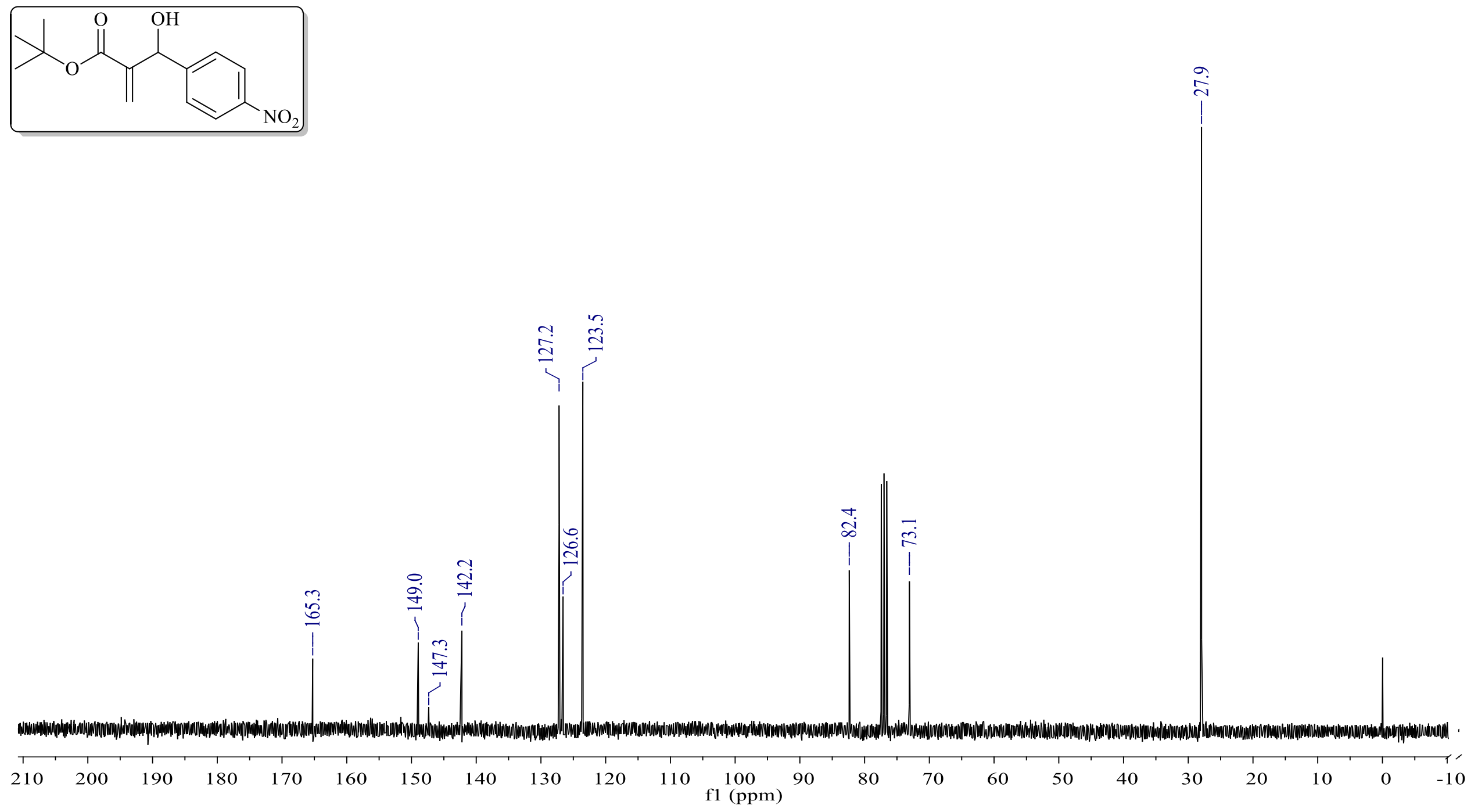

Espectro de RMN de ${ }^{13} \mathrm{C}$ (75 MHz, $\left.\mathrm{CDCl}_{3}\right)$ - AMBH-3e 


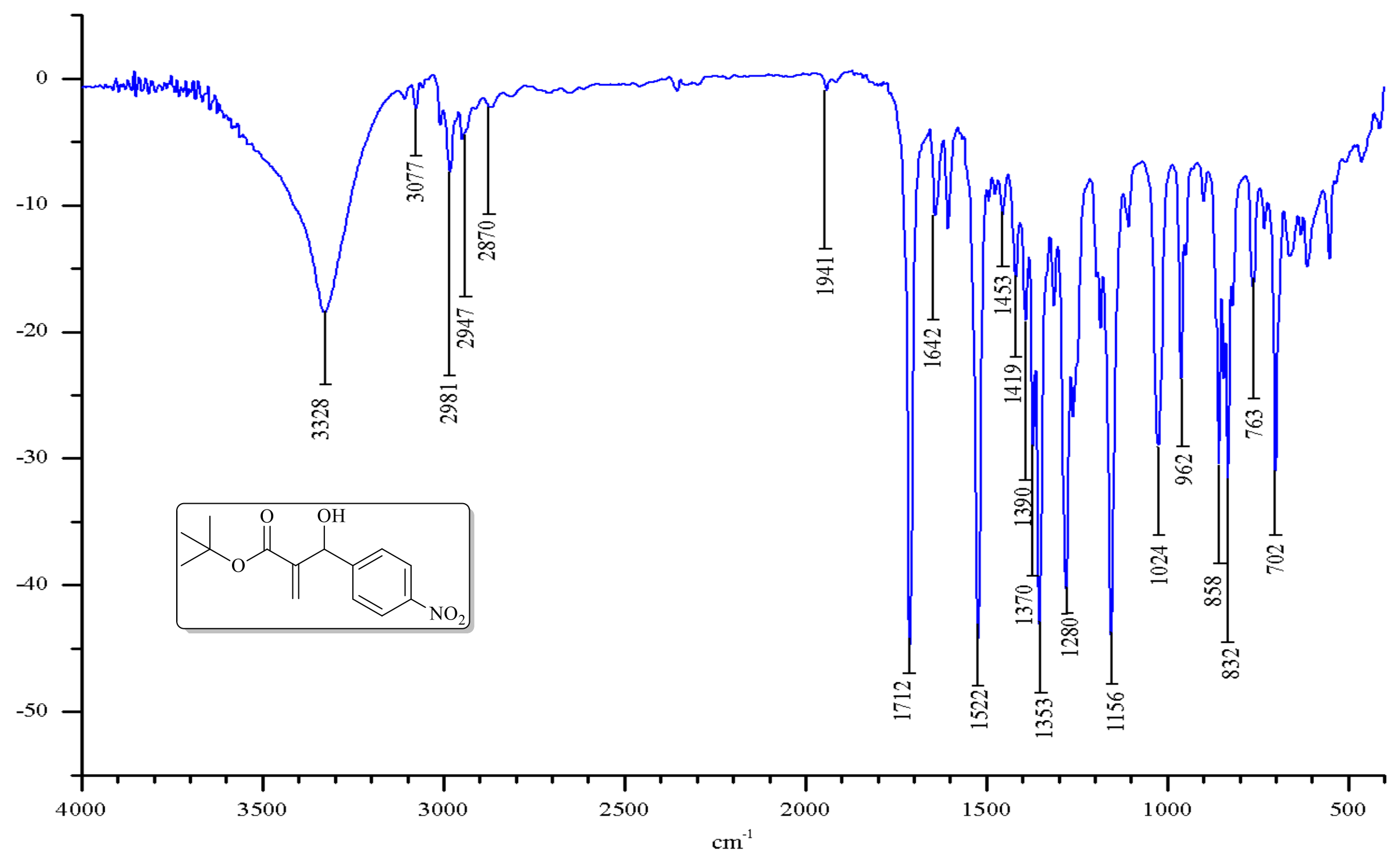

Espectro de infravermelho (KBr) - AMBH-3e 


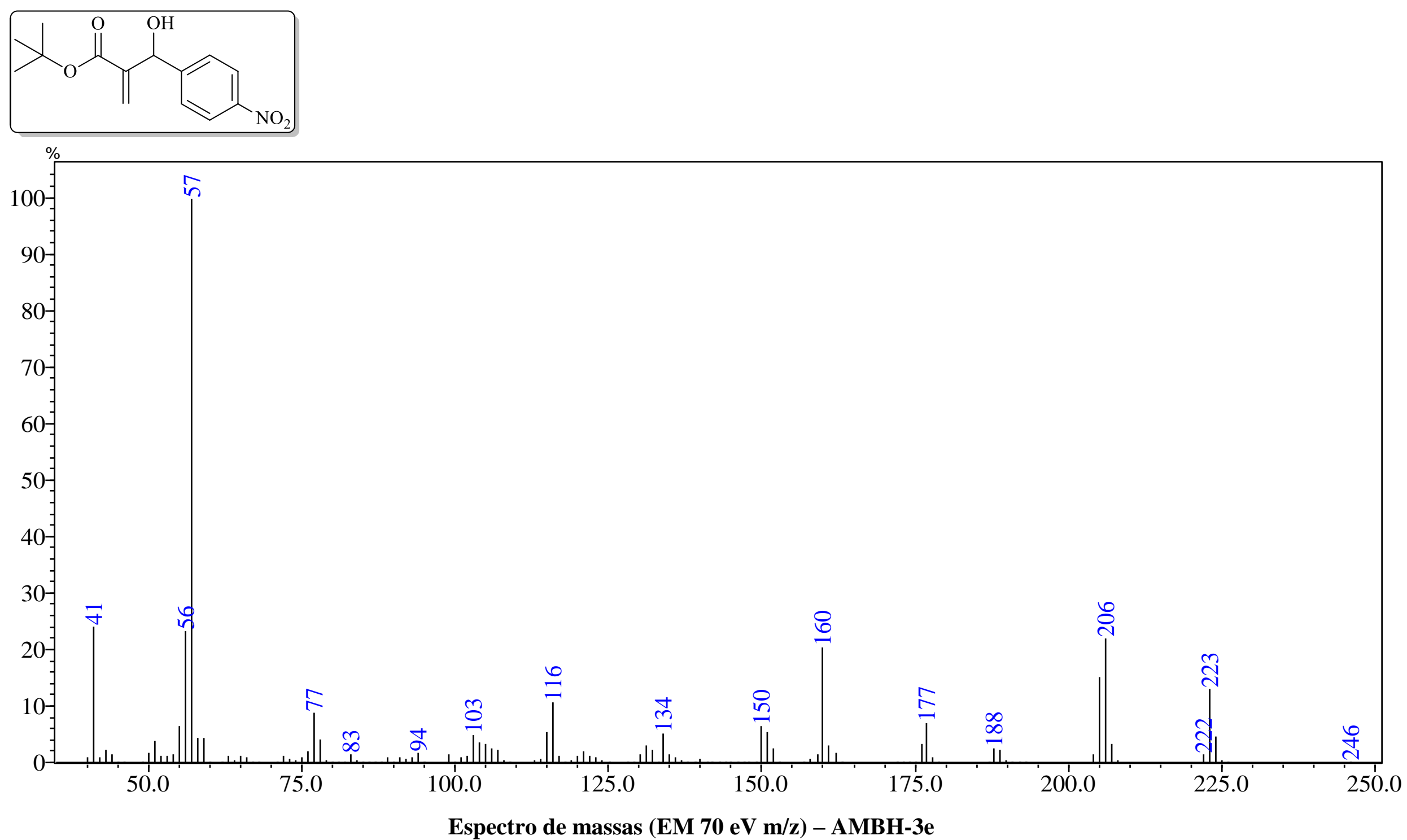


2-((benzo[d][1,3]dioxol-5-il)(hidróxi)metil)acrilato de terc-butila (3f)
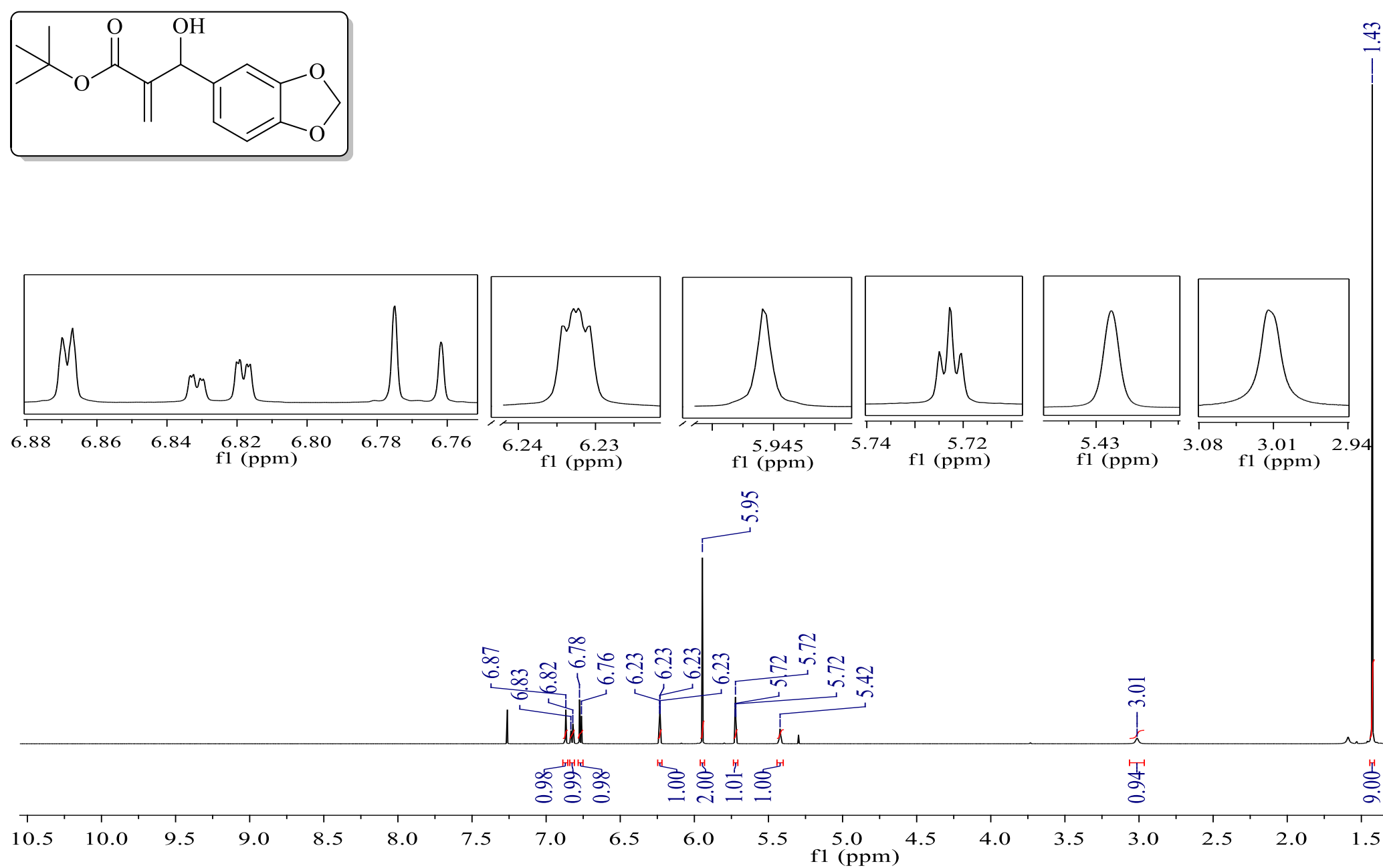

Espectro de RMN de ${ }^{1} \mathrm{H}\left(600 \mathrm{MHz}, \mathrm{CDCl}_{3}\right)-\mathrm{AMBH}-3 \mathrm{f}$ 

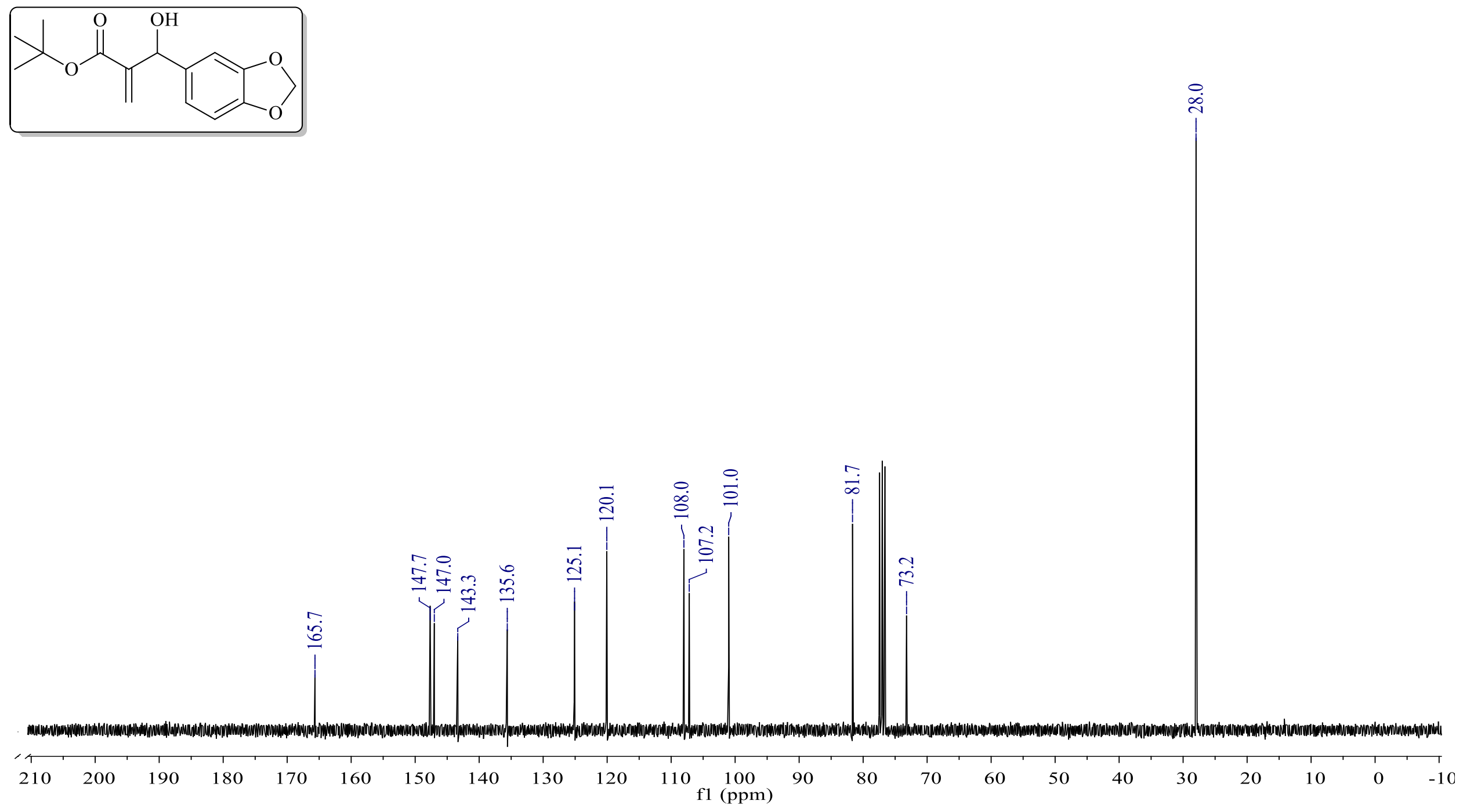

Espectro de RMN de ${ }^{13} \mathrm{C}$ (75 MHz, CDCl$)$ - AMBH-3f 


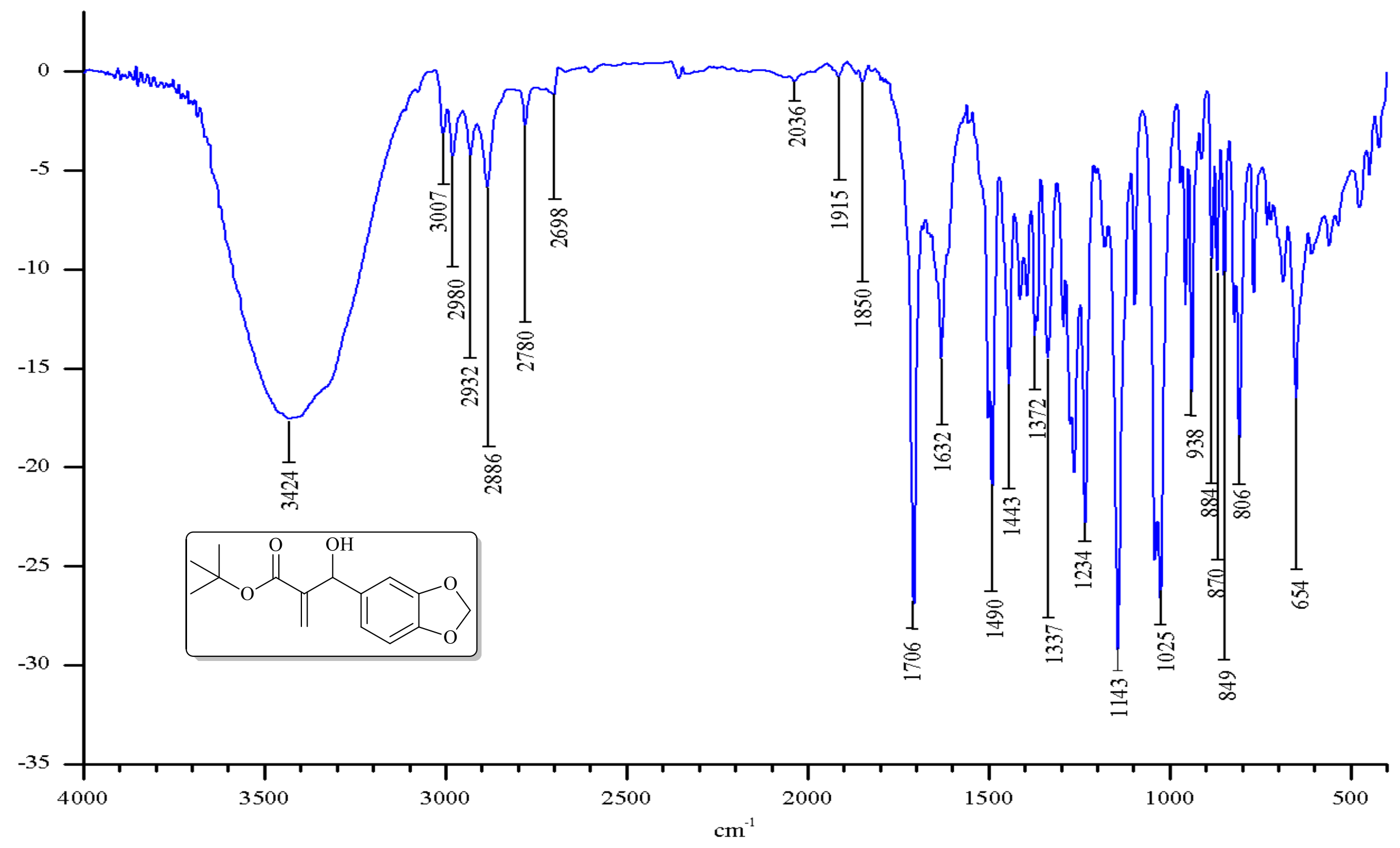

Espectro de infravermelho (KBr) - AMBH-3f 


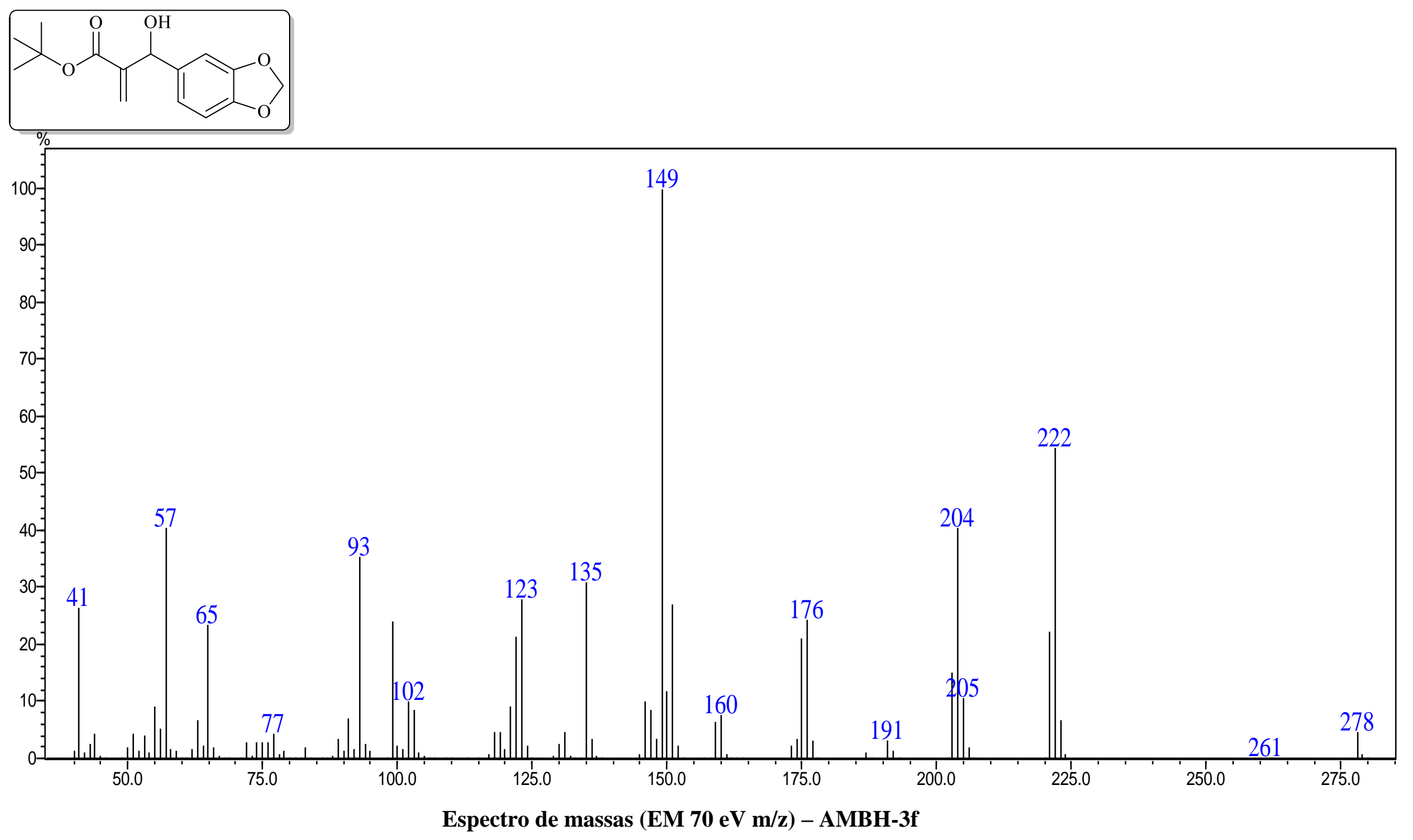




\section{2-((3,4-dimetoxifenil)(hidróxi)metil) acrilato de terc-butila (3g)}
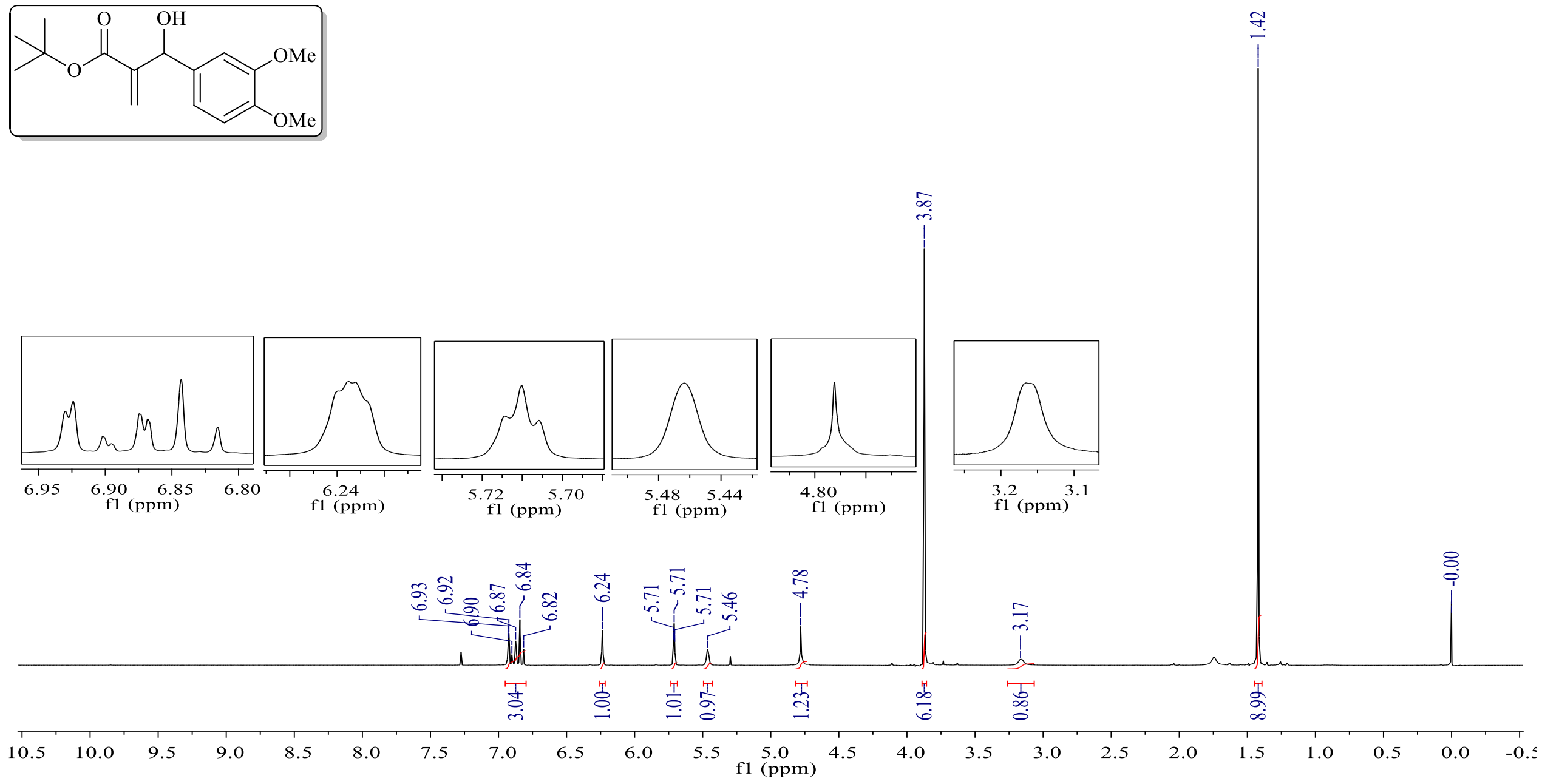

Espectro de RMN de ${ }^{1} \mathrm{H}\left(300 \mathrm{MHz}, \mathrm{CDCl}_{3}\right)$ - AMBH-3g 

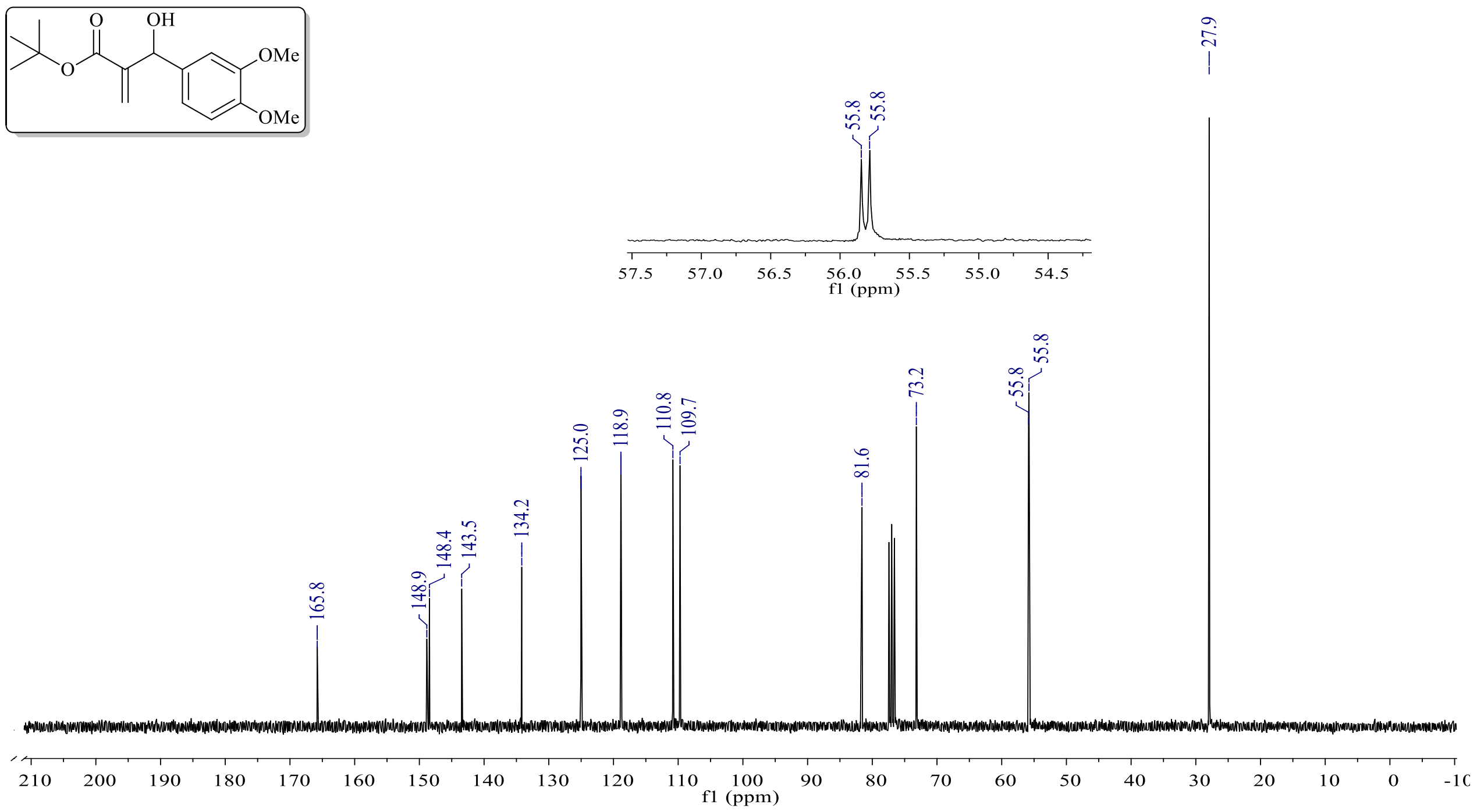

Espectro de RMN de ${ }^{13} \mathrm{C}$ (75 MHz, CDCl 3$)-\mathrm{AMBH}-3 \mathrm{~g}$ 


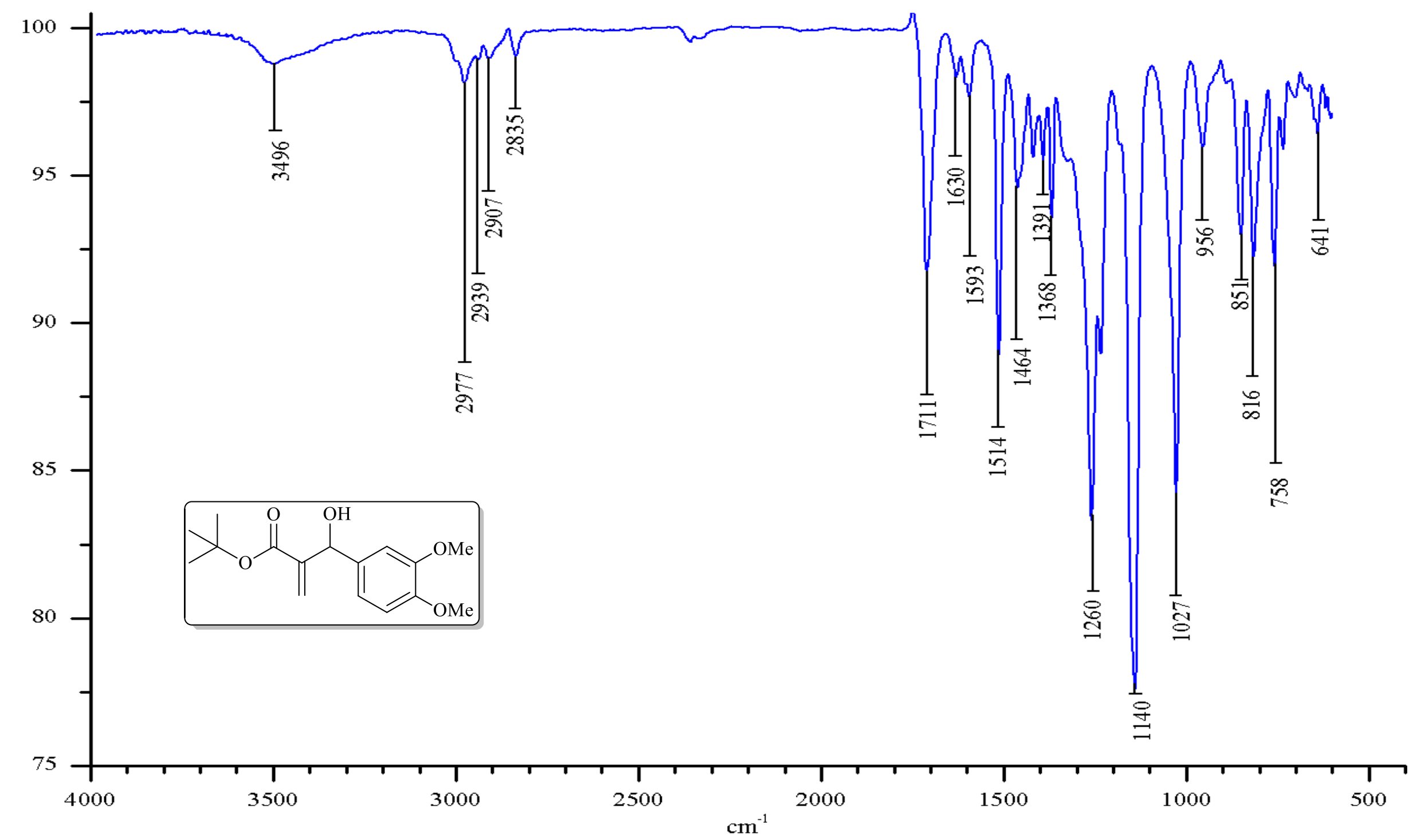

Espectro de infravermelho (ATR) - AMBH-3g 


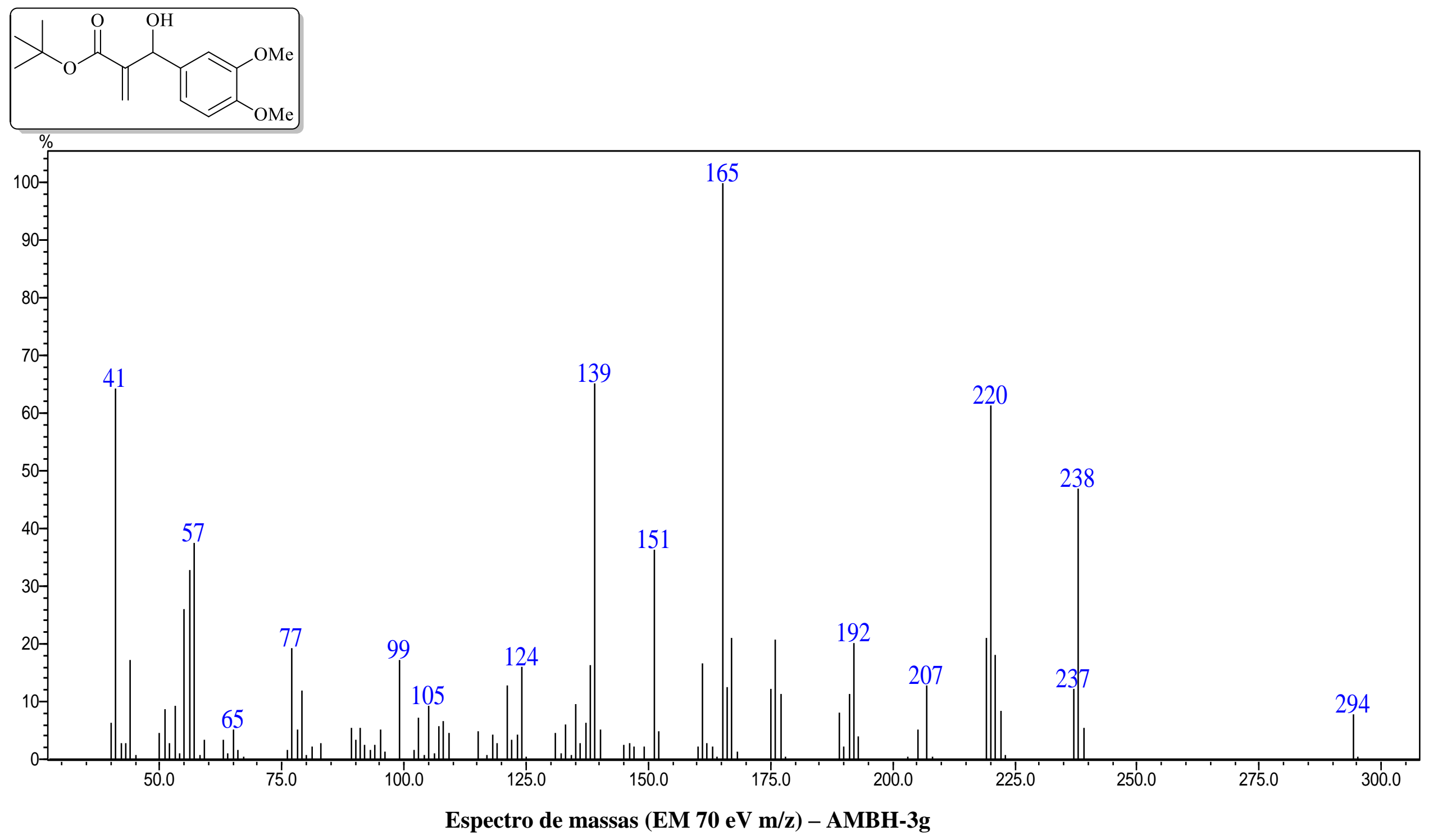


3-hidróxi-2-metilenobutanoato de terc-butila (3h)
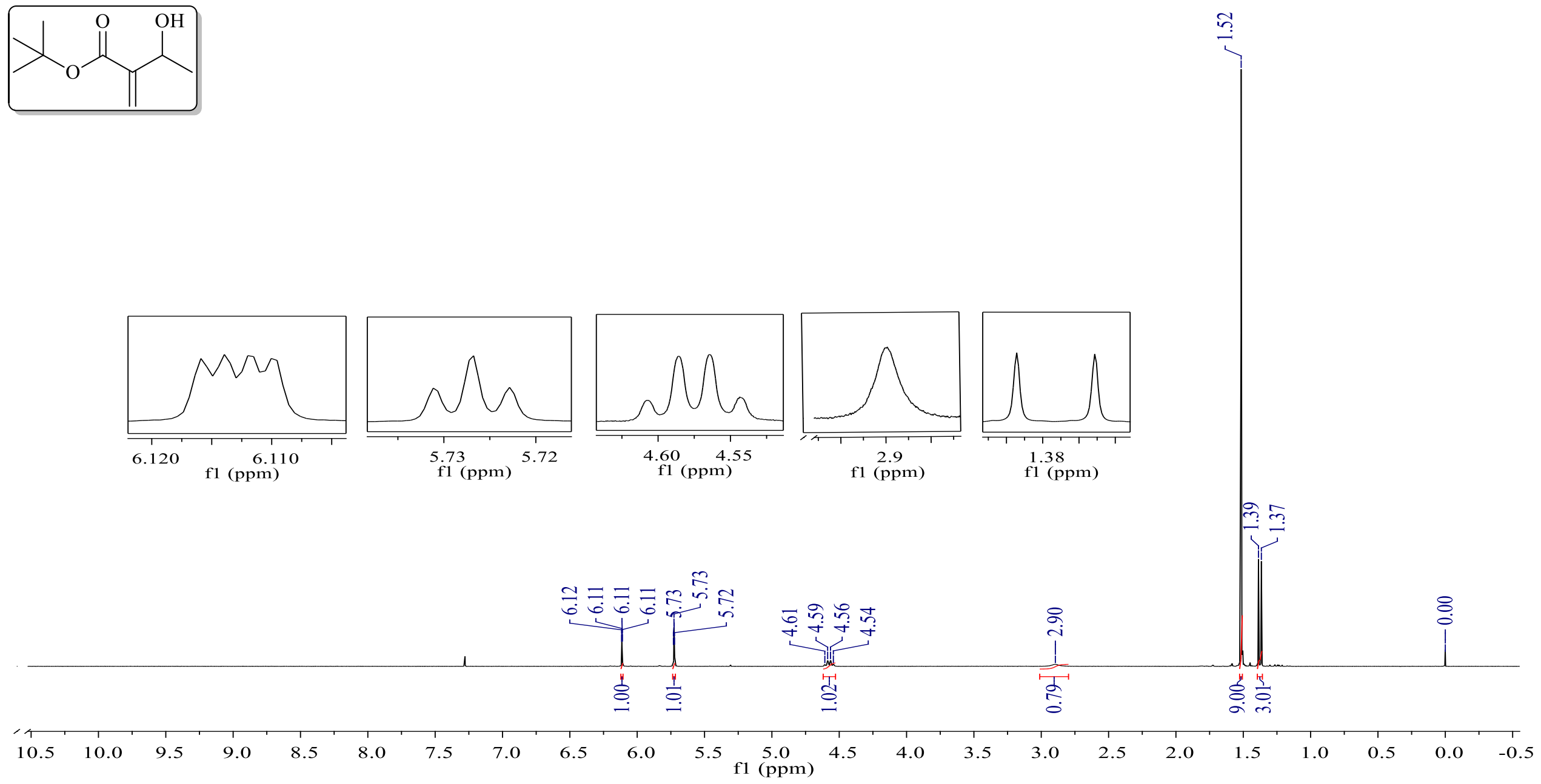

Espectro de RMN de ${ }^{1} \mathrm{H}\left(300 \mathrm{MHz}, \mathrm{CDCl}_{3}\right)$ - AMBH-3h 

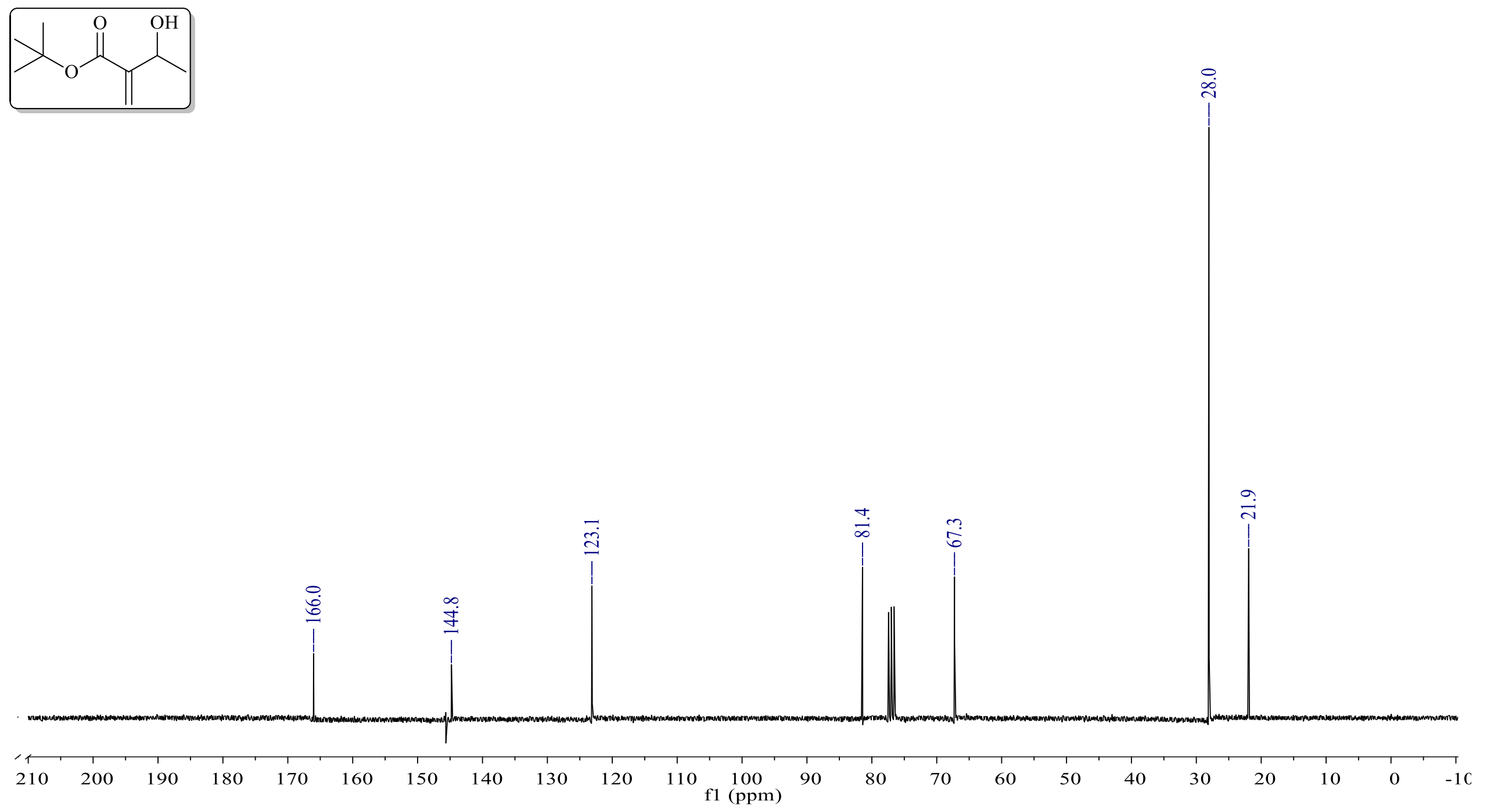

Espectro de RMN de ${ }^{13} \mathrm{C}$ (75 MHz, CDCl 3$)-\mathrm{AMBH}-3 \mathrm{~h}$ 


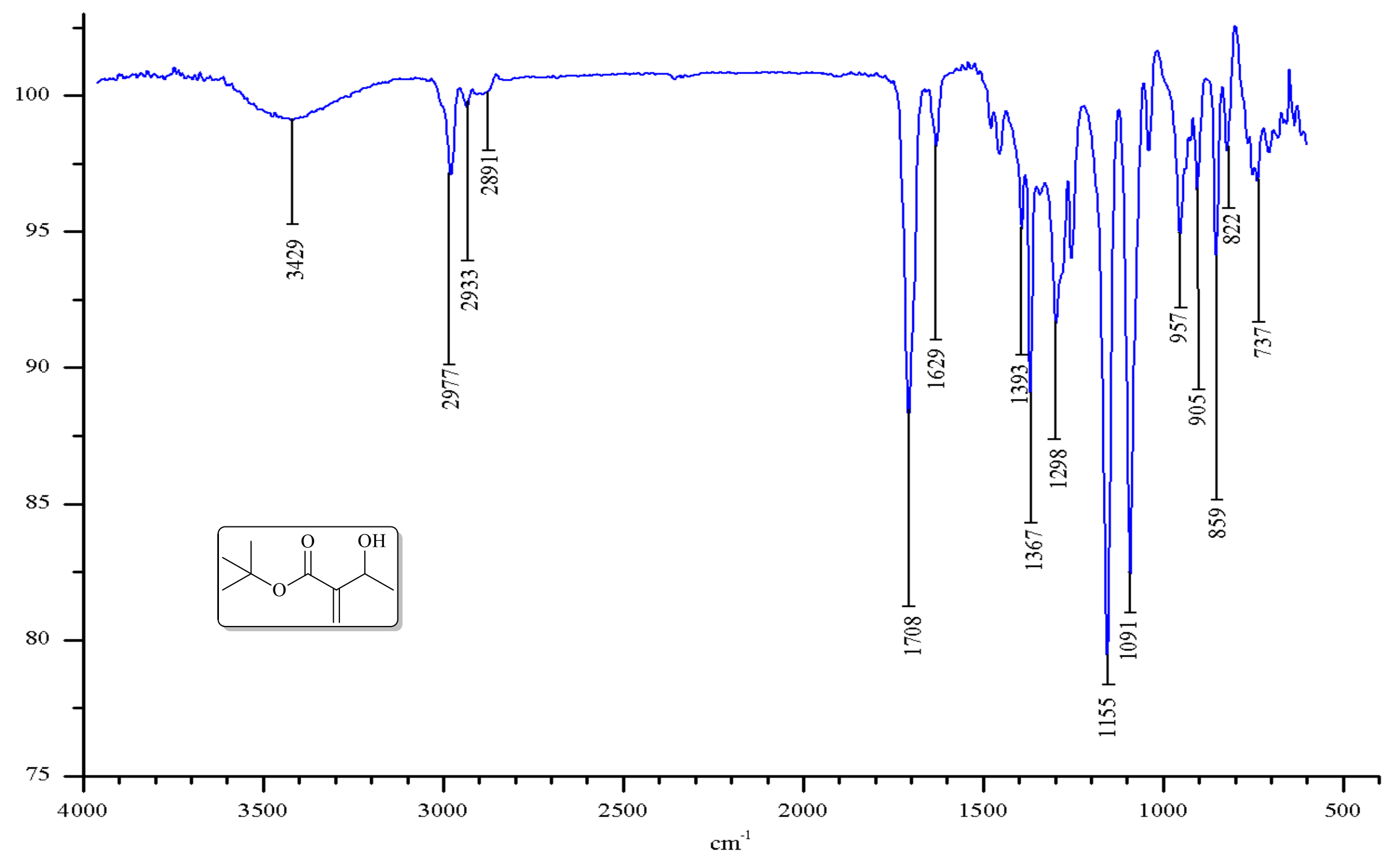

Espectro de infravermelho (ATR) - AMBH-3h 

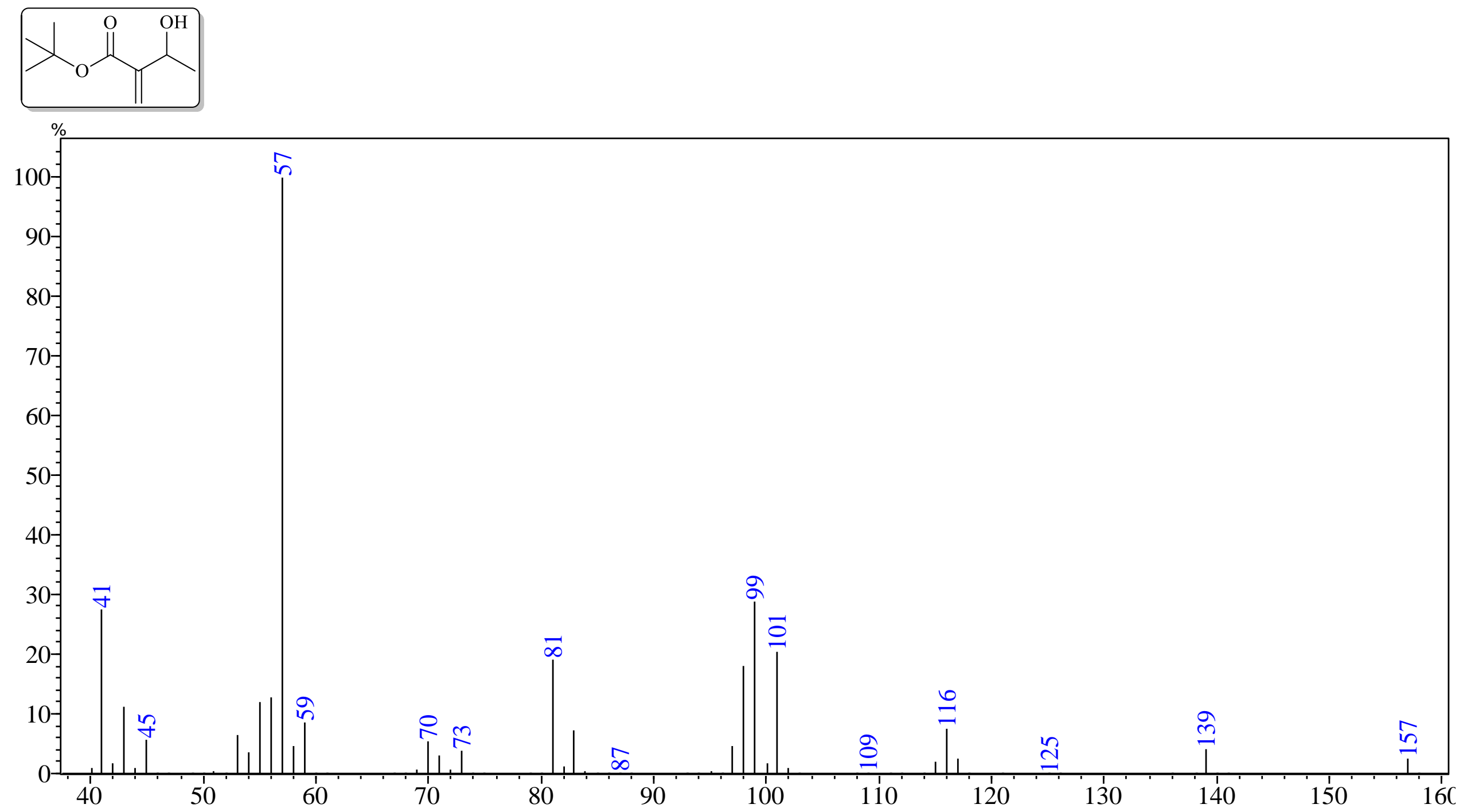

Espectro de massas $(\mathrm{EM} 70 \mathrm{eV} \mathrm{m} / \mathrm{z})$ - AMBH-3h 
3-hidróxi-2-metilenopentanoato de terc-butila (3i)
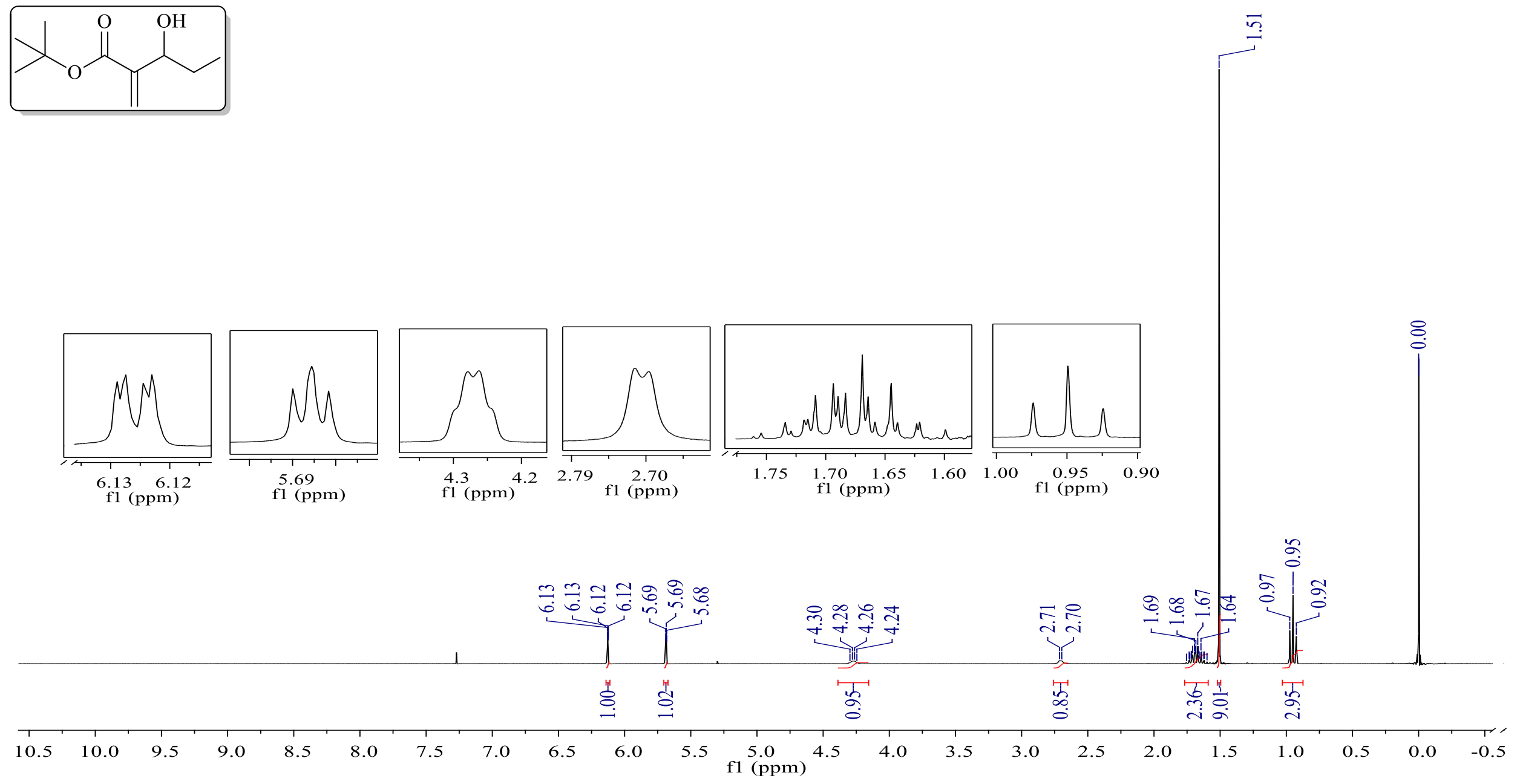

Espectro de RMN de ${ }^{1} \mathrm{H}\left(300 \mathrm{MHz}, \mathrm{CDCl}_{3}\right)$ - AMBH-3i 


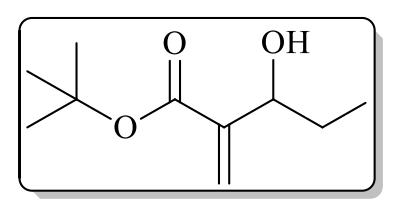

i̊

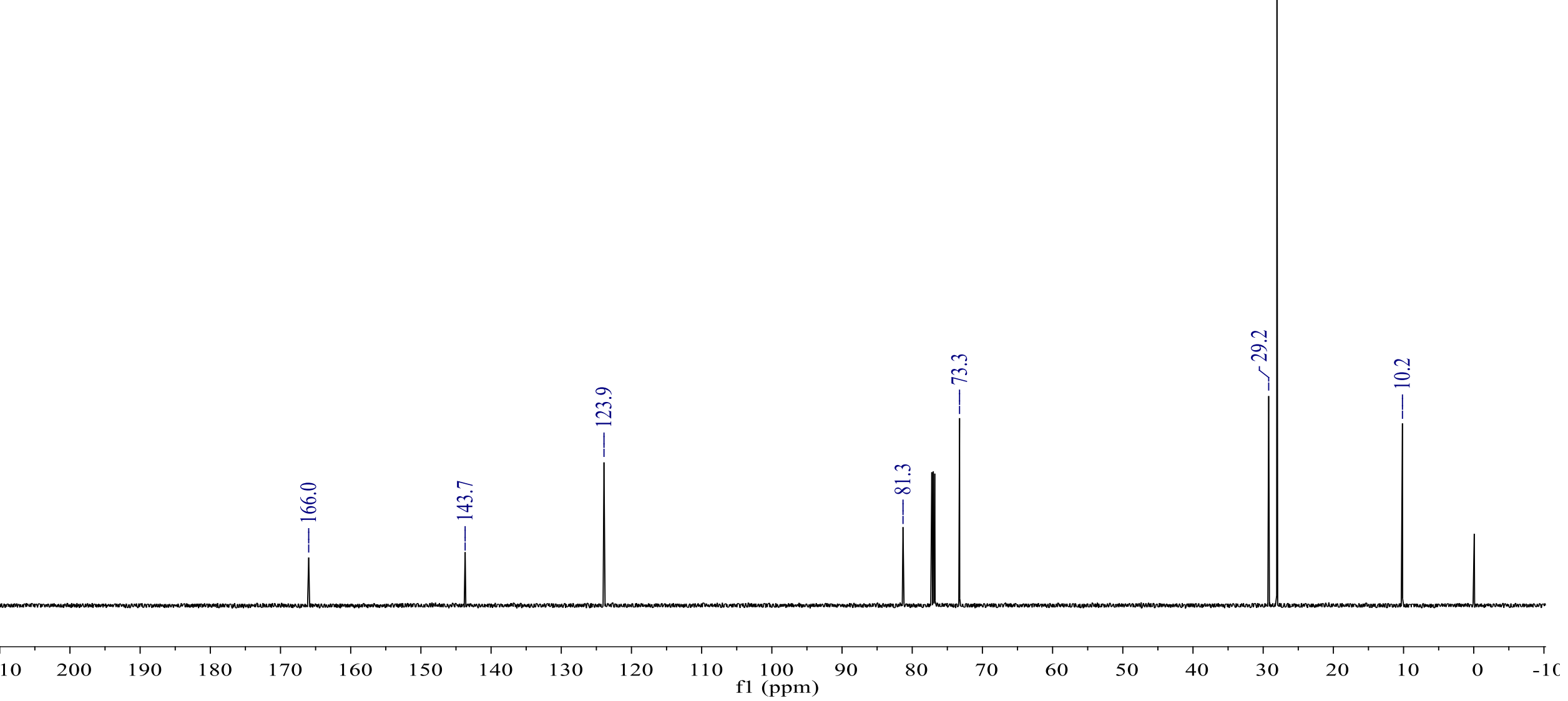

Espectro de RMN de ${ }^{13} \mathrm{C}\left(150 \mathrm{MHz}, \mathrm{CDCl}_{3}\right)$ - AMBH-3i 


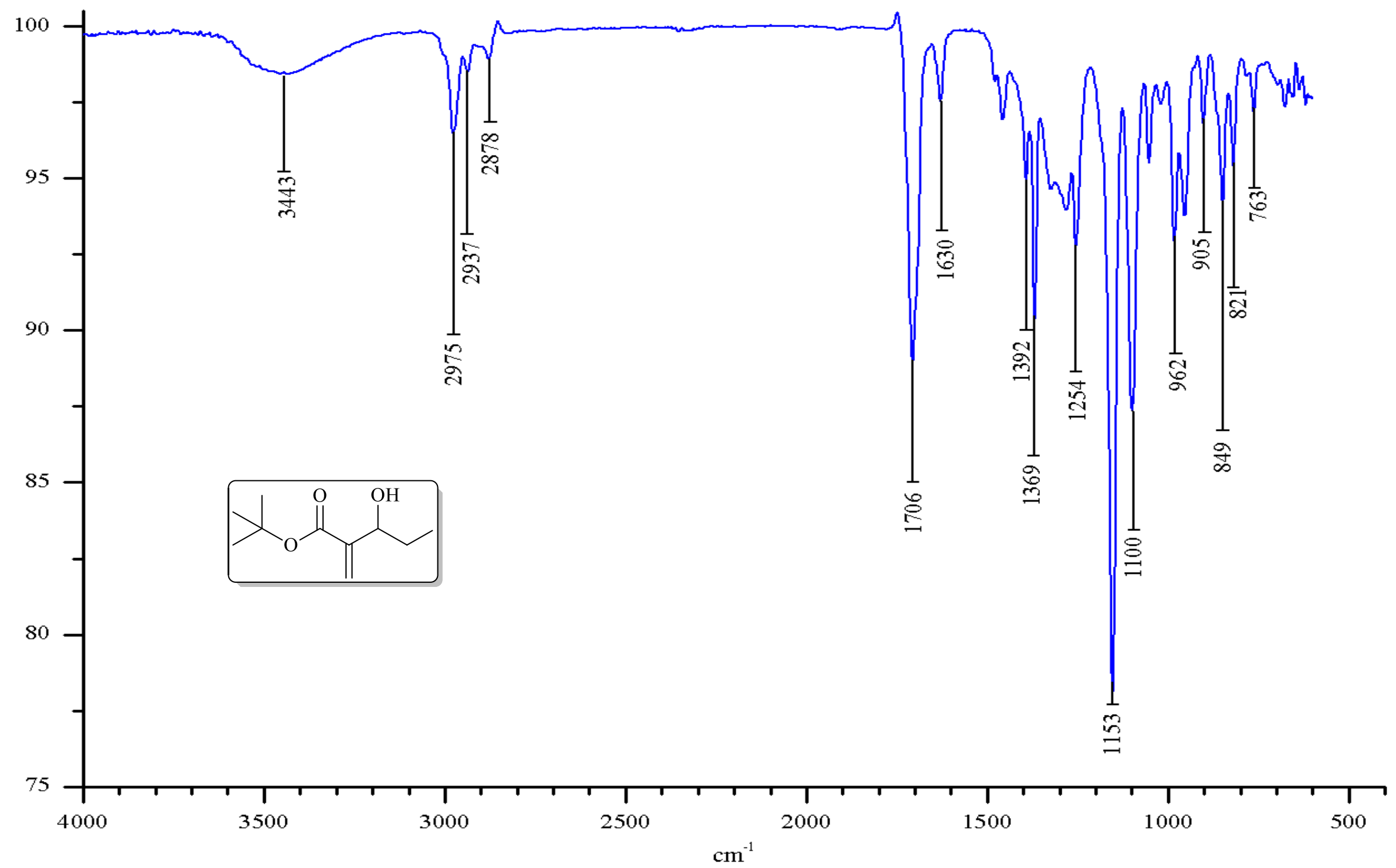

Espectro de infravermelho (ATR) - AMBH-3i 


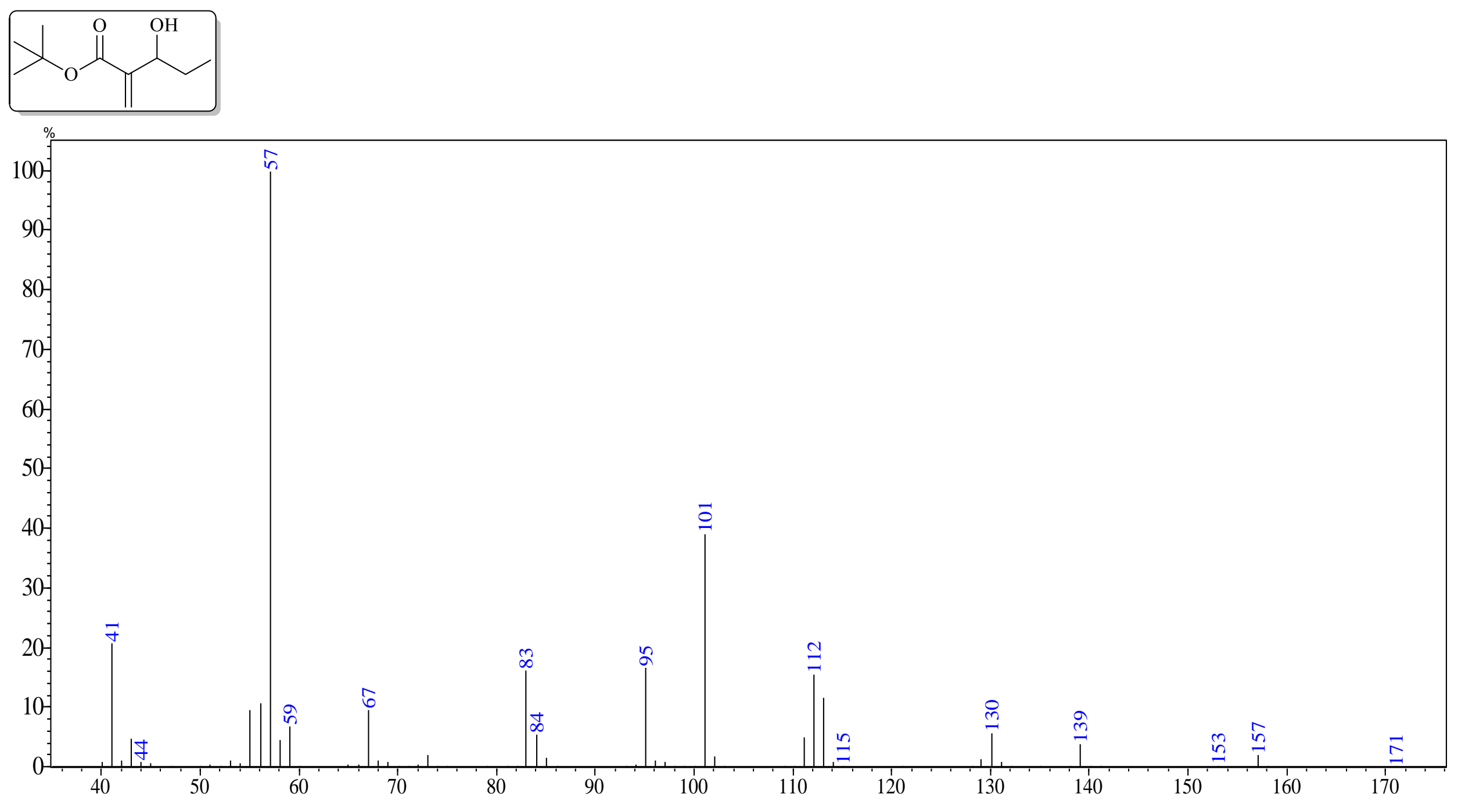

Espectro de massas (EM $70 \mathrm{eV} \mathrm{m/z)}$ - AMBH-3i 


\section{3-hidróxi--2-metilenononanoato de terc-butila (3j)}
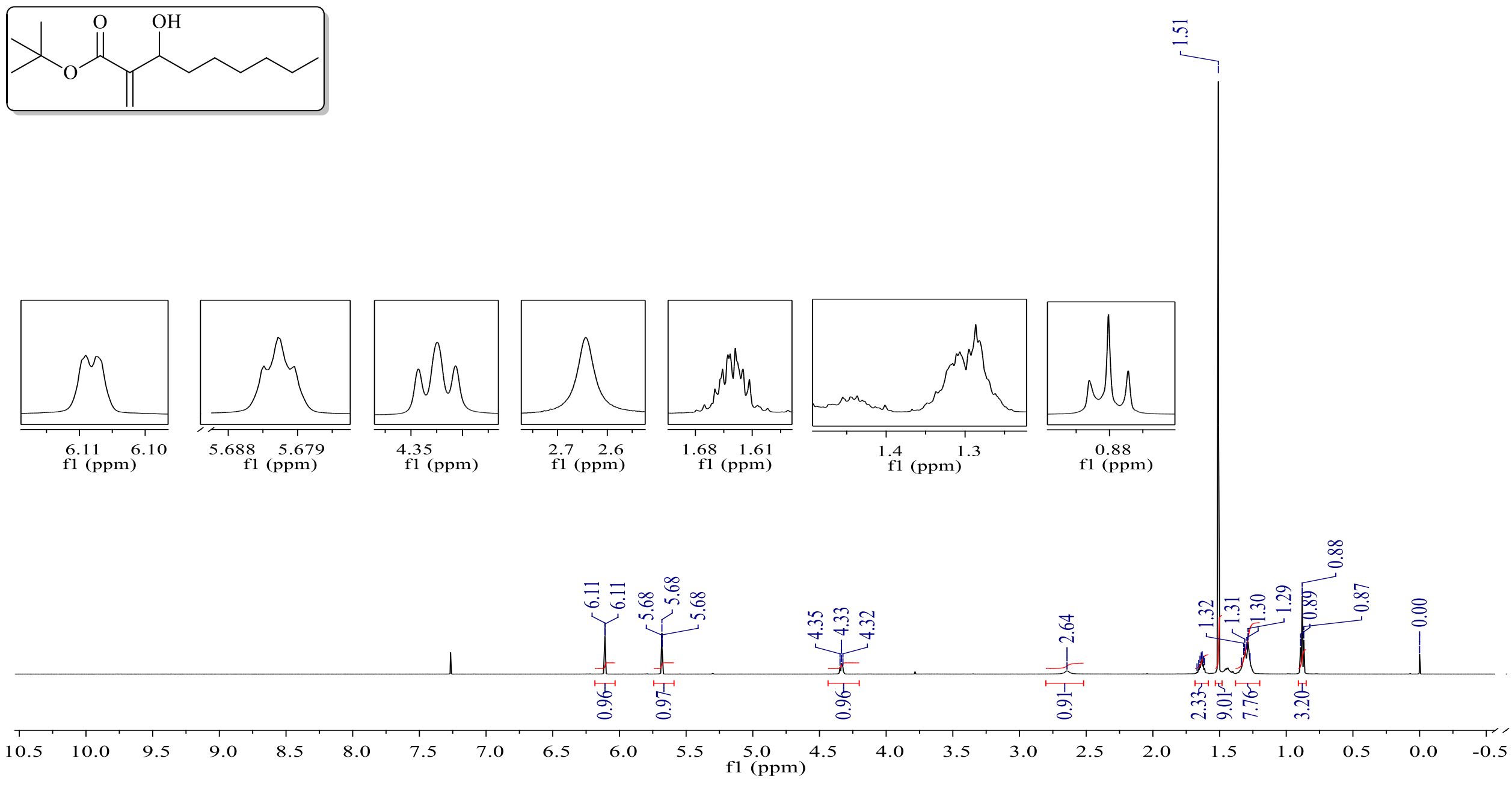

Espectro de RMN de ${ }^{1} \mathrm{H}\left(600 \mathrm{MHz}, \mathrm{CDCl}_{3}\right)-\mathrm{AMBH}-3 \mathrm{j}$ 

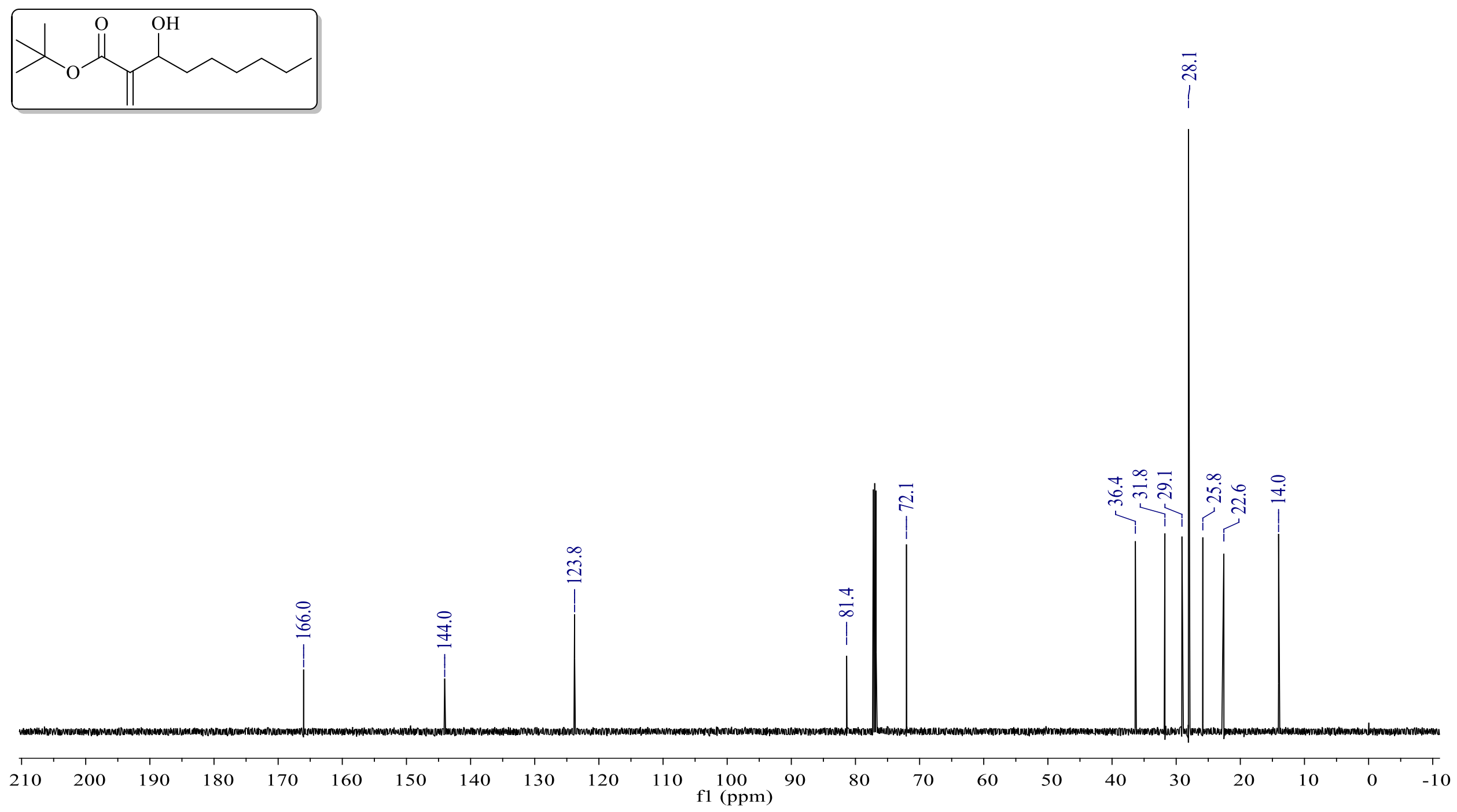

Espectro de RMN de ${ }^{13} \mathrm{C}$ (150 MHz, CDCl $)$ - AMBH-3j 


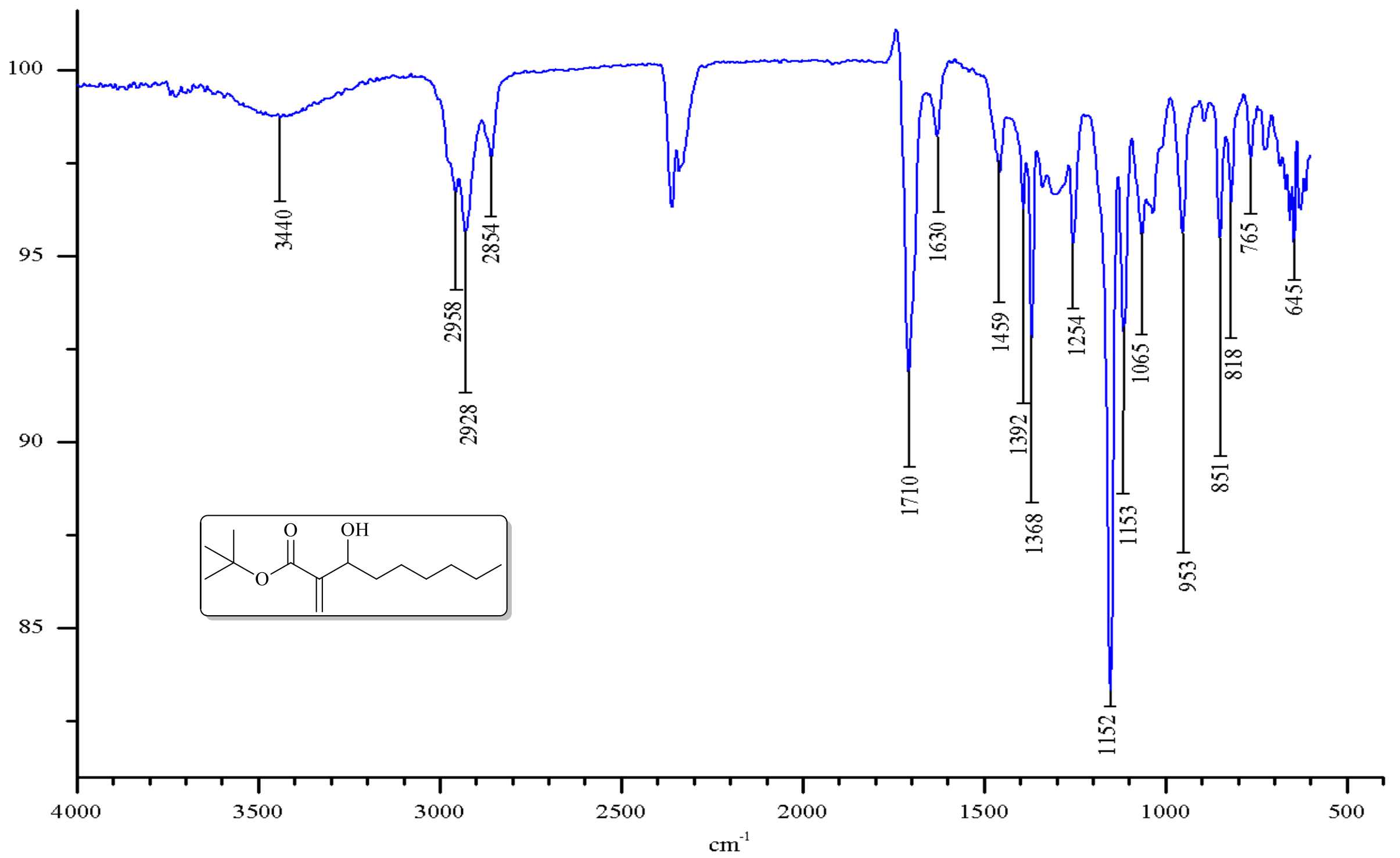

Espectro de infravermelho (ATR) - AMBH-3j 


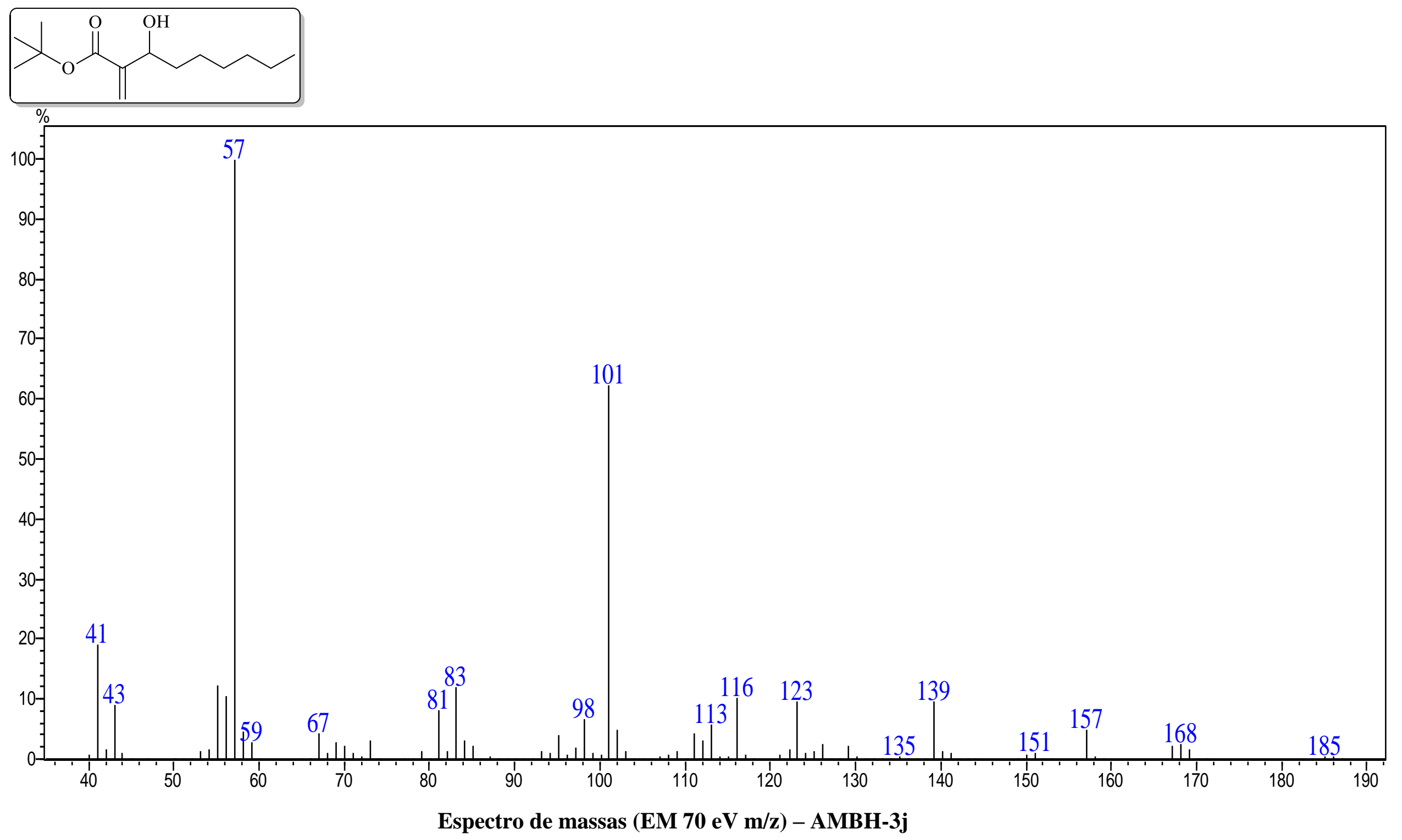




\section{3-hidróxi-4-metil-2-metilenopentanoato de terc-butila (3k)}
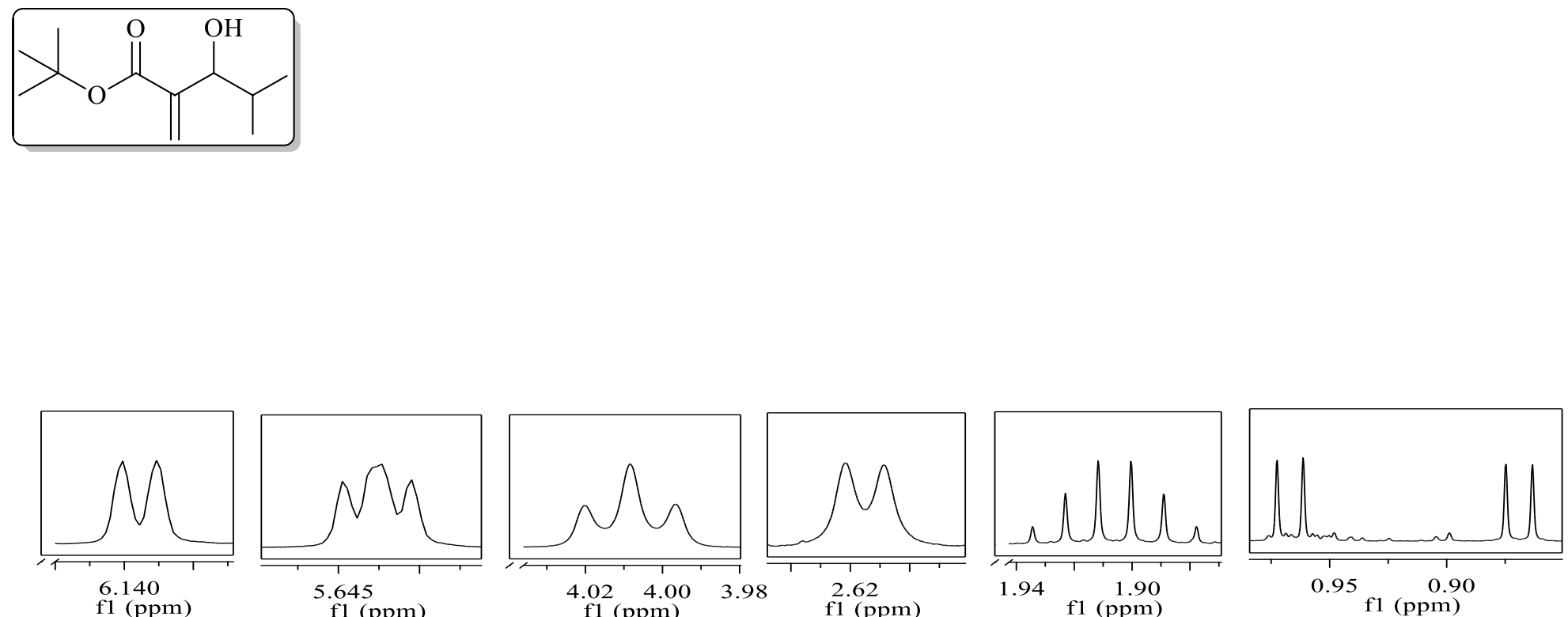

동ㅇㅇㅇㅇㅇㅇ

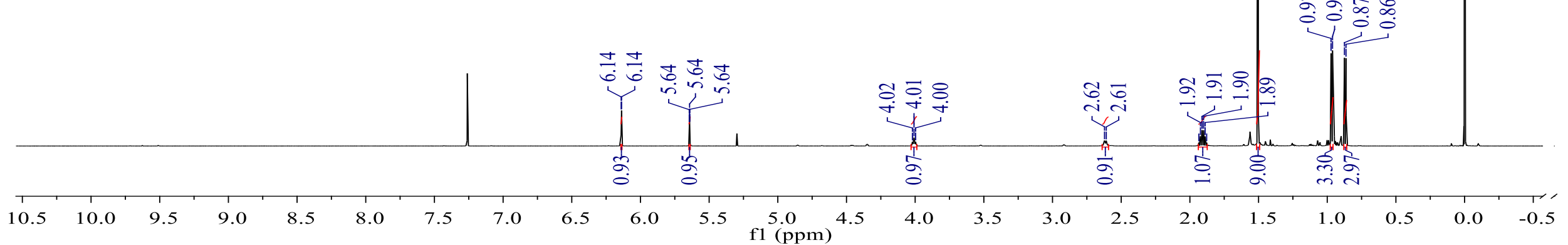

Espectro de RMN de ${ }^{1} \mathrm{H}\left(600 \mathrm{MHz}, \mathrm{CDCl}_{3}\right)-\mathrm{AMBH}-3 \mathrm{k}$ 

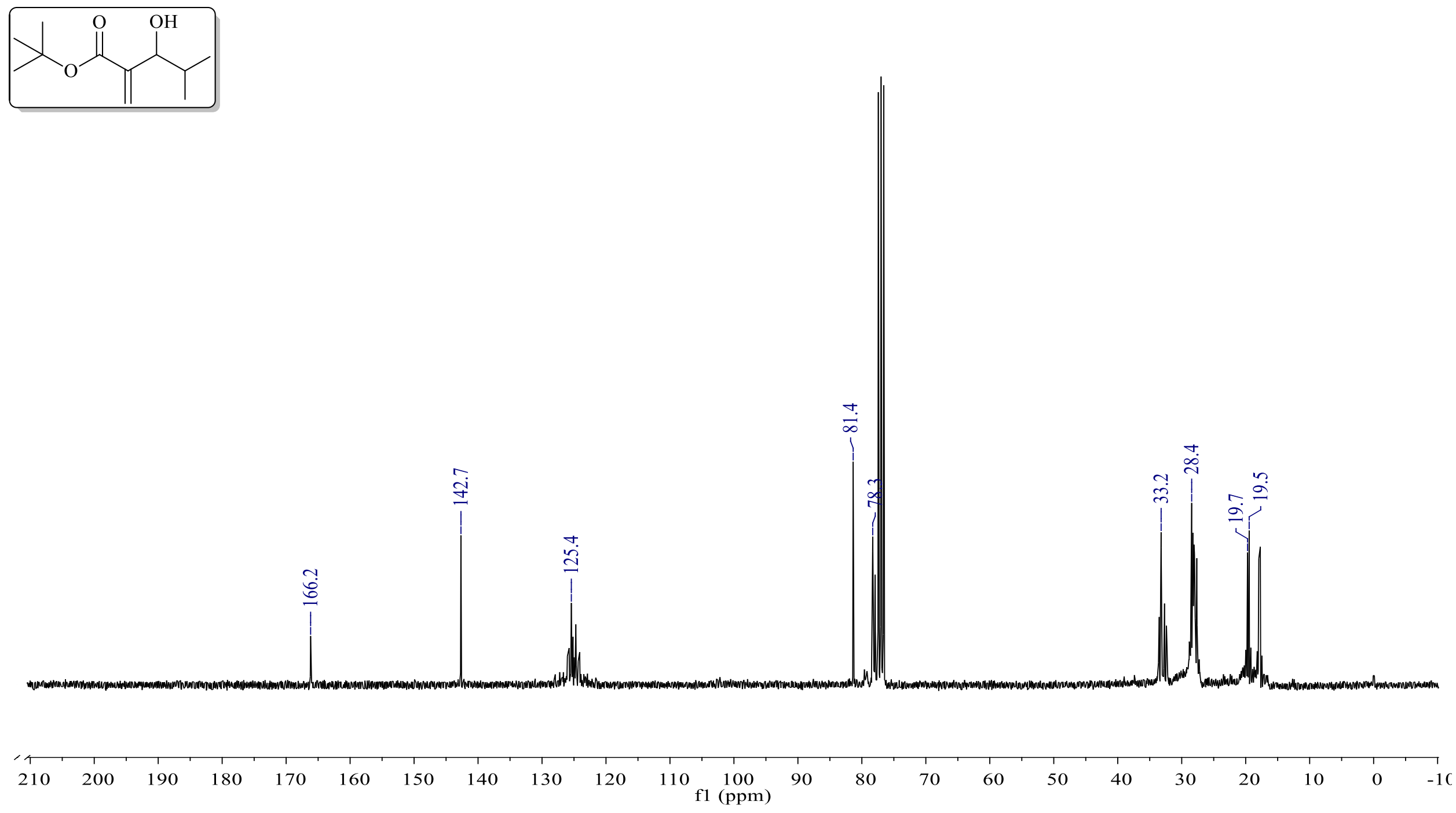

Espectro de RMN de ${ }^{13} \mathrm{C}$ (75 MHz, CDCl 3$)$ - AMBH-3k 


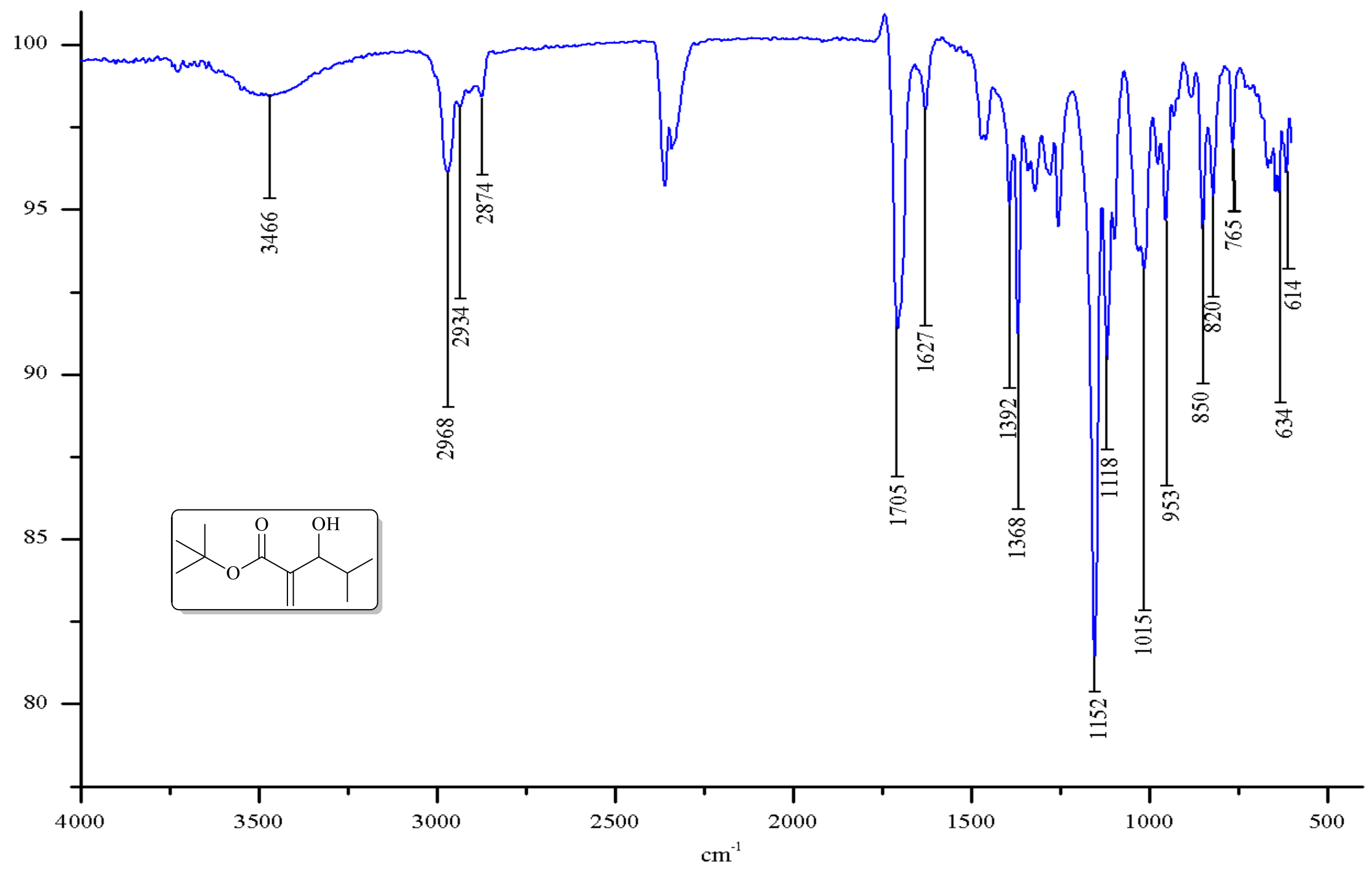

Espectro de infravermelho (ATR) - AMBH-3k 


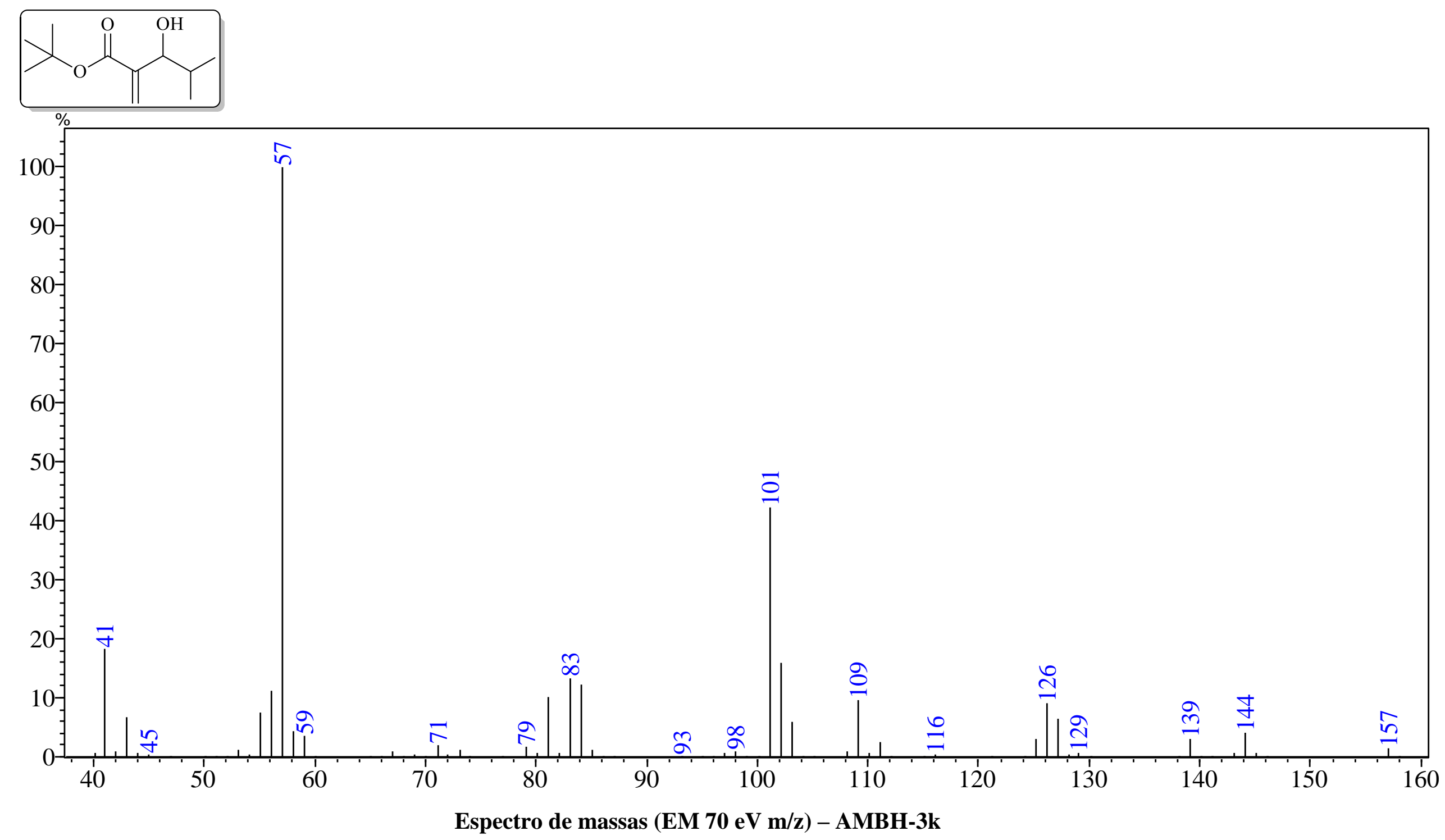




\section{Rearranjo de Hurd-Claisen - Otimização}
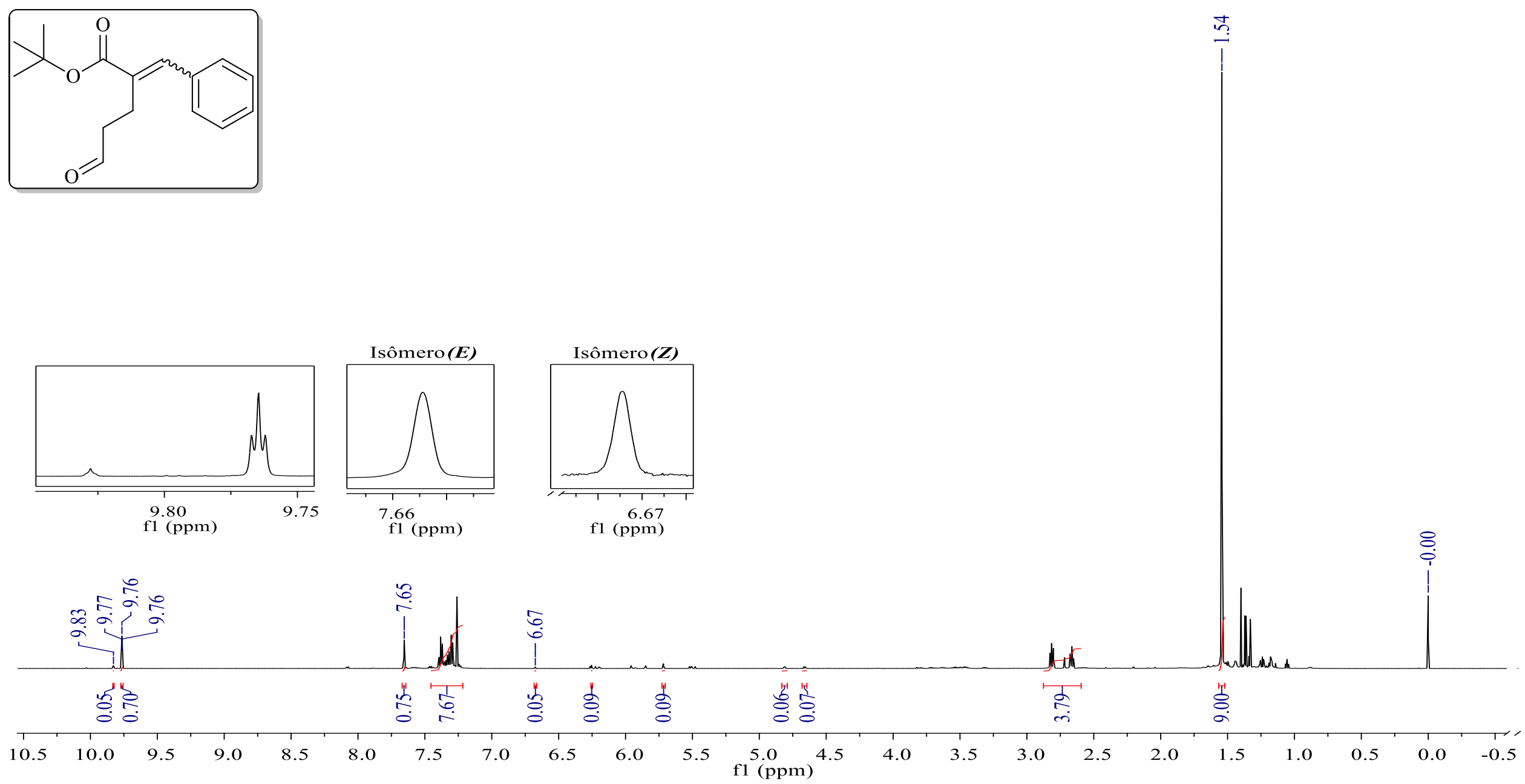

Espectro de RMN de ${ }^{1} \mathrm{H}(600 \mathrm{MHz})$ do bruto de reação do rearranjo de Hurd-Claisen (18 horas) com os isômeros 4a (E) e 4a (Z). 

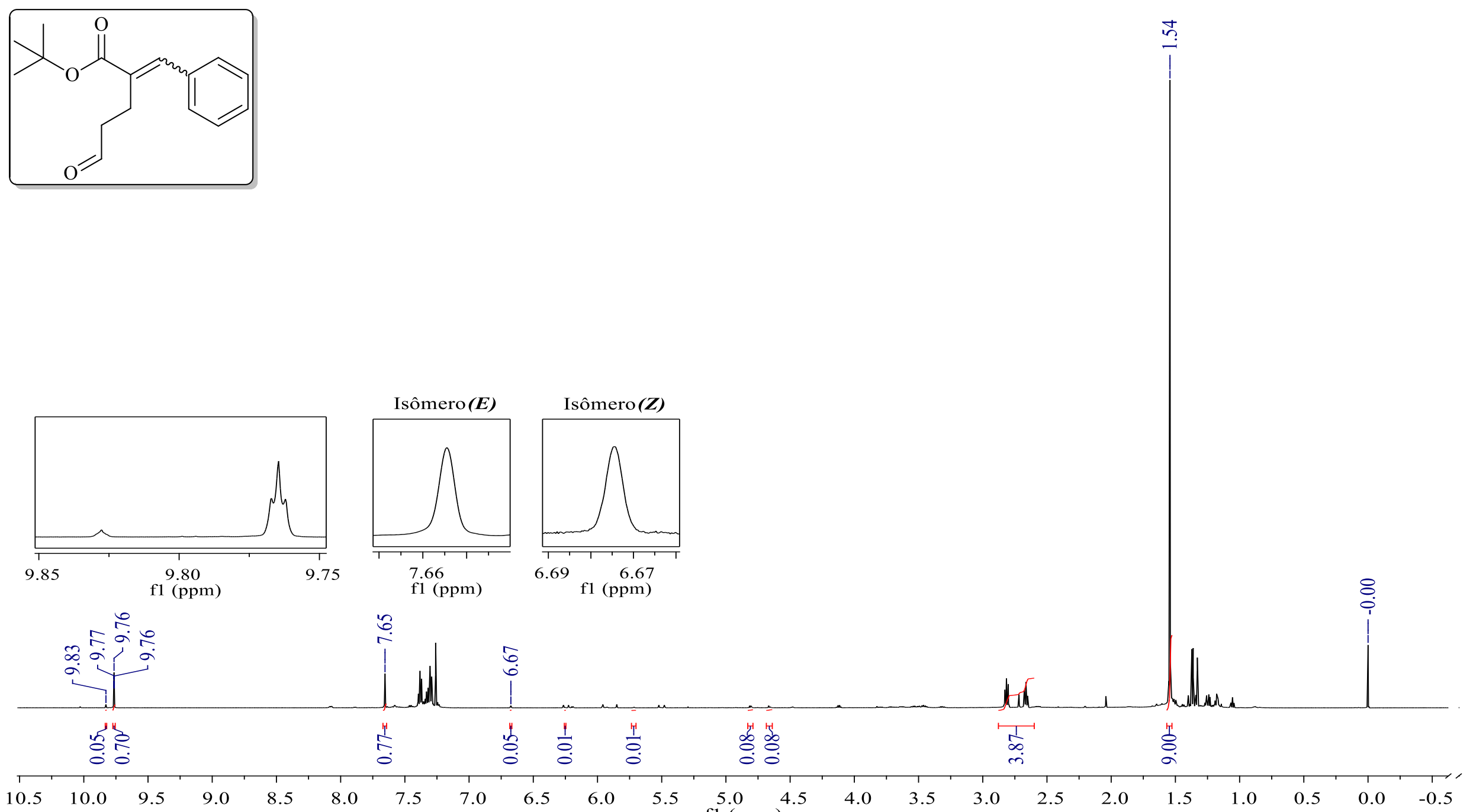

Espectro de RMN de ${ }^{1} \mathrm{H}(600 \mathrm{MHz})$ do bruto de reação do rearranjo de Hurd-Claisen (24 horas) com os isômeros 4a (E) e 4a (Z). 

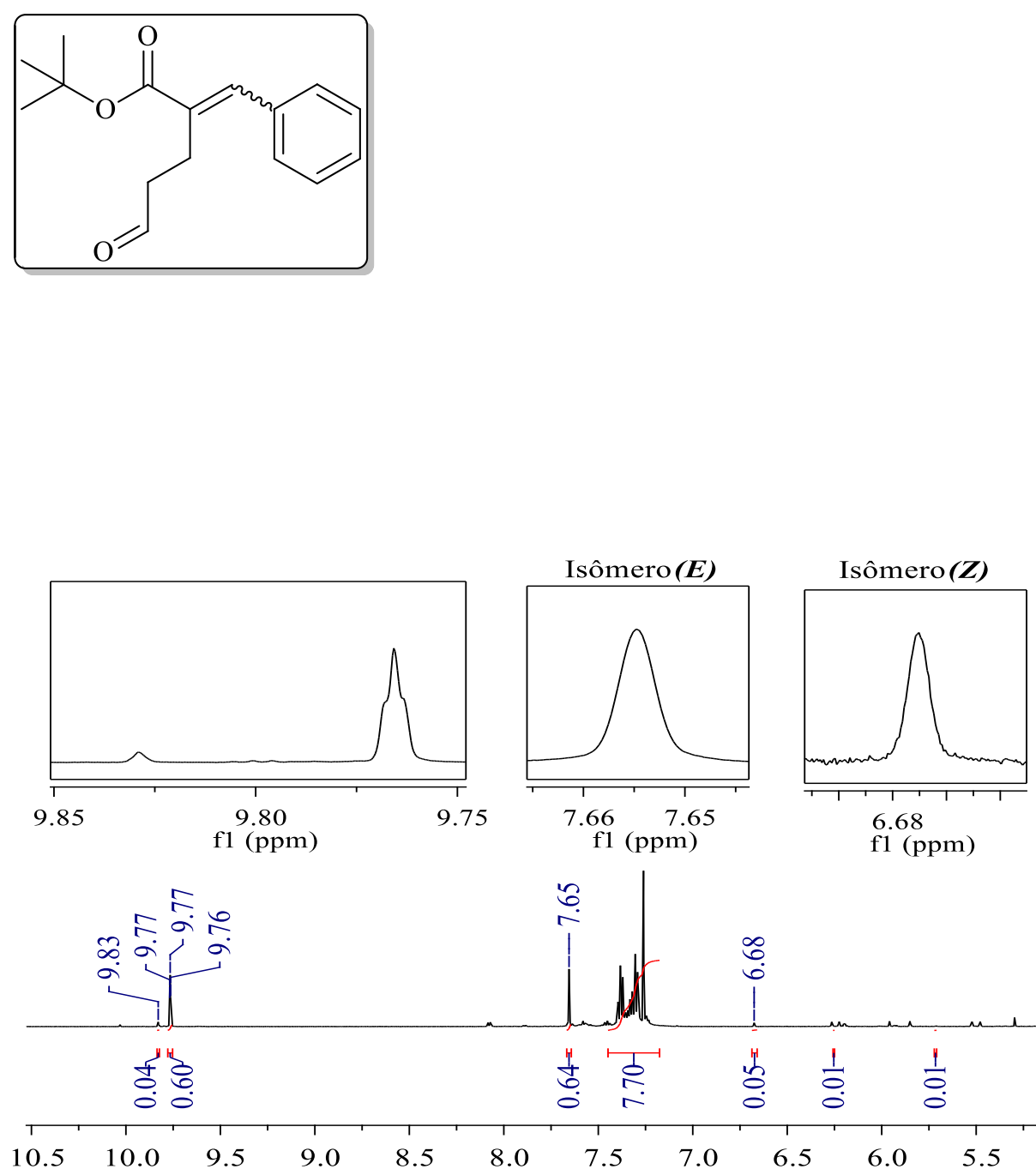

6.68
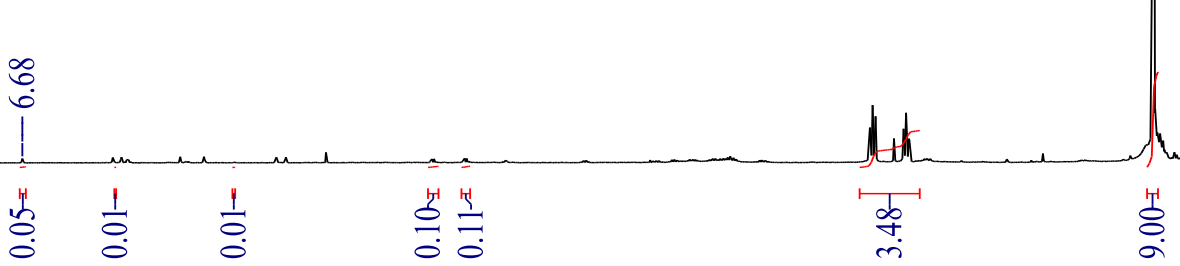

Espectro de RMN de ${ }^{1} \mathrm{H}(600 \mathrm{MHz})$ do bruto de reação do rearranjo de Hurd-Claisen (30 horas) com os isômeros 4a (E) e 4a (Z). 

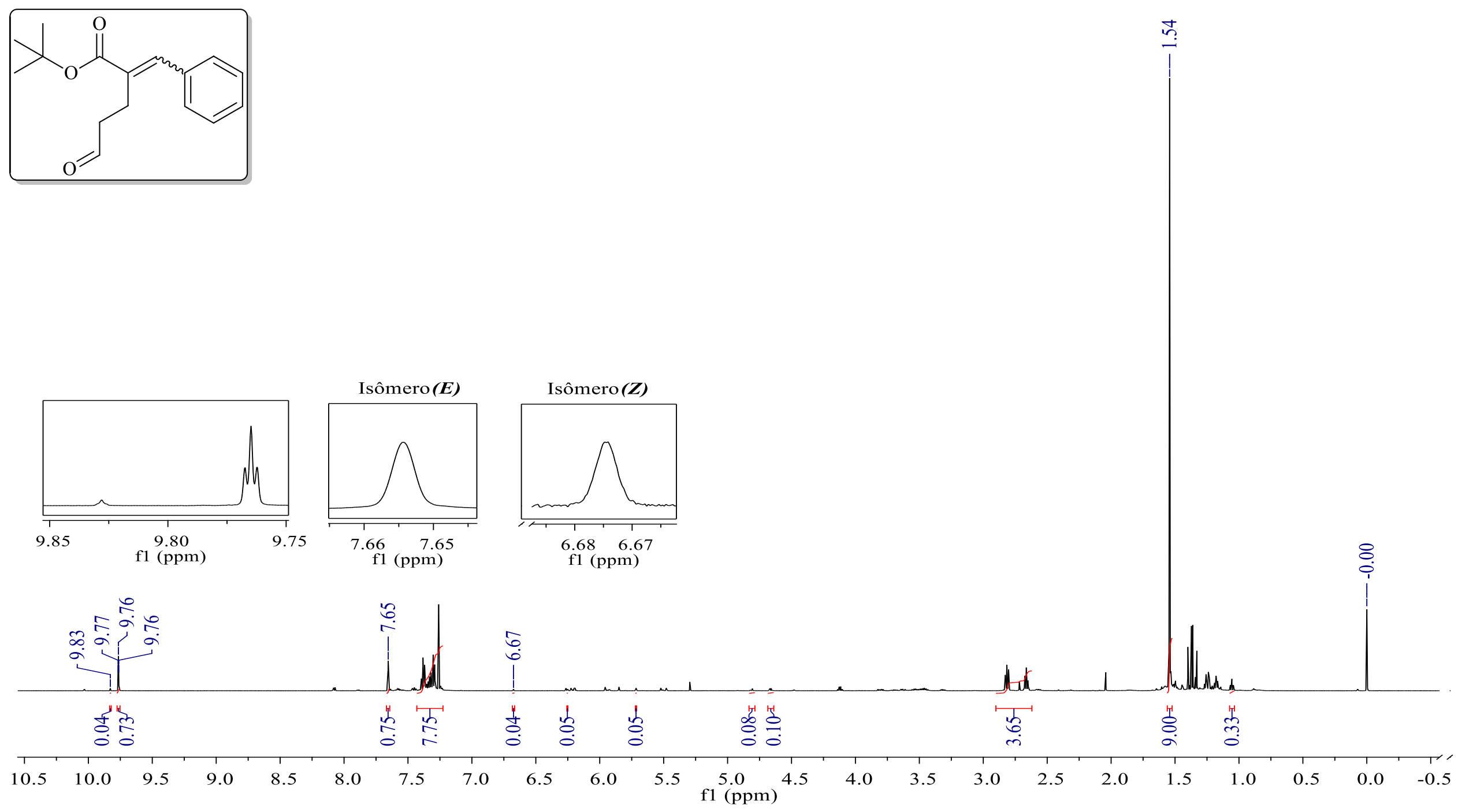

Espectro de RMN de ${ }^{1} \mathrm{H}(600 \mathrm{MHz})$ do bruto de reação do rearranjo de Hurd-Claisen $\left(80^{\circ} \mathrm{C}\right)$ com os isômeros $4 \mathrm{a}(E)$ e $4 \mathrm{a}(Z)$. 

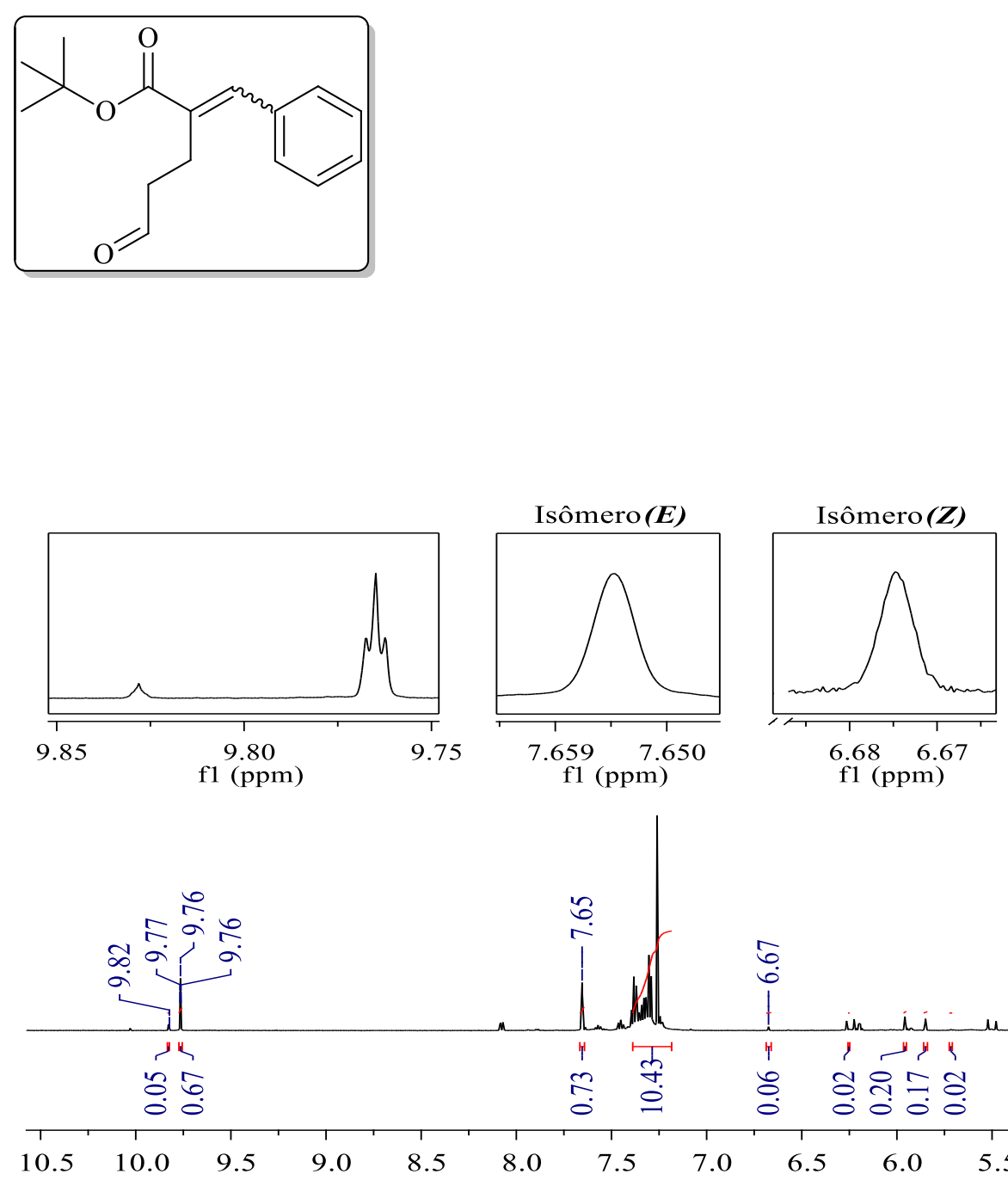

f1 (ppm)

Espectro de RMN de ${ }^{1} \mathrm{H}(600 \mathrm{MHz})$ do bruto de reação do rearranjo de Hurd-Claisen $\left(120^{\circ} \mathrm{C}\right)$ com os isômeros 4 a $(E)$ e $4 a(Z)$. 

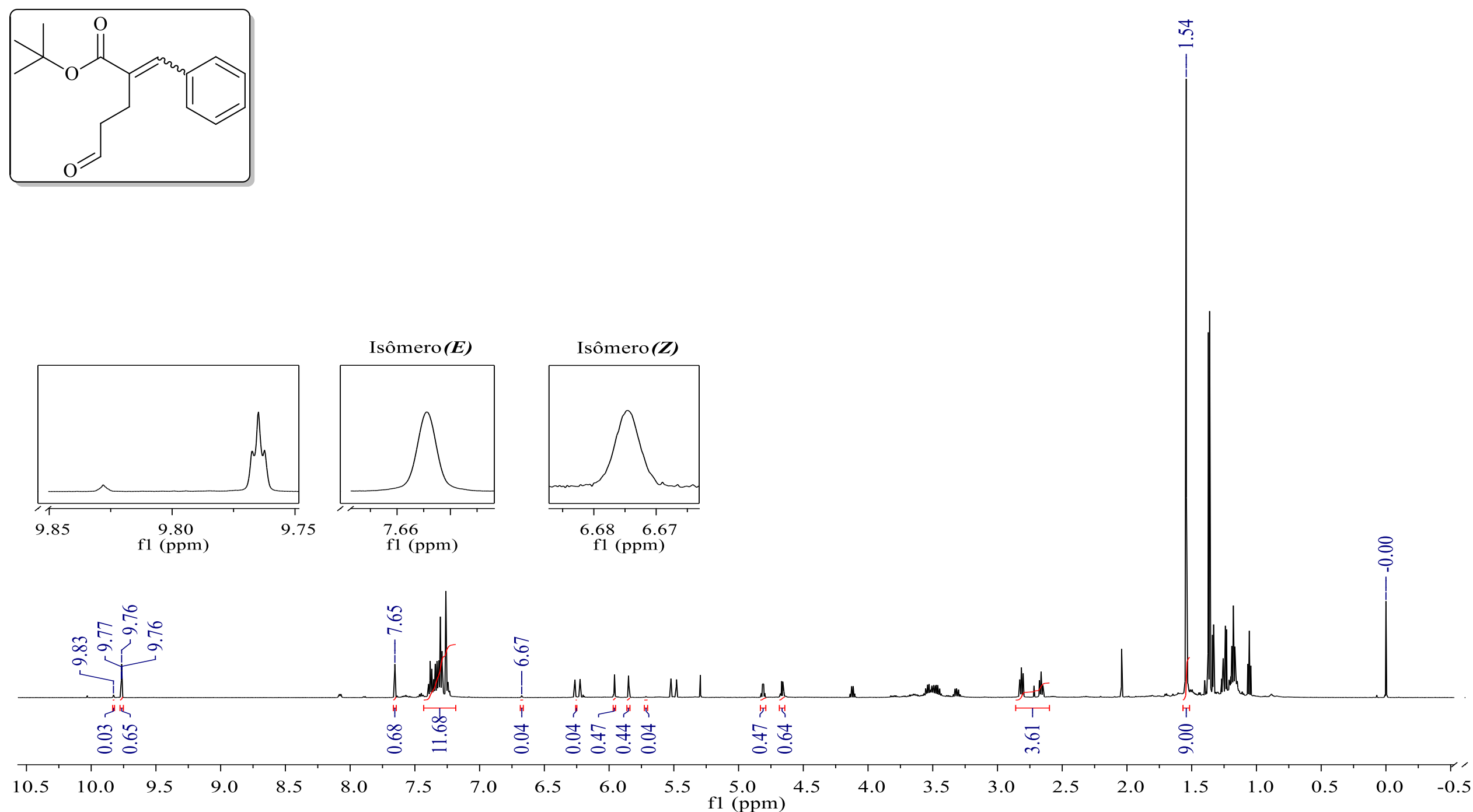

Espectro de RMN de ${ }^{1} \mathrm{H}(600 \mathrm{MHz})$ do bruto de reação do rearranjo de Hurd-Claisen (1,0 mol\% de $\left.\operatorname{Hg}(\mathrm{OAc}) 2\right)$ com os isômeros 4a (E) e 4a (Z) 


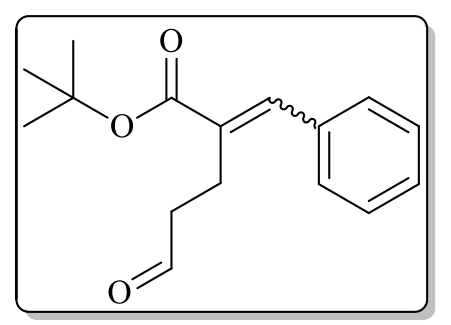

\section{孛}
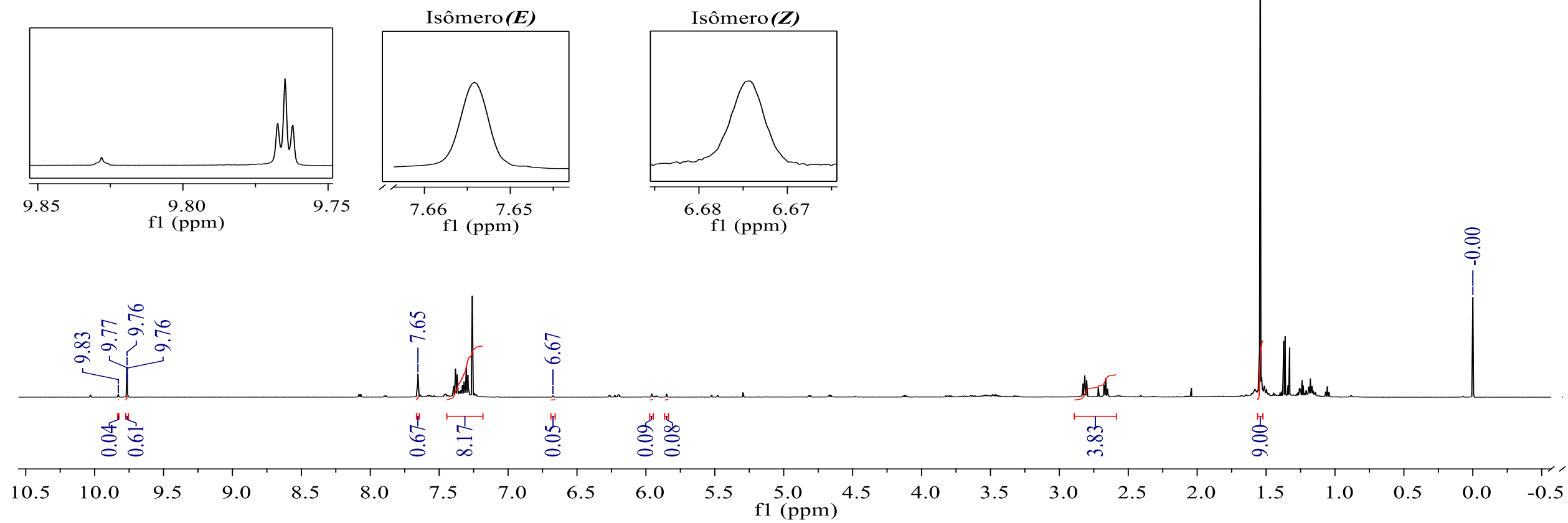

Espectro de RMN de ${ }^{1} \mathrm{H}(600 \mathrm{MHz})$ do bruto de reação do rearranjo de Hurd-Claisen $(5,0 \mathrm{~mol} \%$ de $\mathrm{Hg}(\mathrm{OAc}) 2)$ com os isômeros $4 \mathrm{a}(E)$ e $4 \mathbf{a}(Z)$ 

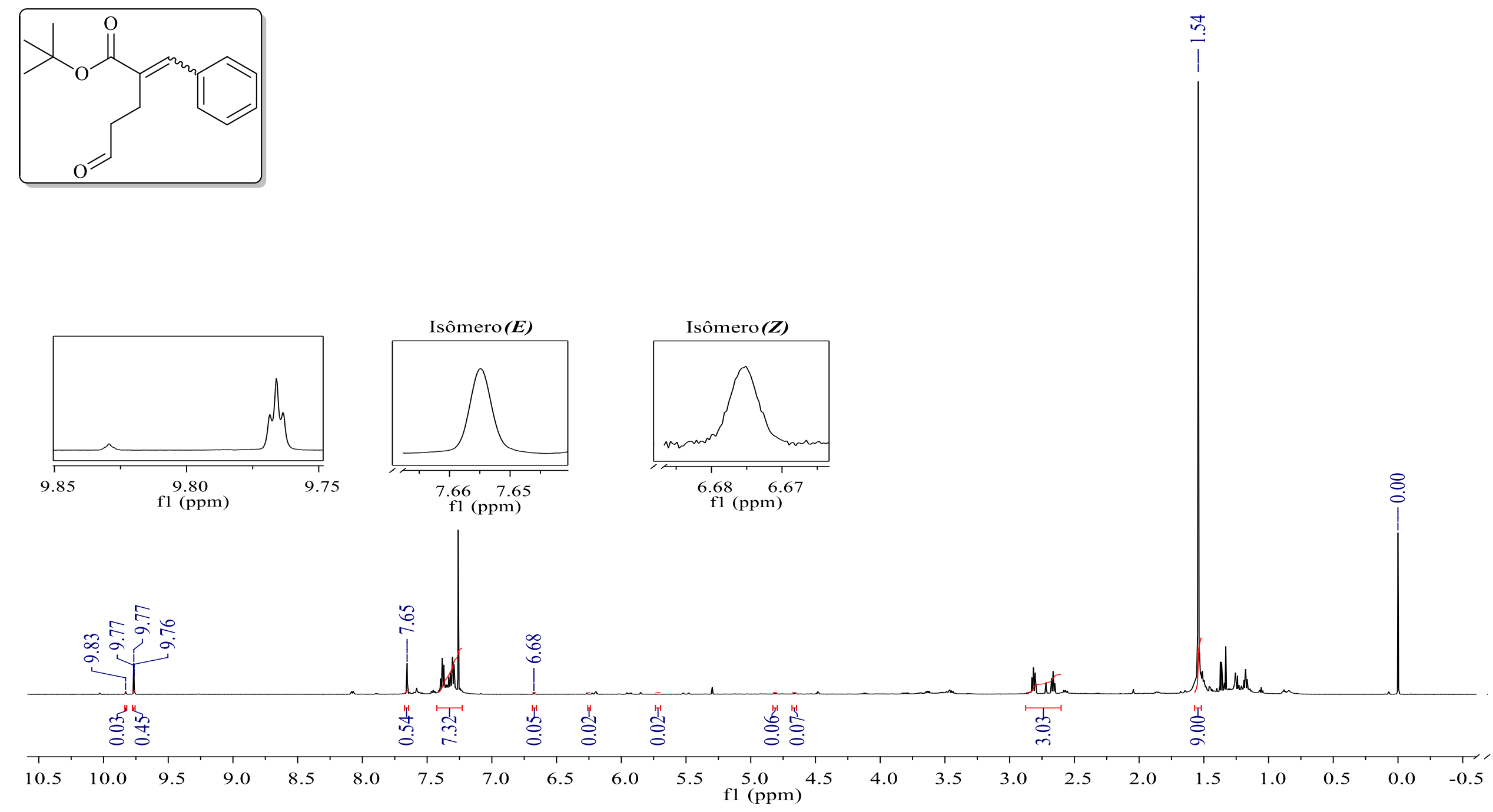

Espectro de RMN de ${ }^{1} \mathrm{H}(600 \mathrm{MHz})$ do bruto de reação do rearranjo de Hurd-Claisen (10 mol\% de $\left.\mathrm{Hg}(\mathrm{OAc}) 2\right)$ com os isômeros 4a (E) e $4 c(Z)$. 


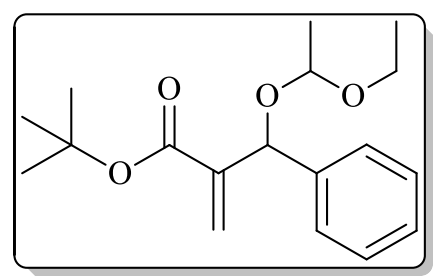

Isômero $(\boldsymbol{E})$
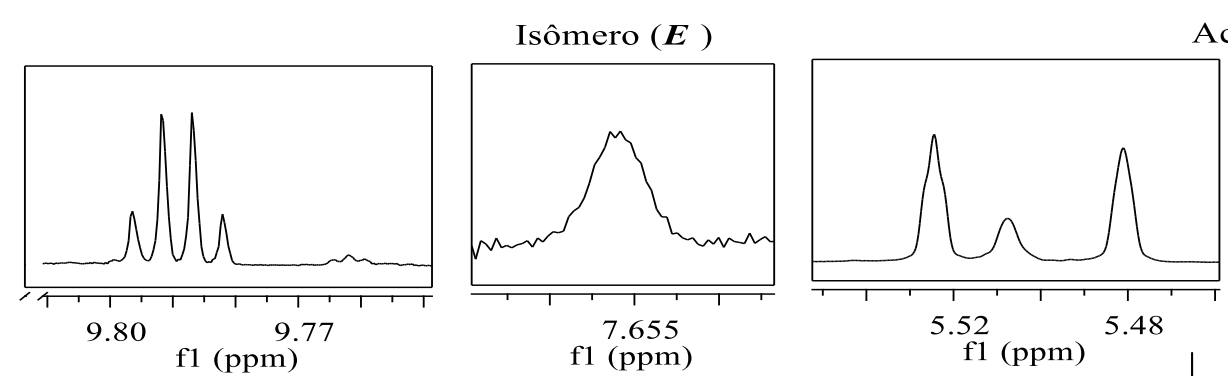

Acetal

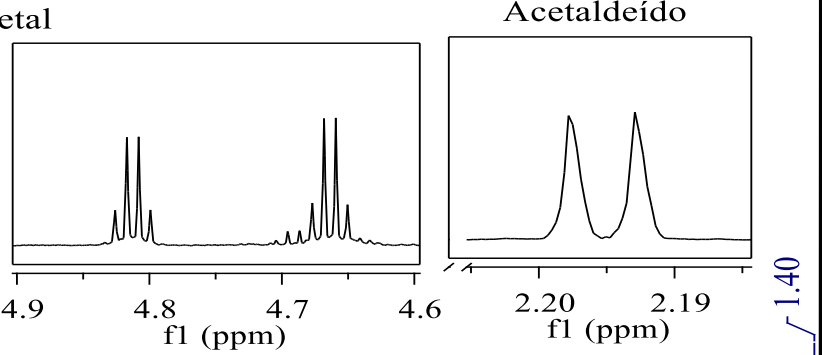

f1 (ppm)

$5.52(\mathrm{ppm})$
$\mathrm{f} 1$

4.8 f1 (ppm)
4.7

f1 (ppm)
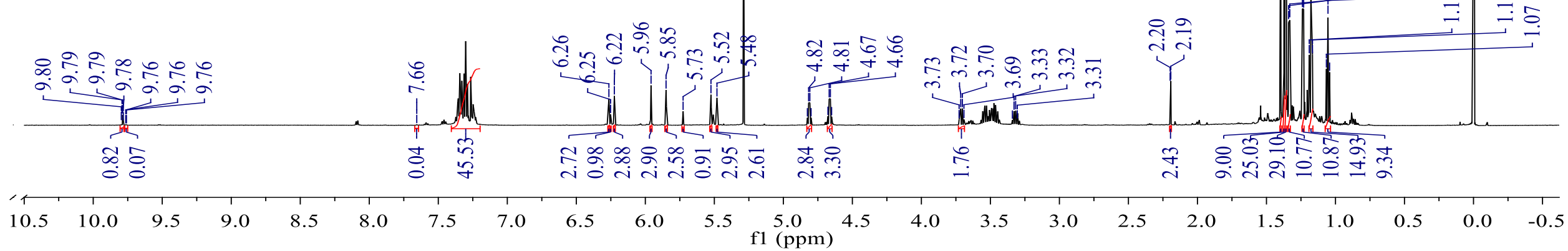

Espectro de RMN de ${ }^{1} \mathrm{H}(600 \mathrm{MHz})$ do bruto de reação do rearranjo de Hurd-Claisen (sem $\left.\mathrm{Hg}(\mathrm{OAc})_{2}\right)$ com os isômeros $4 \mathrm{a}(E)$ e $4 \mathrm{c}(Z)$. 

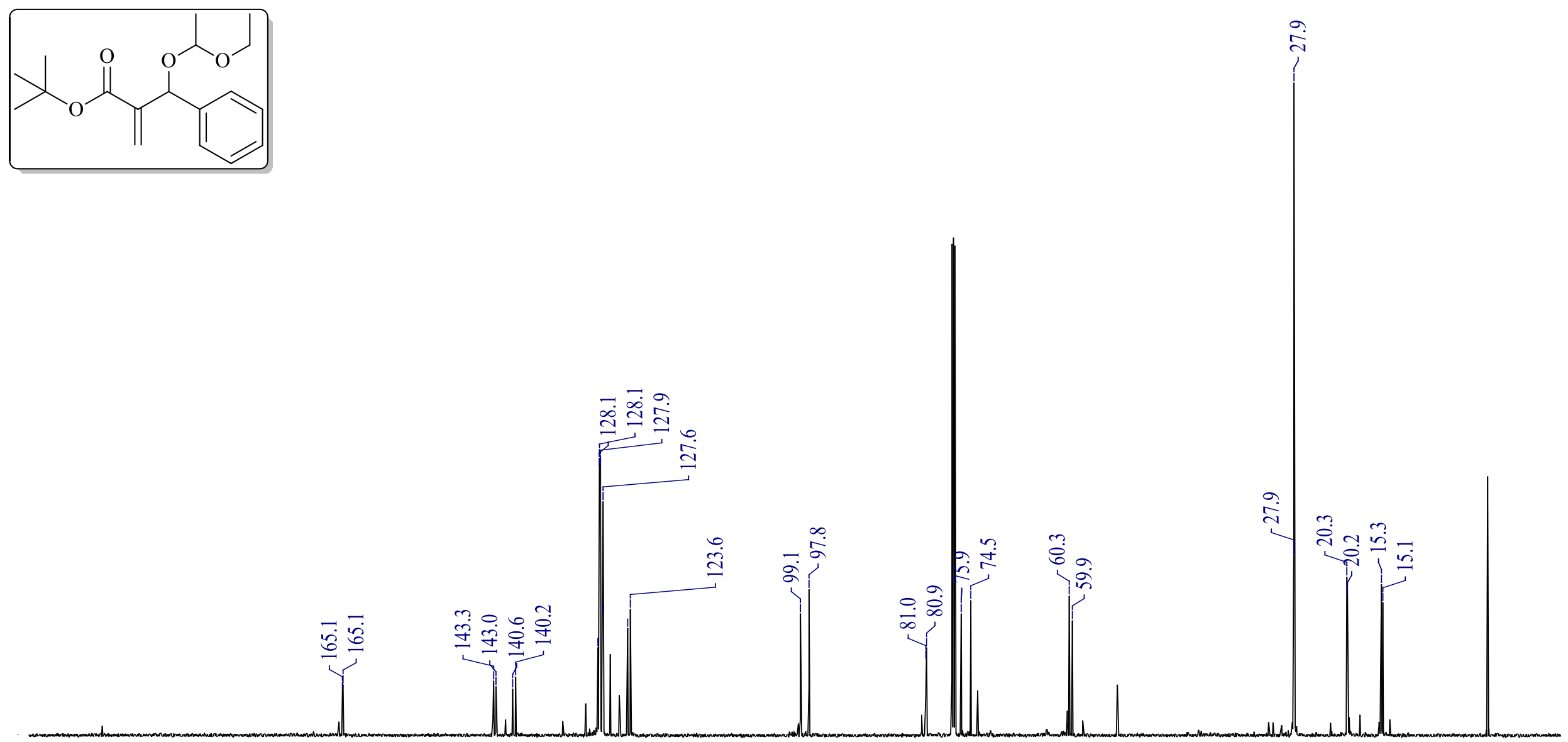

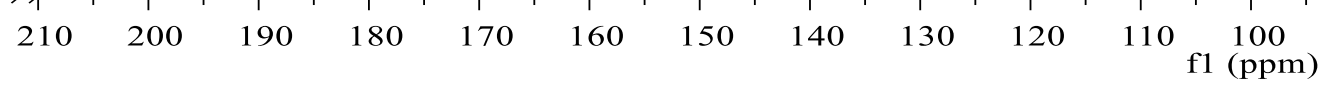

Espectro de RMN de ${ }^{13} \mathrm{C}(150 \mathrm{MHz})$ do bruto de reação do rearranjo de Hurd-Claisen (sem $\left.\mathrm{Hg}(\mathrm{OAc}) 2\right)$ com os isômeros 4a $(E)$ e 4c (Z). 

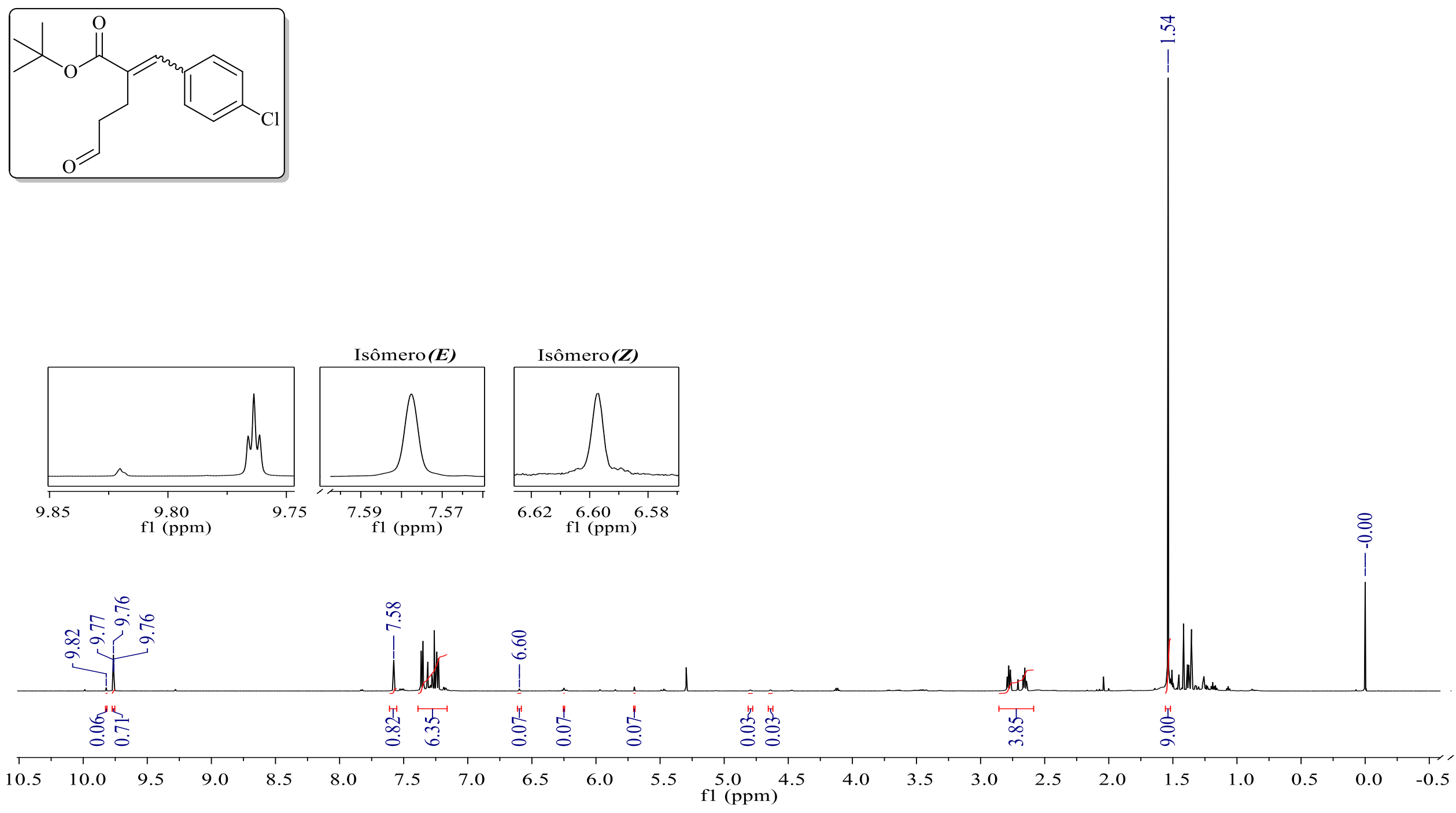

Espectro de RMN de ${ }^{1} \mathrm{H}(600 \mathrm{MHz})$ do bruto de reação do rearranjo de Hurd-Claisen (24 horas) com os isômeros 4c (E) e 4c (Z). 

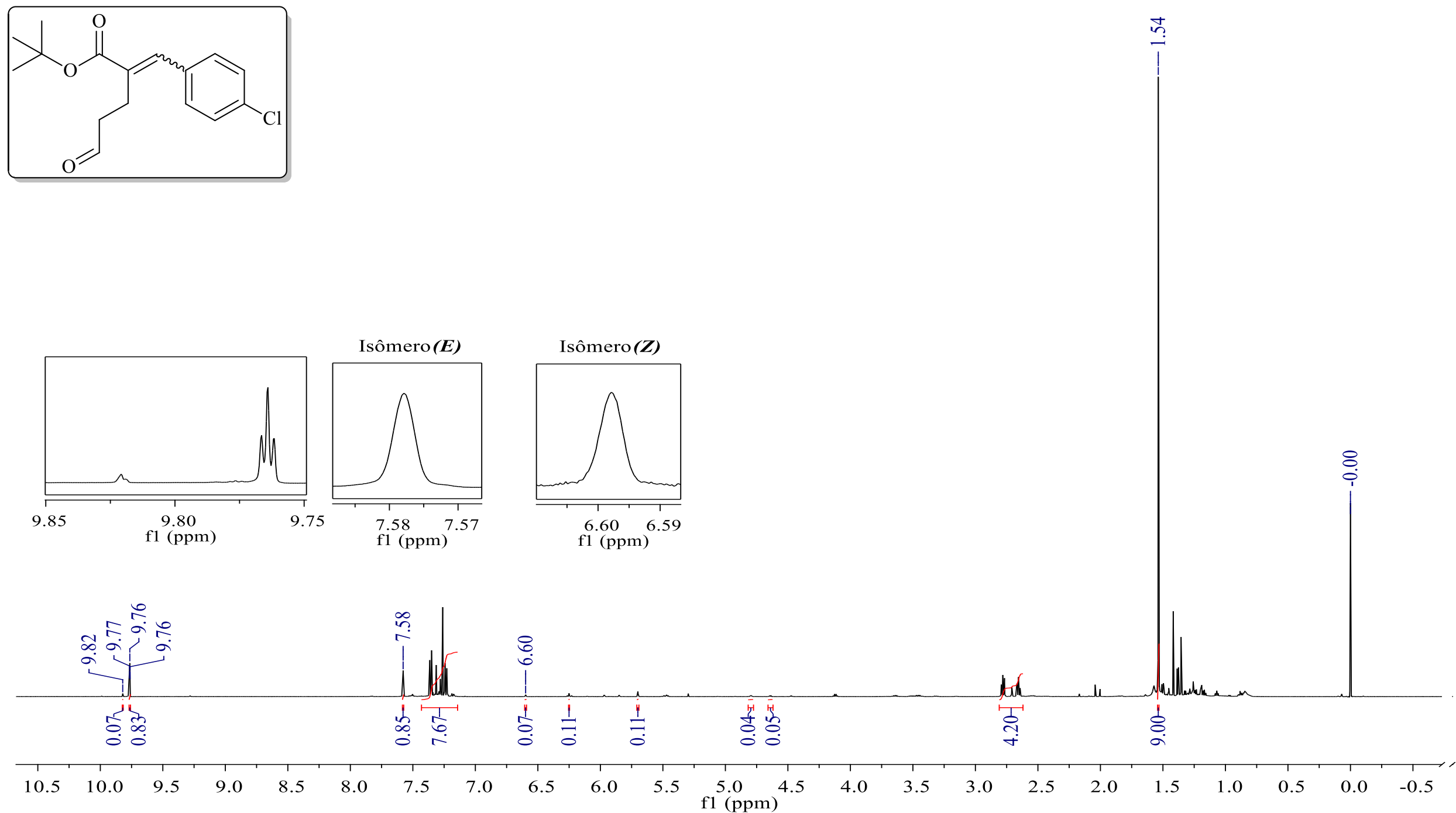

Espectro de RMN de ${ }^{1} \mathrm{H}(600 \mathrm{MHz})$ do bruto de reação do rearranjo de Claisen (48 horas) com os isômeros $4 \mathrm{c}(E)$ e $4 \mathrm{c}(Z)$. 

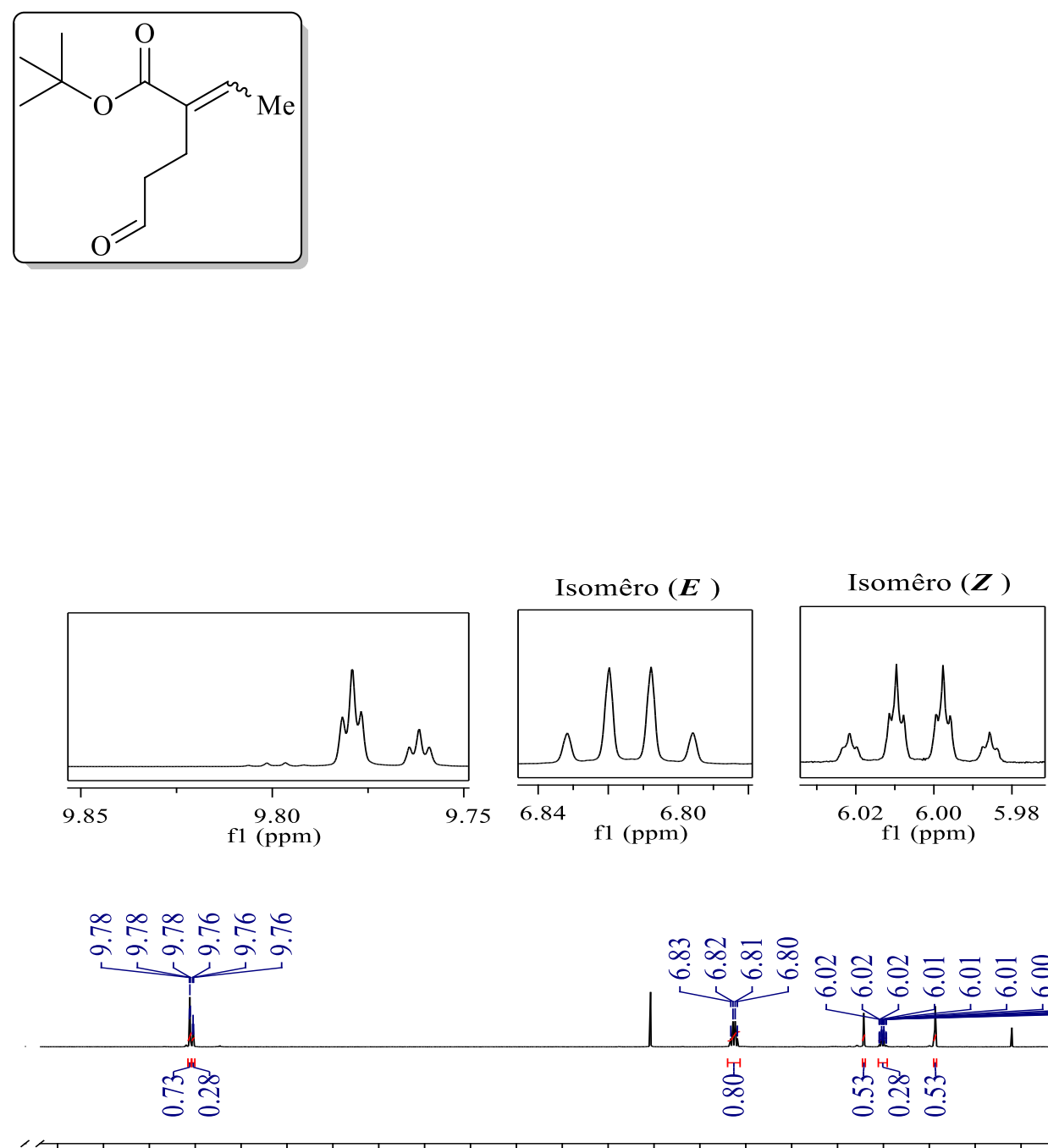

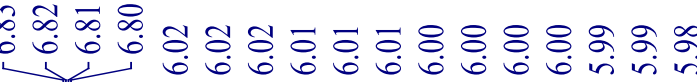
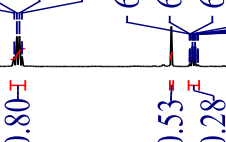

nू. तुํํㅇํㅇ

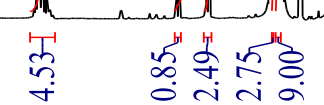

$\begin{array}{llllllll}10.5 & 10.0 & 9.5 & 9.0 & 8.5 & 8.0 & 7.5 & 7.0\end{array}$

6.5

$6.0 \quad 5.5$

5.0
$(\mathrm{ppm})$

$\begin{array}{llll}4.5 & 4.0 & 3.5 & 3.0\end{array}$

$2.5 \quad 2.0$

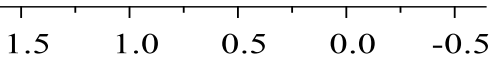

Espectro de RMN de ${ }^{1} \mathrm{H}(600 \mathrm{MHz})$ do bruto de reação do rearranjo de Hurd-Claisen (24 horas) com os isômeros 4h (E) e 4h (Z). 

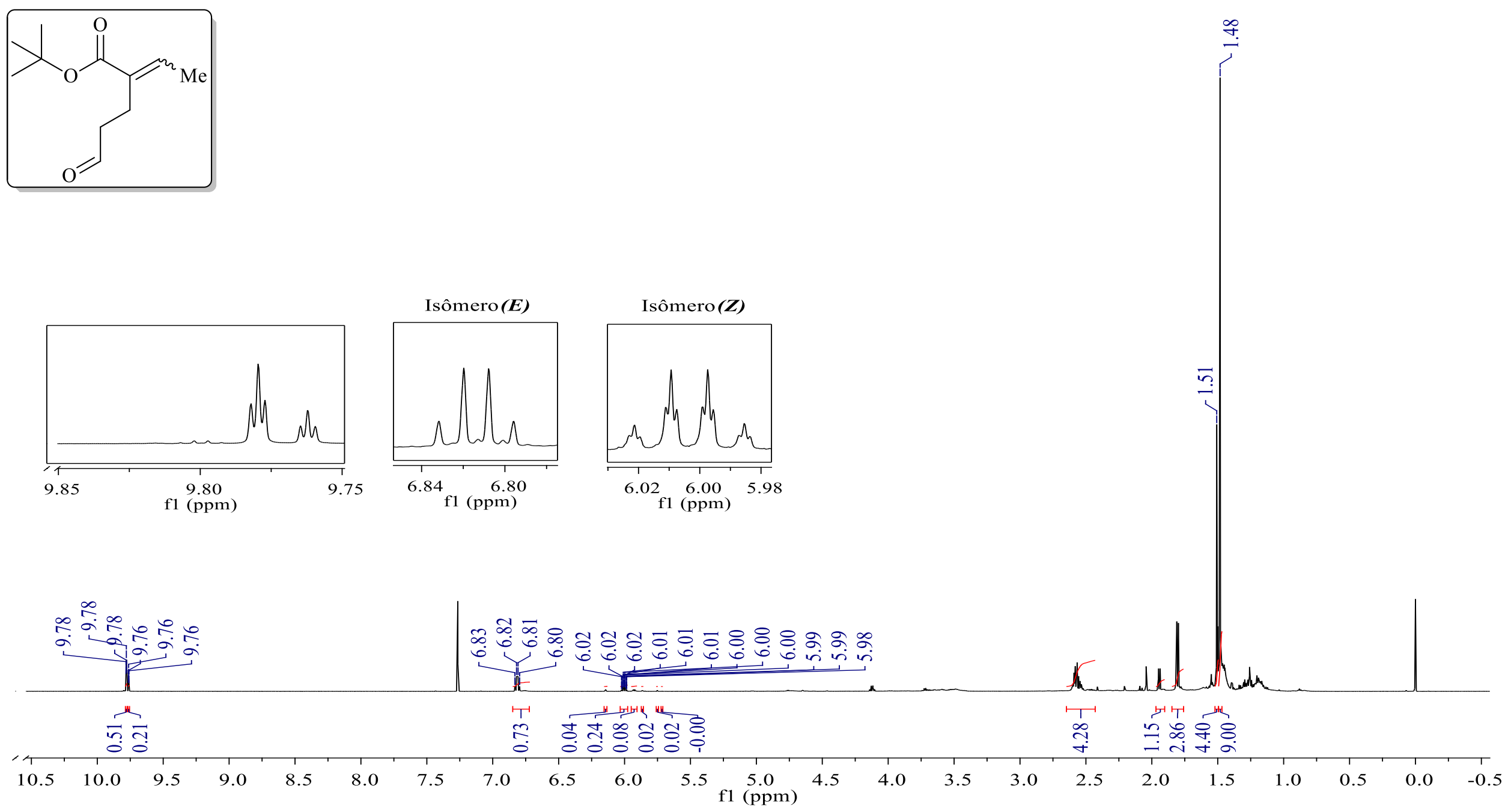

Espectro de RMN de ${ }^{1} \mathrm{H}(600 \mathrm{MHz})$ do bruto de reação do rearranjo de Hurd-Claisen (30 horas) com os isômeros 4h $(E)$ e 4h $(Z)$. 

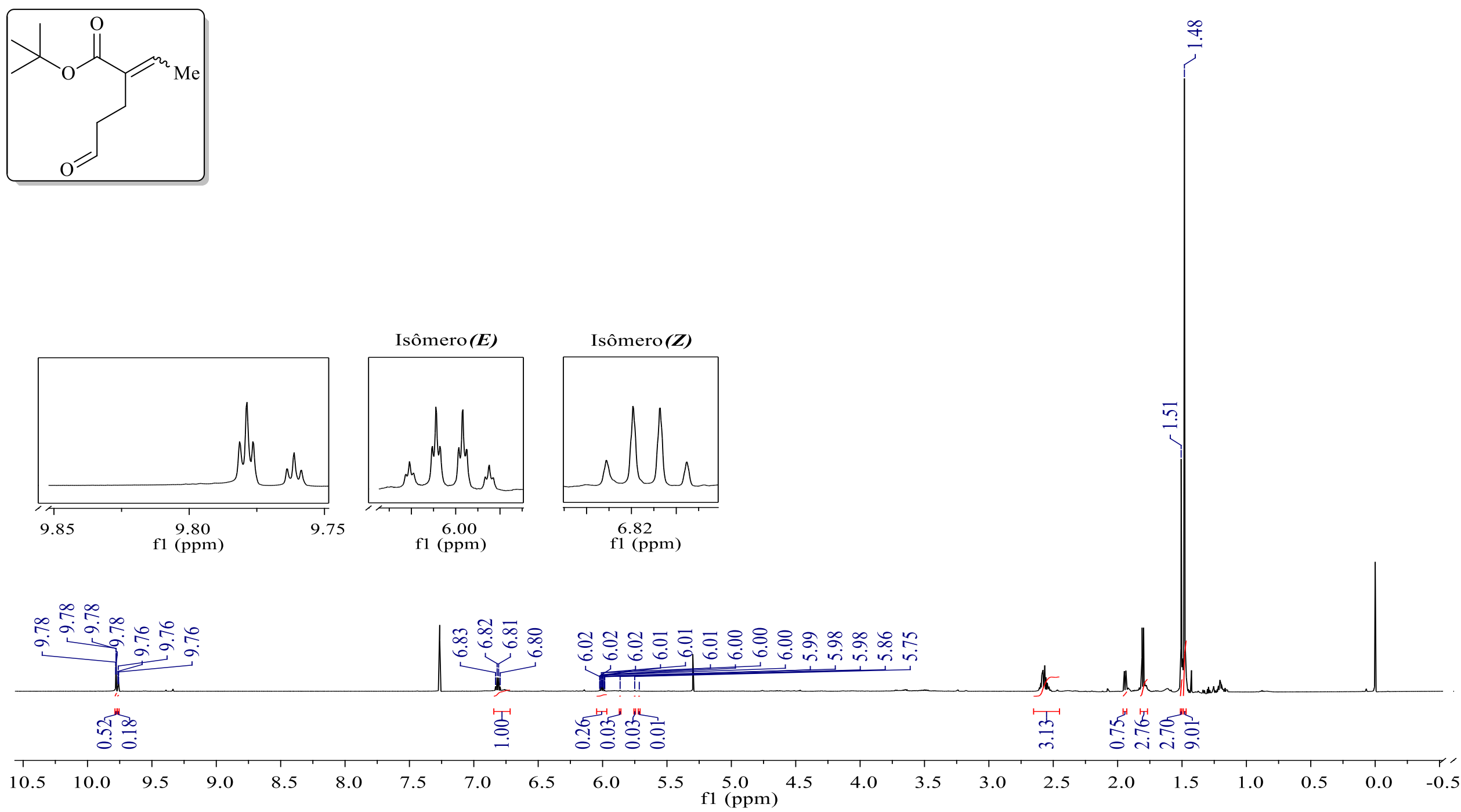

Espectro de RMN de ${ }^{1} \mathrm{H}(600 \mathrm{MHz})$ do bruto de reação do rearranjo de Hurd-Claisen (48 horas) com os isômeros $4 \mathrm{~h}(E)$ e $4 \mathrm{~h}(Z)$. 

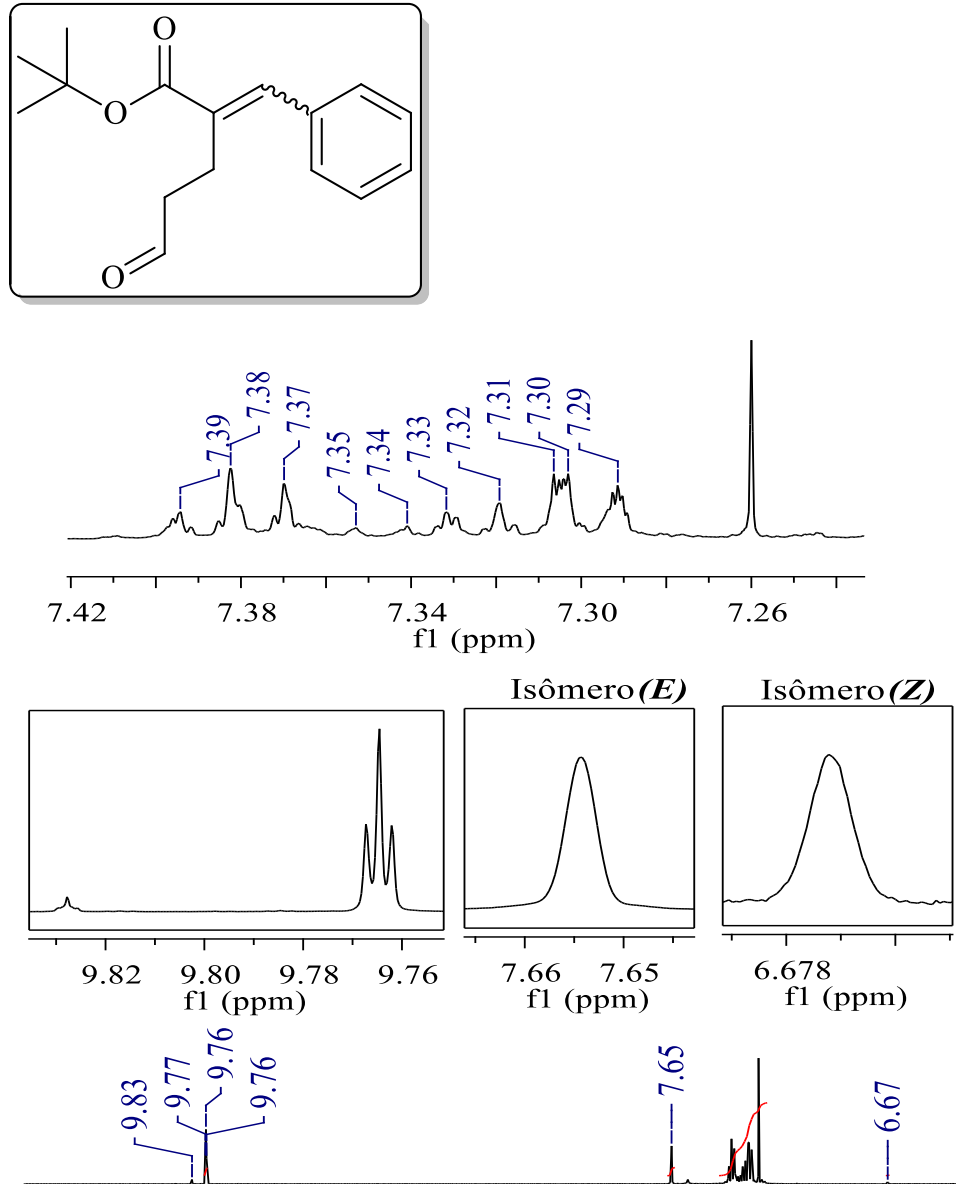

f1 (ppm)
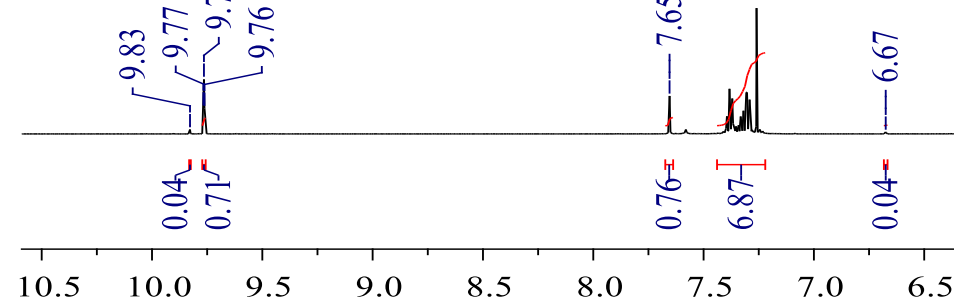

$\frac{1}{6} \frac{1}{\infty}$

荌

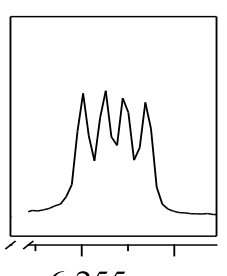

6.255
f1 $(\mathrm{ppm})$
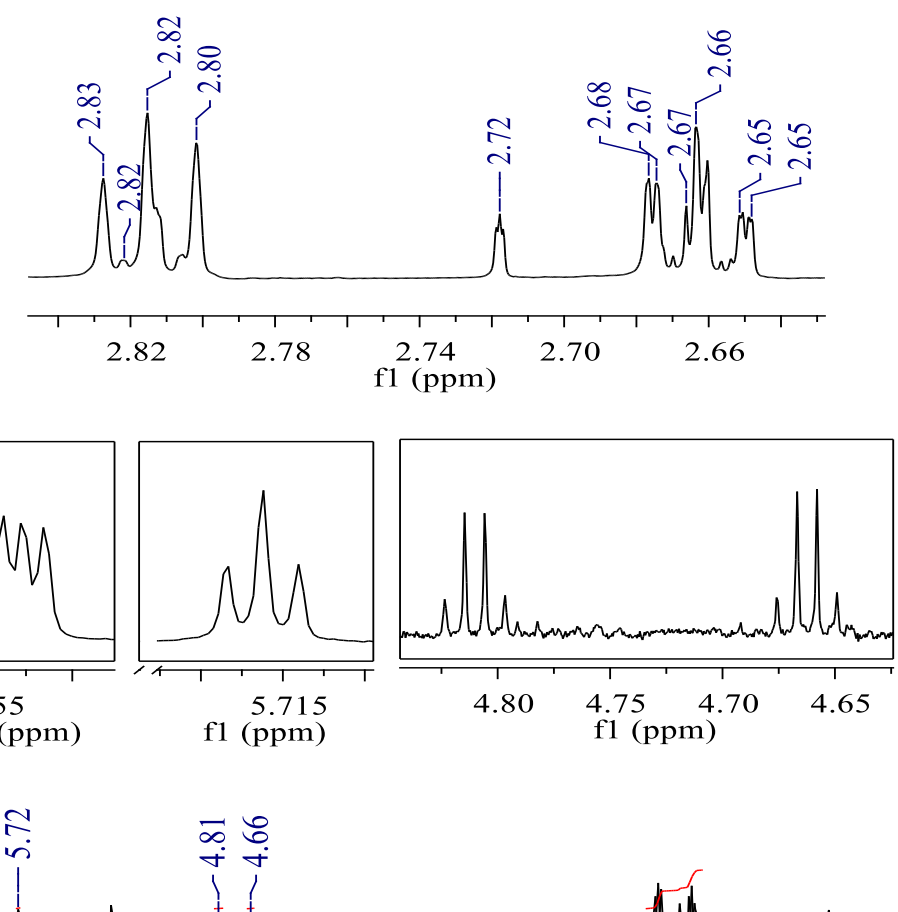

尌产

4.5

f1 $\stackrel{5.0}{(\mathrm{ppm})}$

Espectro de RMN de ${ }^{1} \mathrm{H}(600 \mathrm{MHz})$ do bruto de reação do rearranjo de Hurd-Claisen (condição otimizada) com os isômeros 4a (E) e 4c (Z). 


\section{2-benzidileno-5-oxopentanoato de terc-butila 4a $(E)$}
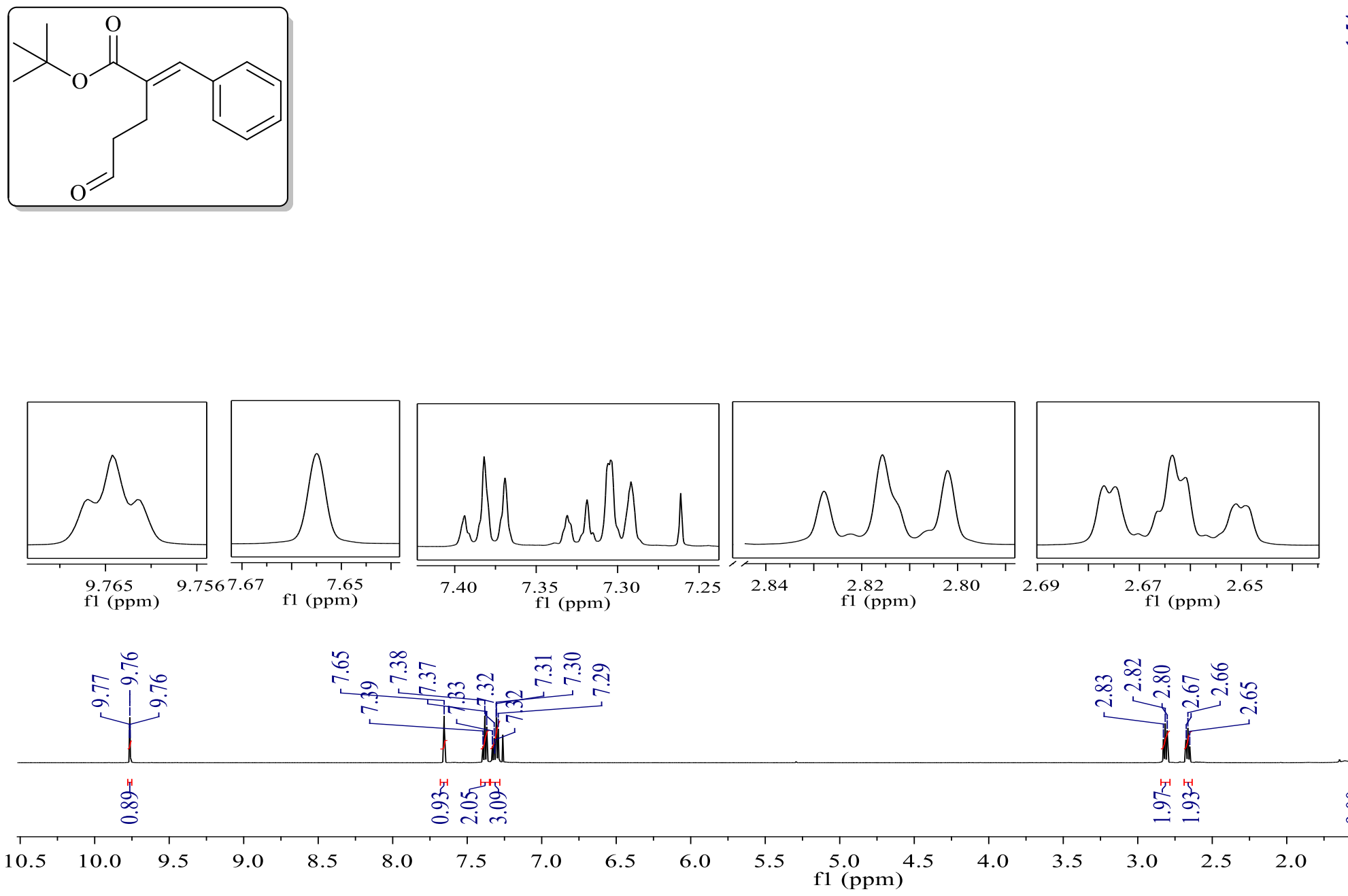

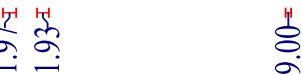

Espectro de RMN de ${ }^{1} \mathrm{H}\left(600 \mathrm{MHz}, \mathrm{CDCl}_{3}\right)$ - Rearranjo de Hurd-Claisen (colunado) 4a $(E)$. 

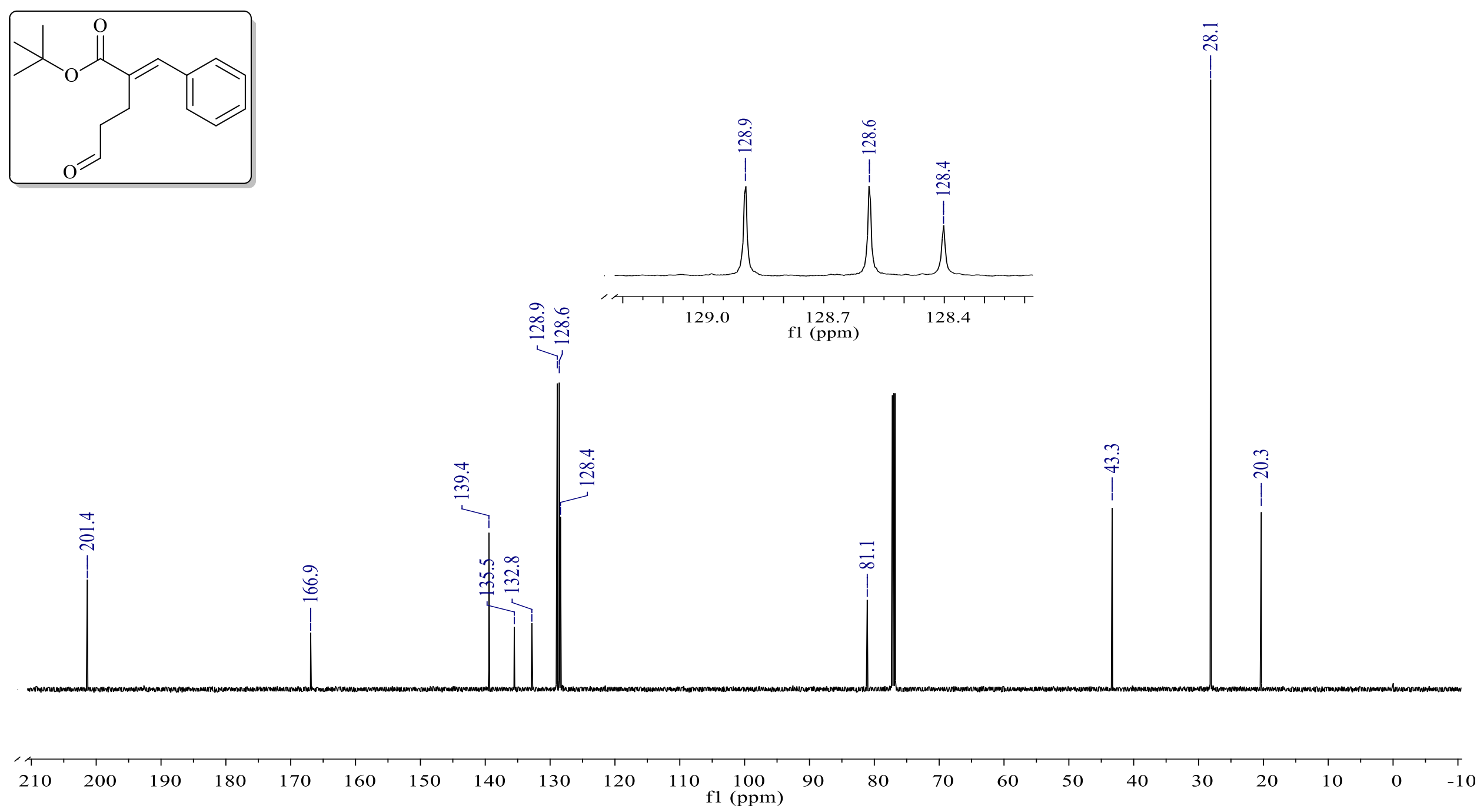

Espectro de RMN de ${ }^{13} \mathrm{C}(150 \mathrm{MHz}, \mathrm{CDCl}$ ) - Rearranjo de Claisen (colunado) 4a $(E)$. 


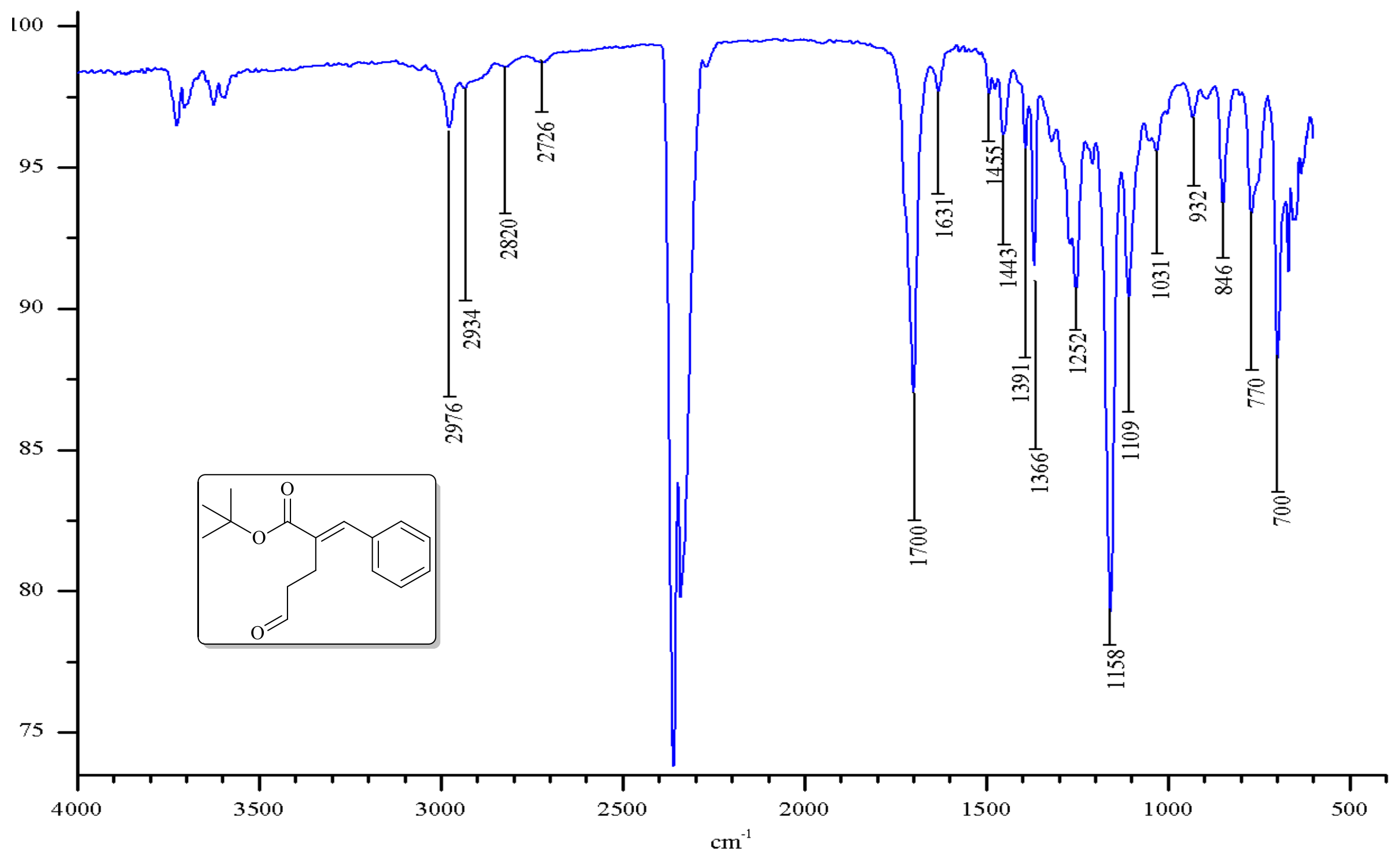

Espectro de infravermelho (ATR) - Rearranjo de Claisen (colunado) 4a (E). 

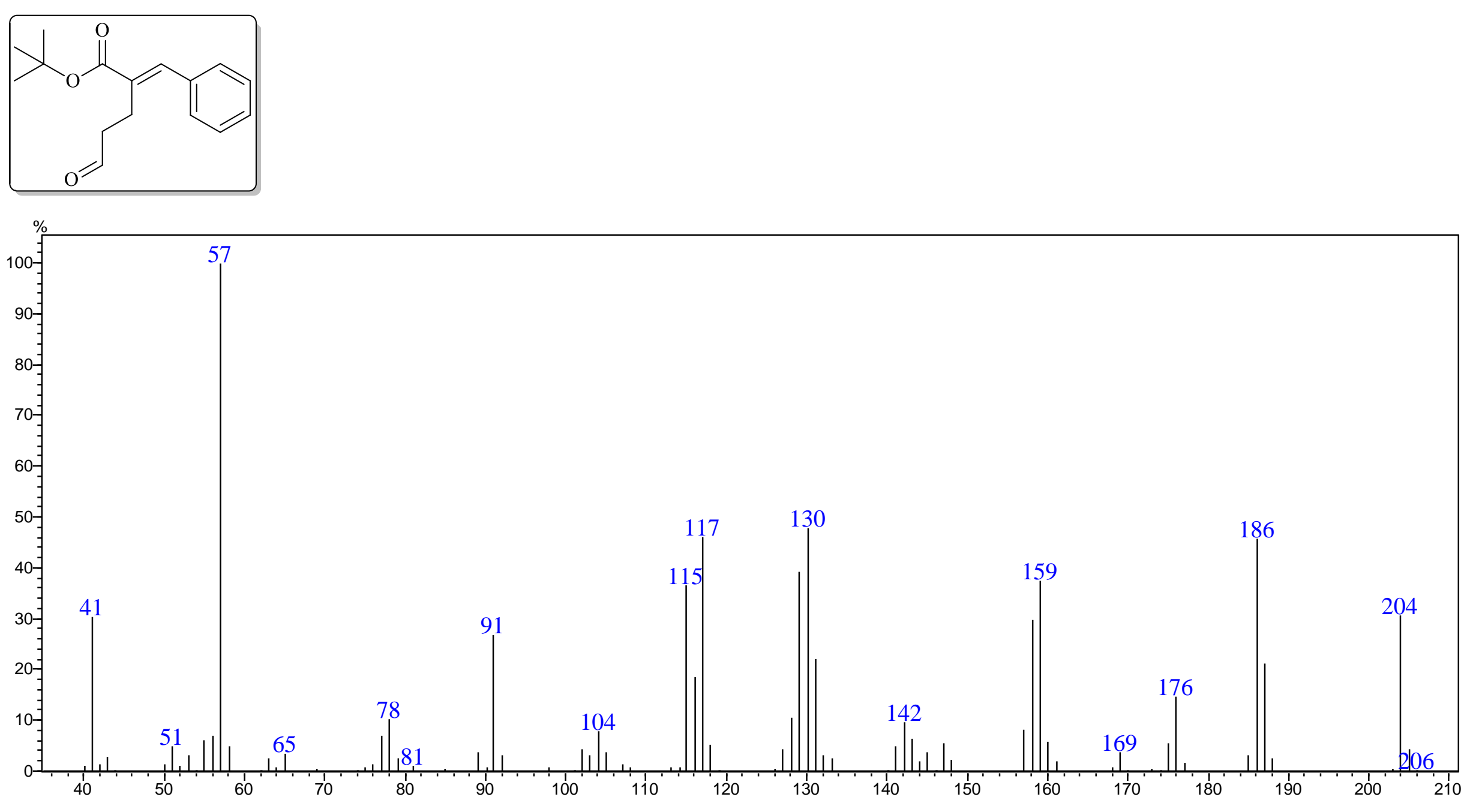

Espectro de massas (EM $70 \mathrm{eV} \mathrm{m/z)}$ - Rearranjo de Hurd-Claisen 4a 


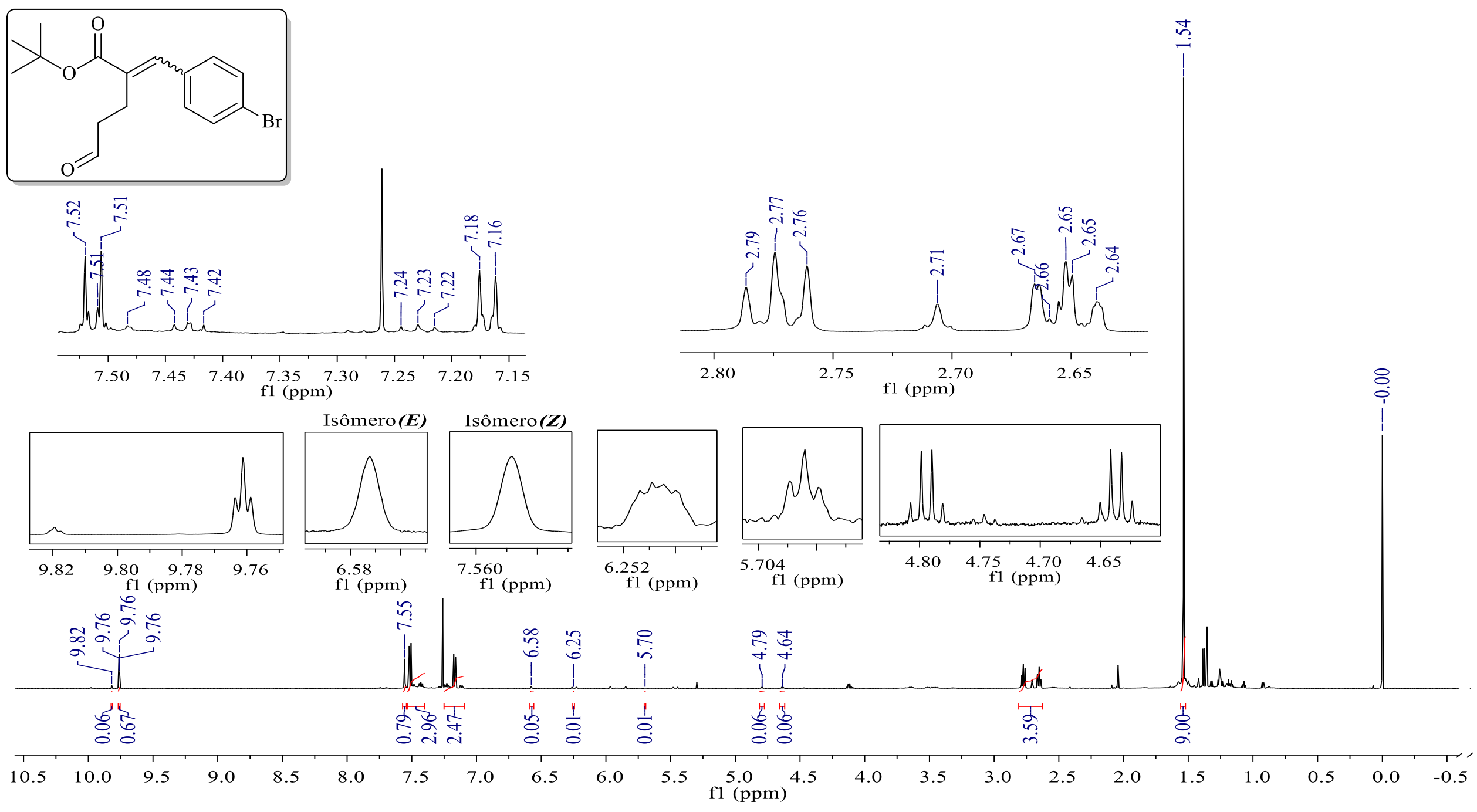

Espectro de RMN de ${ }^{1} \mathrm{H}(600 \mathrm{MHz})$ do bruto de reação do rearranjo de Hurd-Claisen (condição otimizada) com os isômeros 4b (E) e 4b $(Z)$. 


\section{2-(4-bromobenzidileno)-5-oxopentanoato de terc-butila 4b (E)}
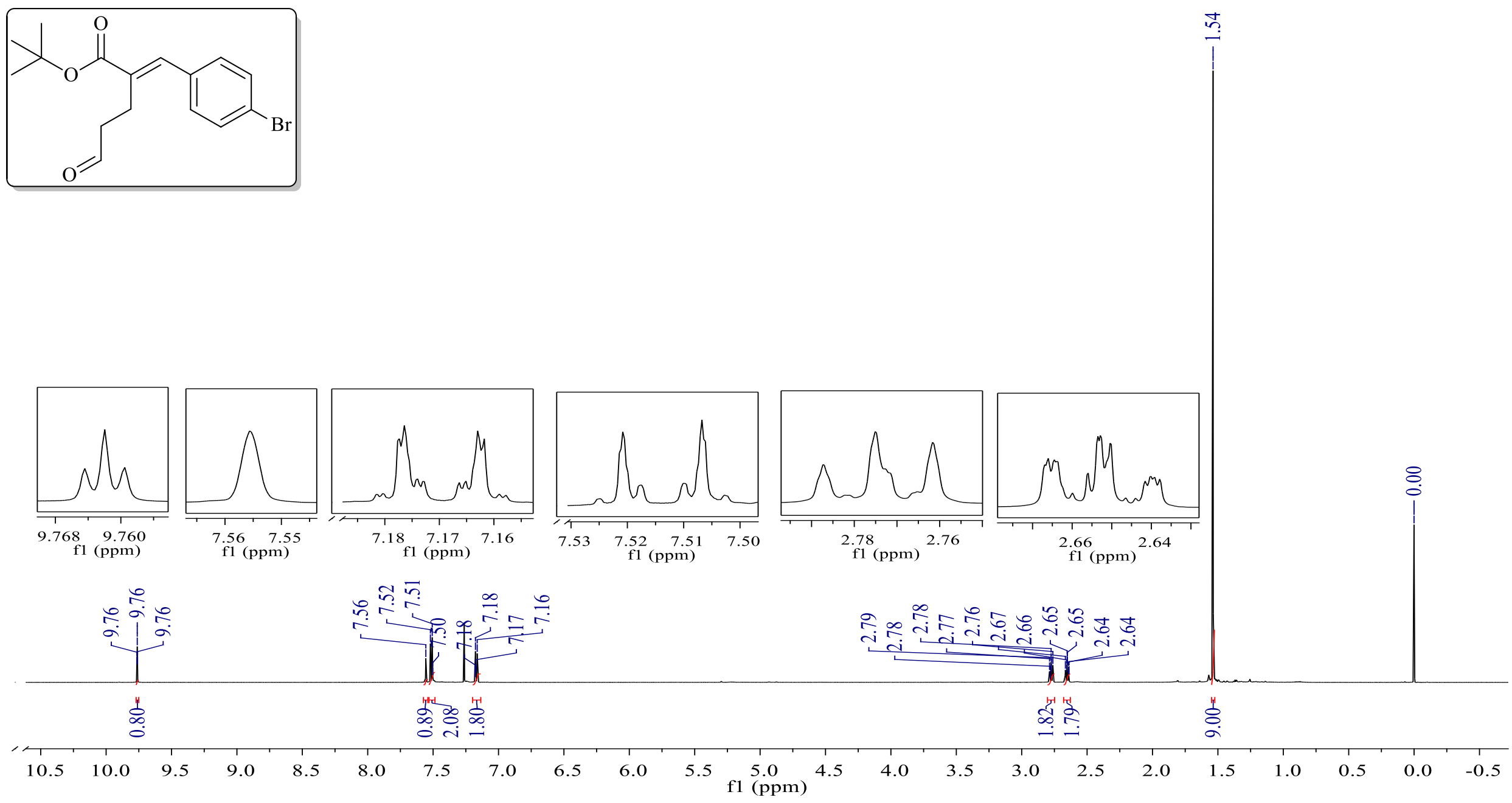

Espectro de RMN de ${ }^{1} \mathrm{H}\left(600 \mathrm{MHz}, \mathrm{CDCl}_{3}\right)$ - Rearranjo de Hurd-Claisen (colunado) 4b (E). 

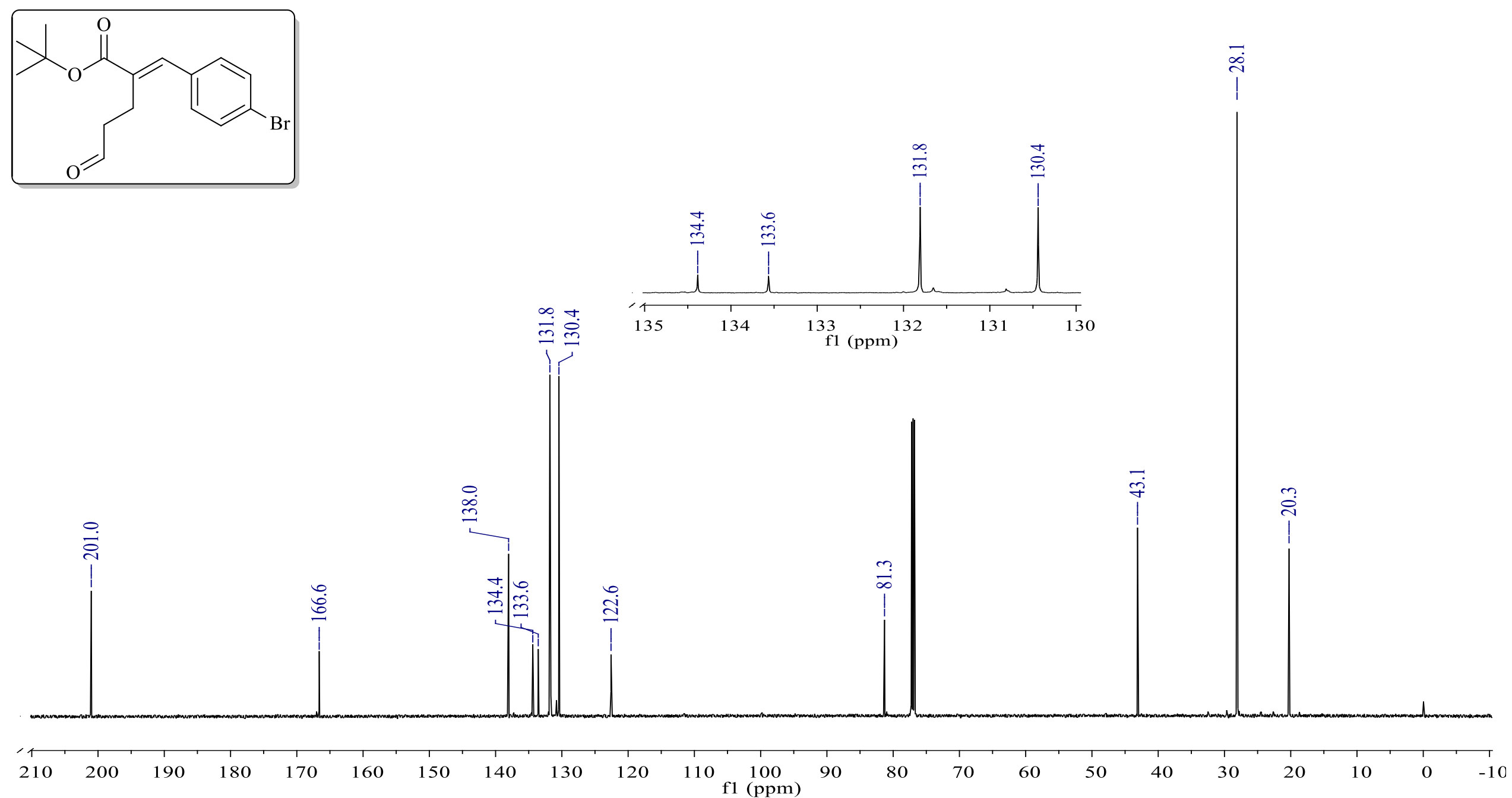

Espectro de RMN de ${ }^{13} \mathrm{C}\left(150 \mathrm{MHz}, \mathrm{CDCl}_{3}\right)$ - Rearranjo de Hurd-Claisen (colunado) 4b (E). 


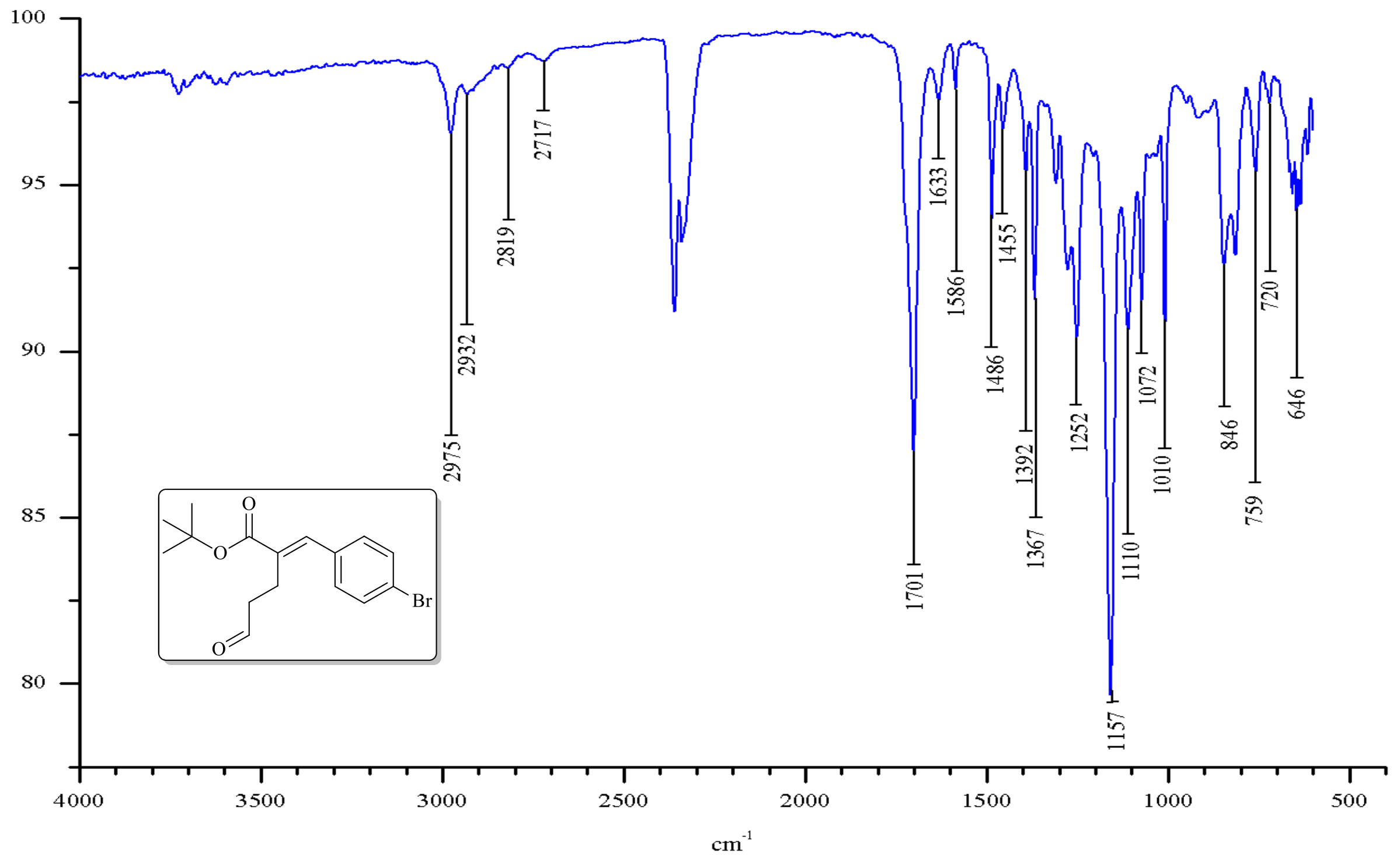

Espectro de infravermelho (ATR) - Rearranjo de Hurd-Claisen (colunado) 4b (E). 

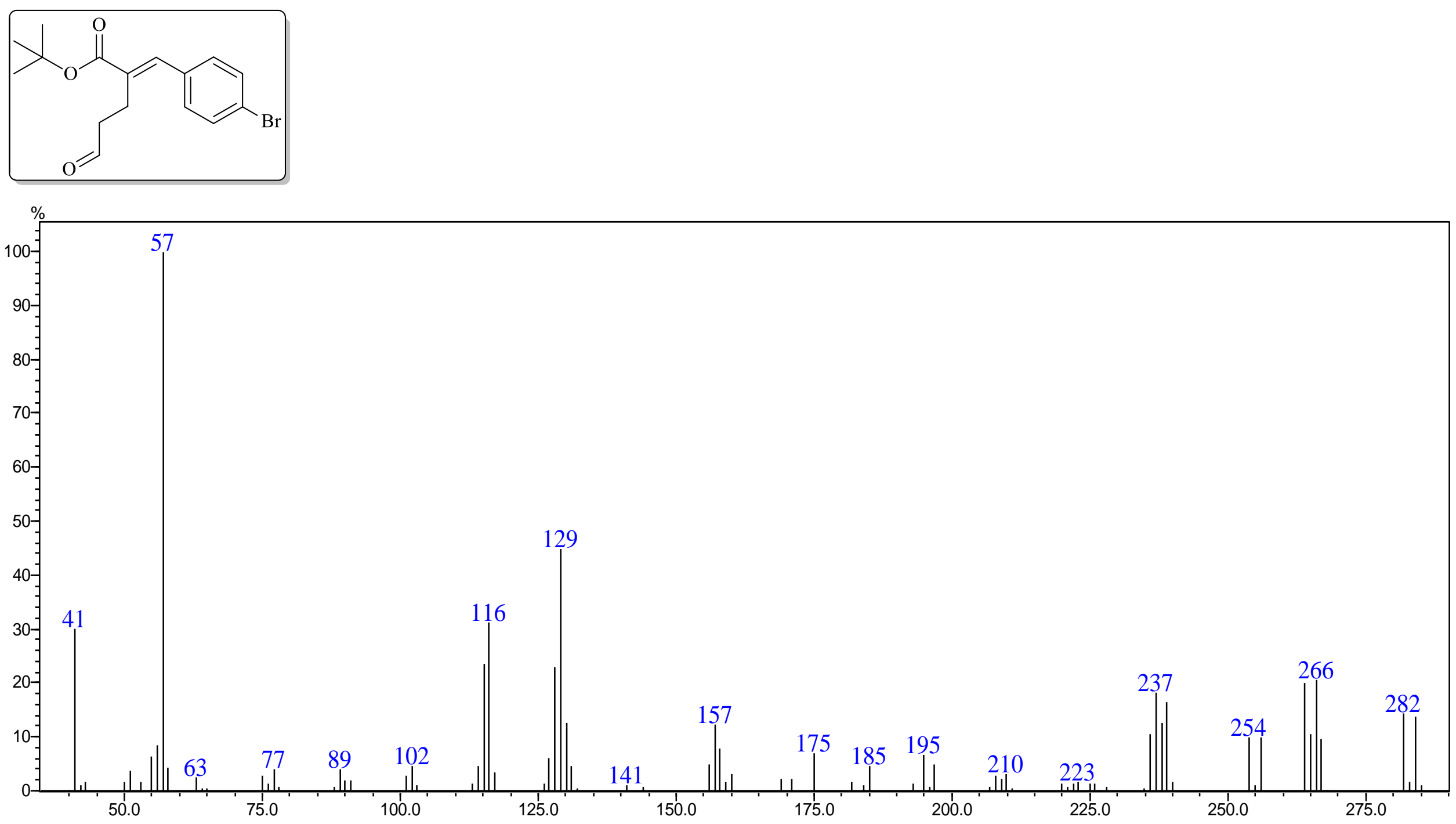

Espectro de massas $(\mathrm{EM} 70 \mathrm{eV}$ m/z) - Rearranjo de Hurd-Claisen 4b 

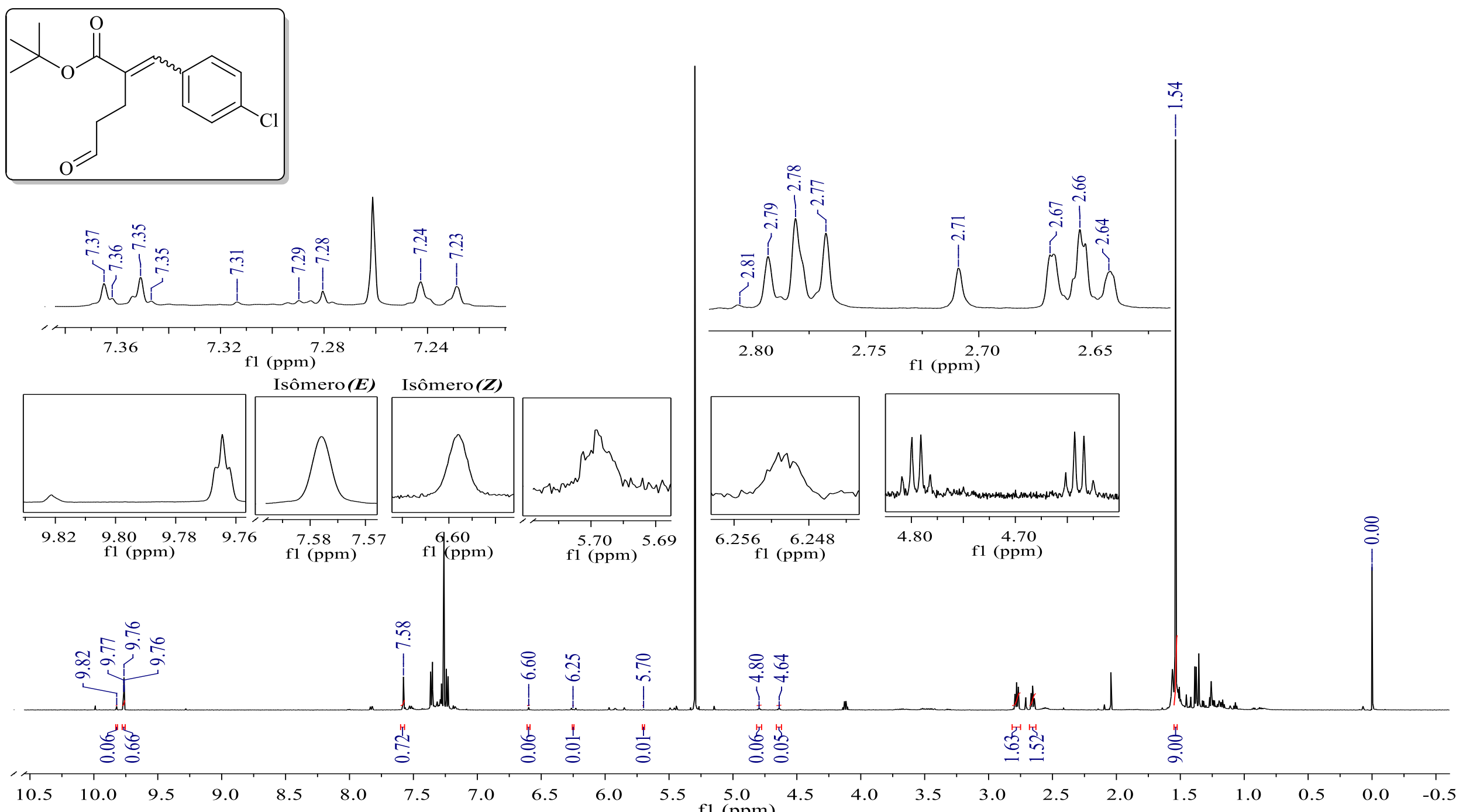

Espectro de RMN de ${ }^{1}$ H (600 MHz) do bruto de reação do rearranjo de Hurd-Claisen (condição otimizada) com os isômeros 4c (E) e 4c (Z). 


\section{2-(4-clorobenzidileno)-5-oxopentanoato de terc-butila 4c $(E)$}
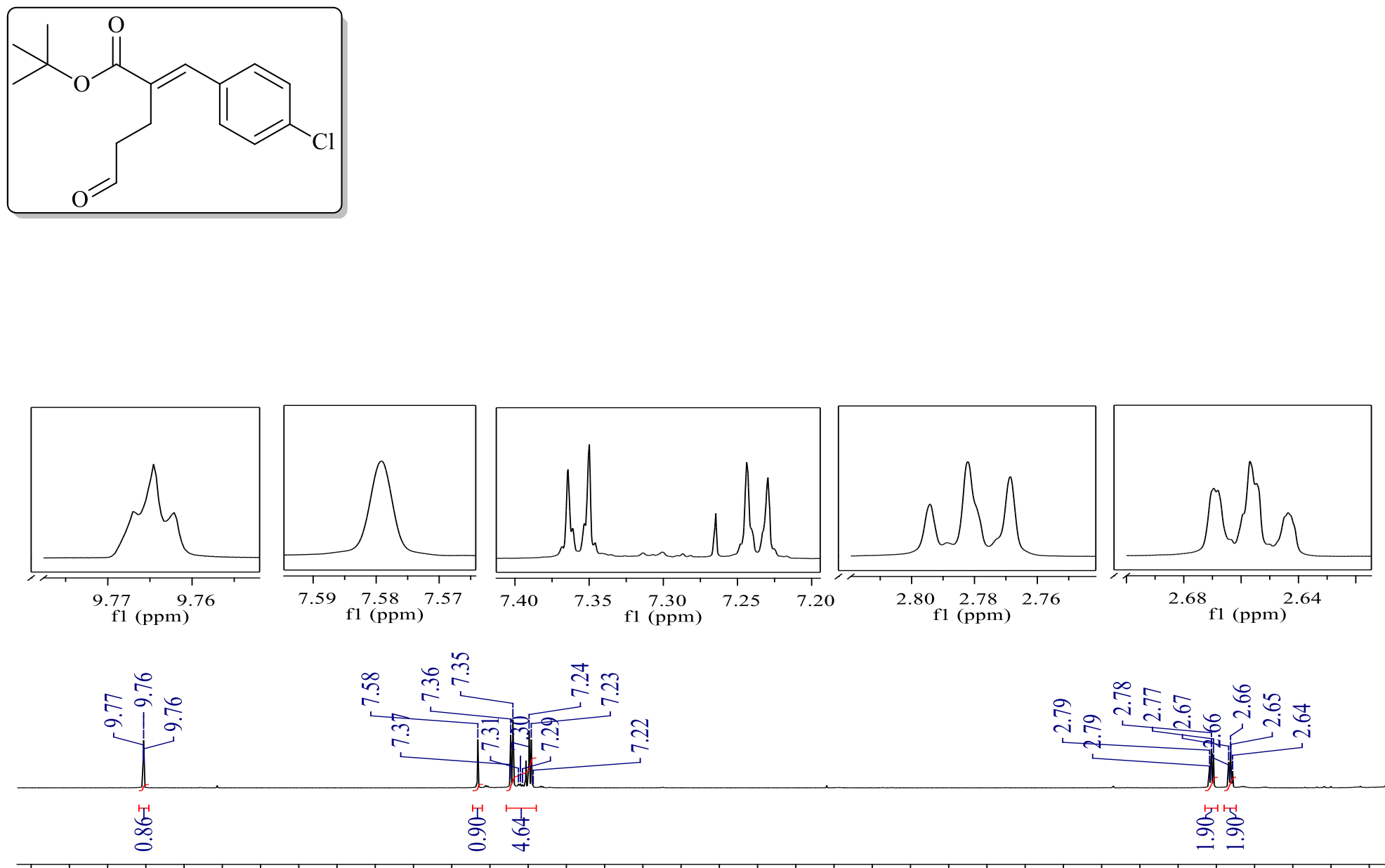

$\begin{array}{lll}10.5 & 10.0 & 9.5\end{array}$

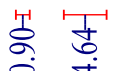

装落

$\stackrel{5.0}{5 .(p p m)} 4.5$

Espectro de RMN de ${ }^{1} \mathrm{H}\left(600 \mathrm{MHz}, \mathrm{CDCl}_{3}\right)$ - Rearranjo de HurdClaisen (colunado) $4 \mathrm{c}(E)$ 

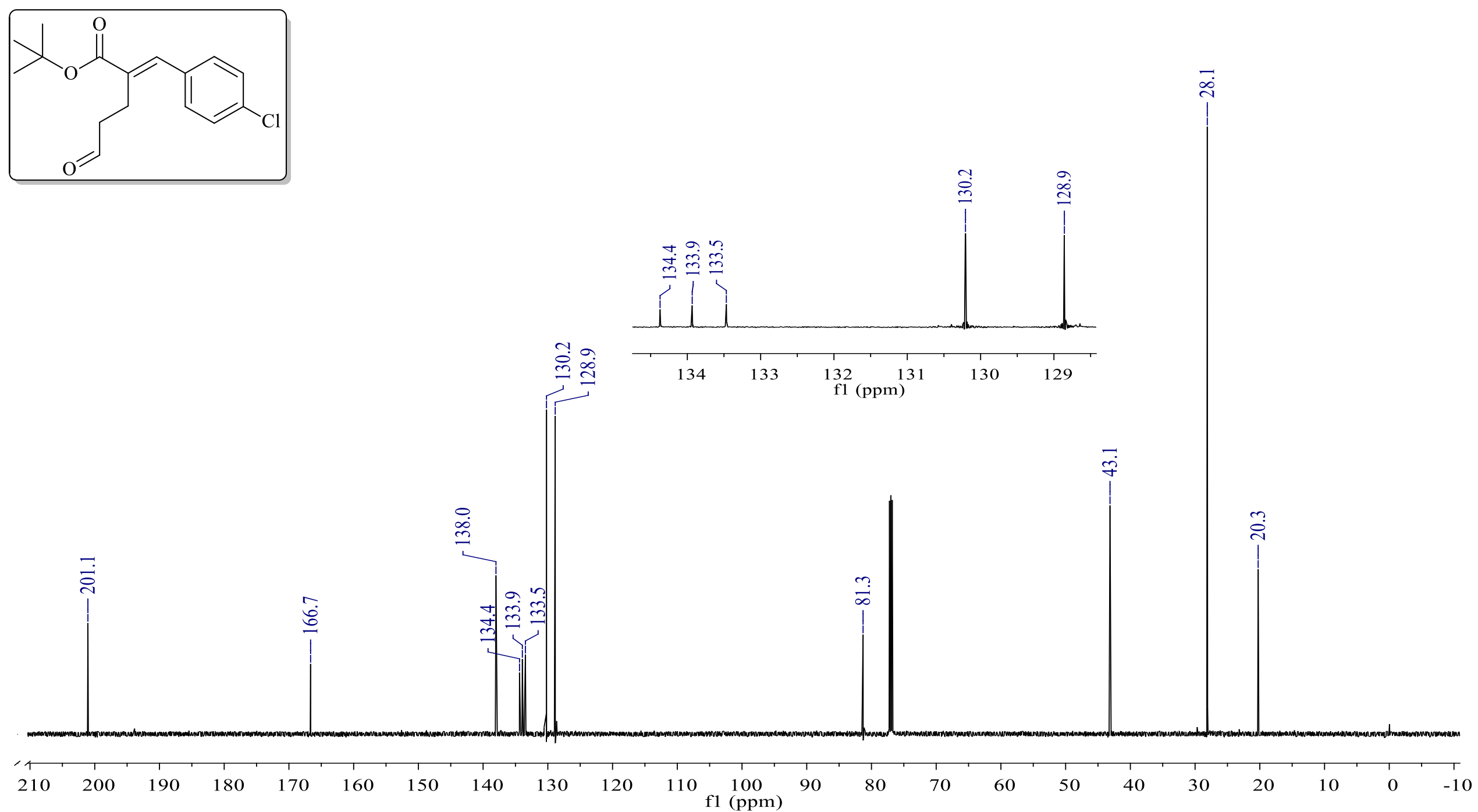

Espectro de RMN de ${ }^{13} \mathrm{C}$ (150 MHz, CDCl$)$ - Rearranjo de Hurd-Claisen (colunado) $4 \mathrm{c}(E)$. 


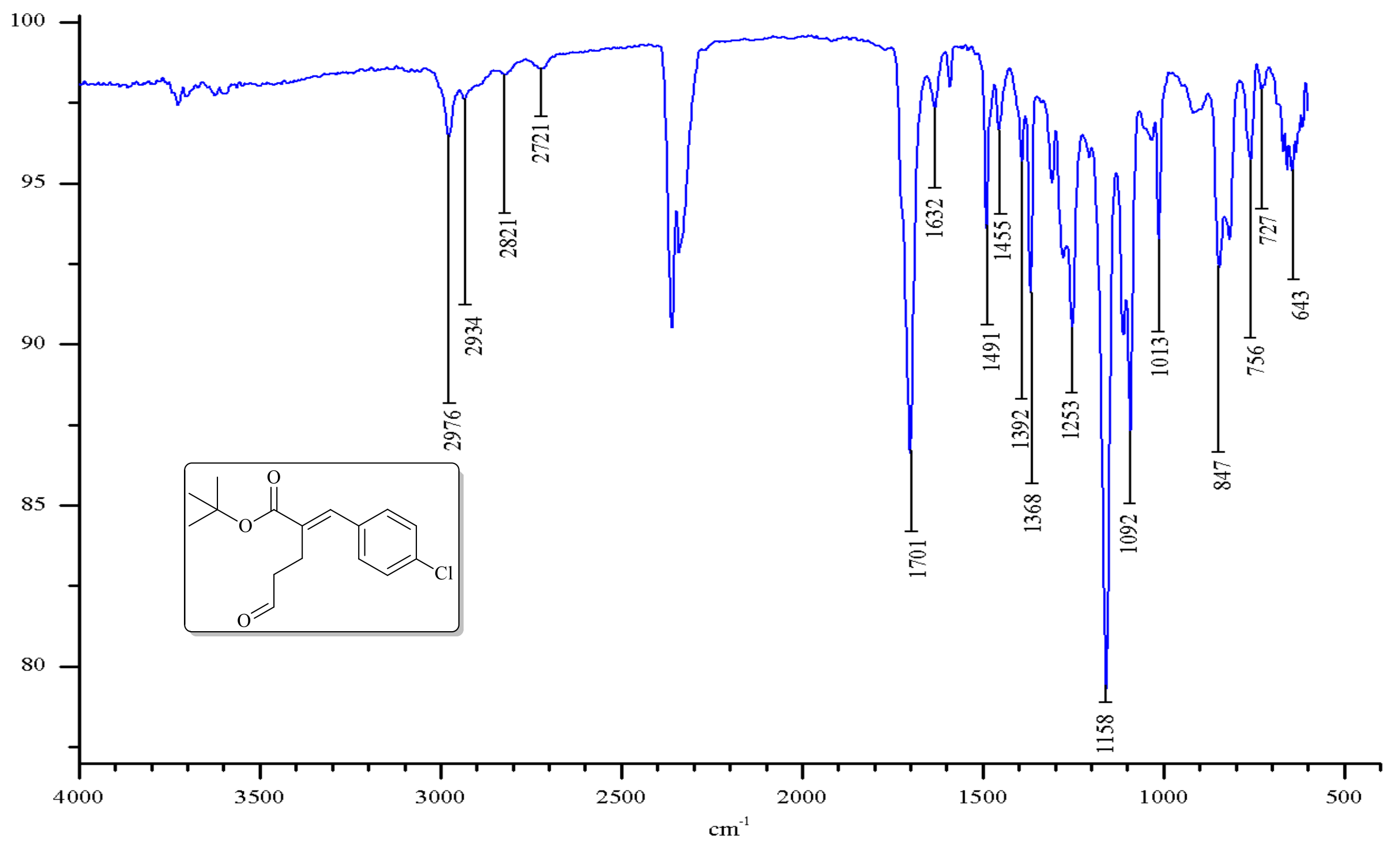

Espectro de infravermelho (ATR) - Rearranjo de Hurd-Claisen (colunado) 4c (E). 

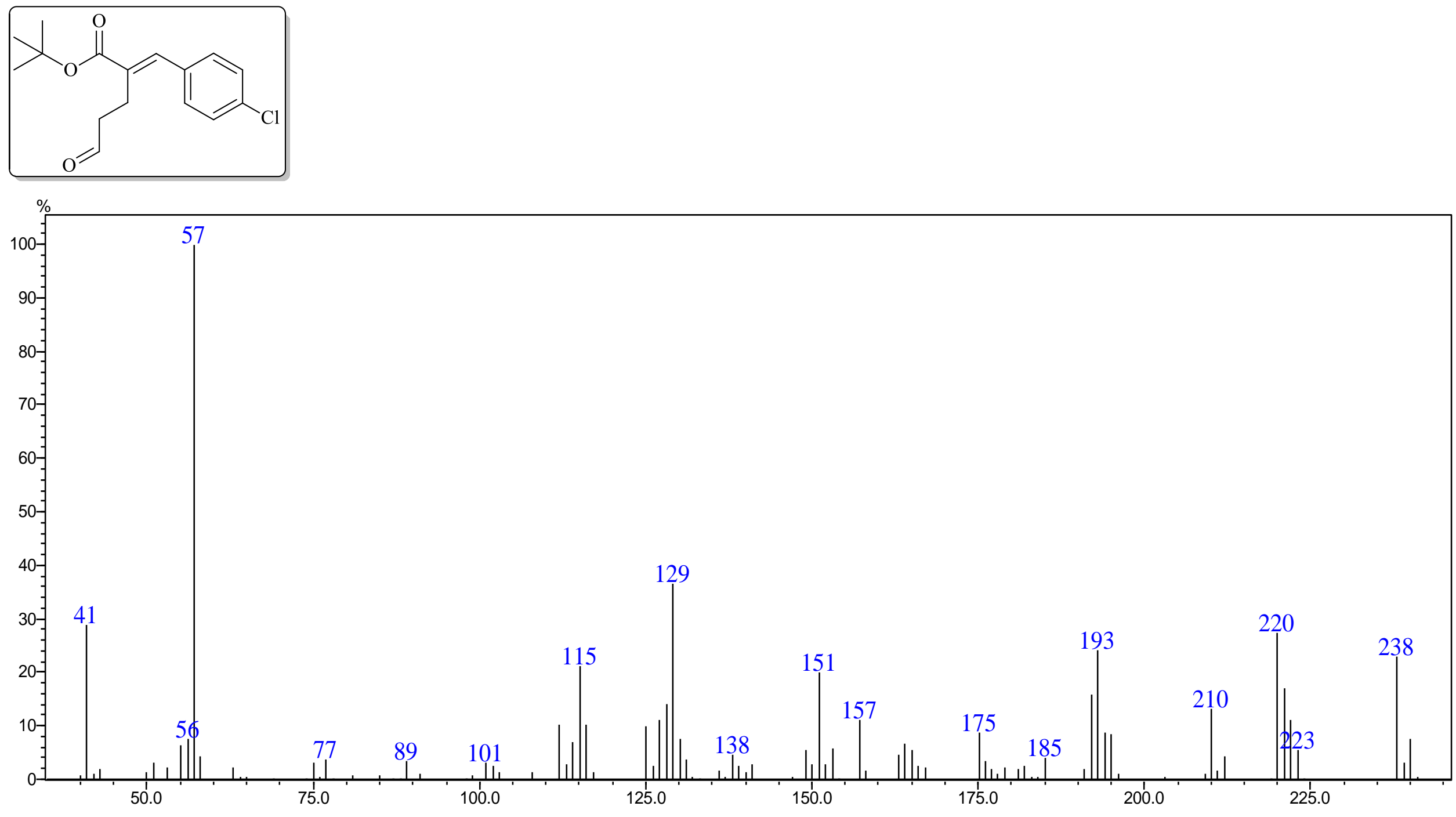

Espectro de massas (EM $70 \mathrm{eV} \mathrm{m/z)} \mathrm{-} \mathrm{Rearranjo} \mathrm{de} \mathrm{Hurd-Claisen} \mathrm{4c}$ 


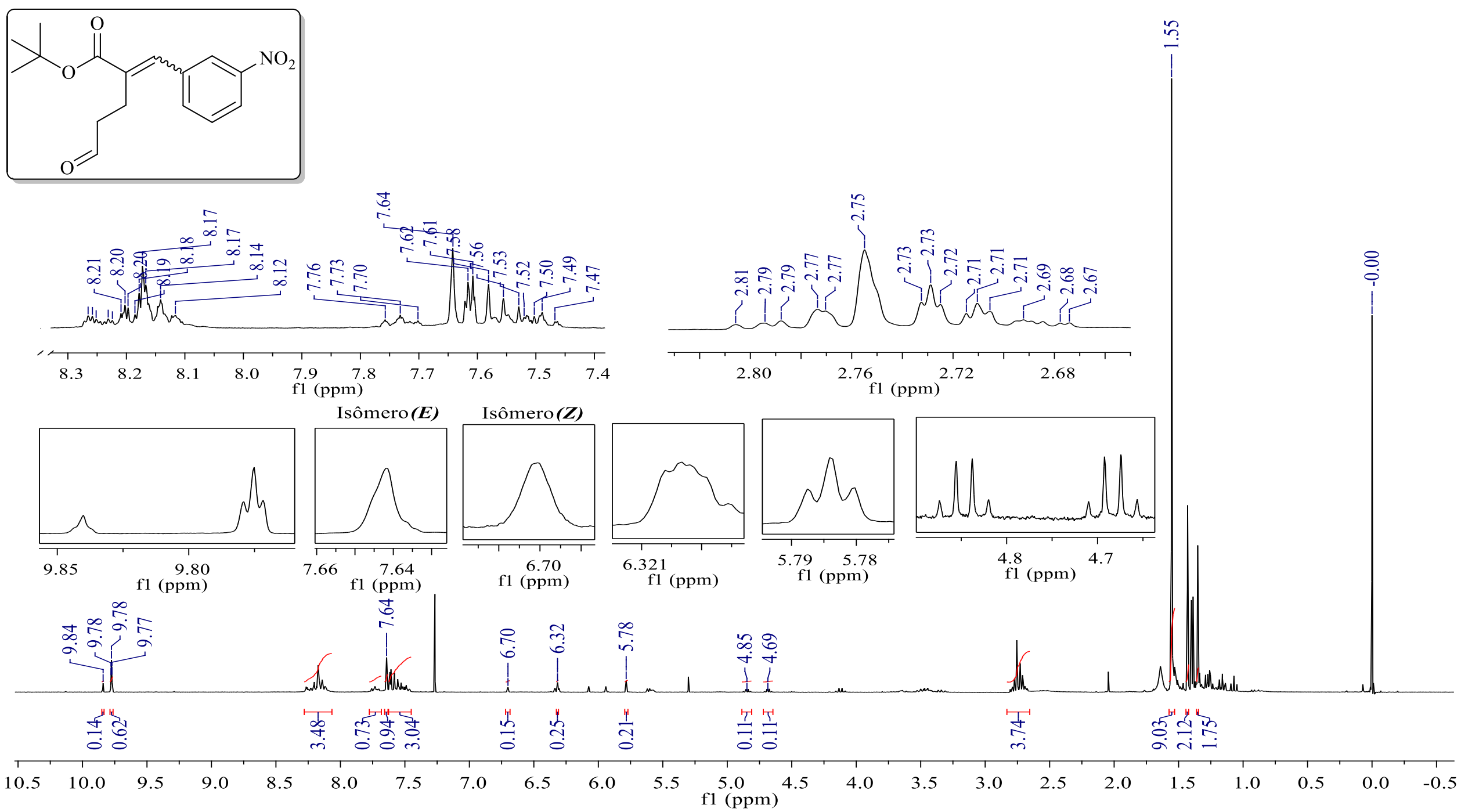

Espectro de RMN de ${ }^{1} \mathrm{H}(600 \mathrm{MHz})$ do bruto de reação do rearranjo de Hurd-Claisen (condição otimizada) com os isômeros 4d (E) e 4d $(Z)$. 
2-(3-nitrobenzidileno)-5-oxopentanoato de terc-butila $4 d(E)$ e $4 \mathrm{~d}(Z)$
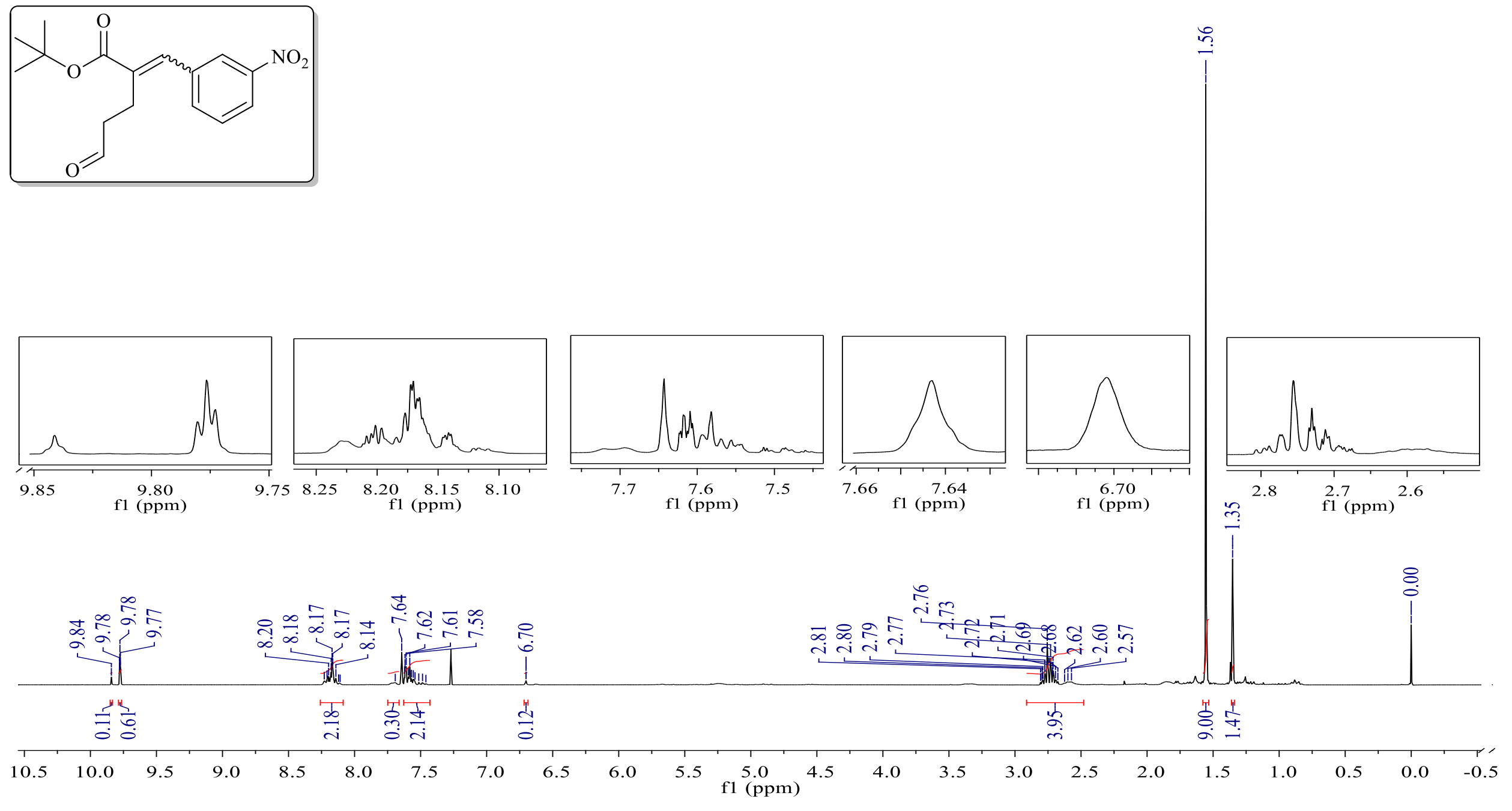

Espectro de RMN de ${ }^{1} \mathrm{H}\left(600 \mathrm{MHz}, \mathrm{CDCl}_{3}\right)$ - Rearranjo de Hurd-Claisen (colunado) 4d (E) 4d (Z). 

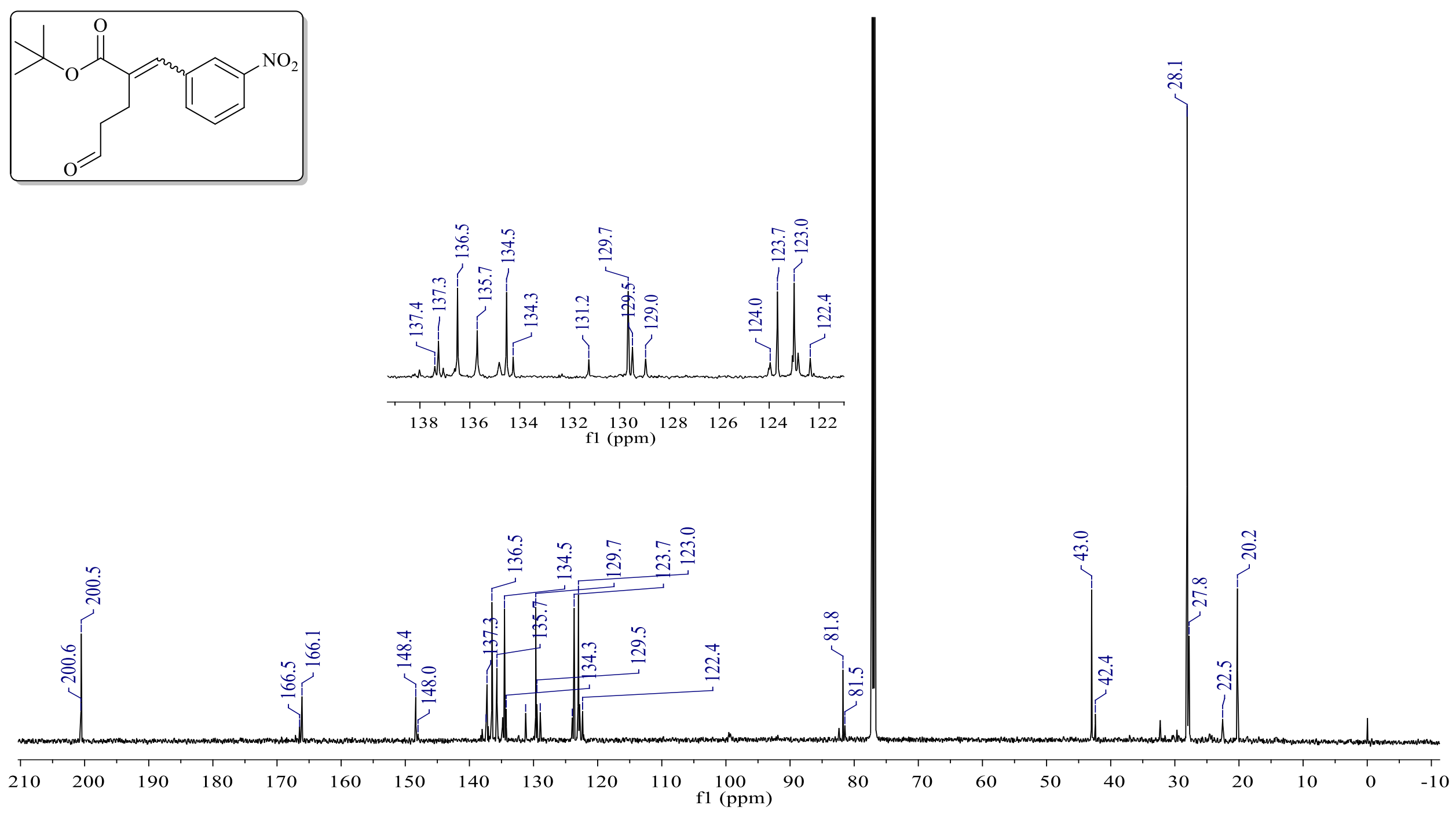

Espectro de RMN de ${ }^{13} \mathrm{C}\left(150 \mathrm{MHz}, \mathrm{CDCl}_{3}\right)$ - Rearranjo de Hurd-Claisen (colunado) 4d (E) 4d (Z). 


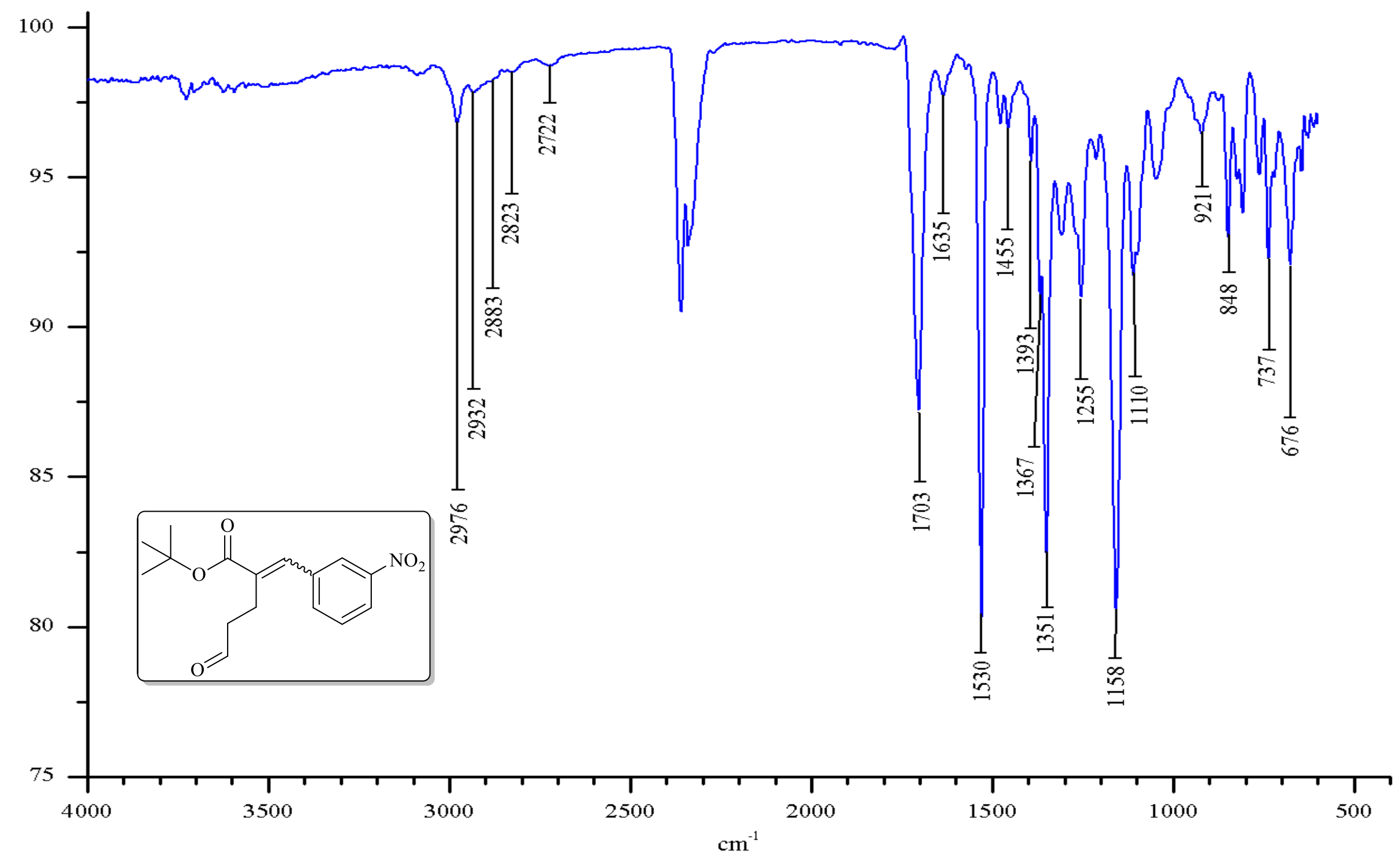

Espectro de infravermelho (ATR) - Rearranjo de Hurd-Claisen (colunado) 4d (E) 4d (Z). 

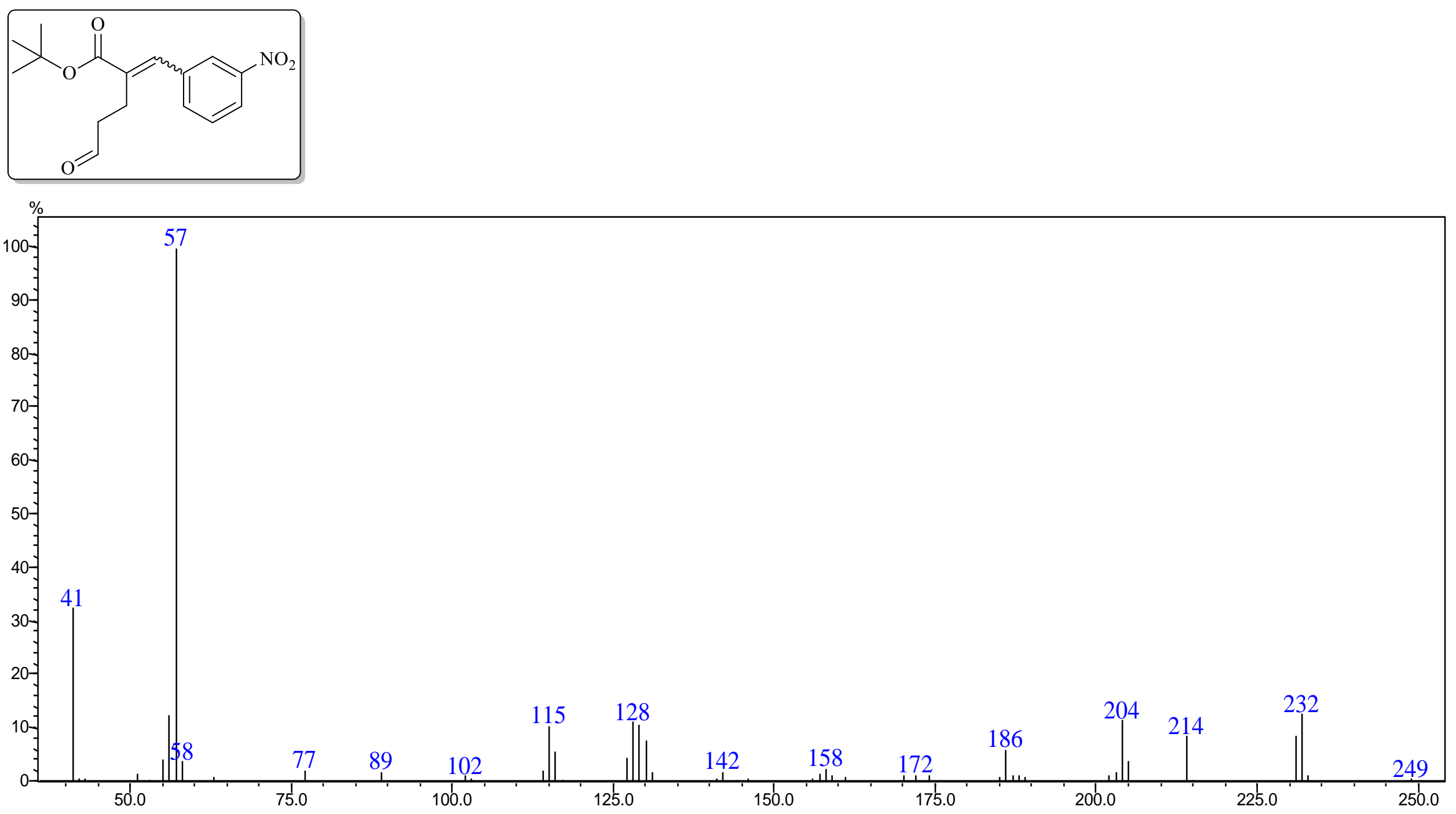

Espectro de massas $(\mathrm{EM} 70 \mathrm{eV}$ m/z) - Rearranjo de Hurd-Claisen (colunado) 4d (E) 4d (Z). 


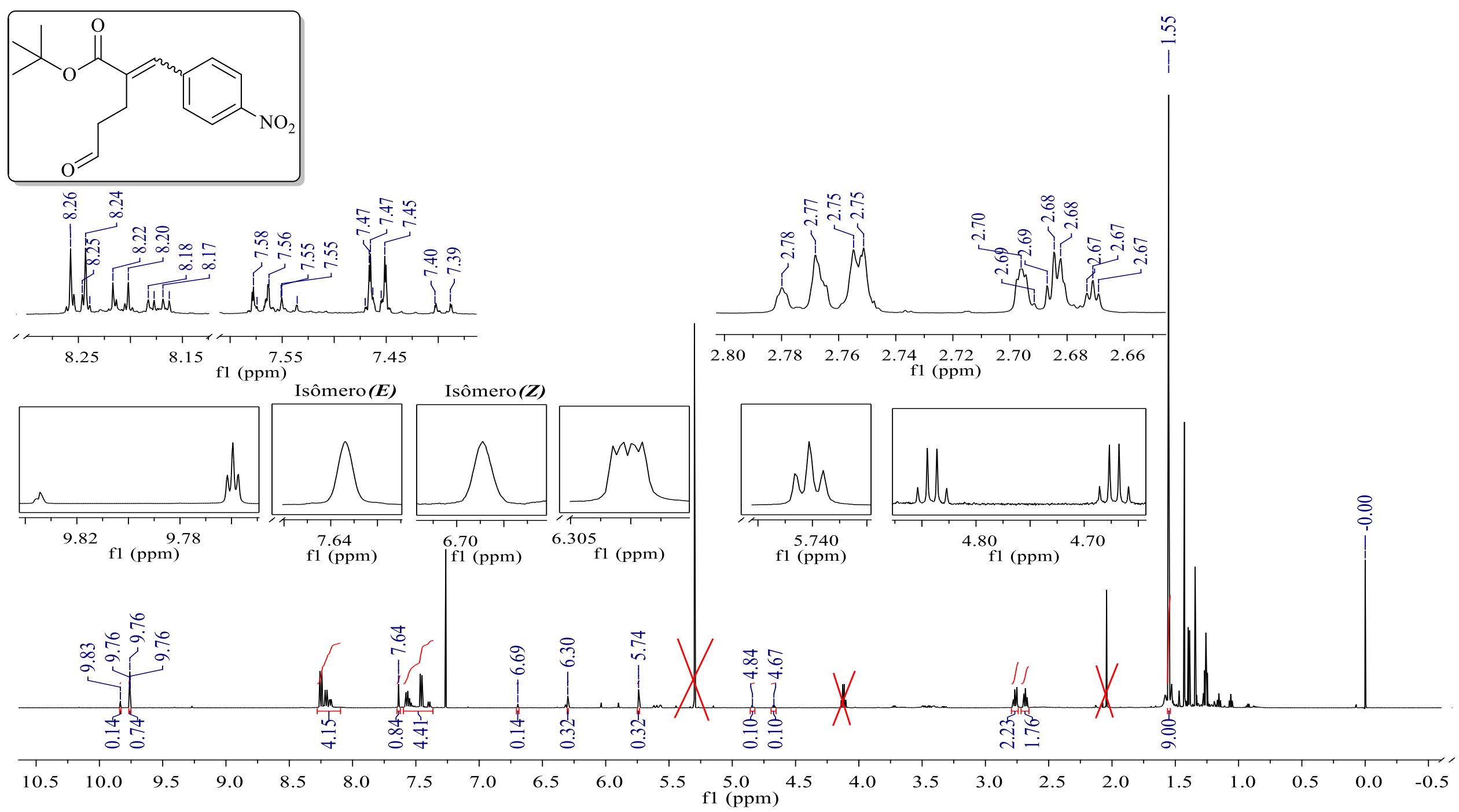

Espectro de RMN de ${ }^{1} \mathrm{H}(600 \mathrm{MHz})$ do bruto de reação do rearranjo de Hurd-Claisen (condição otimizada) com os isômeros 4e (E) e 4e $(Z)$. 


\section{2-(4-nitrobenzidileno)-5-oxopentanoato de terc-butila 4e $(E)$}
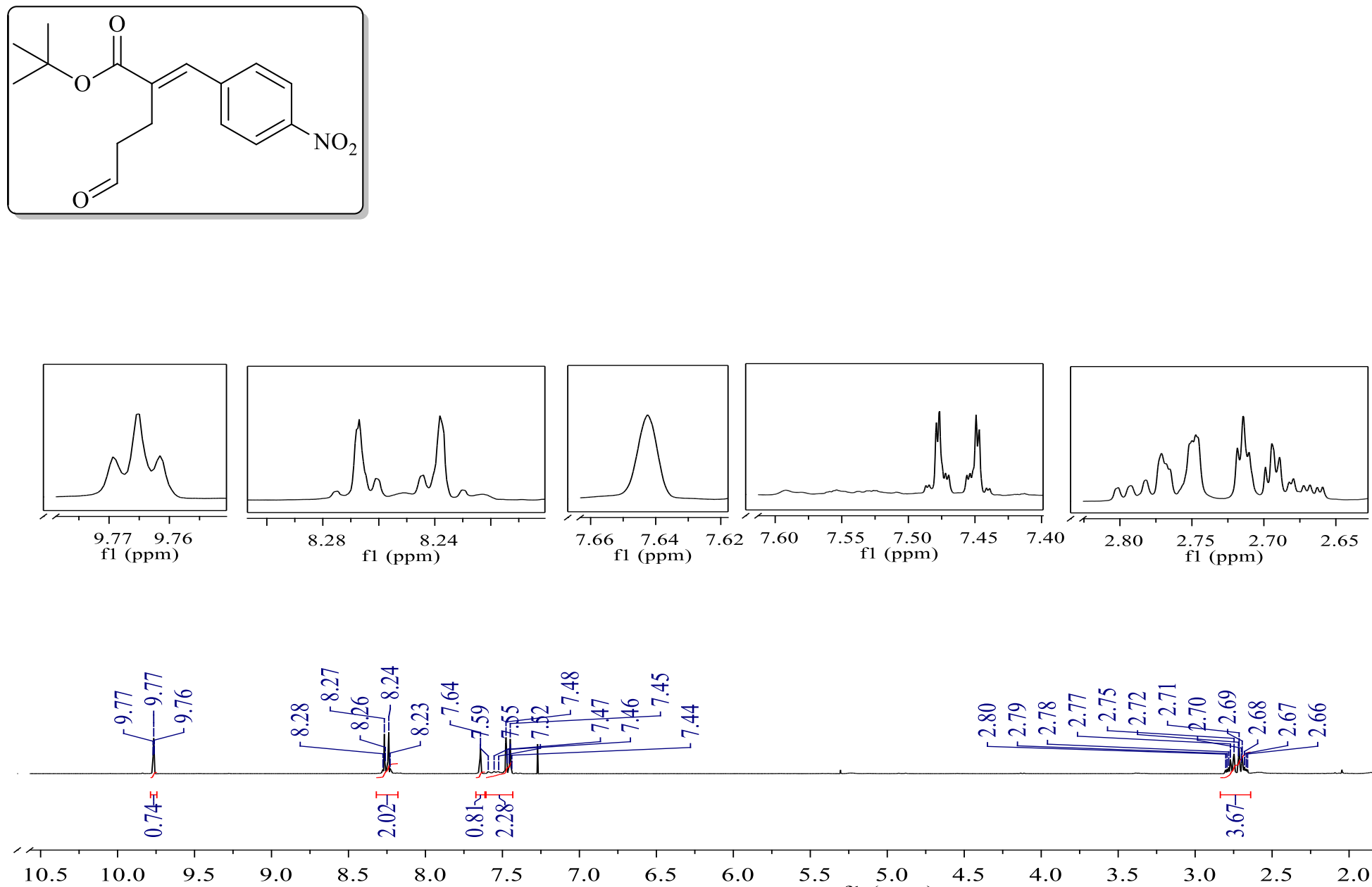

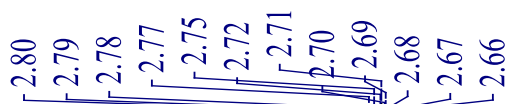

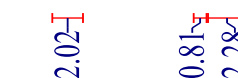

$\begin{array}{llll} & & \\ 7.5 & 7.0 & 6.5\end{array}$

6.0

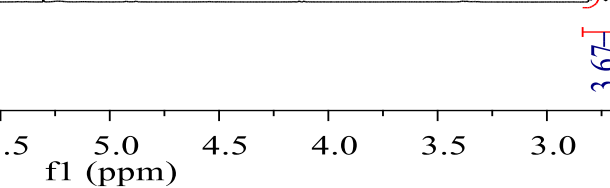

$\frac{1}{0} \quad \frac{1}{0}$

Espectro de RMN de ${ }^{1} \mathrm{H}\left(300 \mathrm{MHz}, \mathrm{CDCl}_{3}\right)$ - Rearranjo de Claisen (colunado) $4 \mathrm{e}(E)$. 

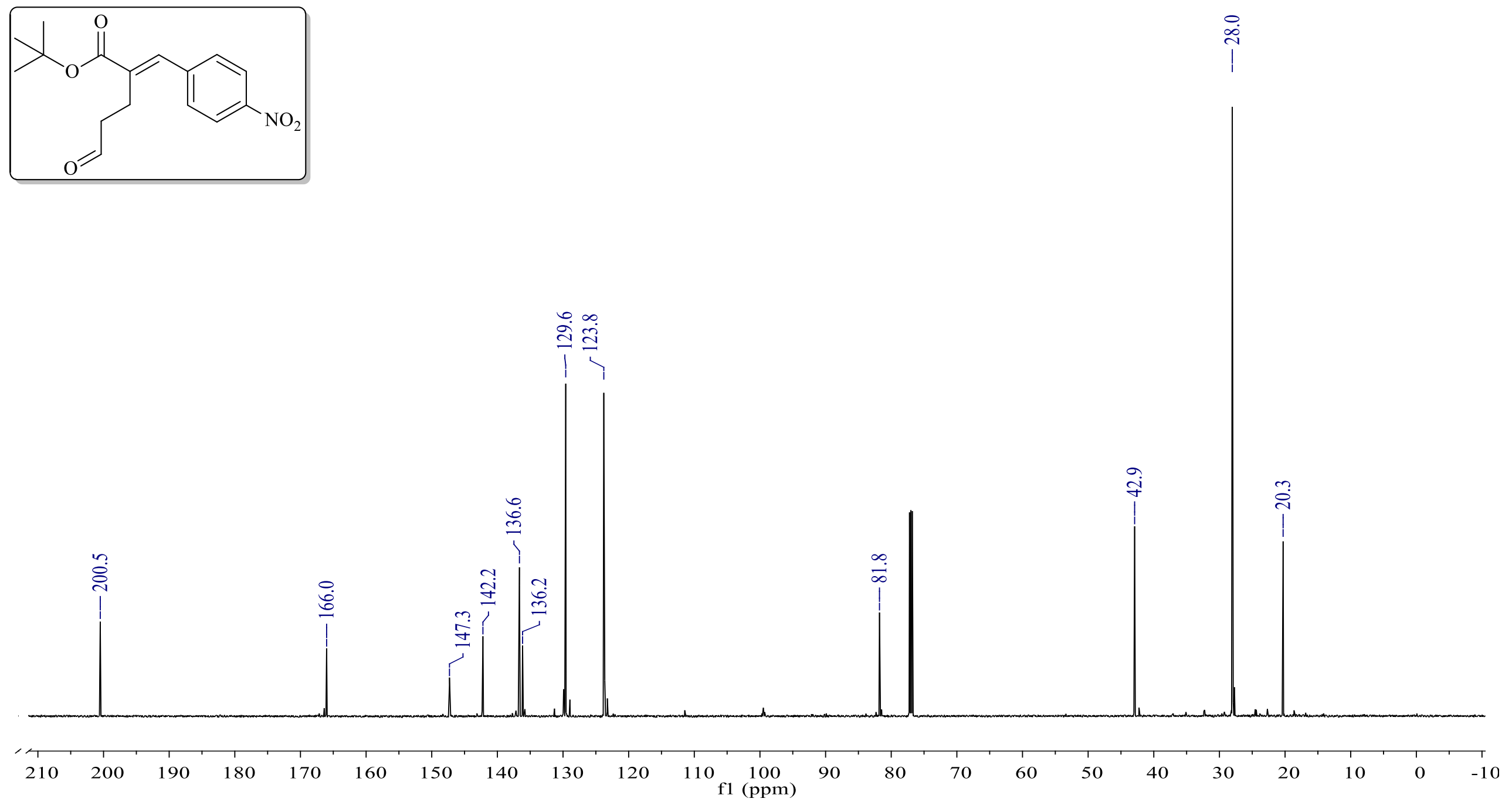

Espectro de RMN de ${ }^{13} \mathrm{C}$ (150 MHz, CDCl$)$ - Rearranjo de Claisen (colunado) 4e (E). 


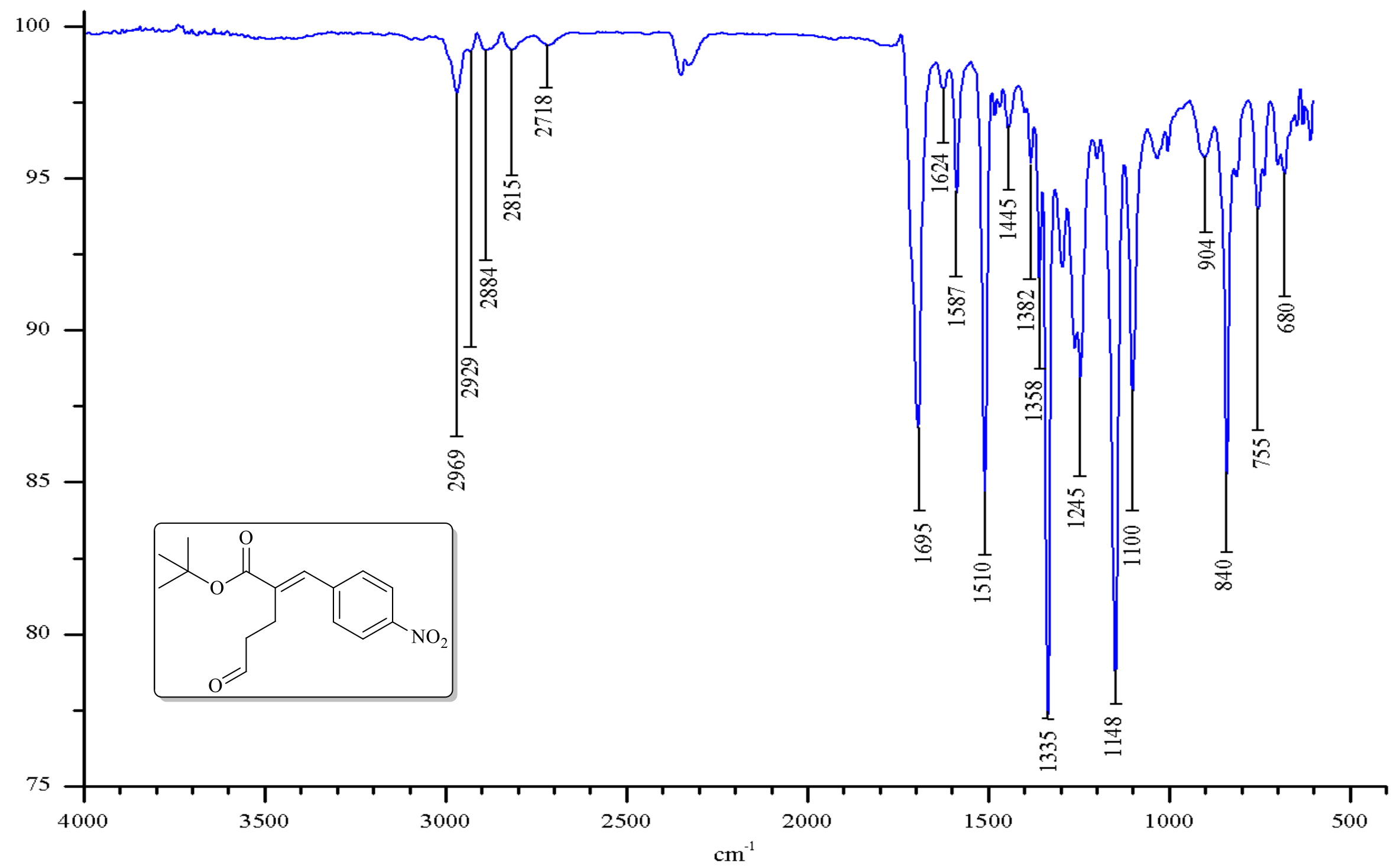

Espectro de infravermelho (ATR) - Rearranjo de Claisen (colunado) 4e (E). 

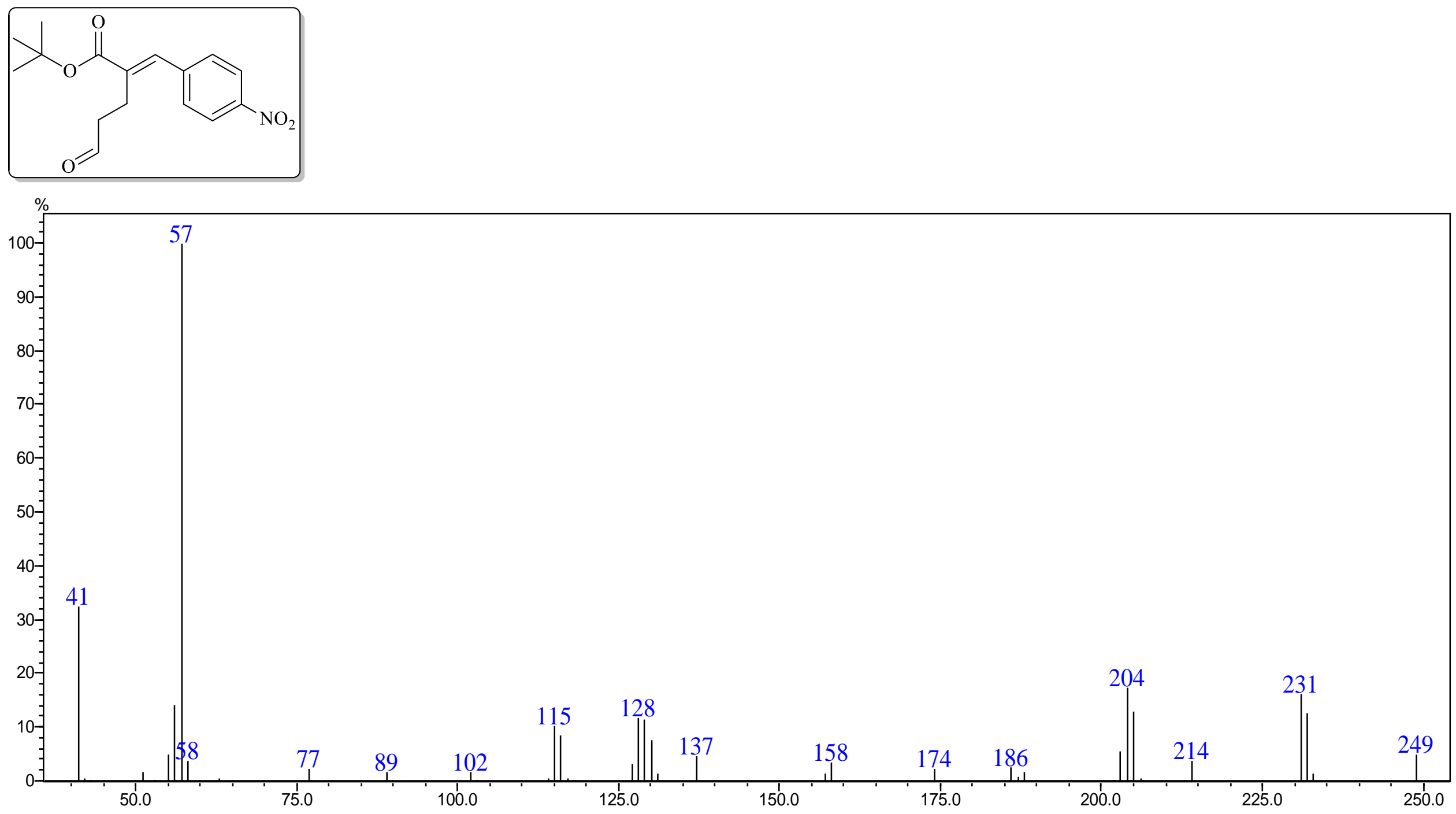

Espectro de massas (EM $70 \mathrm{eV} \mathrm{m} / \mathrm{z})$ - Rearranjo de Hurd-Claisen (colunado) 4e (E). 


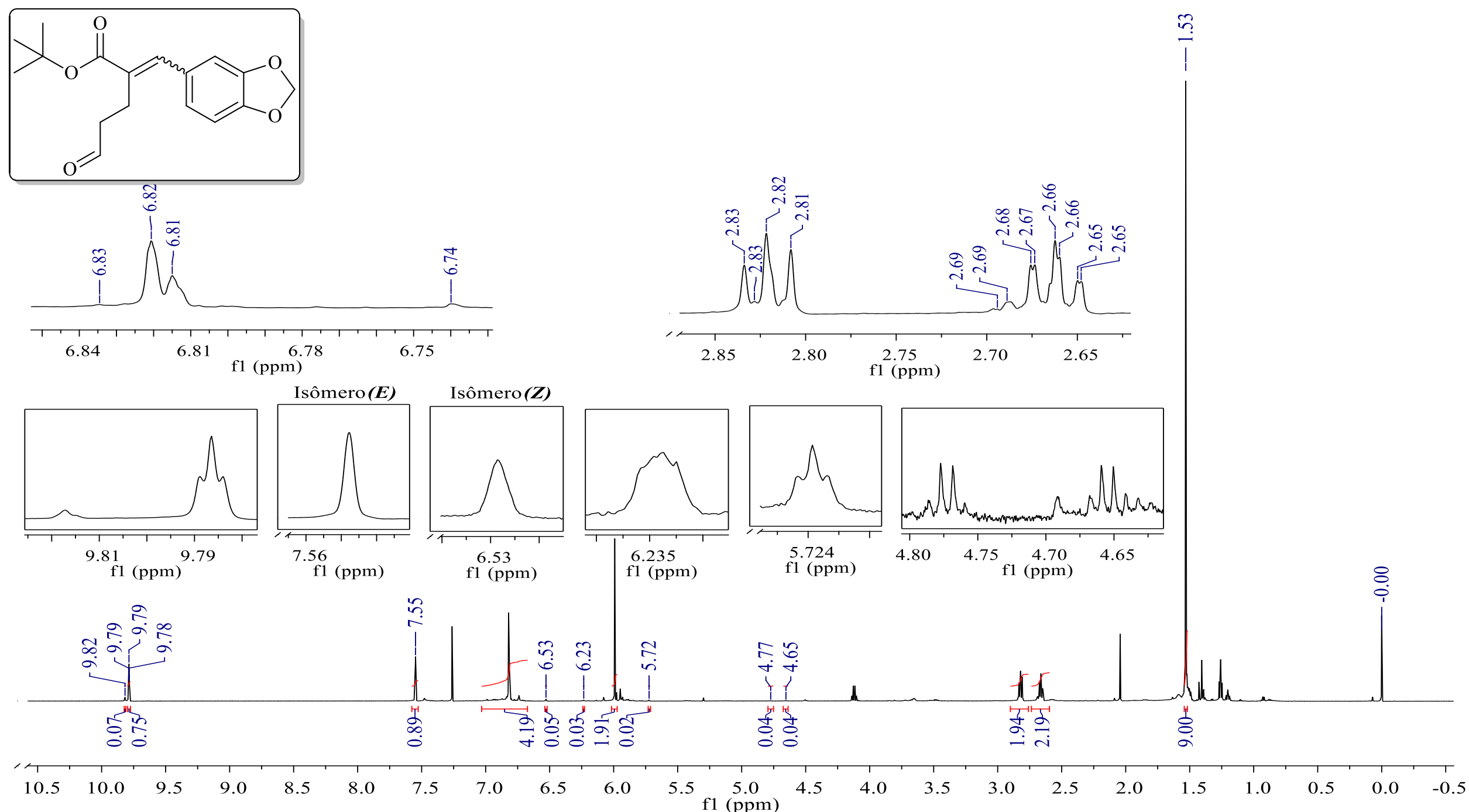

Espectro de RMN de ${ }^{1} \mathrm{H}(600 \mathrm{MHz})$ do bruto de reação do rearranjo de Hurd-Claisen (condição otimizada) com os isômeros $4 \mathrm{f}(\boldsymbol{E})$ e $4 \mathrm{f}$ (Z). 
2-((benzo[d][1,3]dioxol-5-ilmetileno)-5-oxopentanoato de terc-butila $4 \mathrm{f}(E)$
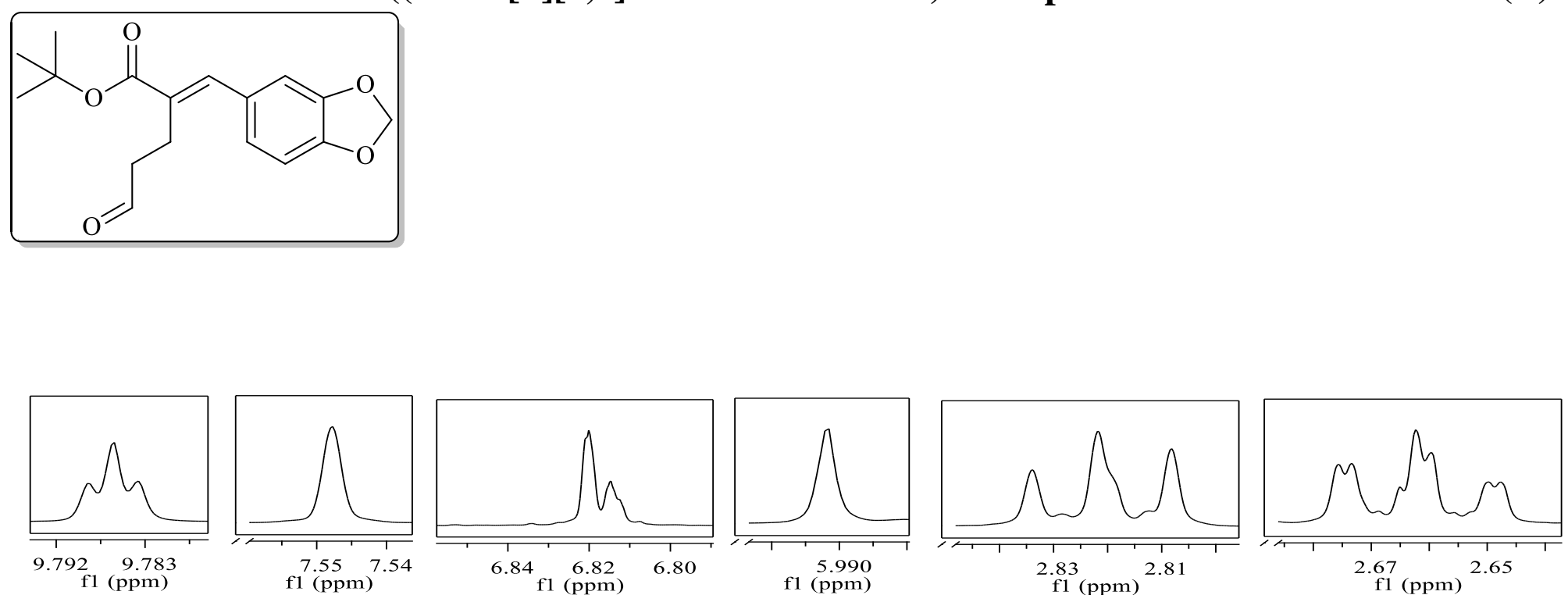

ร
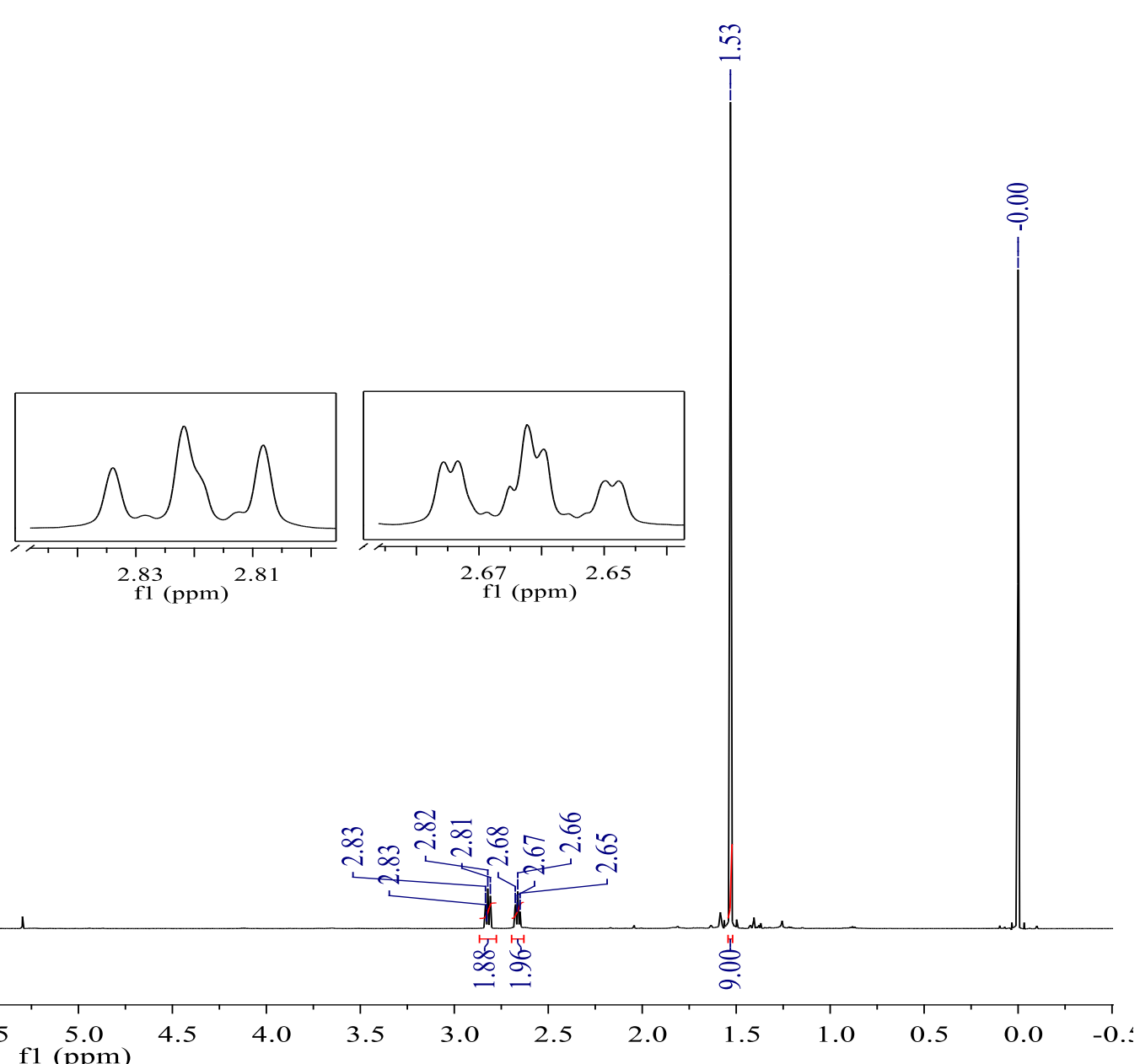

Espectro de RMN de ${ }^{1} \mathrm{H}(600 \mathrm{MHz}, \mathrm{CDCl} 3)$ - Rearranjo de Claisen (colunado) $4 \mathrm{f}(E)$. 

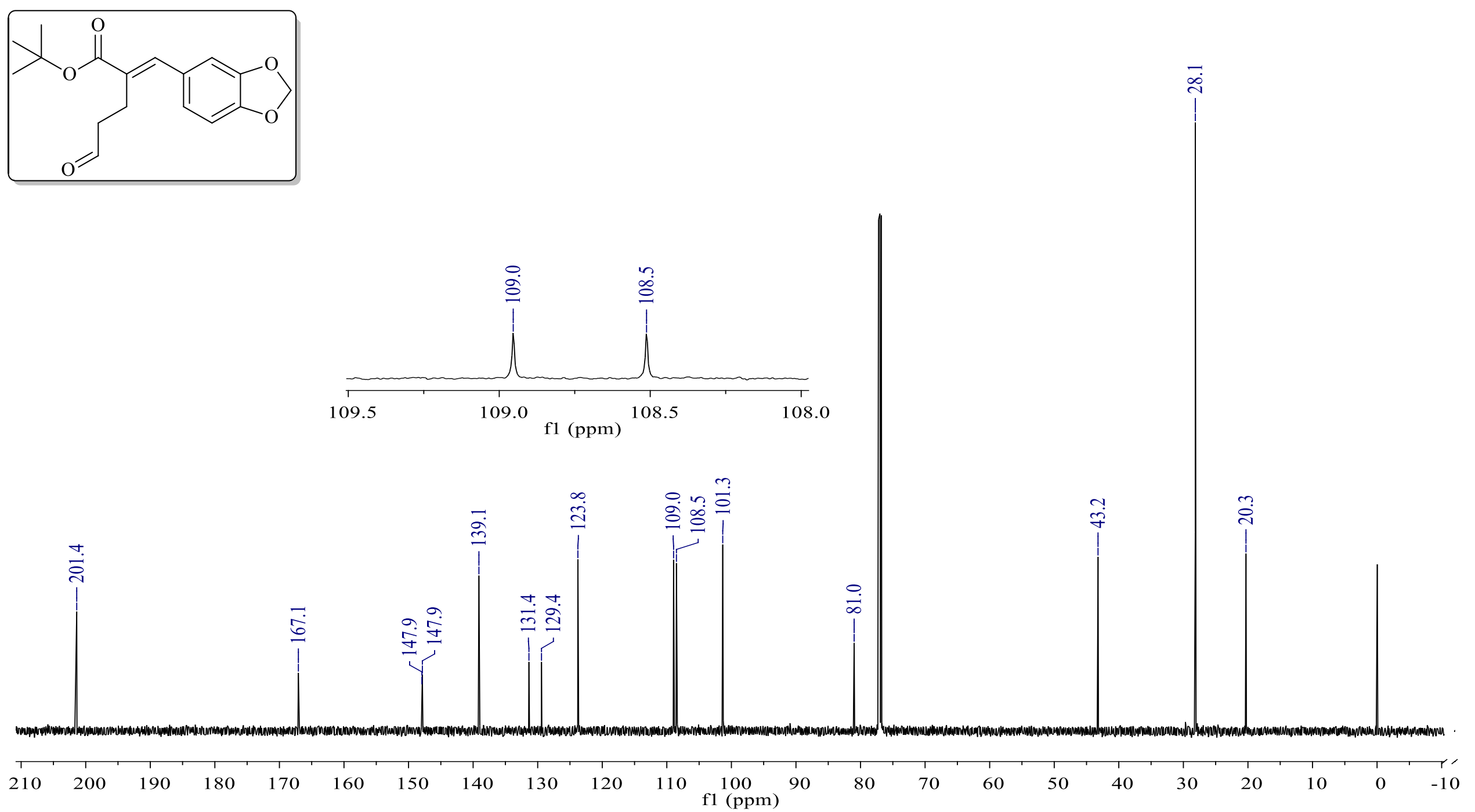

Espectro de RMN de ${ }^{13} \mathrm{C}\left(150 \mathrm{MHz}, \mathrm{CDCl}_{3}\right)$ - Rearranjo de Claisen (colunado) $4 \mathrm{f}(E)$. 


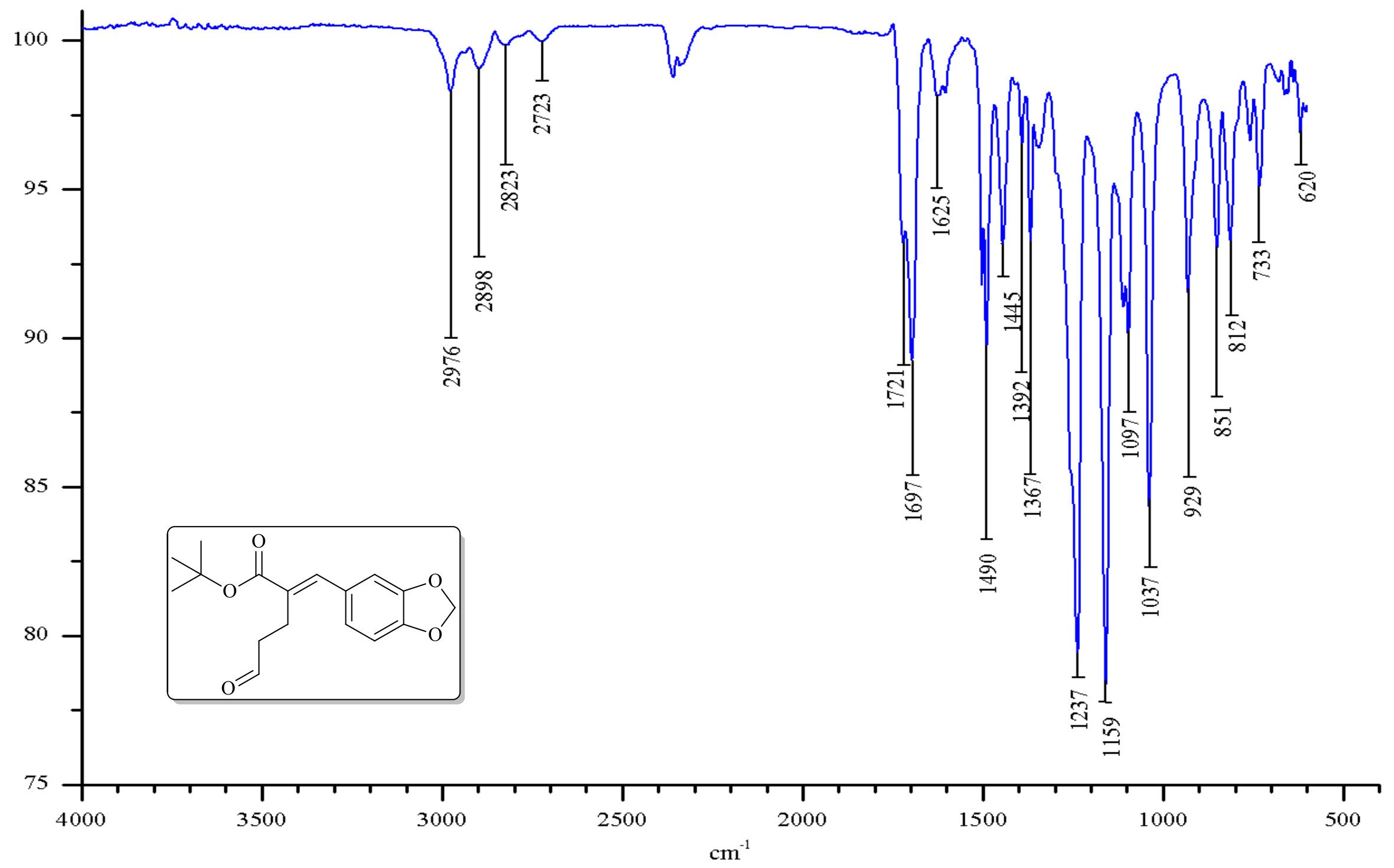

Espectro de infravermelho (ATR) - Rearranjo de Claisen (colunado) $4 f(E)$. 

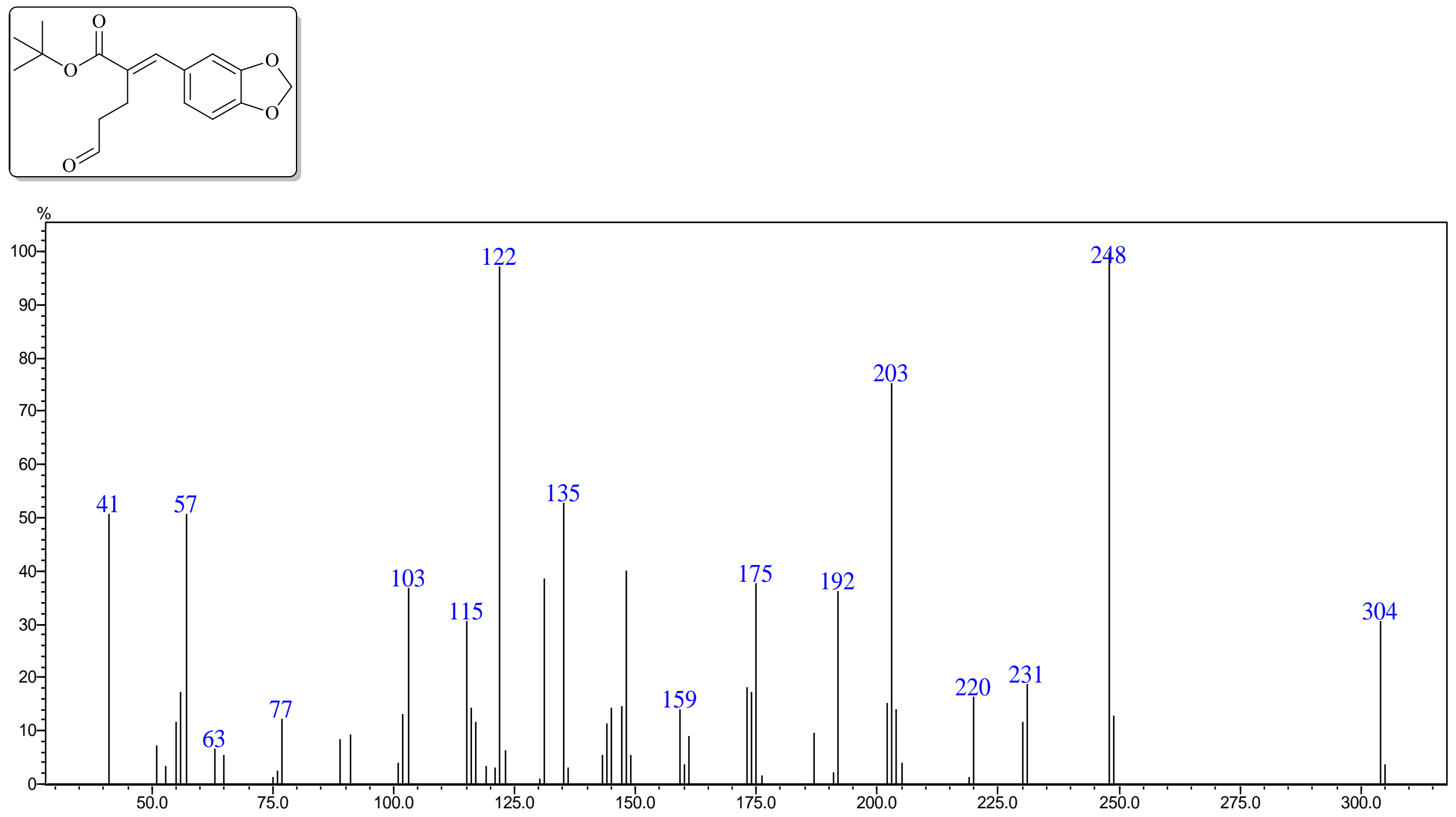

Espectro de massas (EM $70 \mathrm{eV} \mathrm{m/z)}$ - Rearranjo de Hurd-Claisen (colunado) $4 \mathrm{f}(E)$. 


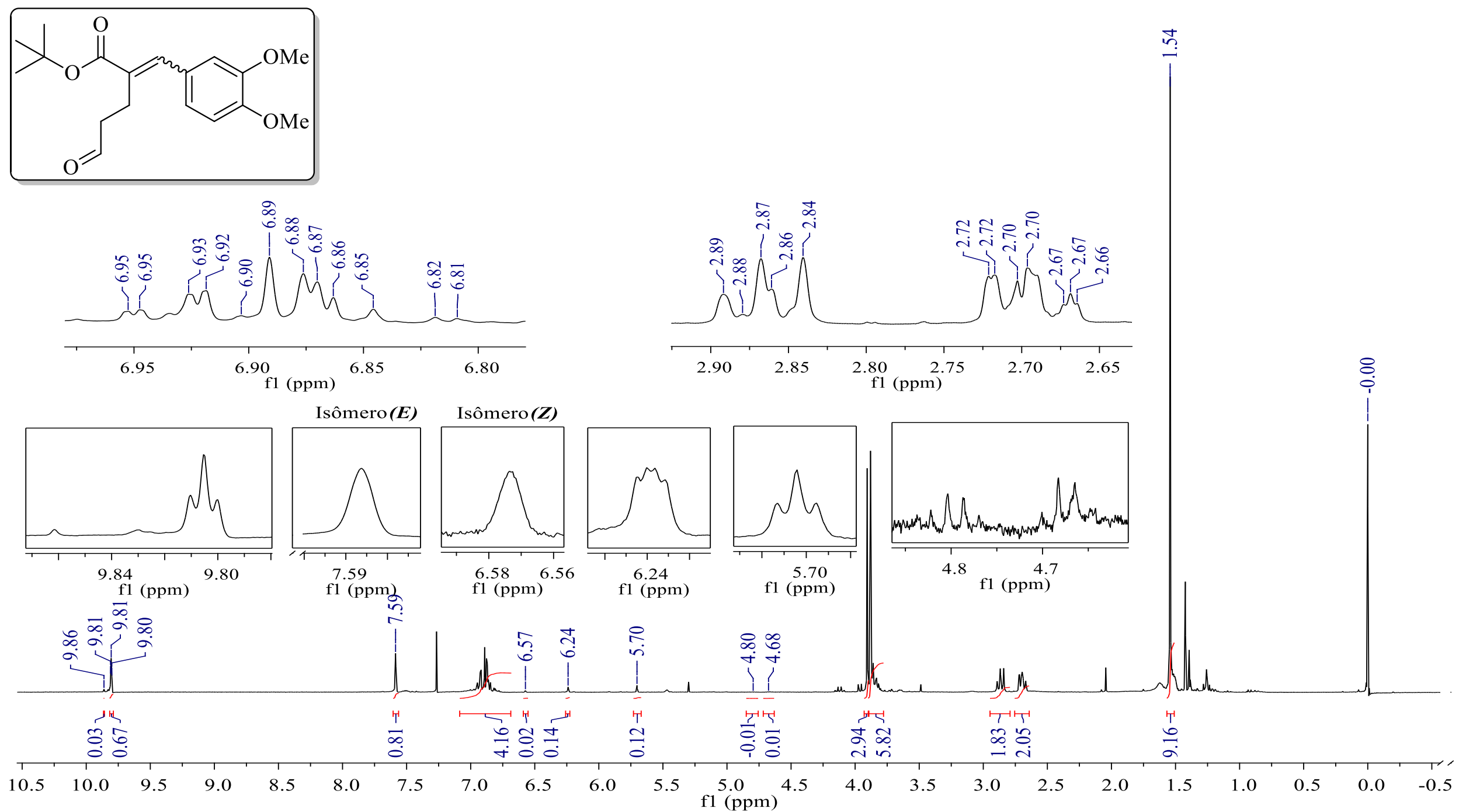

Espectro de RMN de ${ }^{1} \mathrm{H}(600 \mathrm{MHz})$ do bruto de reação do rearranjo de Hurd-Claisen (condição otimizada) com os isômeros $4 \mathrm{~g}(E)$ e $4 \mathrm{~g}$ $(Z)$. 
2-(3,4-dimetoxbenzidileno)-5-oxopentanoato de terc-butila $4 g(E)$
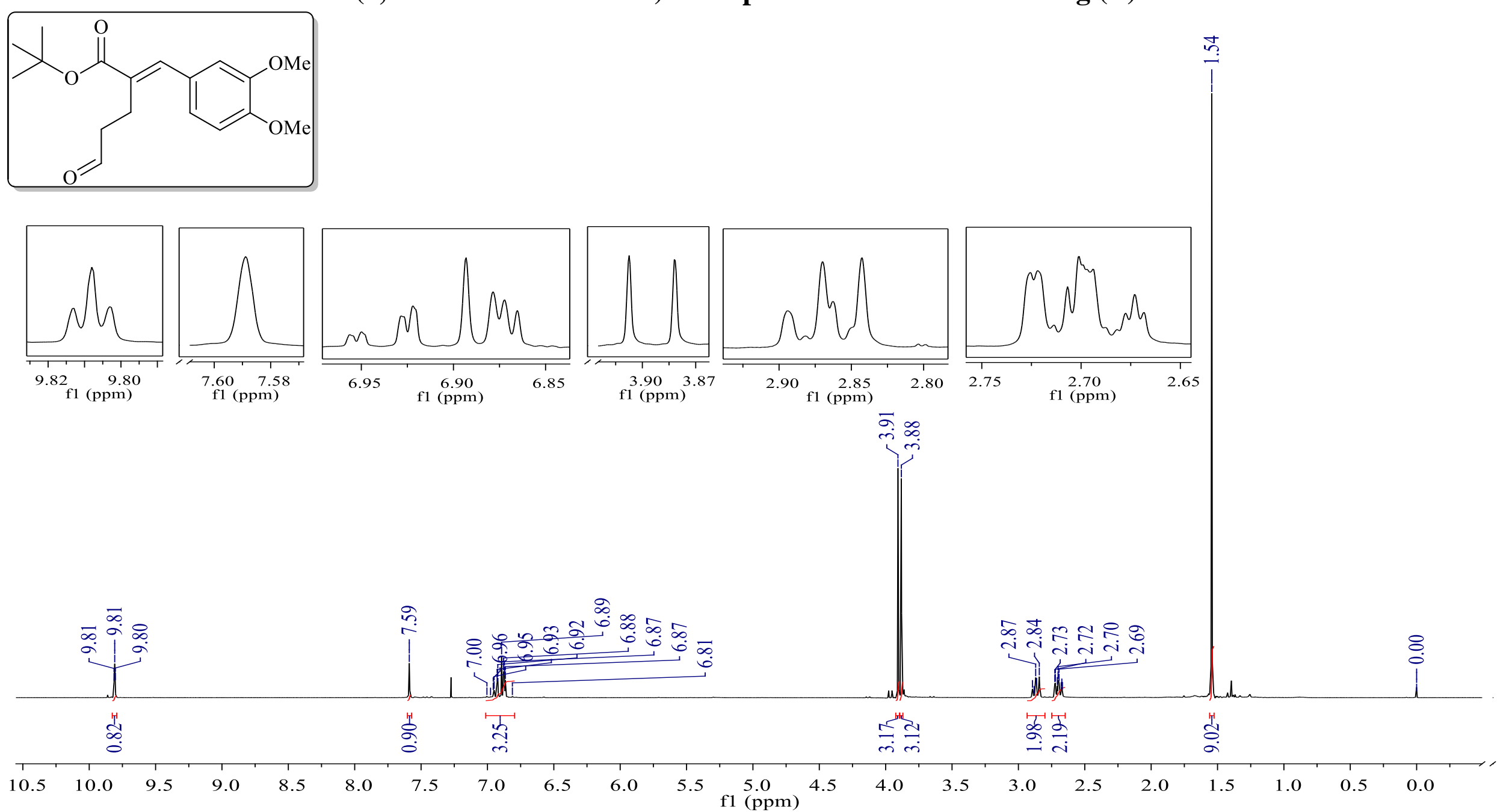

Espectro de RMN de ${ }^{1} \mathrm{H}\left(600 \mathrm{MHz}, \mathrm{CDCl}_{3}\right)$ - Rearranjo de Claisen (colunado) $4 \mathrm{~g}(E)$. 

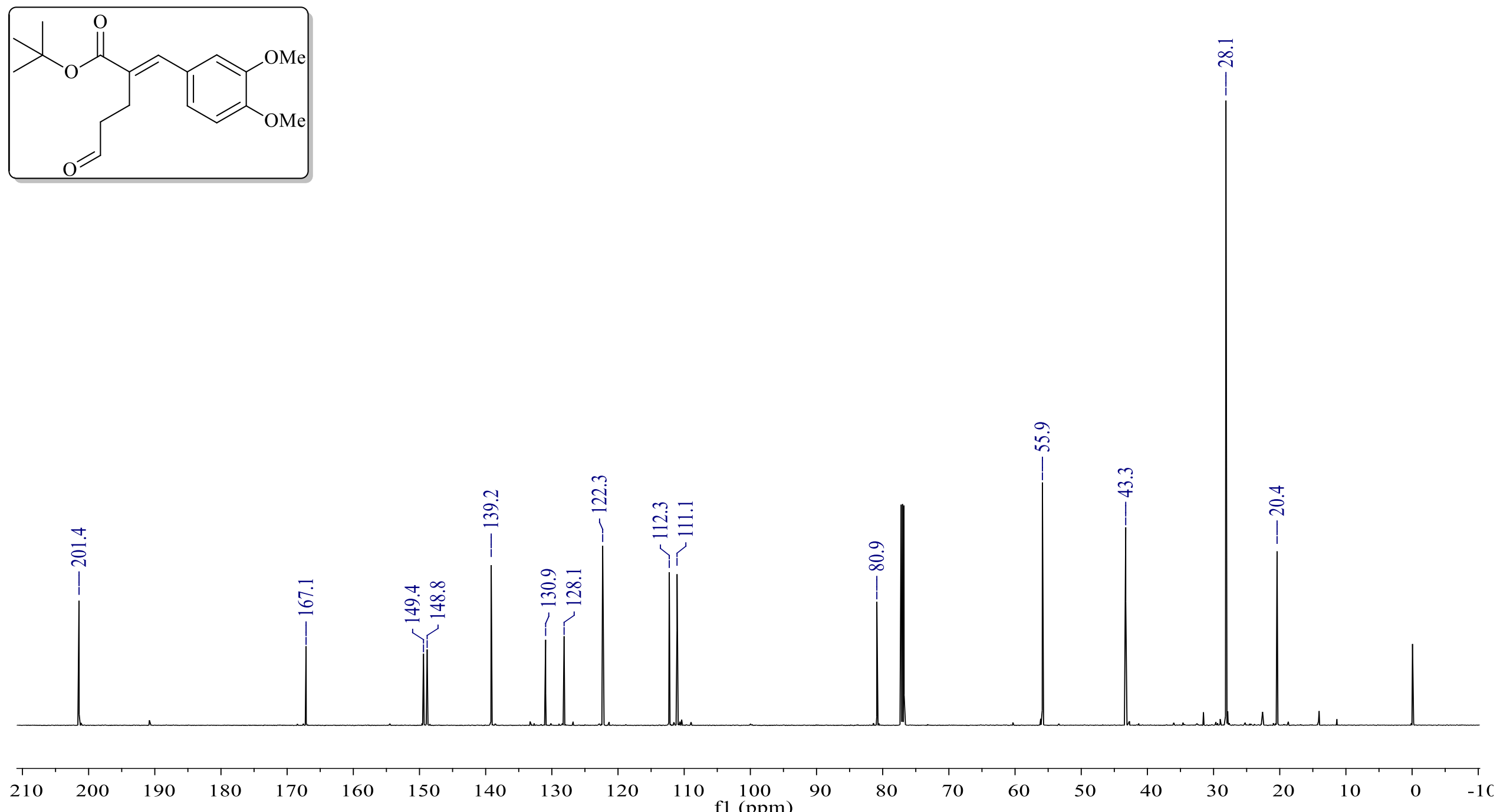

Espectro de RMN de ${ }^{13} \mathrm{C}\left(150 \mathrm{MHz}, \mathrm{CDCl}_{3}\right)$ - Rearranjo de Claisen (colunado) 4g (E). 


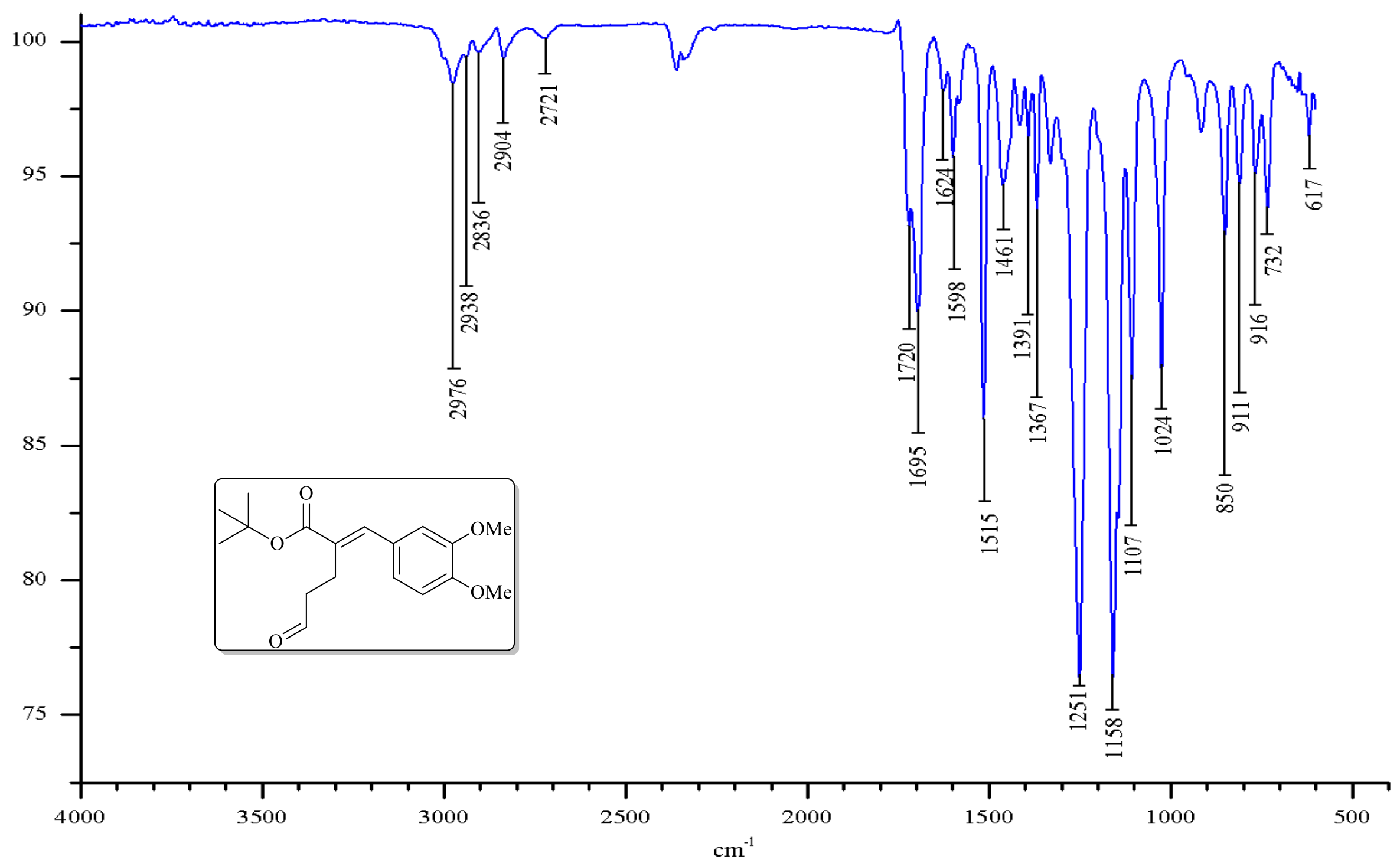

Espectro de infravermelho (ATR) - Rearranjo de Claisen (colunado) 4g (E). 

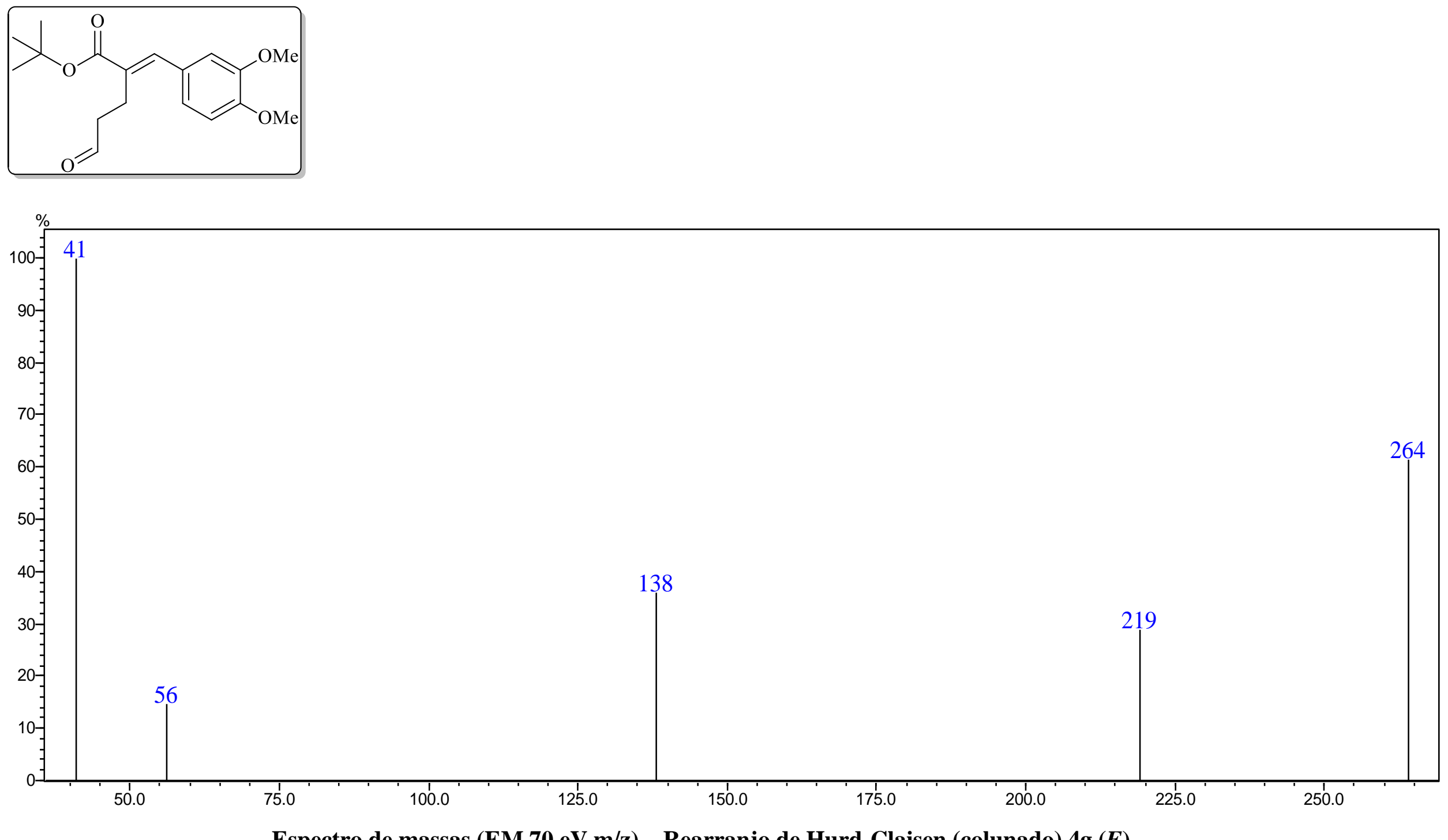

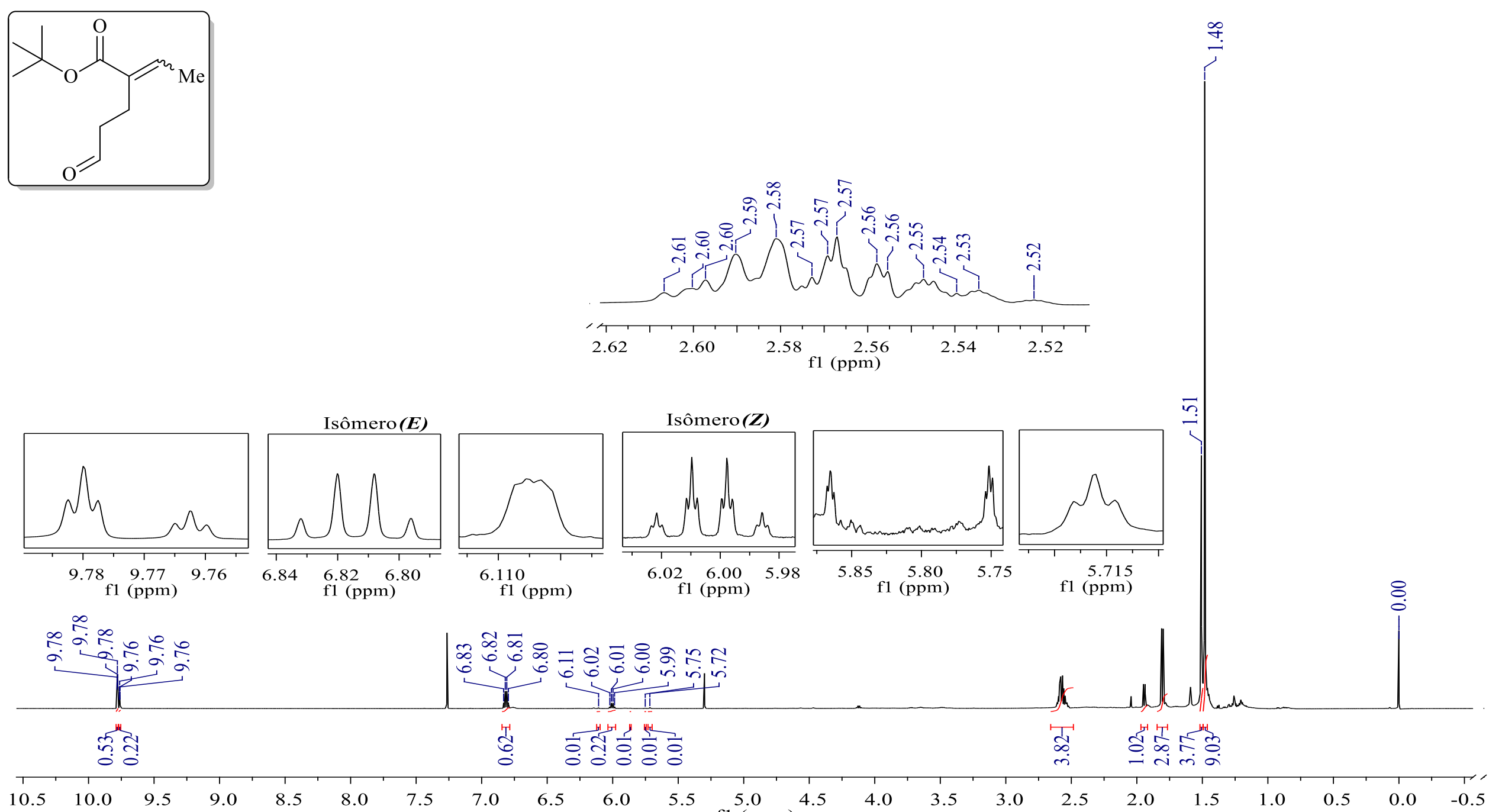

Espectro de RMN de ${ }^{1} \mathrm{H}(600 \mathrm{MHz})$ do bruto de reação do rearranjo de Hurd-Claisen (condição otimizada) com os isômeros 4h $(E)$ e 4h (Z). 
2-etilideno-5-oxopentanoato de terc-butila $4 \mathrm{~h}(E)$ e $4 \mathrm{~h}(Z)$
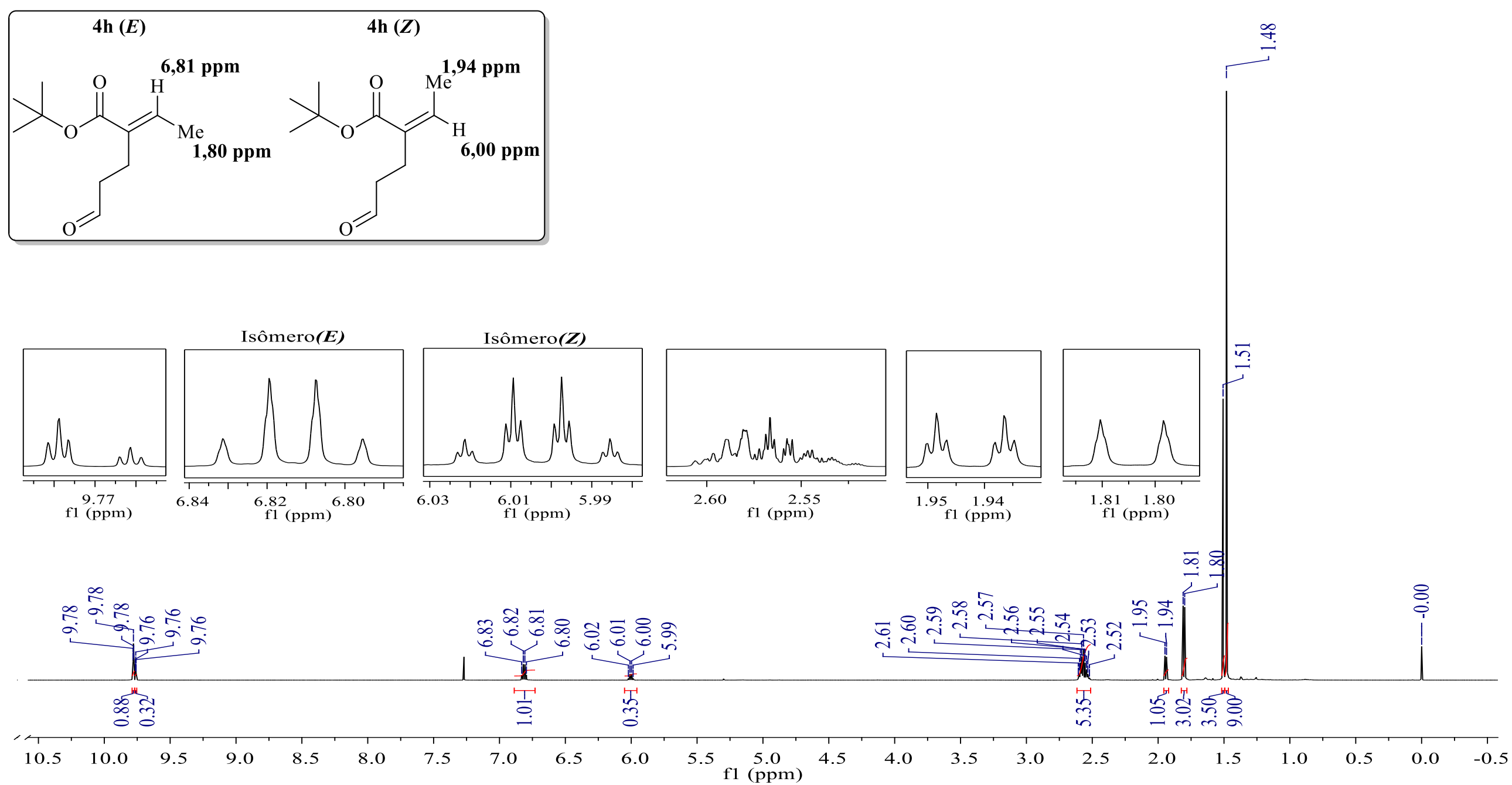

Espectro de RMN de ${ }^{1} \mathrm{H}\left(600 \mathrm{MHz}, \mathrm{CDCl}_{3}\right)$ - Rearranjo de Hurd-Claisen (colunado) 4h (E) e 4h (Z). 

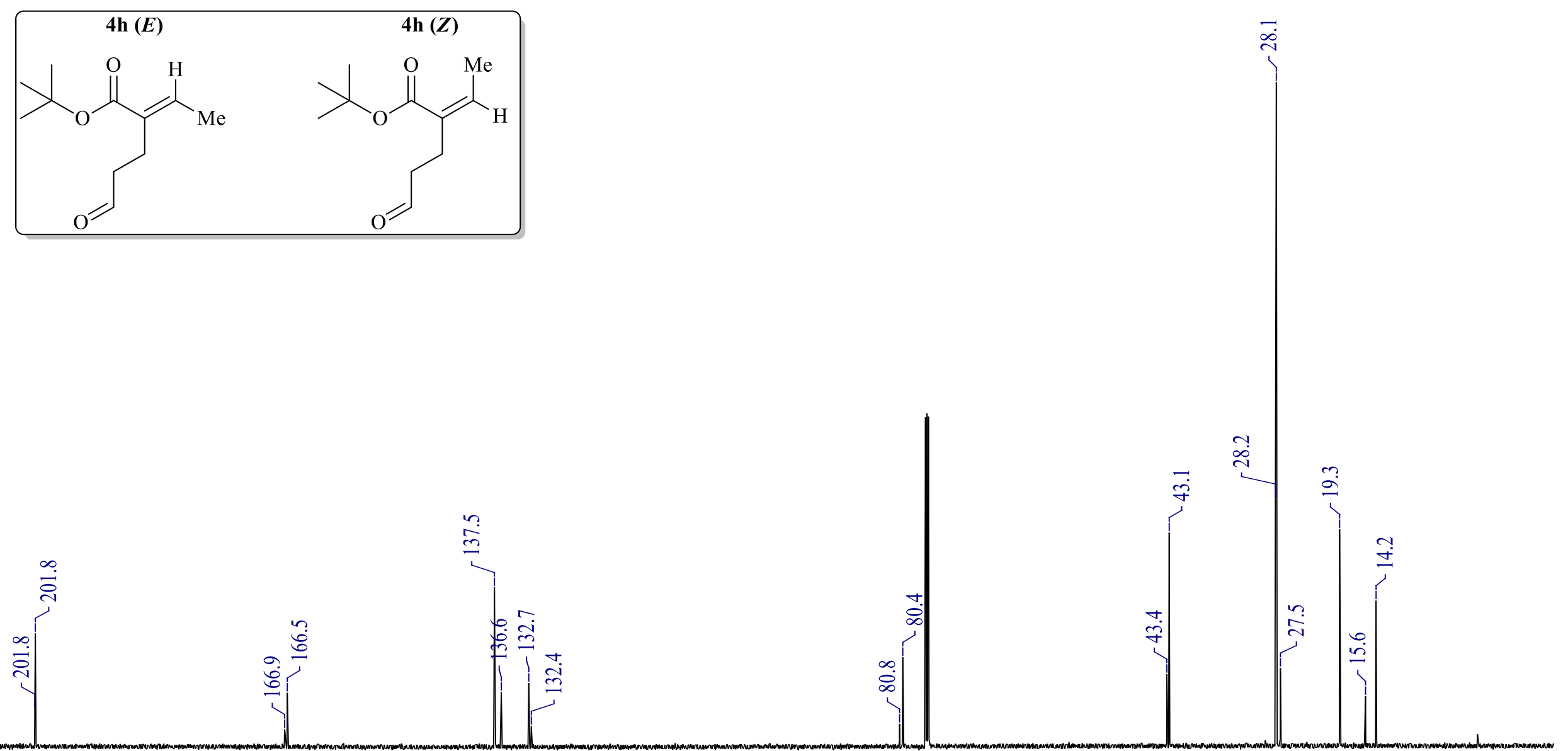

Espectro de RMN de ${ }^{13} \mathrm{C}(150 \mathrm{MHz}, \mathrm{CDCl} 3)$ - Rearranjo de Hurd-Claisen (colunado) $4 \mathrm{~h}(E)$ e $4 \mathrm{~h}(Z)$. 


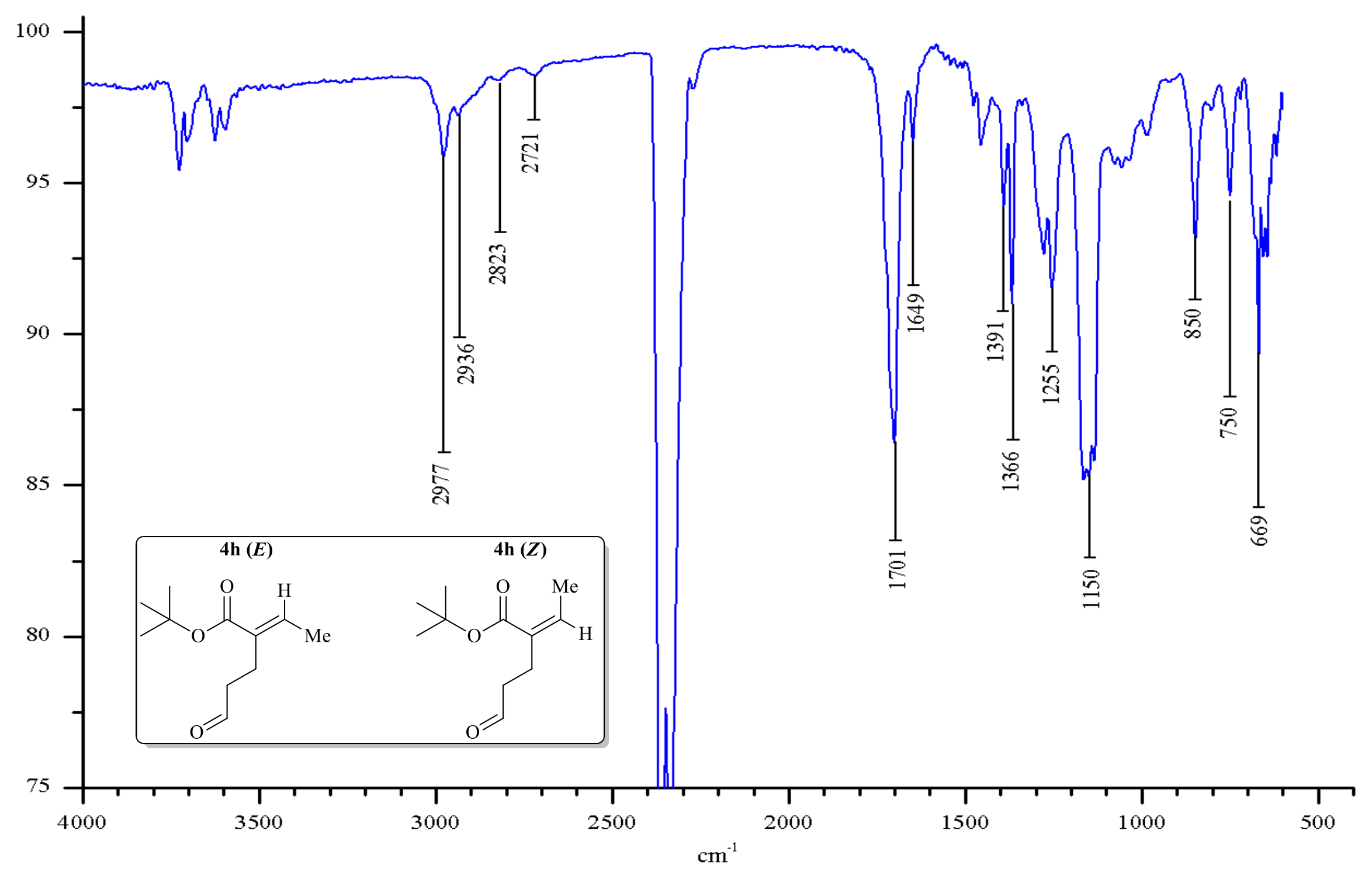

Espectro de infravermelho (ATR) - Rearranjo de Hurd-Claisen (colunado) 4h (E) e 4h (Z). 

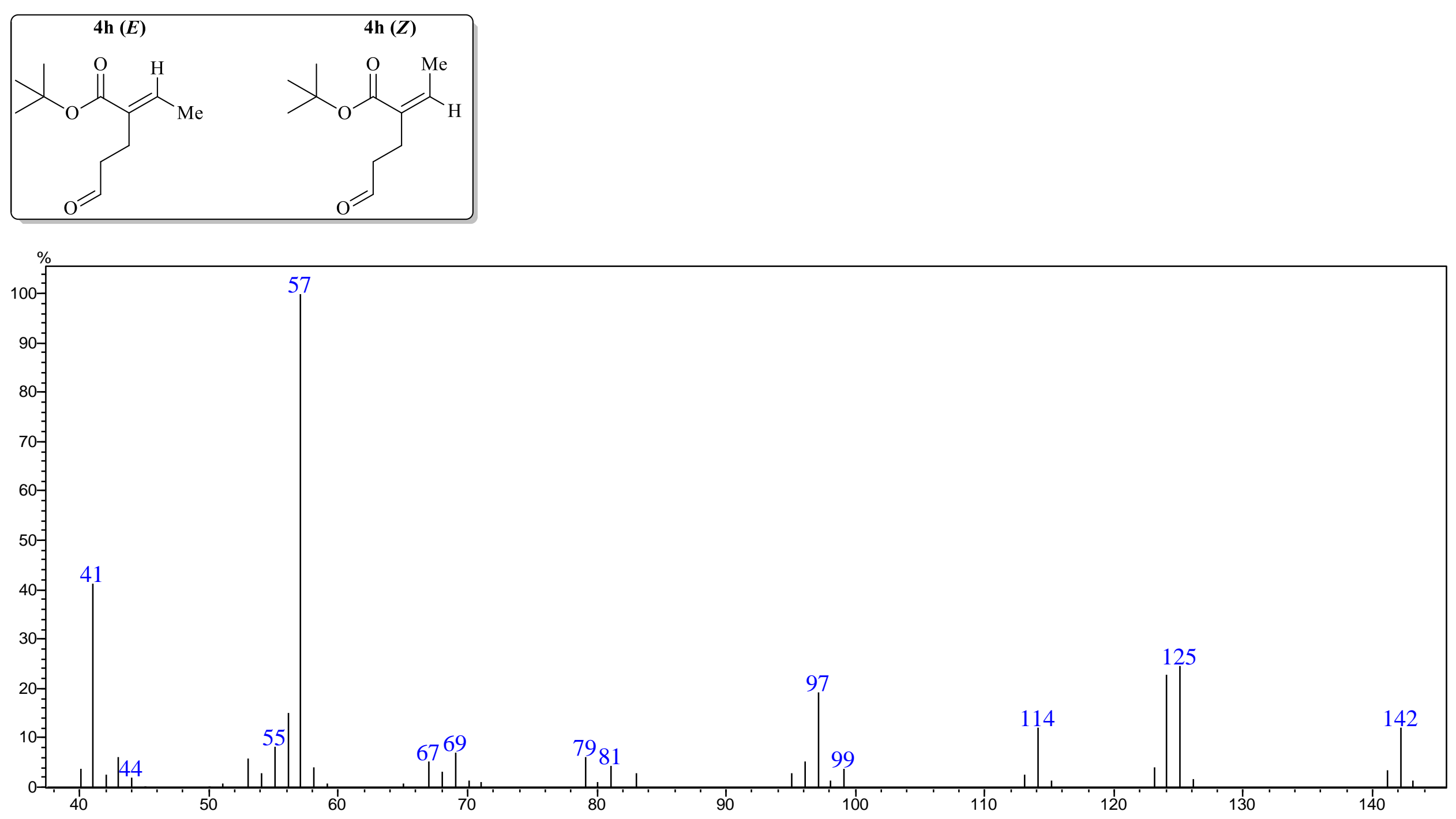

Espectro de massas (EM $70 \mathrm{eV} \mathrm{m/z)} \mathrm{-} \mathrm{Rearranjo} \mathrm{de} \mathrm{Hurd-Claisen} \mathrm{(colunado)} \mathrm{)} \mathrm{4h} \mathrm{(E)} \mathrm{e} \mathrm{4h} \mathrm{(Z).}$ 

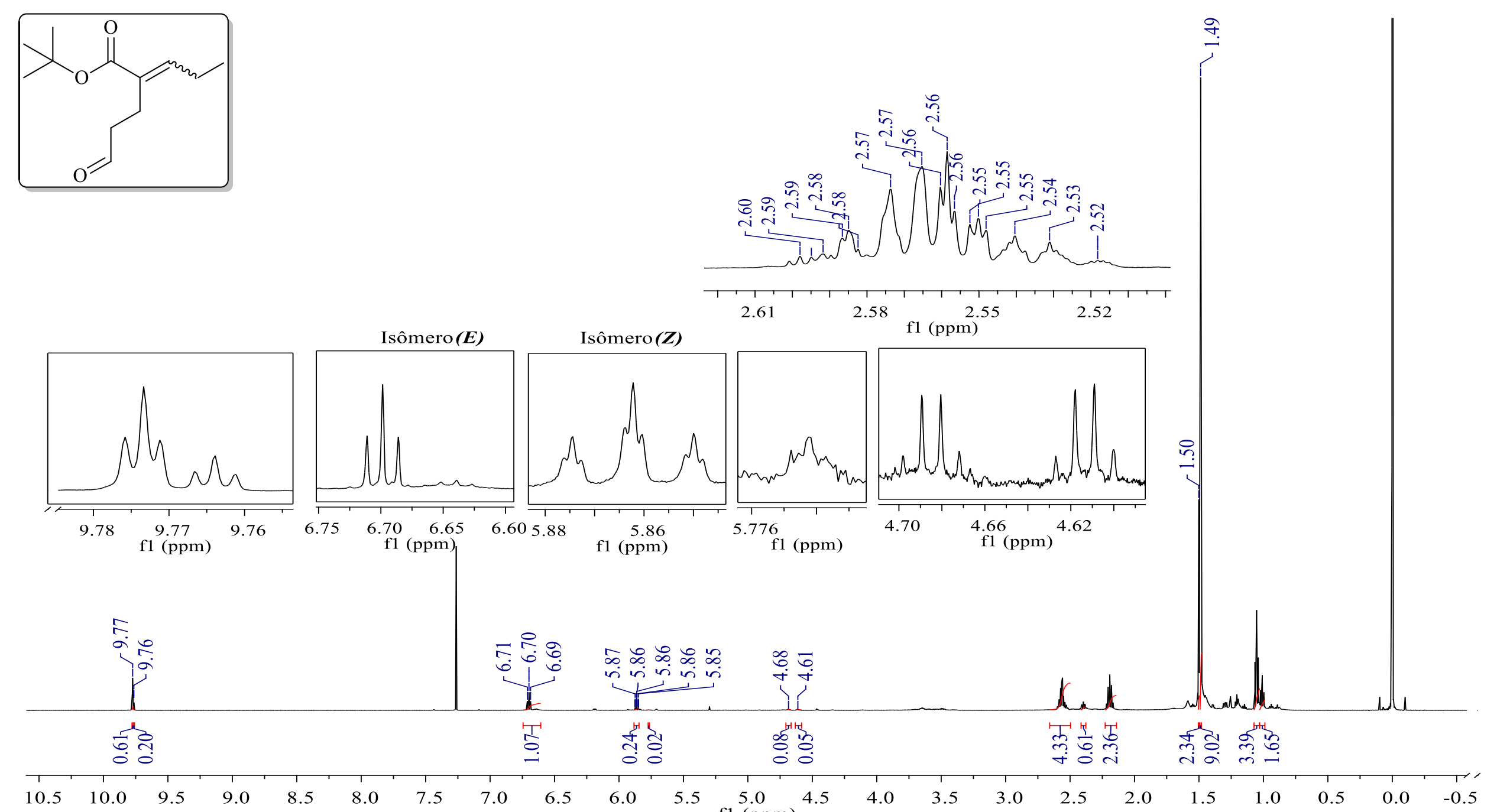

Espectro de RMN de ${ }^{1} \mathrm{H}(600 \mathrm{MHz})$ do bruto de reação do rearranjo de Hurd-Claisen (condição otimizada) com os isômeros 4i (E) e 4i (Z). 
2-(3-oxopropil)pent-2-enoato de terc-butila $4 \mathrm{i}(E)$ e $4 \mathrm{i}(Z)$
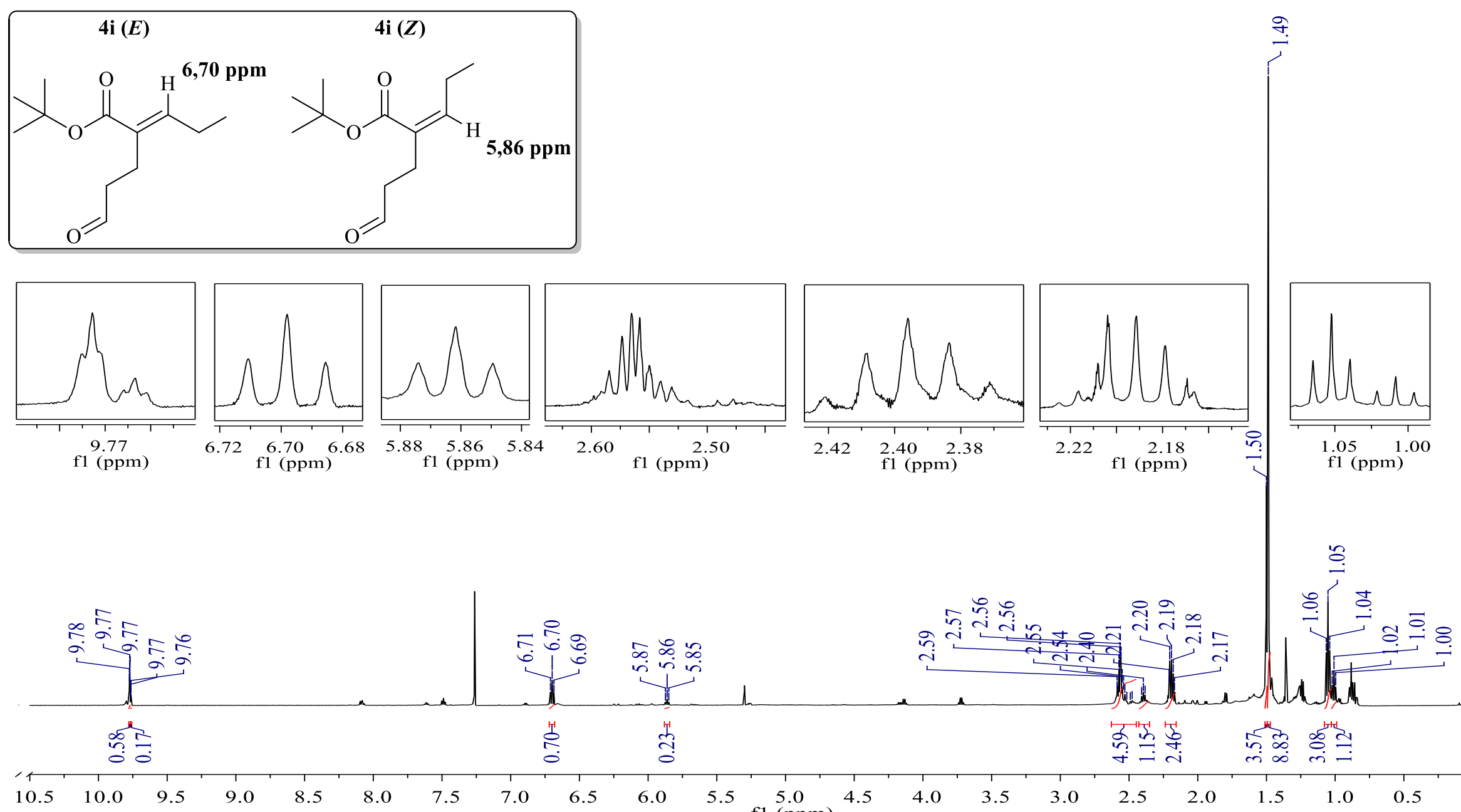

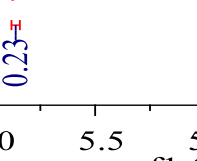

Espectro de RMN de ${ }^{1} \mathrm{H}\left(600 \mathrm{MHz}, \mathrm{CDCl}_{3}\right)$ - Rearranjo de Hurd-Claisen (colunado) 4i (E) e 4i (Z). 

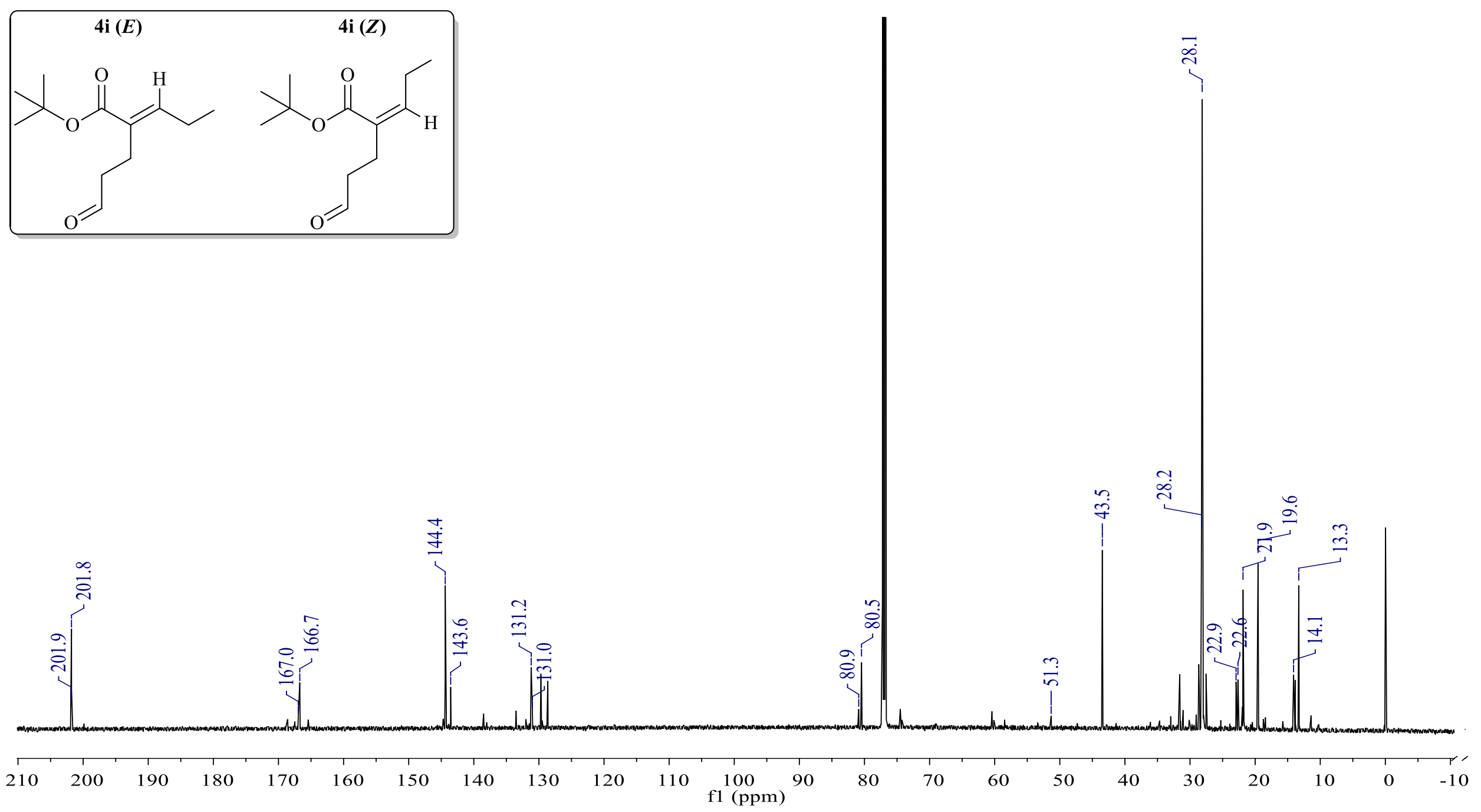

Espectro de RMN de ${ }^{13} \mathrm{C}$ (150 MHz, CDCl 3 ) - Rearranjo de Hurd-Claisen (colunado) 4i (E) e 4i (Z). 


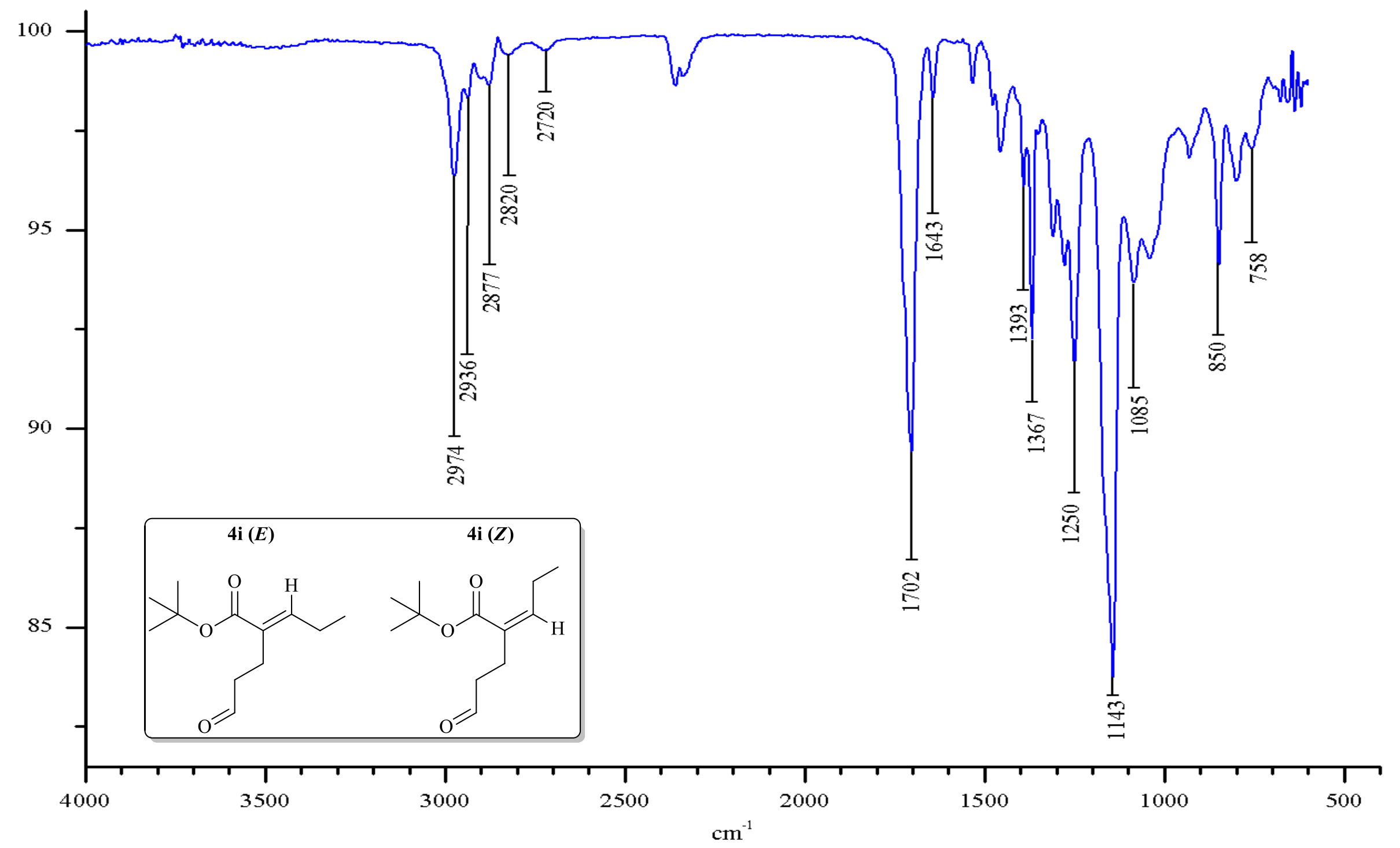

Espectro de infravermelho (ATR) - Rearranjo de Hurd-Claisen (colunado) 4i (E). e 4i (Z). 

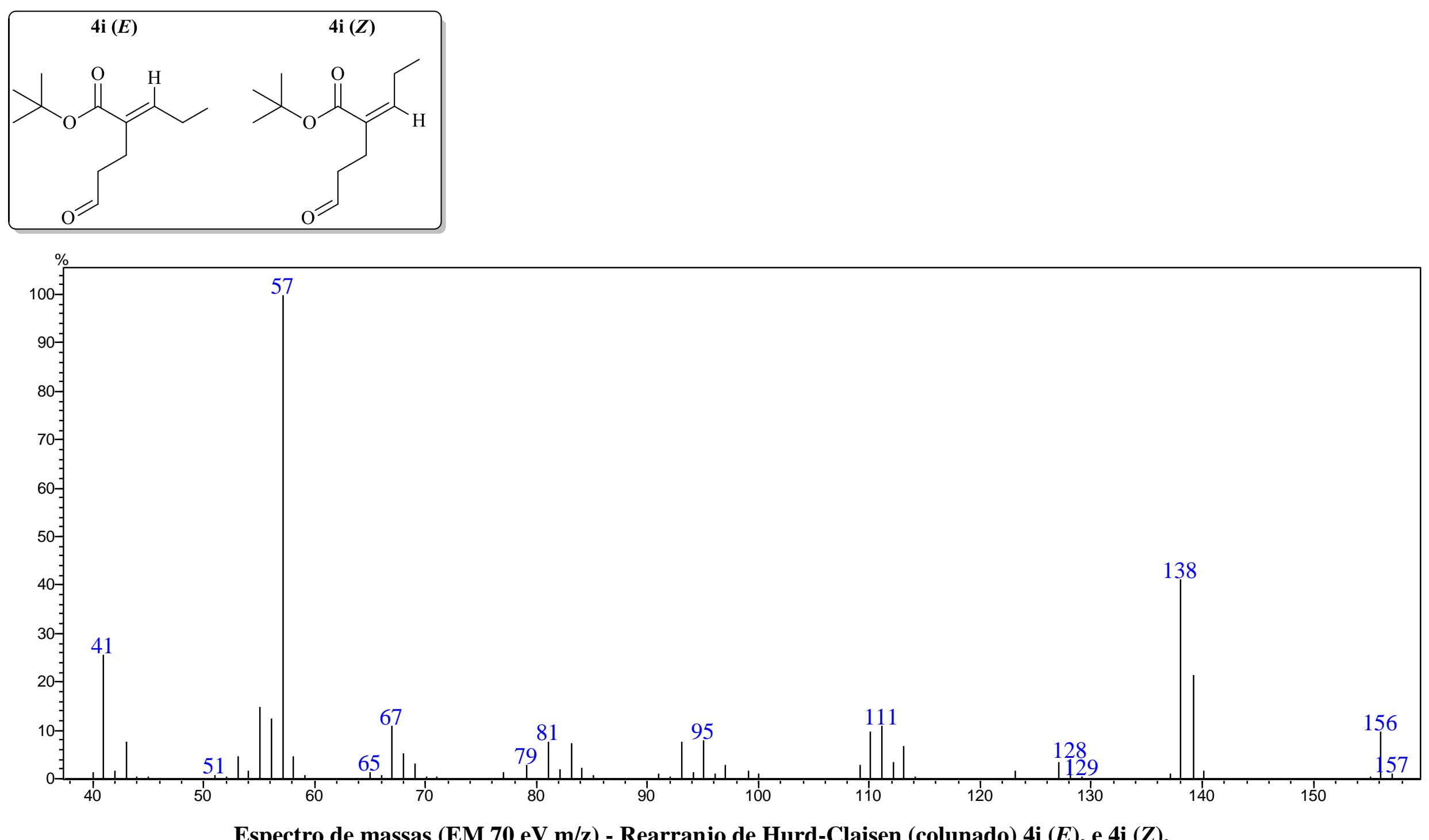

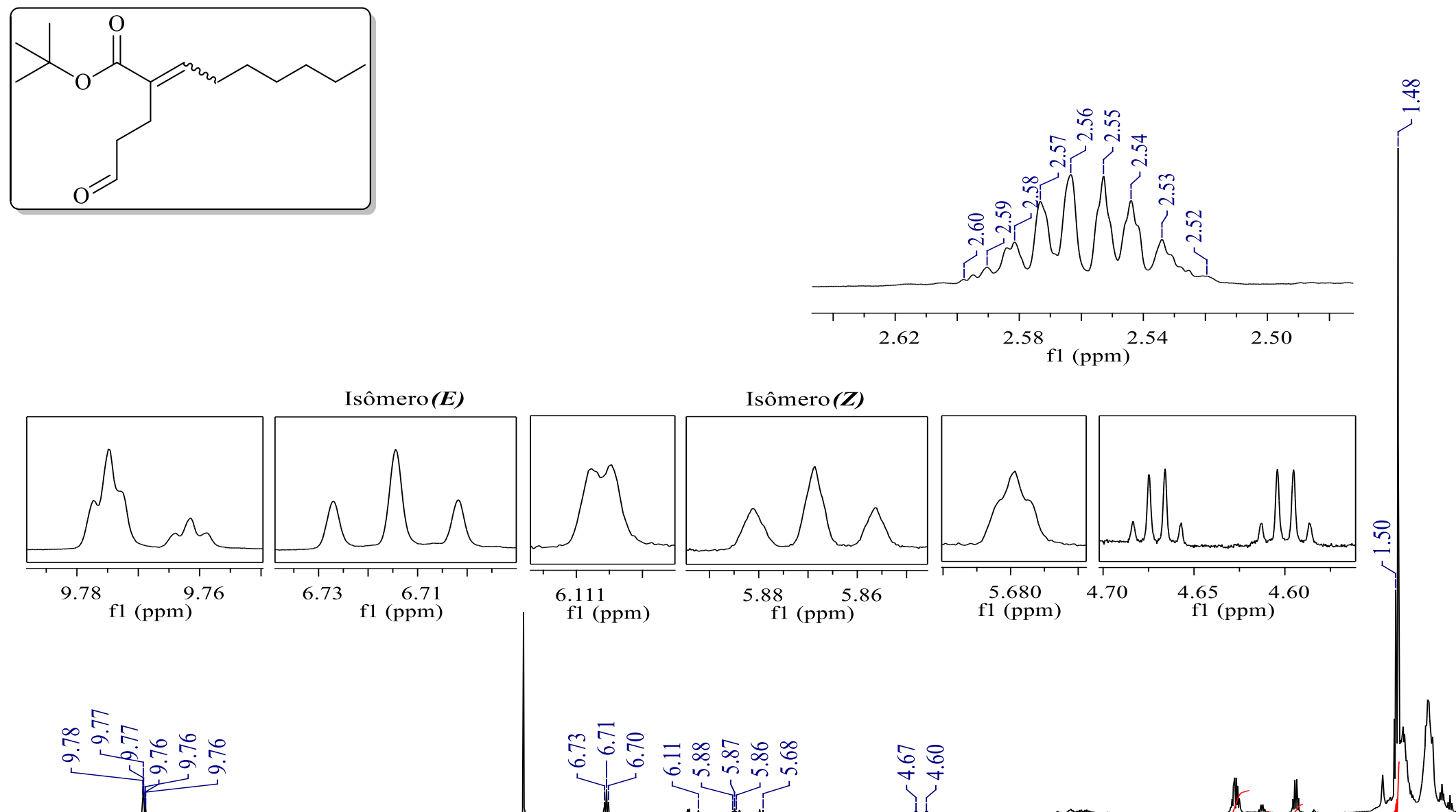

Isômero(Z)
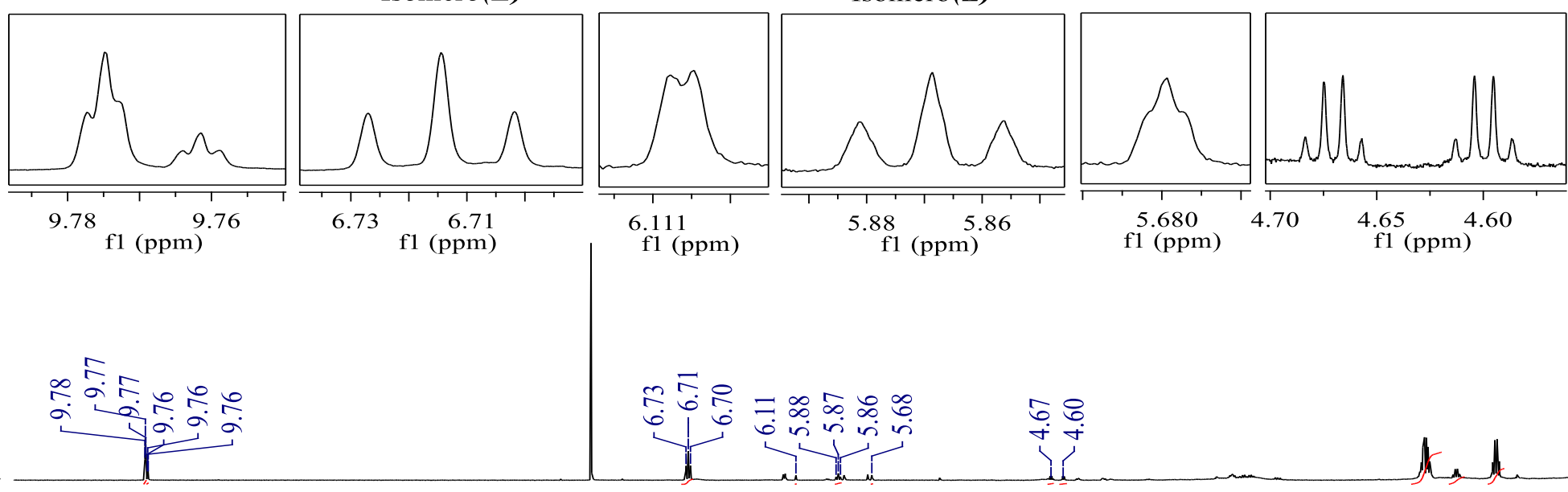

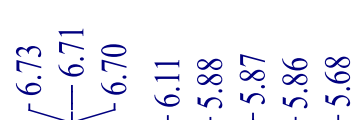

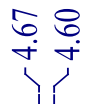

t.

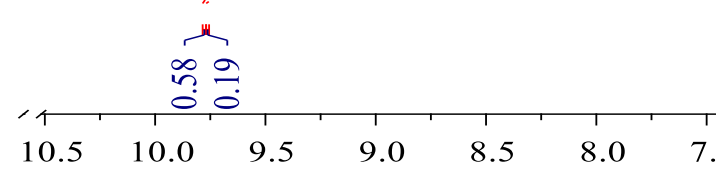

每

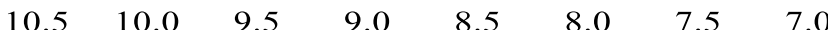
$6.5-6.0$

$5.5 \begin{gathered}5.0 \\ \mathrm{f} 1 \mathrm{(ppm)}\end{gathered}$

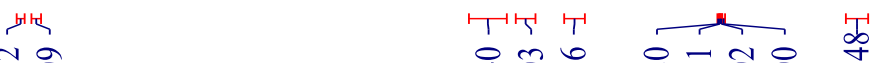

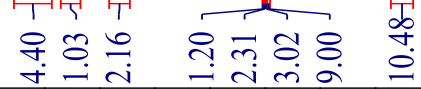

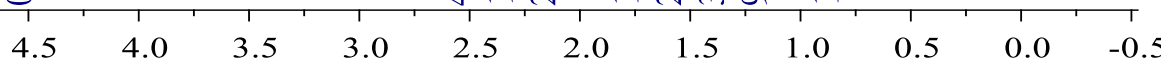

Espectro de RMN de ${ }^{1} \mathrm{H}(600 \mathrm{MHz})$ do bruto de reação do rearranjo de Hurd-Claisen (condição otimizada) com os isômeros 4j (E) e 4j $(Z)$. 
2-(3-oxopropil)non-2-enoato de terc-butila $4 \mathbf{j}(E)$ e $4 \mathrm{j}(Z)$
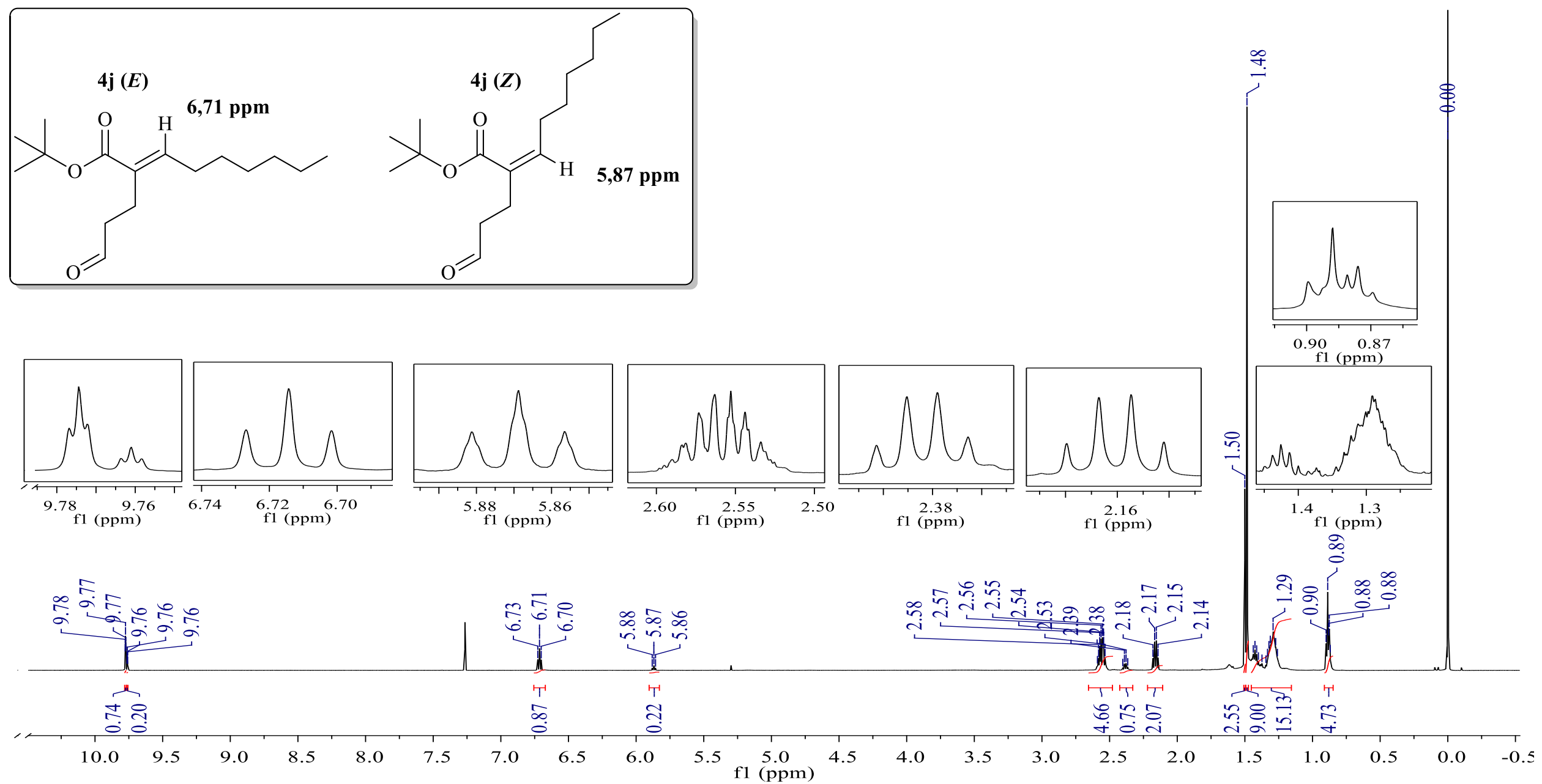

Espectro de RMN de ${ }^{1} \mathrm{H}\left(600 \mathrm{MHz}, \mathrm{CDCl}_{3}\right)$ - Rearranjo de Hurd-Claisen (colunado)4j (E) e 4j (Z). 

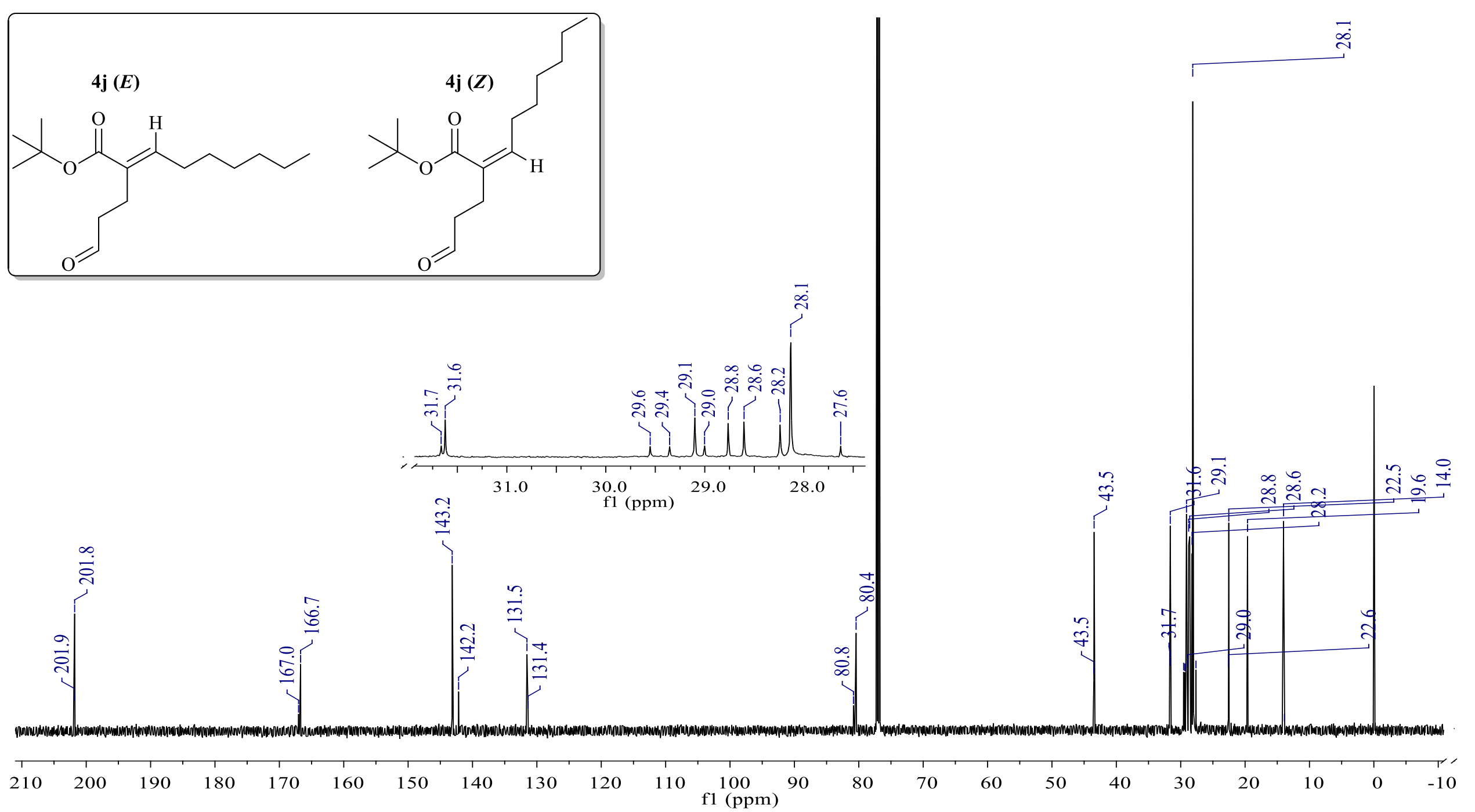

Espectro de RMN de ${ }^{13} \mathrm{C}\left(150 \mathrm{MHz}, \mathrm{CDCl}_{3}\right)$ - Rearranjo de Hurd-Claisen (colunado) $4 \mathrm{j}(E)$ e 4j (Z). 


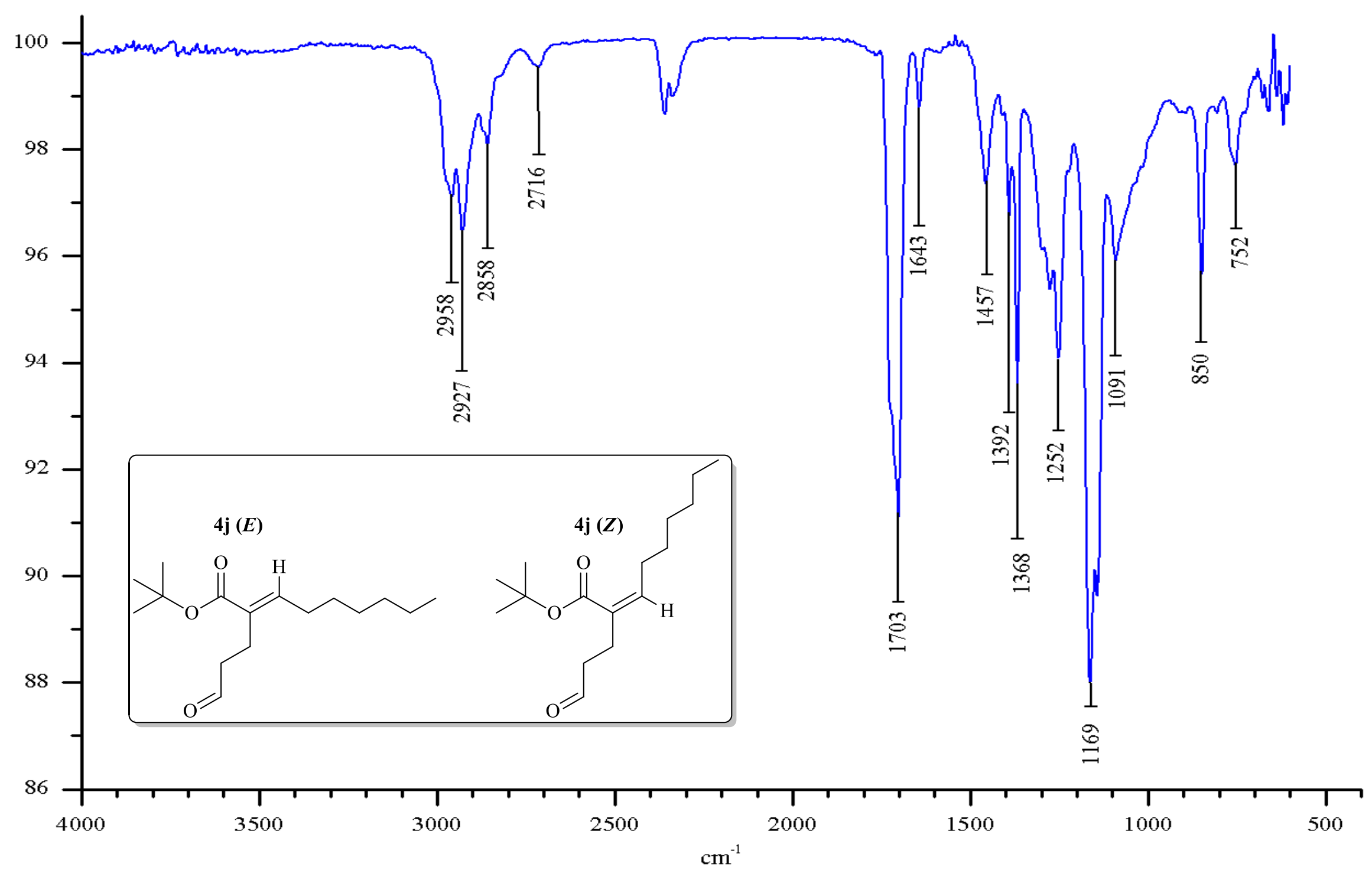

Espectro de infravermelho (ATR) - Rearranjo de Claisen (colunado) 4j (E). (E) e 4j (Z). 

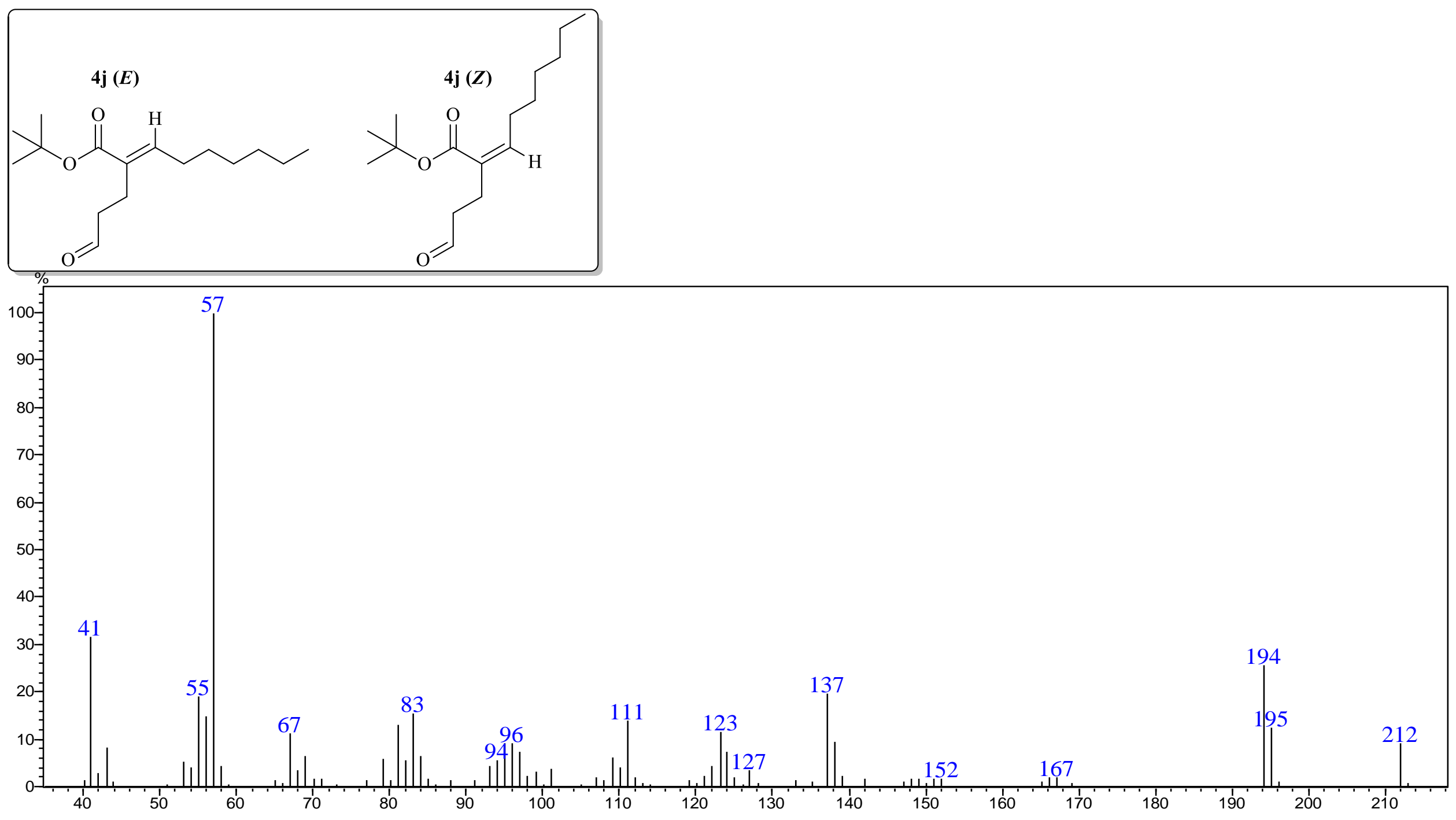

Espectro de massas (EM $70 \mathrm{eV}$ m/z) - Rearranjo de Hurd-Claisen (colunado) 4j (E). e 4j (Z). 

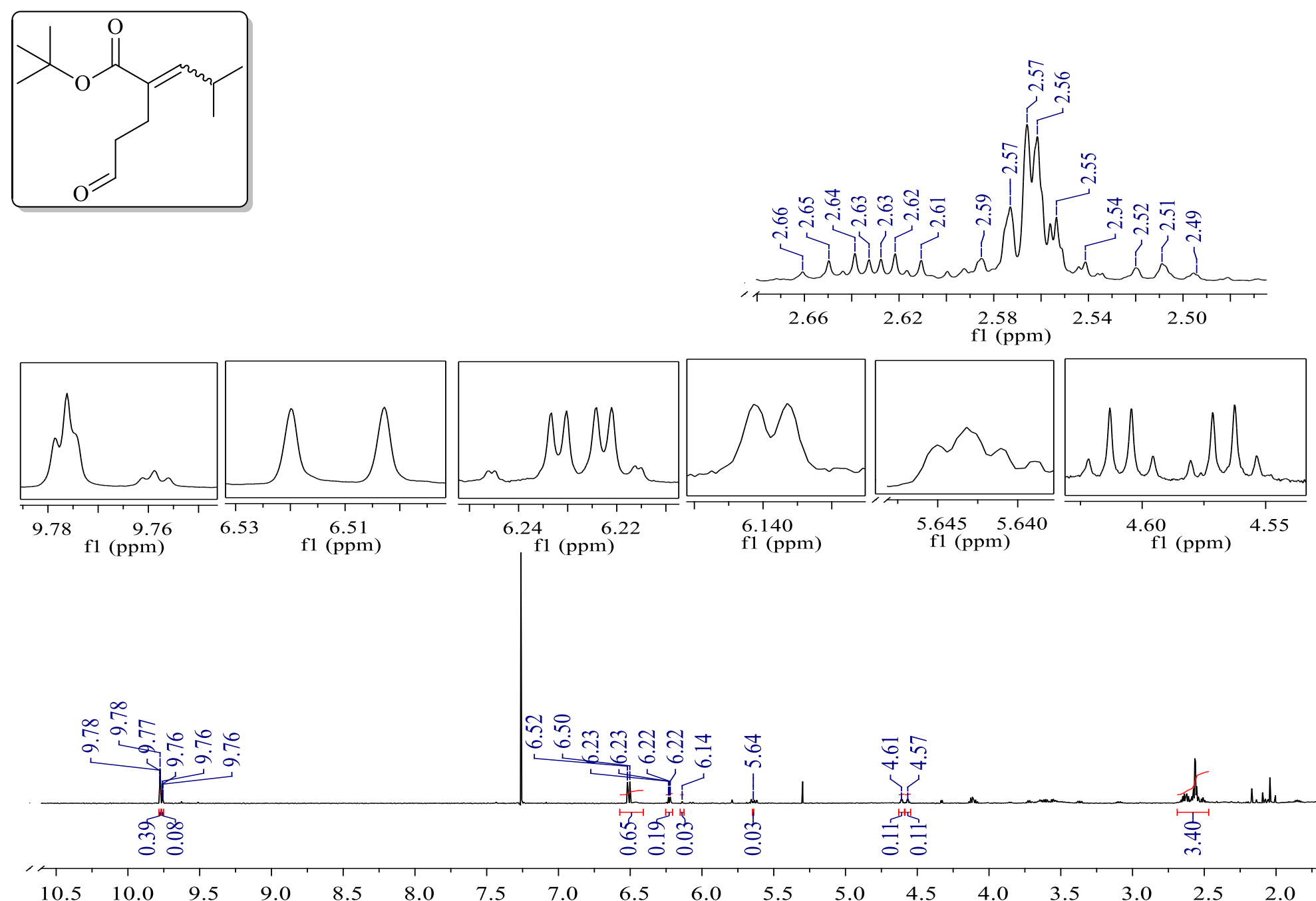

Espectro de RMN de ${ }^{1} \mathrm{H}(600 \mathrm{MHz})$ do bruto de reação do rearranjo de Hurd-Claisen (condição otimizada) com os isômeros 4k (E) e 4k $(Z)$. 
4-metil-2-(3-oxopropil)pent-2-enoato de terc-butila $4 \mathbf{k}(E)$ e $4 \mathbf{k}(Z)$
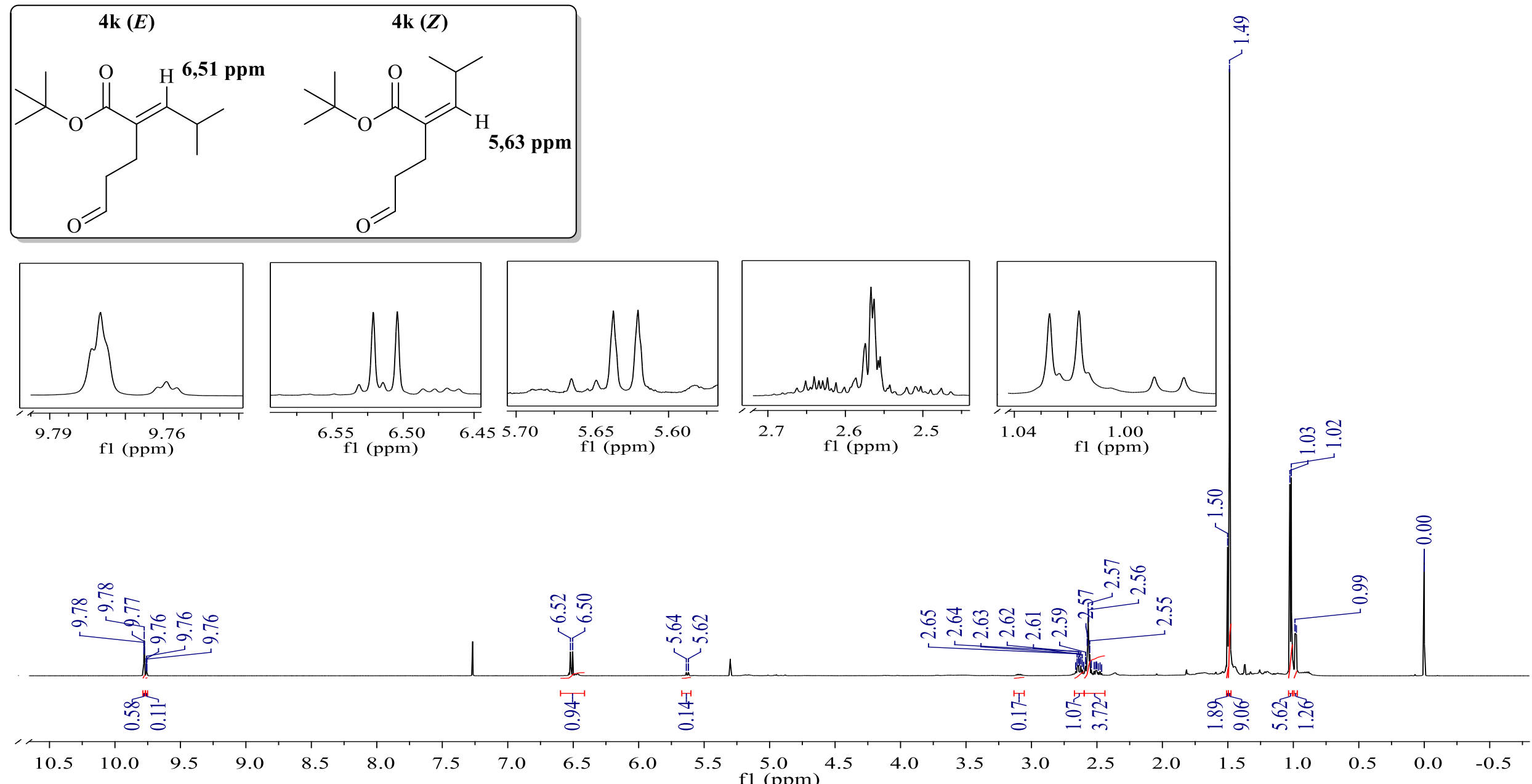

Espectro de RMN de ${ }^{1} \mathrm{H}\left(600 \mathrm{MHz}, \mathrm{CDCl}_{3}\right)$ - Rearranjo de Hurd-Claisen (colunado)4k $(E)$ e $4 \mathrm{k}(Z)$. 

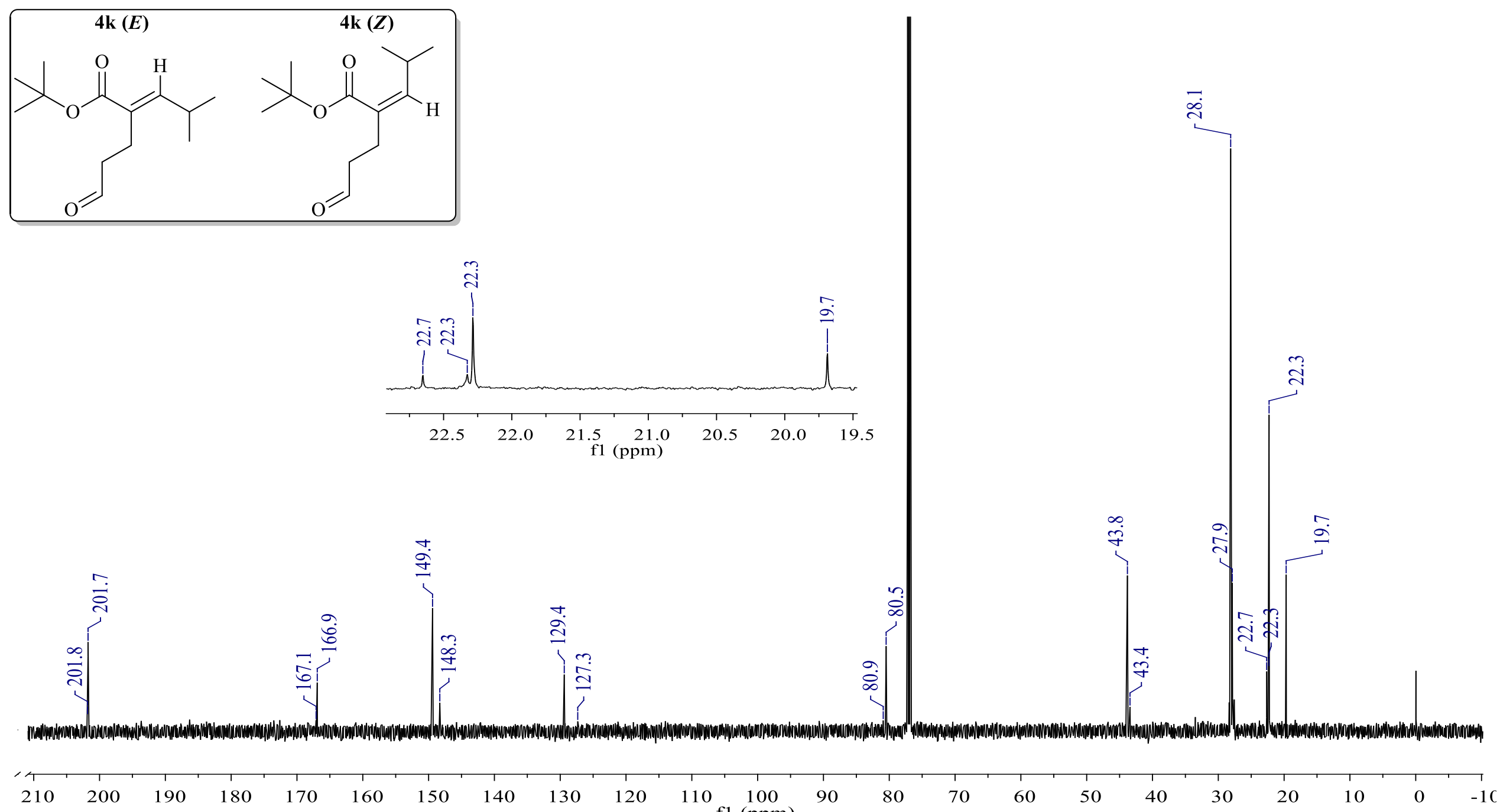

Espectro de RMN de ${ }^{13} \mathrm{C}\left(150 \mathrm{MHz}, \mathrm{CDCl}_{3}\right)$ - Rearranjo de Hurd-Claisen (colunado) 4k (E) e 4k (Z). 


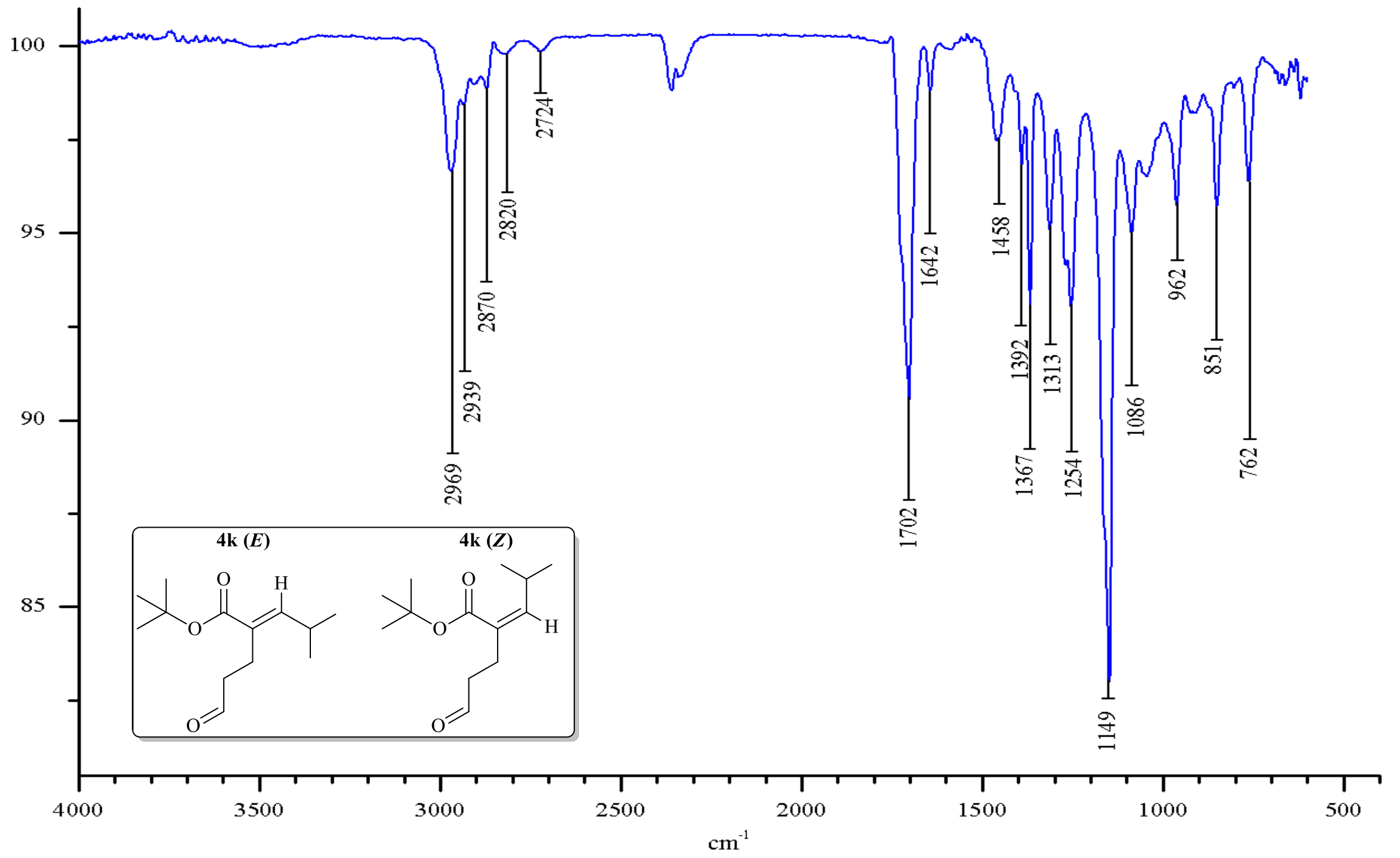

Espectro de infravermelho (ATR) - Rearranjo de Hurd-Claisen (colunado) 4k (E). (E) e 4k (Z). 

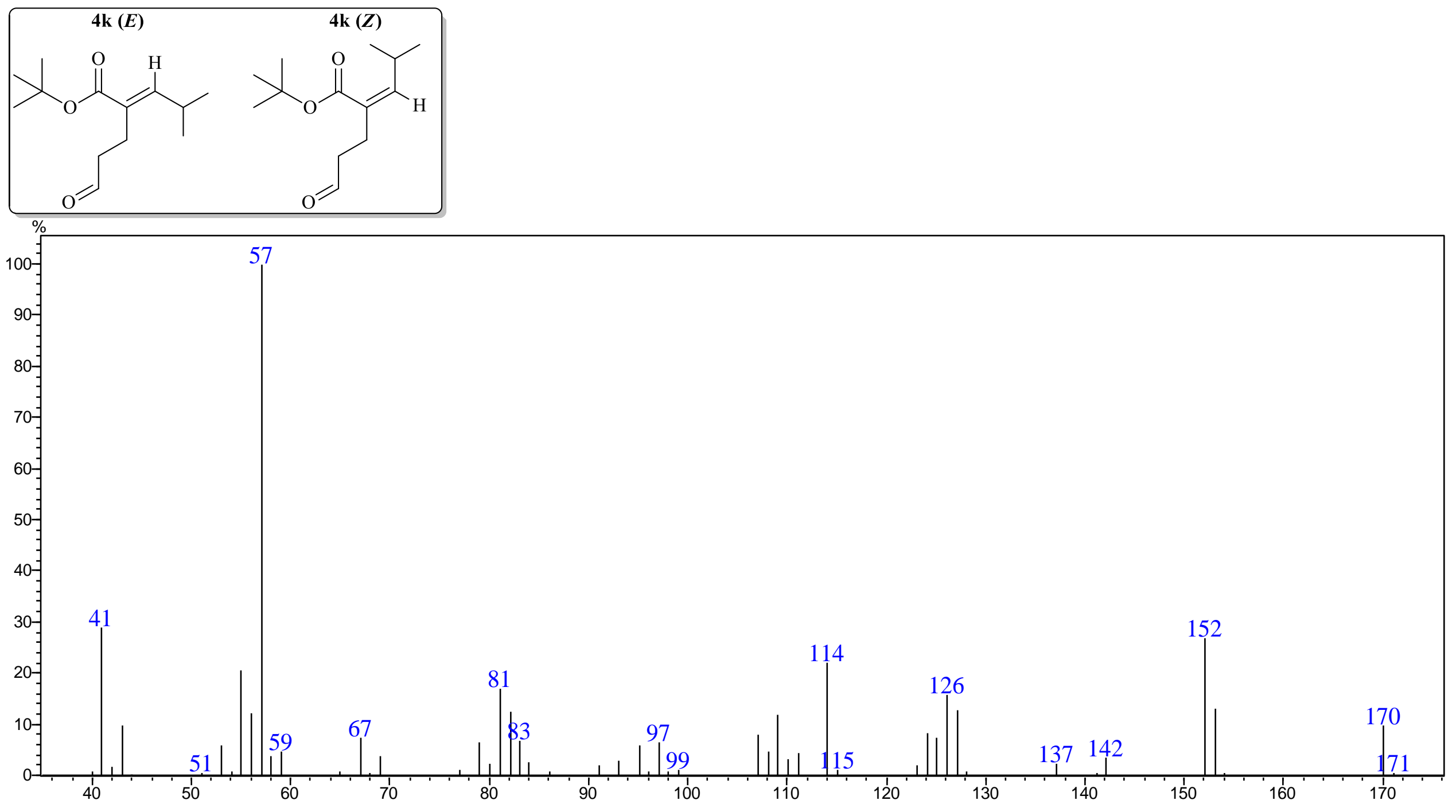

Espectro de massas (EM $70 \mathrm{eV} \mathrm{m/z)}$ - Rearranjo de Hurd-Claisen (colunado) 4k (E). e 4k (Z). 